ROMANIAN ACADEMY

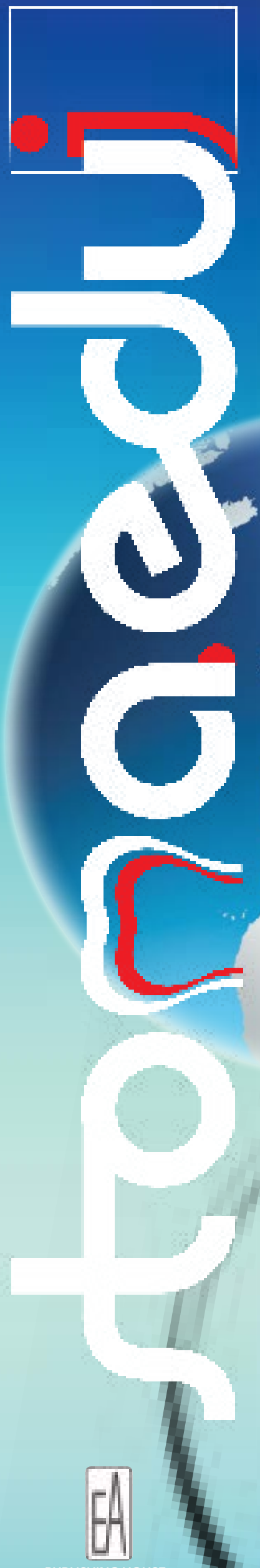

STOMATOLOGY EDU JOURNAL

since 2014

2020 VOLUME 7 ISSUE 3 


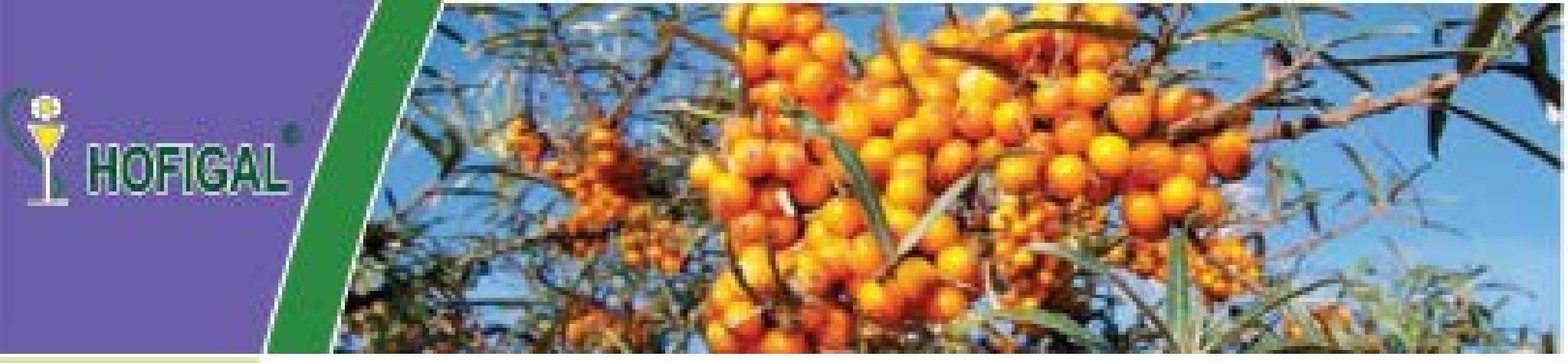

\section{Hofident $Q_{10}$}

Product presantation: Solulon for ard holent.

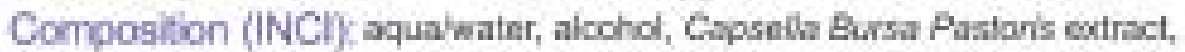

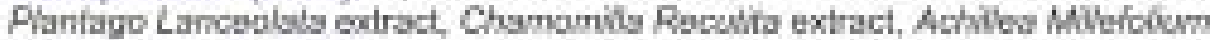

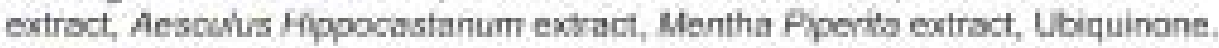

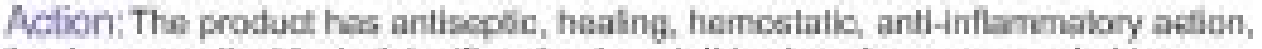

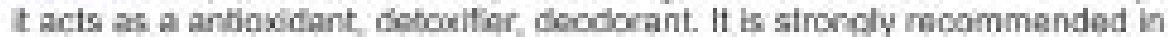

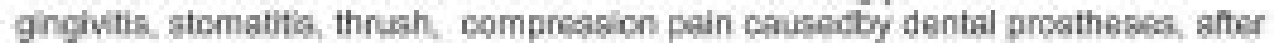

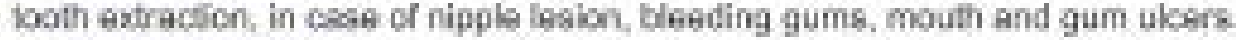

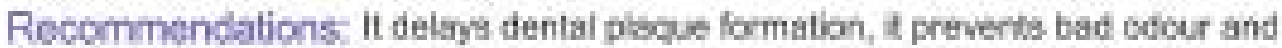
proides daly touth hyient.

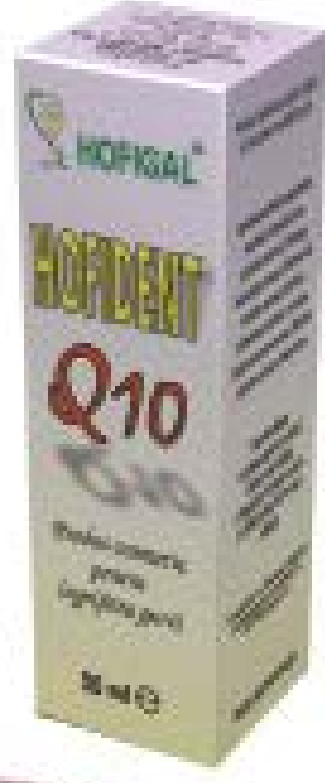

\section{Hoflmun ${ }^{\oplus}$ FORTE}

Product presentaton:

Chasche tablels to stimulate the inmune spotem

Composilion: Each thewable tablat containg reapbery fuil

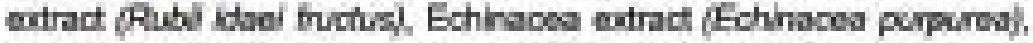

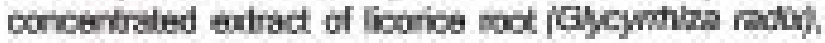
magnedum seostate and axipianta.

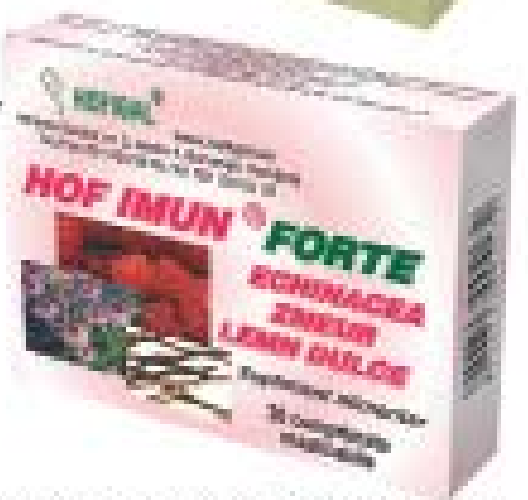

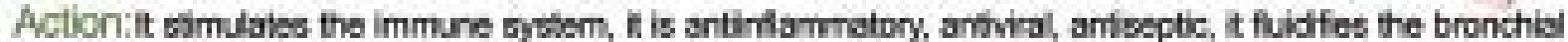

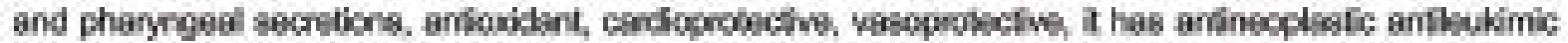
action, (due to the eloglo add), it antrbules to wound haikg tarfies and remheralxes (t) rogulates the pobsesum batencel it has antuber effects and is an oweral body tonic.

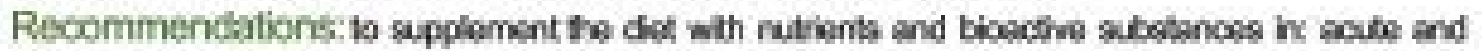

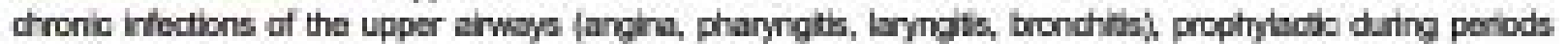

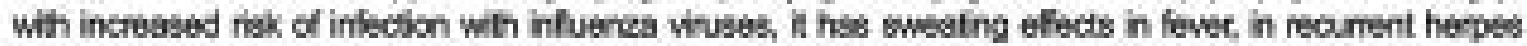

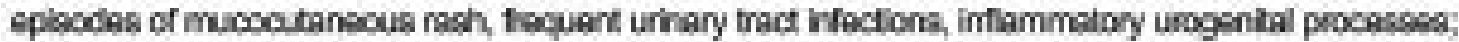

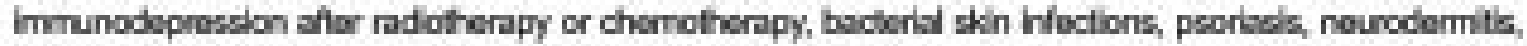

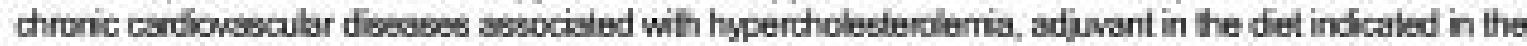

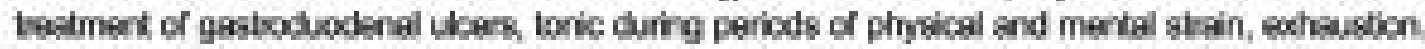

\section{7}

\section{BLCOPNTEO}

itinate lan: mont thit

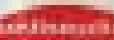

Fintirt

intity

inthing

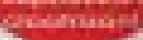

Mirit

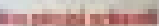

\section{Bucoprotect gel}

Product pregentation. Gel for onal hygene.

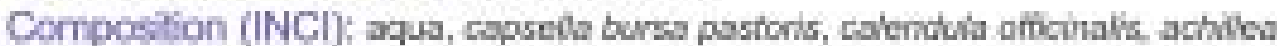

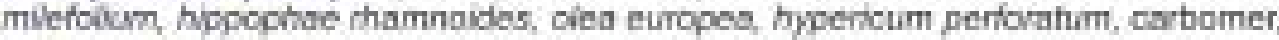

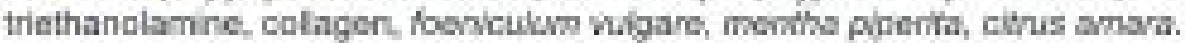

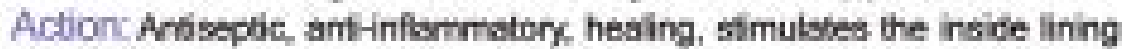

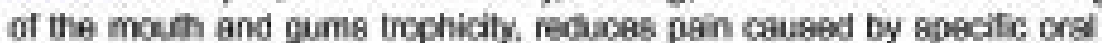
diseases iginghils, stomalifs, bsions of the prosthest, thrush, parbotonblest Recommenditions Fights eqund bad breath ondhost 


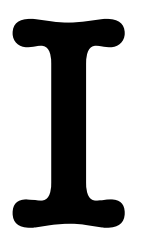

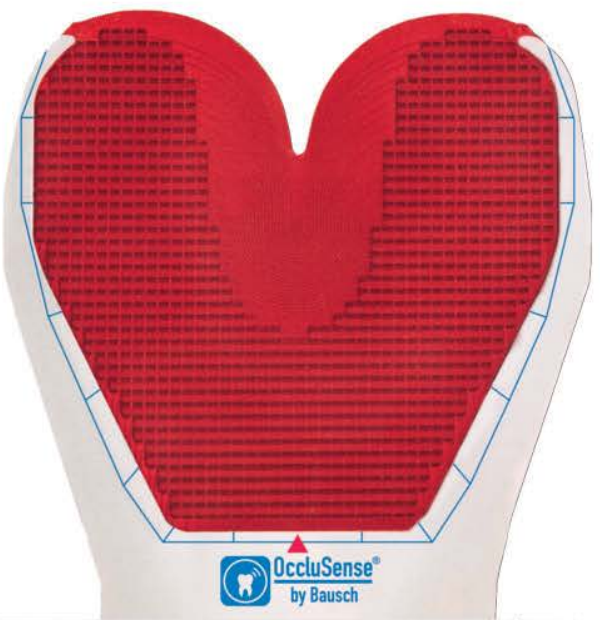

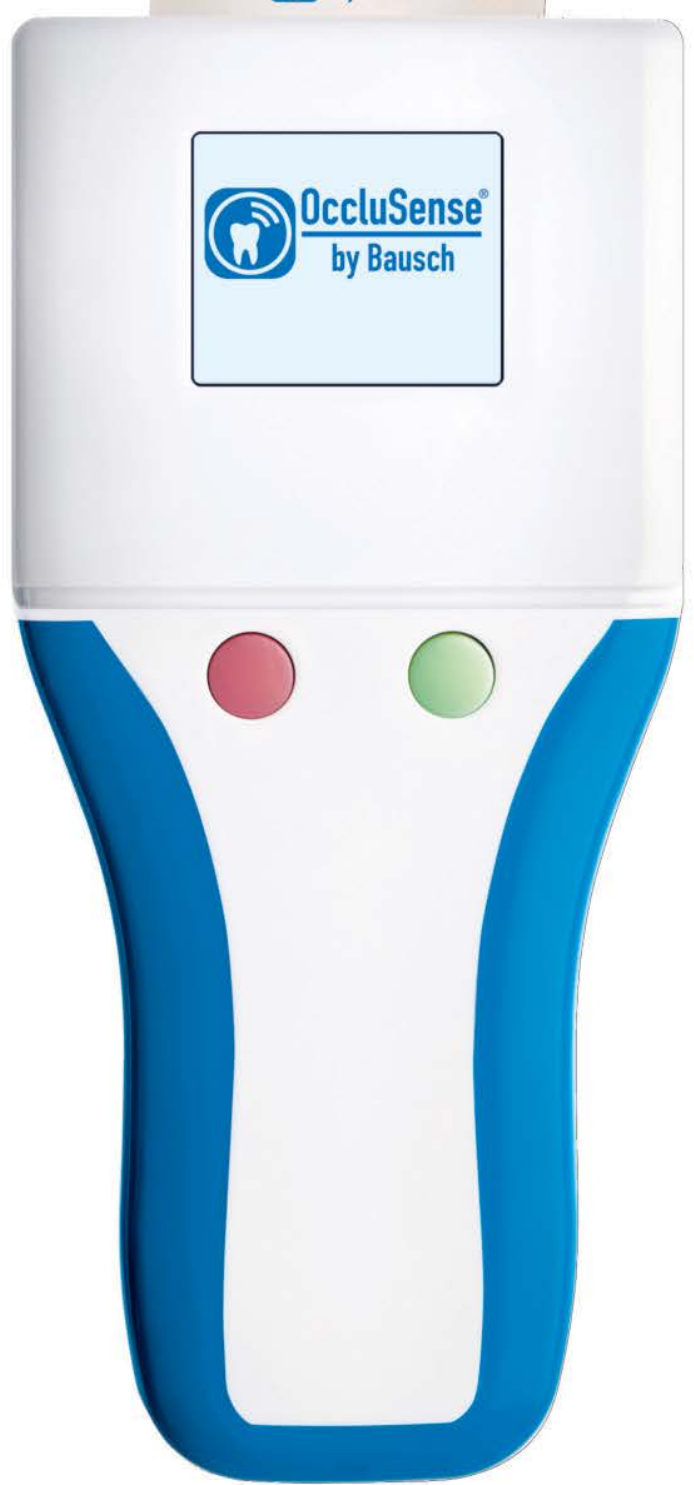

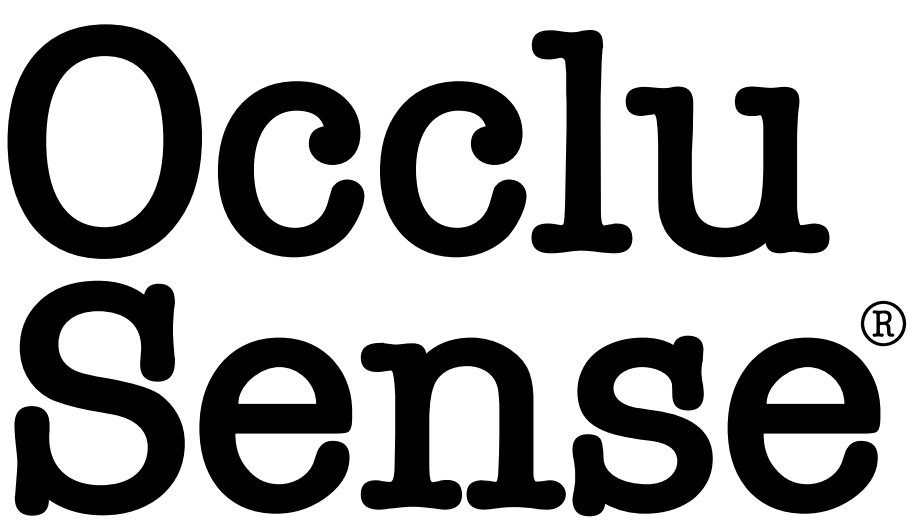

\section{Innovative device for digital occlusion control.}

Take advantage of the award-winning OccluSense ${ }^{\circledR}$ system:

- 60 microns thin, flexible pressure sensors record both static and dynamic occlusion

- Data transfer to OccluSense ${ }^{\circledR}$-iPad-App via wireless network

- Ergonomic design for intuitive handling

- Additionally, red colour coating marks the occlusal contacts on the patient's teeth

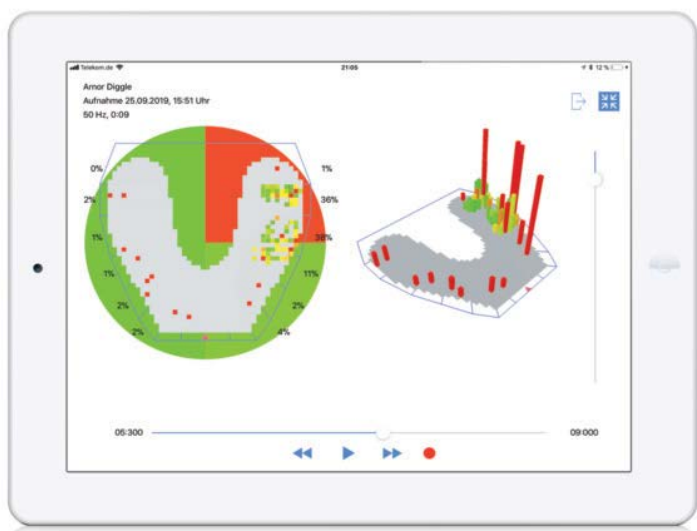

\section{(W) $\frac{\text { OccluSense }}{\text { by Bausch }}$}

WE MAKE OCCLUSION VISIBLE ${ }^{\circledR}$

Dr. Jean Bausch GmbH \& Co. KG | Oskar-Schindler-Str. 4 | 50769 Köln | Germany
More information: www.occlusense.com and YouTube 
2020

Volume 7

Issue 3

Pages 151-226

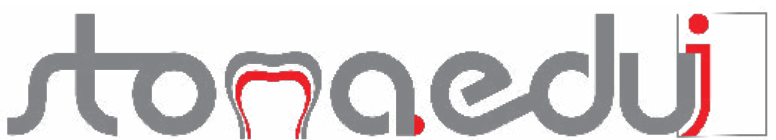

A WORLD OF EDUCATIONAL RESOURCES FOR EACH PRACTICE ISSN (print) 2360-2406; ISSN (on-line) 2502-0285; ISSN-L 2360-2406

\section{EDITORIAL}

151 The lure of interdisciplinary orthodontics

Alexandru Simion Ogodescu

d. https://doi.org/10.25241/stomaeduj.2020.7(3).edit.1

\section{CONTINUING EDUCATION ONLINE}

153 JADA CE Online

\section{ORIGINAL ARTICLES}

155

DENTAL MATERIALS: Cytotoxicity of indirect restorative materials on fibroblast cells: in-vitro study Ayşe Atay, Vildan Bozok Çetintaş, Pelin Guneri, Beste Becerikli Kivrak, Ebru Cal d. https://doi.org/10.25241/stomaeduj.2020.7(3).art.1

163

COMMUNITY DENTISTRY: Influence of the COVID - 19 pandemic on dental practice: why measures should be taken - the experience of an European University Hospital (part 1)

Constantinus Politis, Annette Schuermans, Katrien Lagrou, Mia Vande Putte, Jean-Pierre Kruth

do) https://doi.org/10.25241/stomaeduj.2020.7(3).art.2

CARIOLOGY: Knowledge about dentin hypersensitivity:

175 A questionnaire-based survey among dental students and young dentists Emilia Bologa, Simona Stoleriu, Angela Cristina Ghiorghe, Galina Pancu, Irina Nica, Sorin Andrian

d) https://doi.org/10.25241/stomaeduj.2020.7(3).art.3

ORTHODONTICS: Evaluation of upper arch changes in patients with 184 unilateral cleft lip and palate after maxillary expansion using digital

Fabrizia d'Apuzzo, Ludovica Nucci, Abdolreza Jamilian, Rosario Rullo, Vincenzo Grassia, Letizia Perillo

d6) https://doi.org/10.25241/stomaeduj.2020.7(2).art.4

191 DENTAL PUBLIC HEALTH:Unmet dental treatment need impairs quality of life in Hepatitis C virus-infected patients

Miguel Angel Farias, Silvia Andrea Medici, Aldo Fabián Squassi, Gabriel Antonio Sánchez d) https://doi.org/10.25241/stomaeduj.2020.7(3).art.5

197 OCCLUSION ANDTMJ:The influence of occlusion on masticatory efficiency considering relevant influencing factors Gregor Slavicek

d) https://doi.org/10.25241/stomaeduj.2020.7(3).art.6
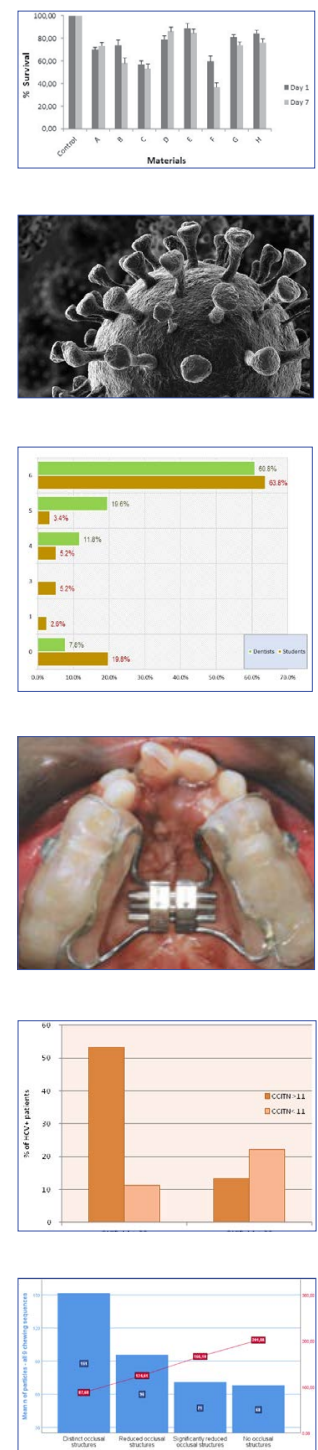


\section{REVIEW ARTICLE}

10 ORTHODONTICS: Returning to the orthodontic practice amid

209 COVID-19 crisis

Letizia Perillo, Ludovica Nucci, Oded Yitschaky, Gennaro Carrino, Rossella Carrino, Stella Chaushu

d.) https://doi.org/10.25241/stomaeduj.2020.7(3).art.7

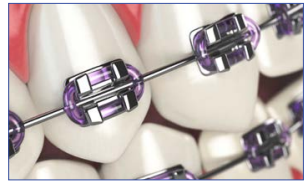

\section{PRODUCT NEWS}

Degranulation kit by Strauss \& Co: ensuring optimal mechanical debridement of the inflammatory tissue Florin - Eugen Constantinescu

do) https://doi.org/10.25241/stomaeduj.2020.7(3).prodnews.1

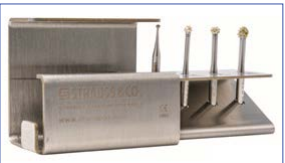

\section{BOOK REVIEWS}

219 Advances in Esthetic Implant Dentistry Abdelsalam Elaskary

de) http://www.stomaeduj.com 10.25241/stomaeduj.2020.7(3).bookreview.1

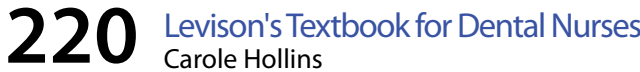

d) http://www.stomaeduj.com 10.25241/stomaeduj.2020.7(3).bookreview.2 $220 \begin{aligned} & \text { Dental Reception and Supervisory Management } \\ & \text { Glenys Bridges }\end{aligned}$

d) http://www.stomaeduj.com 10.25241/stomaeduj.2020.7(3).bookreview.3

221 Oral and Maxillofacial Radiology: A Diagnostic Approach David MacDonald

de) http://www.stomaeduj.com 10.25241/stomaeduj.2020.7(3).bookreview.4

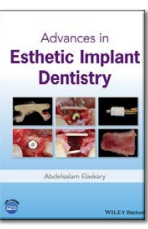

222 Dental Management of the Pregnant Patient

Christos A. Skouteris

di) http://www.stomaeduj.com 10.25241/stomaeduj.2020.7(3).bookreview.5
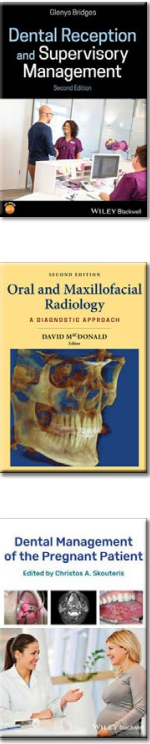

222 Basic Guide to Dental Sedation Nursing

do) http://www.stomaeduj.com 10.25241/stomaeduj.2020.7(3).bookreview.6

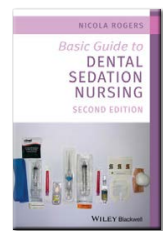

\section{INSTRUCTIONS FOR AUTHORS}

224 instructions for authors 
Eng, PhD, J A Jones Distinguished Professor, Acad (AR)

Constantin lonescu-Târgoviste MD, PhD, Professor, Acad (AR) "Carol Davila" University of Medicine and Pharmacy, Bucharest, Romania
Gabriel Octavian Lazăr
Phys, PhD, Professor "Carol Davila" University of Medicine and Pharmacy, Bucharest, Romania
Gabriel Octavian Lazăr
Phys, PhD, Professor "Vasile Alecsandri" University of Bacău, Bacău, România

\section{CO-EDITORS-IN-CHIEF (AMERICAS)}

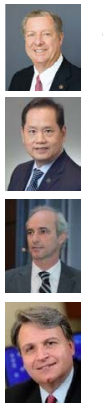

James Richard Hup

BS, DMD, MD, JD, MBA, Professor

Washington State University, Spokane, WA, USA

Hom-Lay Wang

DDS, MSD, PhD, Professor

University of Michigan, Ann Arbor, MI, USA

Mauro Marincola

MD, DDS, Clinical Professor

State University of Cartagena, Cartagena, Colombia

George E. Romanos

Stony Brook University, Stony Brook, NY, USA

CO-EDITORS-IN-CHIEF (ASIA-PACIFIC)

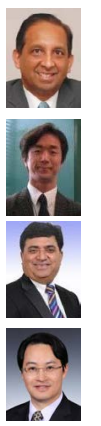

Lakshman Perera Samaranayake

Hon DSC, FDSRCS (Edin), FDS RCPS (Glas), FRACDS, FRCPath (UK), BDS, DDS

(Glas), FHKCPath, FCDSHK, FHKAM (Pathology), FHKAM (Dental Surgery)

Emeritus Professor, Department of Oral Biosciences, Faculty of Dentistry

Immediate-past Dean, University of Hong Kong, Hong Kong

Hiroshi Ogawa

DDS, MDSc, PhD, Associate Professor

Niigata University, Niigata, Japan

Mahesh Verma

BDS, MDS, MBA, FAMS, FDSRCS (England), FDSRCPSG (Glasgow), FDSRCS

(Edinburgh) PhD (HC), Professor

Maulana Azad Institute of Dental Sciences, New Delhi, India

Yongsheng Zhou

DDS, PhD, Professor and Chair, Associate Dean Department of Prosthodontics, School of Stomatology (PKUSS), Peking
University, Beijing, P.R.China

EMERITUS EDITORS-IN-CHIEF

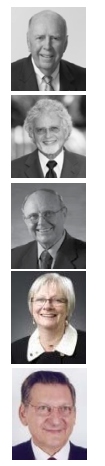

Peter E. Dawson

列

Saint Petersburg, FL, USA

\section{Adi A. Garfunkel}

DMD, PhD, Professor Emeritus

Hadassah Hebrew University, Jerusalem, Israel

\section{Robert Louis Ibsen}

DDS, OD, FAGD, FACD, FICD

Founder \& President DenMat Corporation, Santa Maria, CA, USA

\section{Birte Melsen}

DDS, Dr Odont, Professor

Aarhus University, Aarhus, Denmark

Alexandre Mersel

DDS, PhD, Professor, Director of Studies

Geneva Institute of Medical Dentistry (GIMD), Versoix, Switzerland
CO-EDITORS-IN-CHIEF (EUROPE)

Gavriel Chaushu

DMD, MSc, Professor, Head

Rabin Medical Center, Beilinson Campus, Petah Tikva, Israel The Maurice and Gabriela Goldschleger School of Dental Medicine

Tel Aviv University, Tel Aviv, Israel

Mutlu Özcan

DDS, PhD, Professor, Head Division of Dental Biomaterials Clinic of Reconstructive Dentistry, Center of Dental Medicine (ZZM) University of Zürich, Zürich, Switzerland

Letizia Perillo MD, MS, PhD, Professor
Matizia Perillo Head, Dean, University of Campania Luigi Vanvitelli, Naples, Italy

Hande Şar Sancakli DDS, PhD, Associate Professor

FDI Regional CE Director Europe, Geneva-Cointrin, Switzerland

SENIOR EDITORS

Bruce Robert Donoff

DMD, MD, Professor, Dean Medicine Harvard University, Boston, MA, USA

Rolf Ewers

MD, DMD, PhD Professor and Chairman em. Medical University of Vienna, Vienna, Austria

Adrian Podoleanu Eng, PhD, Professor, FinstP, FOSA, FSPIE, Professor University of Kent, Canterbury, Kent, UK

Kasturi Warnakulasuriya

MDSc (Melb), PhD (Bristol), FDSRCS (Eng) FRACDS, FRCPath (UK), FFOP(RCPA),
FICD FILT FMedSci, Professor
King's College London, London, UK

MDSc (Melb), PhD (Bristol), FDSRCS (Eng) FRACDS, FRCPath (UK), FFOP(RCPA),
FICD FILT FMedSci, Professor
King's College London, London, UK

EMERITUS EDITORS-IN-CHIEF

Prathip Phantumvanit

DDS, MS, FRCDT, Professor Thammasat University, Bangkok, Thailand

Rudolf Slavicek

MD, DMD, Professor
Medical University of Vienna, Vienna, Austria

Jacques Vanobbergen

MDS, PhD, Professor Em. Professor and Chairman Gent University, Gent, Belgium

\section{Julian B. WOELFEL}

DDS, FACD, FICD, Professor Emeritus College of Dentistry, The Ohio State University, Columbus, Ohio, U.S.A

\section{David Wray}

MD (Honours), BDS, MB ChB, FDS, RCPS (Glasgow), FDS RCS (Edinburgh) F Med

Sci Professor Emeritus, Professor, University of Glasgow, Glasgow, UK
ASSOCIATE EDITORS-IN-CHIEF SECTIONS Gottfried Schmalz, DDS, PhD, Drhc, Acad (Leopoldina) - Editor-in-Chief

Basic Research / Dental Materials / Dental Technology Gottfried Schmalz, DDS, PhD, Drhc, Acad (Leopoldina) Section Editor-in-Chief

University of Regensburg, Regensburg, Germany

Annalisa Monaco, DDS, MSc, PhD

University of L'Aquila, L'Aquila, Italy

Clinical Research / Oral and Dental Diagnosis / Dental Radiology / Evidence-Based Dentistry

Amid I Ismail, BDS, MPH, MBA, Dr PH, Dean -

Section Editor-in-Chief

Temple University, Philadelphia, PA, USA

Chiarella Sforza, MD, PhD

University of Milan, Milan, Italy

Community Dentistry / Oral Epidemiology / Oral Health / Dental Public Health / Health Promotion

Poul Erik Petersen, DDS, Dr Odont, BA, MSc, WHO Senior

Consultant - Section Editor-in-Chief

University of Copenhagen, Copenhagen, Denmark
Noemí Bordoni, DDS, PhD, Director Public Health Research Institute, Buenos Aires, Argentina Cariology / Pedodontics / Oro-Dental Prevention Luca Levrini, DDS, PhD - Section Editor-in-Chief University of Insubria, Varese, Italy Ralf Janda, DDS, PhD Heinrich-Heine-University, Düsseldorf, Germany

Minimally Invasive Dentistry / Dental Lase Akira Aoki, DDS, PhD - Section Editor-in-Chief Tokyo Medical and Dental University (TMDU), Tokyo, Japan Roman Šmucler, MD, PhD

Charles University, Prague, Czech Republic

Aestethic Dentistry / Dental Photography Douglas A. Terry, DDS, PhD - Section Editor-in-Chief University of Texas, Houston, TX, USA Galip Gürel, DDS, MSC

Dentis Dental Clinic, Istanbul, Turkiye

Endodontics and Traumatology / Dental Microscopy Arnaldo Castellucci, DDS, PhD - Section Editor-in-Chief Florence, Italy
Zrinka Tarle, DMD, PhD, Dean

University of Zagreb, Zagreb, Croatia

Periodontology / Oral Microbiology / Dental Hygiene Mariano Alonso Sanz, DDS, MSD, PhD -

Section Editor-in-Chief

Complutense University of Madrid, Madrid, Spain

Anton Sculean, DMD, MS, Dr he

University of Bern, Bern, Switzerland

Oral Medicine / Oral Pathology

Mei-Qing Wang, DDS, PhD, Head - Section Editor-in-Chief Air Force Medical University (AFMU), Xi'an, Shaanxi, P.R.China

Maria Greabu, Chem, PhD, Head

"Carol Davila" University of Medicine and Pharmacy Bucharest, Bucharest, Romania

Occlusion and TMJ / Orofacial Pain / Dental Occlusion and Posture

Rafael Benoliel, DDS, PhD, BDS, Associate Dean -

Section Editor-in-Chief

The State University of New Jersey, Newark, NJ, USA

Peter Hermann, DMD, MSc, PhD, Head, Vice-Rector

Semmelweis University Budapest, Budapest, Hungary 
Orthodontics and Dento-Facial Orthopedics

Abdolreza Jamilian, DDS, PhD - Section Editor-in-Chief

Tehran University of Medical Sciences, Islamic Azad University, Tehran, Iran

Ecaterina Ionescu, DDS, PhD, Vice-Rector

"Carol Davila" University of Medicine and Pharmacy Bucharest Bucharest, Romania

Anesthesiology / Dentoalveolar Surgery / Maxillofacial Surgery / Oral Implantology / Emergencies at the Dentist's Michael Frank, DDS, PhD, ERO President, President Denta Chamber Hesse - Section Editor-in-Chief German Dental Chamber, Frankfurt am Main, Germany Giorgio Lombardo, MD, DDS

University of Verona, Verona, Italy

Prosthetic Dentistry / Oral Rehabilitation / Gerodontology Vjekoslav Jerolimov, DDS, PhD, Acad (CASA) -

Section Editor-in-Chief

University of Zagreb, Zagreb, Croati

Veronica Mercut, DMD, PhD

Vice-Rector, University of Medicine and Pharmacy Craiova, Dolj, Romania

Restorative Dentistry / Computerized Dental Prosthetics François Duret, DDS, DSO, PhD, MS, MD, PhD, Acad (ANCD) Section Editor-in-Chief

University of Montpellier, Montpellier, France

Georg B. Meyer, DMD, PhD, Drhc

Chairman, Ernst-Moritz-Arndt University, Greifswald, Germany

\section{ASSOCIATE EDITORS SECTIONS} Fawad Javed, BDS, PhD - Editor-in-Chief

Basic Research / Dental Materials / Dental Technology Vasile Iulian Antoniac, Eng, PhD, Habil, Vice Dean Section Editor-in-Chief

University "Politehnica” of Bucharest, Bucharest, Romania Horia Octavian Manolea, DMD, PhD, Head

University of Medicine and Pharmacy of Craiova, Craiova Romania

Clinical Research / Oral and Dental Diagnosis Dental Radiology / Evidence-Based Dentistry Fawad Javed, BDS, PhD - Section Editor-in-Chief University of Rochester, NY, USA

Dalia Kaisarly, BDS, MDSC, PhD

University of Munich,

Munich, Germany

Cariology / Pedodontics / Oro-Dental Prevention Sorin Andrian, DDS, PhD - Section Editor-in-Chief "Gr. T. Popa" University of Medicine and Pharmacy, lasi, lasi, Romania

Dana Cristina Bodnar, DDS, PhD

"Carol Davila" University of Medicine and Pharmacy

Bucharest, Bucharest, Romania

Aestethic Dentistry / Dental Photography Lucian Toma Ciocan, DMD, PhD, Head -

Section Editor-in-Chief

"Carol Davila" University of Medicine and Pharmacy

Bucharest, Bucharest, Romania

Daniele Maria Gibelli, MD, PhD

University of Milan, Milan, Italy

Endodontics and Traumatology / Dental Microscopy

Paula Perlea, DDS, PhD - Section Editor-in-Chief

"Carol Davila" University of Medicine and Pharmacy

Bucharest, Bucharest, Romania

Iulia Romanova, DMS, PhD

Odessa National Medical University "ONMedU”, Odessa,

Ukraine

Periodontology / Oral Microbiology / Dental Hygiene Jon Byron Suzuki, DDS, PhD, MBA, Associate Dean Section Editor-in-Chief

Temple University, Philadelphia, PA, USA

Alina Pūrienè, BS, PhD, Dr hábil

Vilnius University, Vilnius, Lithuania

Oral Medicine / Oral Pathology

Mare Saag, DDS, PhD - Section Editor-in-Chief

University of Tartu, Tartu, Estonia

Nikola Petricevic, DMD, PhD

University of Zagreb, Zagreb, Croatia
Occlusion and TMJ / Orofacial Pain / Dental Occlusion and Posture

Noshir R. Mehta, DMD, MDS, MS, Associate Dean -

Section Editor-in-Chief

Tufts University, Boston, MA, USA

Jean-Daniel Orthlieb, DDS, PhD, Vice-Dean

Aix Marseille University, Marseille, France

Orthodontics and Dento-Facial Orthopedics

Alexandru Simion Ogodescu, DDS, PhD, Head

Section Editor-in-Chief

"Victor Babes" University of Medicine and Pharmacy

Timisoara, Timisoara, Romania

Fabrizia d'Apuzzo, DDS, MSc PhD, Research Fellow

University of Campania "Luigi Vanvitelli", Naples, Italy

Anesthesiology / Dentoalveolar Surgery /

Maxillofacial Surgery / Oral Implantology /

Emergencies at the Dentist's

Cristian Niky Cumpătă, DMD, MD, MSc, PhD

Section Editor-in-Chief

"Titu Maiorescu" University Bucharest, Bucharest, Romania

Joel Motta Junior, DMD, PhD

State University of Londrina, Londrina, Brazil

Prosthetic Dentistry / Oral Rehabilitation /

Gerodontology

Anastassia E Kossioni, DDS, PhD

- Section Editor-in-Chief

University of Athens, Athens, Greece

Vygandas Rutkūnas, DDS, PhD

Vilnius University, Vilnius, Lithuania

Restorative Dentistry / Computerized Dental

Prosthetics

Roberto Carlo Spreafico, MD, DMD -

Section Editor-in-Chief

Busto-Arsizio, Milan, Italy

Joannis Katsoulis, DMD, PhD,

University of Bern, Bern, Switzerland

Community Dentistry / Oral Epidemiology / Oral Health / Dental Public Health / Health Promotion Aldo Fabián Squassi, DDS, PhD, Chair

- Section Editor-in-Chief

University of Buenos Aires, Buenos Aires, Argentina

Mihnea loan Nicolescu, DMD, MD, PhD

"Carol Davila" University of Medicine and Pharmacy Bucharest, Bucharest, Romania

EDITORIAL ADVISORY BOARD SECTIONS Stephen F. Rosenstiel, BDS, MSD, Prof. Em.

Editor-in-Chief

Basic Research / Dental Materials / Dental Technology

Nicoleta llie, Dipl-Eng, PhD - Section Editor-in-Chief

Ludwig-Maximilians-Universität München, München, Germany

Bogdan Calenic, DDS, PhD

"Carol Davila" University of Medicine and Pharmacy Bucharest,

Bucharest, Romania

Andrei Cristian Ionescu, DDS, PhD

University of Milan, Milan, Italy

Nikolay Ishkitiev, DMD, PhD

Medical University of Sofia, Sofia, Bulgaria

Clinical Research / Oral and Dental Diagnosis /

Dental Radiology / Evidence-Based Dentistry

Rodolfo Isaac Miralles Lozano, MD, PhD

- Section Editor-in-Chief

University of Chile, Santiago, Chile

Cristina Teodora Preoteasa, DMD, PhD

"Carol Davila" University of Medicine and Pharmacy Bucharest,

Bucharest, Romania

Robert Sabiniu Serban, Eng, PhD, MS

"Carol Davila" University of Medicine and Pharmacy Bucharest,

Bucharest, Romania

Sorin Uram-Ṭuculescu, DDS, PhD

Virginia Commonwealth University, Richmond, VA, USA

Community Dentistry / Oral Epidemiology / Oral Health / Dental Public Health / Health Promotion Amar Hassan Khamis Mohamed Omer, PhD, DEA, MSc, BSC

- Section Editor-in-Chief

Mohammed Bin Rashid University of Medicine and Health

Sciences, Dubai, UAE

Rayleigh Ping-Ying Chiang, MD, MMS

Taipei Veterans General Hospital, Taipei, Taiwan

Nina Mussurlieva, DDS, PhD

Medical University of Plovdiv, Plovdiv, Bulgaria
Mihaela Răescu, DDS, PhD

"Titu Maiorescu" University, Bucharest, Romania

Cariology / Pedodontics / Oro-Dental Prevention Vlademir Margvelashvili, MD, PhD, DMSci -

Section Editor-in-Chief

Tbilisi State University, Tbilisi, Georgia

Dorjan Hysi, DDS, PhD

University of Medicine of Tirana, Tirana, Albania

Rodica Luca, DDS, PhD

"Carol Davila" University of Medicine and Pharmacy Bucharest, Bucharest, Romania

Tamara Tserakhava, DDS, PhD

Belarusian State Medical University, Minsk, Belarus

Minimally Invasive Dentistry / Dental Lase

Domenico Massironi, DDS-Section Editor-in-Chief

MEG - Master Educational Group, Melegnano (MI), Italy

Claudia Maria de Felicio, MD, PhD

Universidade de São Paulo (USP) Ribeirão Preto, Brazil

Joanna Kempler, DDS, PhD

University of Maryland, Baltimore, MD, USA

Enrico Manca, DDS, PhD

Dental Clinic Dr. Enrico Manca, Cagliari, Italy

Aestethic Dentistry / Dental Photography

Bernard Touati, DDS, PhD - Section Editor-in-Chief

Paris V University, Paris, France

John C. Kois, DMD, MSD

Kois Center, LLC, Seattle, WA, USA

Nissan Joseph, DMD

Tel Aviv University, Tel Aviv, Israe

Sanda-Mihaela Popescu, DDS, MSC, PhD

University of Medicine and Pharmacy of Craiova,

Craiova, Romania

Periodontology / Oral Microbiology / Dental Hygiene Radmila R. Obradović, DDS, PhD-

Section Editor-in-Chief

University of Niš, Nišs, Serbia

Petr Bartak, DDS Charles

University in Prague, Prague, Czech Republic

Gabriela Băncescu, MD, MSc, PhD

"Carol Davila", University of Medicine and Pharmacy Bucharest,

Bucharest, Romania

Marian Neguț, MD, PhD, Acad (ASM)

"Carol Davila", University of Medicine and Pharmacy Bucharest,

Bucharest, Romania

Oral Medicine / Oral Pathology

Asja Celebić, DDS, MSc, PhD -

Section Editor-in-Chief

University of Zagreb, Zagreb, Croatia

Romeo Călărașu, MD, PhD, Acad (ASM)

"Carol Davila", University of Medicine and Pharmacy Bucharest,

Bucharest, Romania

Ingrìda Čèma, DDS, PhD

Riga Stradins University, Riga, Latvi

Valeriu Fala, DM, PhD, MSC

"Nicolae Testemițanu" State University of Medicine and Pharmacy,

Chişinău, Republic of Moldova

Occlusion and TMJ / Orofacial Pain /

Dental Occlusion and Posture

Marcus Oliver Ahlers, DDS, PhD

Section Editor-in-Chief

Hamburg University Eppendorf, Hamburg, Germany

Minh Son Nguyen, DDS, PhD, Head

Danang University of Medical Technology and Pharmacy,

Danang, Vietnam

Sever Toma Popa, DDS, PhD

"Iuliu Hațieganu" University of Medicine and Pharmacy, ClujNapoca, Romania

Gregor Slavicek, DDS, PhD

Steinbeis University Berlin, Berlin, Germany

Orthodontics and Dento-Facial Orthopedics

Mariana Păcurar, DDS, PhD -

Section Editor-in-Chief

University of Medicine and Pharmacy, Târgu Mures, Romania

Fabio Savastano, MD, MOrth

Jaume I University, Castellón de la Plana, Castellón, Spain

Elina Teodorescu, DMD, PhD

"Carol Davila" University of Medicine and Pharmacy Bucharest,

Bucharest, Romania

Irina Nicoleta Zetu, DDS, PhD

"Gr. T. Popa" University of Medicine and Pharmacy,

lasi, Romania 
Anesthesiology / Dentoalveolar Surgery /

Maxillofacial Surgery / Oral Implantology /

Emergencies at the Dentist's

Nardi Casap-Caspi, DMD, MD - Section Editor-in-Chie

Hebrew University Hadassah Jerusalem, Jerusalem, Israel

Andrezza Lauria de Moura, DMD, PhD

Federal University of Amazonas (FAO-UFAM)

Manaus - AM, Brazil

Marius Steigmann, DDS, PhD

Steigmann Implant Institute, Neckargemund, Germany

Gianluca Martino Tartaglia, DDS, PhD

University of Milan, Milan, Italy

Prosthetic Dentistry / Oral Rehabilitation /

Gerodontology

Elena Preoteasa, DDS, PhD - Section Editor-in-Chief

"Carol Davila" University of Medicine and Pharmacy

Bucharest, Bucharest, Romania

Emilian Hutu, DDS, PhD

"Carol Davila" University of Medicine and Pharmacy Bucharest, Bucharest, Romania

Marina Meleșcanu-Imre, DDS, PhD

"Carol Davila" University of Medicine and Pharmacy

Bucharest, Bucharest, Romania

Martina Schmid-Schwap, DDS, PhD

Medical University of Vienna, Vienna, Austria
Restorative Dentistry / Computerized Dental Prosthetics

Stephen F. Rosenstiel, BDS, MSD, Prof. Em.

Section Editor-in-Chief

The Ohio State University, Columbus, USA

Henriette Lerner, DMD, PhD

HL Dentclinic \& Academy, Baden-Baden, Germany

Mariam Margvelashvili-Malament, DDS, MSC, PhD

Tufts University, Boston, MA, USA

Alexandru Eugen Petre, DDS, PhD

"Carol Davila" University of Medicine and Pharmacy

Bucharest, Bucharest, Romania

ENGLISH LANGUAGE EDITOR-IN-CHIEF

Roxana-Cristina Petcu, Phil, PhD, Professor

Faculty of Foreign Languages, University of Bucharest

Bucharest, Romania

ENGLISH LANGUAGE EDITORS

Valeria Clucerescu, Bio.

Diana Florea, Phil, PhD

HONORARY STATISTICAL ADVISERS

Radu Burlacu, PhD, Bucharest, Romania

loan Opriș, PhD, Associate Scientist, Miami, USA
BOOKS REVIEWERS

Iulia Ciolachi, DMD, Bucharest, Romania

Florin-Eugen Constantinescu, DMD, PhD Student

Bucharest, Romania

JOURNAL MANAGER

Ioana Bălan, Maths, MSc, Bucharest, Romania

PROJECT EDITOR

Irina-Adriana Beuran, $\mathrm{DMD}, \mathrm{PhD}$

Faculty of Dental Medicine, "Carol Davila" University of Medicine

and Pharmacy Bucharest, Bucharest, Romania

Alexandra Popa, Holistic Dental \& Medical Institute of Bucharest

- ROPOSTURO, Bucharest, Romania

TECHNICAL EDITORS

Gabriel Octavian Lazar, Bucharest, Romania

Valentin Miroiu, Bucharest, Romania

Edgar Moraru, Bucharest, Romania

DTP / GRAPHIC \& WEB DESIGNER

Valentin Miroiu, Bucharest, Romania

www.miroiu.com

\section{INDEXING DATABASES}
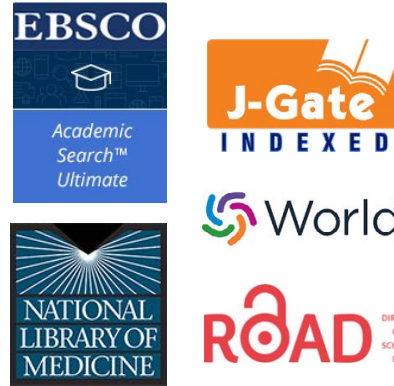

Dimensions KUDOS Crossref

I N D E X E D

II UIVERSITY

(5) WorldCat

(a) Scilit

SHERPA

R०MEO Academia, edu

IIIIIIE

INTRRNATIONAL COMMITTFEF OS
MEDICAL JOURNAL EDITORS

ROAD Google publons

INFOBASE INDEX

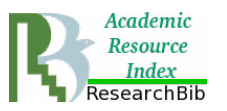

The Stomatology Edu Journal (Stoma Edu J) is a scientific magazine of the Romanian Association of Oral Rehabilitation and Posturotherapy - ROPOSTURO, a partner of the FDI regular member, the Romanian Society of Stomatology - RSS (founded in 1923) under the aegis of The Romanian Academy.

\section{Editor Office}

Stomatology Edu Journal, 102-104 Mihai Eminescu st.

$2^{\text {nd }}$ District, RO-020082 Bucharest, ROMANIA

Tel/Fax: +40314327930

e-mail: stomatology.edu@gmail.com,

www.stomaeduj.com

Editors-in-Chief

Marco Ferrari, Constantinus Politis

Marian-Vladimir Constantinescu

Managing Editor

Florin-Eugen Constantinescu

\section{ROPOSTURO}

Romanian Association of Oral Rehabilitation and

Posturotherapy

10, Ionel Perlea St., ${ }^{\text {st }}$ District

R0-010209 Bucharest, Romania

Tel: +4021314 1062; Fax: +40213121357

e-mail: roposturo@gmail.com

www.roposturo.ro

Technical Editors

Gabriel Octavian Lazar, Valentin Miroiu

Edgar Moraru

Project Editor

Irina-Adriana Beuran

Design Editor

Dragoș Georgian Guțoi

Cover by

Arch. Florin Adamescu

\section{Publisher Office}

Romanian Academy Publishing House

Calea 13 Septembrie, ${ }^{\text {th }}$ District

R0-050711 Bucharest, Romania

Tel: +40213188146

$\mathrm{Fax}+40213182444$

e-mail: edacad@ear.ro

www.ear.ro

Technical Editor

Doina Argesanu

Editorial Assistant

Monica Stanciu

Computer Editing

Iolanda Povară 


\section{THE LURE OF INTERDISCIPLINARY} ORTHODONTICS

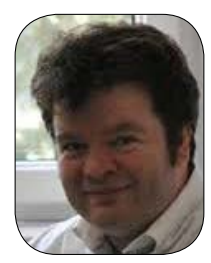

Alexandru Simion OGODESCU

DDS, PhD, Dr Habil

Professor \& Chairperson

Associate Editor Sections - Editor-in-Chief

Dear readers,

For 20 years I have been passionate about interdisciplinary collaboration between different specialties in dentistry and orthodontics. My doctoral studies, extensive research, publications, conferences, monographs have focused on interdisciplinary orthodontics and most of my daily clinical work as an orthodontist is dedicated to these interdiciplinary cases.

At first, few believed in this concept: my orthodontist colleagues were distrustful of the possibilities of adult orthodontics, periodontists did not believe that teeth with bone loss have an...,orthodontic future", prosthodontists were used to "straightening" teeth prosthodontically, while implantology was not a common therapeutic option. Often when I presented them with a case of interdisciplinary orthodontics, the attitude was rather more skeptical than enthusiastic.

The rescue came in 2003 at the Congress of the European Orthodontics Society (EOS) in Prague, when I heard Professor Vincent Kokich (USA) - one of the world's leading specialists in orthodontics, probably the most passionate supporter of interdisciplinary orthodontics and an excellent speaker in the field, insisting on how important it is, especially for the young generation of specialists, to "grow" together in interdisciplinary teams, where each member informs the other on the latest therapeutic possibilities in his specialty. This sincere and continuous mutual information has led to the elaboration of therapeutic principles and protocols of interdisciplinary collaboration through which each discipline assists the other, together offering higher quality medical services to the patient (Ogodescu A, 2006).

The internships attended at the Pedodontics-Orthodontics Department of the University of Zurich, Switzerland is where I learned from dear friends, Prof. Dr. Werner Frunz, Dr. Wanda Gnoinski, Dr. Rolland Maenchen, Prof. Dr. Marc Schaetzle how useful interdisciplinary collaboration can really be.

Almost no one at that time conceived of postponing prosthodontic treatment for 6-12 months to upright a lower second molar, to wait 3-6 months for the egression of a subgingivally decayed root, to correct a crossbite, a rotation, or to postpone insertion of an implant for 6 months to extrude a compromised root in order to create alveolar bone. In the case of patients with dento-maxillary abnomalies secondary to periodontal disease, no one saw orthodontics as a solution for their recovery either, but the fascination exercised by this new area of orthodontics was on its way and slowly it managed to convince more and more specialists.

As I stated in 2006 in my doctoral thesis, the implementation of this new concept is best summarized by the term TEAM ("together everyone achieves more") and the logo that I launched then for the new discipline is still valid today.

The success of establishing such a team of different specialties (orthodontics, periodontics, prosthodontics, maxillofacial surgery, occlusology, radiology, paedodontics) is based on a series of considerations: good communication, excellence in specialty, mutual respect and trust. I was lucky to have special colleagues in Timisoara with whom I could solve the most difficult cases. Together we trained, learned from each other and came to develop interdisciplinary cooperation protocols. In 2008 we published the first monograph on interdisciplinary orthodontic treatments in adults. For almost 10 years I have been teaching an optional course to sixth year students at the Faculty of Dentistry entitled: „Principles of interdisciplinary orthodontic treatment". 
Today I am really satisfied to watch my former students excel in the therapy of complex cases via an interdisciplinary approach. Young prosthodontics specialists no longer conceive of grinding sound teeth, instead they ask us, orthodontists, to recalibrate spaces for them to insert implants. The goals of preprosthodontic orthodontics have changed. Fellow periodontologists, with whom we work on the same substrate, the alveolar bone, have a completely different view on the advantages of orthodontic treatments in patients with a periodontal disease and the situations in which periodontal therapy favors orthodontic treatment. Implantologists have the patience to extrude compromised roots for implant site development, they help us to increase the anchorage in orthodontics, in the expansion of the jaw.

Patients have also learned the benefits of interdisciplinary orthodontics, many more adults are now asking for orthodontic treatments in combination with their periodontal or prosthodontic treatments.

Technology has evolved enormously, the digitalization of orthodontics is taking shape, and communication - so important in the interdisciplinary team - is easier today than ever.

Many dental clinics have specialist doctors who work together and share their knowledge to achieve better oral rehabilitation of patients.

My twenty-year old dream has come true. The appeal of interdisciplinary collaboration finally overcame the fear of communicating between colleagues from various specialties. The initial difficulties and distrust in the field of interdisciplinary orthodontics are a thing of the past and today excellence characterizes this dynamic field.

May this beautiful and complex specialty live a very long life as it has given me so much satisfaction throughout all these years!

Sincerely yours,

\author{
A.S. Ogodescu \\ DDS, PhD, Dr Habil, ORCIDiD: https://orcid.org/0000-0001-9797-7157 \\ Professor \& Chairperson \\ Senior specialist ODFO \\ Department of Pedodontics-Orthodontics \\ Faculty of Dental Medicine \\ "Victor Babeș" University of Medicine and Pharmacy Timișoara \\ Timișoara, Romania \\ Associate Editor Sections - Editor-in-Chief
}




\section{stoma.eduj}

Stoma Edu J. 2020;7(3):153

From The Journal of the American Dental Association

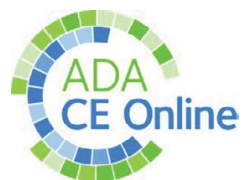

\section{JADA ONLINE CE EXAMS}

http://jada.ada.org/ce/home

http://jada.ada.org/ceworksheets

September 2020

Andrei C. Ionescu, Maria G. Cagetti, Jack L. Ferracane, Franklin Garcia-Godoy, Eugenio Brambilla

TOPOGRAPHIC ASPECTS OF AIRBORNE CONTAMINATION CAUSED BY THE USE OF DENTAL HANDPIECES INTHE OPERATIVE ENVIRONMENT

J Am Dent Assoc. 2020 July 01, 151 (9): 660-667. Doi: 10.1016/j.adaj.2020.06.002

https://jada.ada.org/article/S0002-8177(20)30430-X/fulltext

This article has an accompanying online continuing education activity available at: http://jada.ada.org/ce/home. 


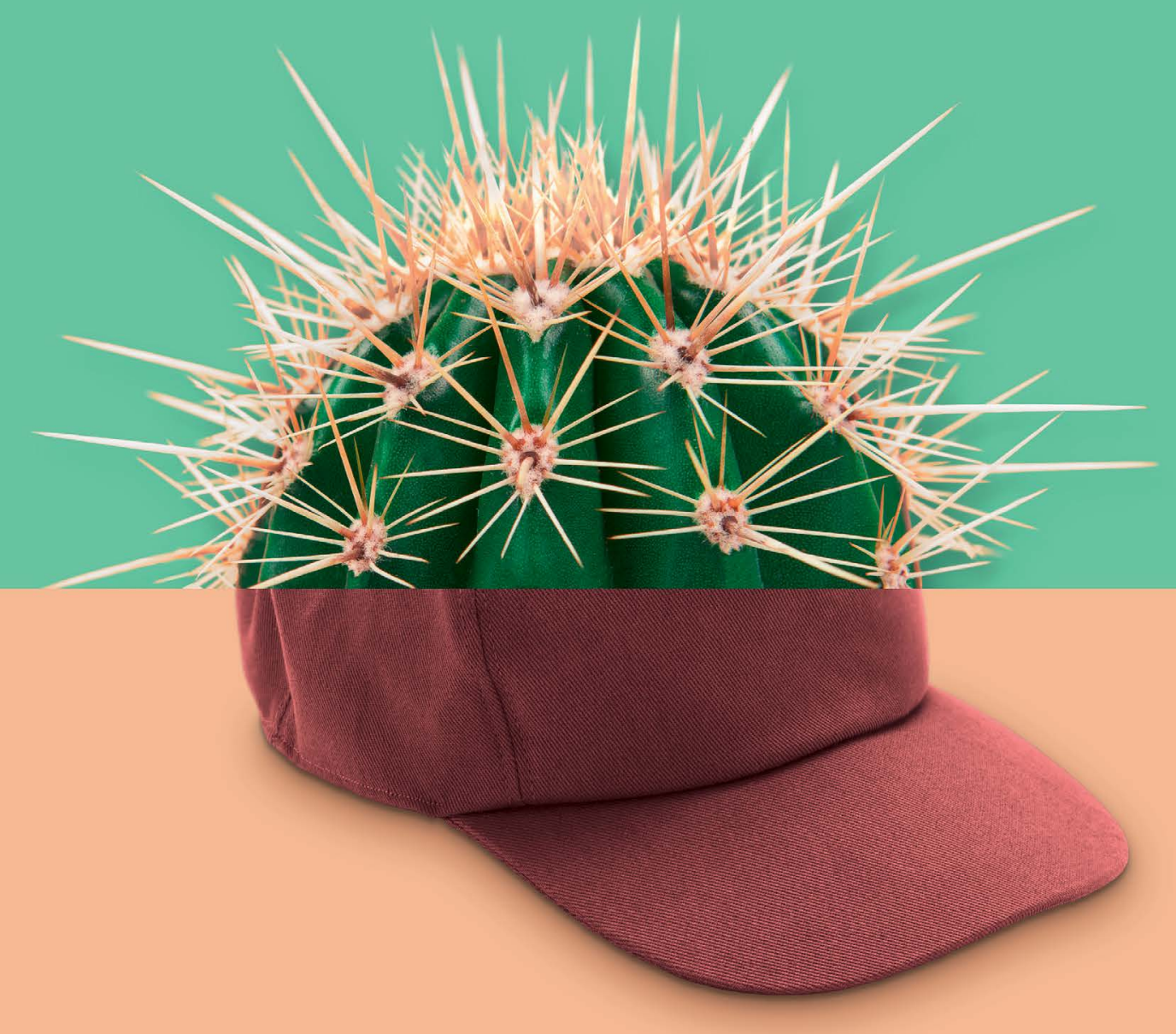

DAC Universal S

\section{Hazards turned harmless.}

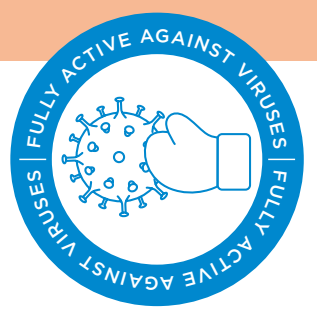

You think you will never win the fight against germs but Dentsply Sirona turns hygiene risks into manageable maintenance. With DAC Universal S you'll benefit from an automated and quick way of cleaning, lubricating and sterilizing dental instruments. The process takes approx. 21 minutes making it possible to comply with hygiene requirements by simply pressing a button. Your patients and your team can fully rely on our comprehensive protection against hazards.

Find out more at dentsplysirona.com/safehygiene

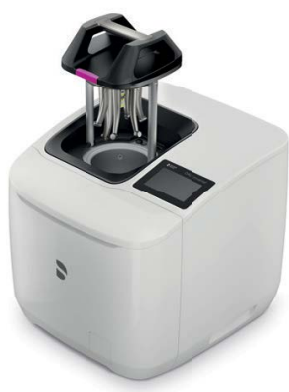




\title{
CYTOTOXICITY OF INDIRECT RESTORATIVE MATERIALS ON FIBROBLAST CELLS: IN-VITRO STUDY
}

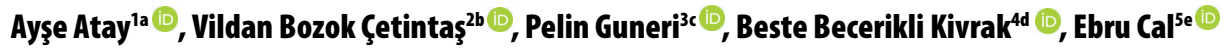 \\ 'Department of Prosthodontics, Faculty of Dentistry, Altinbaș University, TR-34147, Bakırkoy/lstanbul, Turkey \\ 2Department of Medical Biology, Faculty of Medicine, Ege University, TR-35100, Bornova/Izmir, Turkey \\ ${ }^{3}$ Department of Oral and Maxillofacial Radiology, Faculty of Dentistry, Ege University, TR-35100, Bornova/lzmir, Turkey \\ ${ }^{4}$ Private Clinic, İzmir/Turkey \\ ${ }^{5}$ Department of Prosthodontics, Faculty of Dentistry, Ege University, TR-35100, Bornova/Izmir, Turkey
}

\begin{abstract}
1aDDS, PhD, Assistant Professor; email: ayseatay82@hotmail.com; https://orcid.org/0000-0002-5358-0753
${ }^{2 b}$ DDS, Associate Professor; email: vildanbcetintas@gmail.com; https://orcid.org/0000-0003-3915-6363

${ }_{3}^{3}$ DDS, PhD, Professor; email: peleen_2000@yah00.com; https://orcid.org/0000-0001-9423-919

${ }^{4 d}$ DDS, PhD; email: beste_becerikli@hotmail.com; https://orcid.org/0000-0002-7650-9749

${ }^{5 e} \mathrm{DDS}$, PhD, Professor; email: ebrucal68@gmail.com; https://orcid.org/0000-0002-1908-9733
\end{abstract}

Introduction The aim of this study was to assess the cytotoxicity profiles of eight different fixed prosthetic restoration materials [Gold-based alloy (A), Chromium-Cobalt alloy (B) and Nickel-Chromium alloy (C), fiberreinforced-resin-blocks $(D)$, resin-nano-ceramic $(E)$, lithium-disilicate-glass-ceramics $(F)$, monolithic-zirconia $(\mathrm{G})$ and feldspathic-ceramic $(\mathrm{H})]$ by using cell culture methods on the $\mathrm{L} 929$ mouse fibroblast cells.

Methodology 36 disc-shaped samples of each test material were prepared $(5 \times 2 \mathrm{~mm}, \mathrm{~N}=288)$. After sterilization, discs were placed in EMEM and incubated at $37^{\circ} \mathrm{C}$. Mediums were collected and filtered from each of four samples in $1^{\text {st }}$ and $7^{\text {th }}$ days. After 24 hours incubation, cells were treated with $100 \mu \mathrm{l}$ medium extracts of materials. Viability of cells was measured after 48 hours. Cytotoxicity was assessed with XTT and xCELLigence tests. Apoptosis was analysed using Annexin-V/PI staining. All data were statistically analysed with One-way ANOVA and Tukey's multiple range tests $(p<0.05)$.

Results Considering the cell viability and apoptosis rate significant differences were found after the $1 \mathrm{st}$ and 7 th days of incubation periods for each material group $(p<0.05)$. Among the material groups significant differences were observed $(p<0.05)$. $F$ group showed the lowest cell viability and showed highest apoptosis rate $(p<0.05)$. Along the entire test period, E group showed the highest cell viability and lowest apoptosis rate $(p<0.05)$.

Conclusion All fixed restoration materials investigated in the study exposed various levels of cytotoxicity, with significant differences among the test groups.

\section{KEYWORDS}

Dental Alloys; CAD-CAM Materials; Cytotoxicity; Apoptosis; Fibroblasts.

\section{INTRODUCTION}

In parallel with the improvements in dental technology and material science, innovative materials are being developed to beused in fixed prosthetic restorations, which are in direct contact with bone, connective tissue or oral epithelium. Dental casting alloys that play an important role in restorative dentistry are widely used as restorative materials in dental applications [1]. Recently, the use of cast alloys has become very limited due to the improvements of full ceramic restorations and more durable resinbased composites. Nevertheless, for fixed prosthetic restorations, dental alloys have continued to be used as the primary material [2]. In general, alloys usually include at least four and often six or more metals,

(c) (1) (2) OPEN ACCESS This is an Open Access article under the CC BY-NC 4.0 license Peer-Reviewed Article

Citation: Atay A, Bozok Cetintas V, Guneri P, Becerikli Kivrak B, Cal E. Cytotoxicity of indirect restorative materials on fibroblast cells: in-vitro study. Stoma Edu J. 2020;7(3):155-162.

Received: June 23, 2020; Revised: July 27, 2020; Accepted: August 06, 2020; Published: August 10, 2020

*Corresponding author: Assistant Professor Dr. Ayșe Atay, Department of Prosthodontics, Faculty of Dentistry, Altinbaș University, Incirli Avenue No:11/A, 34147, Bakırkoy, Istanbul, Turkey

Tel.: +90-212-709 45 28, Fax: +90-212-445 81 71; e-mail: ayse.atay@altinbas.edu.tr

Copyright: $\odot 2020$ the Editorial Council for the Stomatology Edu Journal. 
I Table 1. The codes, brand names, compositions and manufacturers of the materials.

\begin{tabular}{|c|c|c|c|c|}
\hline Code & Brand & Material type & Chemical composition & Manufacturer \\
\hline A & PX Premium Bio & Au alloy & $\begin{array}{l}\text { Au } 86.5 \%, \text { Pt } 11.5 \% \text {, Zn } 1.4 \%, \text { Rh, Fe, } \\
\text { Mn, Ta }<1 \%\end{array}$ & PX Dental SA, Marin, Switzerland \\
\hline B & Strabond CoS & Cr-Co alloy & $\begin{array}{l}\text { Co } 59 \% \text {, Cr } 25 \%, \text { W } 9.5 \% \text {, Mo } 3.5 \% \text {, } \\
\text { Si } \% 1, \text { C, Fe, Mn, N <1\% }\end{array}$ & Scheftner Dental Alloys, Germany \\
\hline C & MoguCera N & $\mathrm{Ni}-\mathrm{Cr}$ alloy & $\begin{array}{l}\mathrm{Ni} 62 \%, \mathrm{Cr} 24 \% \text {, Mo } 11 \% \text {, Si 1.6\%, } \\
\mathrm{Mn}<1 \%\end{array}$ & Scheftner Dental Alloys, Germany \\
\hline D & TriLor $^{\oplus}$ & $\begin{array}{l}\text { Fiber reinforced } \\
\text { resin block }\end{array}$ & $\begin{array}{l}\text { Epoxy resin matrix and } \\
\text { multidirectional integrated } \\
\text { fiberglass }\end{array}$ & Bioloren, S.r.l., Italy \\
\hline$E$ & Lava Ultimate & $\begin{array}{l}\text { Resin nano } \\
\text { ceramic }\end{array}$ & $\begin{array}{l}\text { Matrix: Bis-GMA, UDMA, Bis-EMA, } \\
\text { TEGDMA } \\
\text { Filler: } \mathrm{SiO}_{2^{\prime}} \mathrm{ZrO}_{2^{\prime}} \text { aggregated } \mathrm{ZrO}_{2} / \\
\mathrm{SiO}_{2} \text { cluster }(80 \mathrm{wt} \%)\end{array}$ & 3M-ESPE, Seefeld, Germany \\
\hline $\mathrm{F}$ & Rosetta SuperMill & $\begin{array}{l}\text { Lithium } \\
\text { disilicate glass- } \\
\text { ceramic }\end{array}$ & $\begin{array}{l}\mathrm{Li}_{2} \mathrm{O} 10-15 \%, \mathrm{SiO}_{2} 71-80 \%, \mathrm{~B}_{2} \mathrm{O}_{3} \\
0-6 \%, \mathrm{P}_{2} \mathrm{O}_{5} 2-5 \%, \mathrm{Al}_{2} \mathrm{O}_{3} 2-5 \% \text {, other } \\
\text { oxides and colorants 5-12\% }\end{array}$ & Hass Corporation, Korea \\
\hline G & InCoris TZI & $\begin{array}{l}\text { Monolithic } \\
\text { zirconia }\end{array}$ & $\begin{array}{l}\mathrm{ZrO}_{2}+\mathrm{HfO}_{2}+\mathrm{Y}_{2} \mathrm{O}_{3} \geq 99.0 \%, \mathrm{Y}_{2} \mathrm{O}_{3} 5.4 \% \\
\mathrm{Al}_{2} \mathrm{O}_{3}<0.35 \%, \mathrm{~F}_{2} \mathrm{O}_{3}<0.01 \% \text {, other } \\
\text { oxides }<0.2 \%\end{array}$ & $\begin{array}{l}\text { Sirona Dental Systems GmbH, } \\
\text { Bensheim, Germany }\end{array}$ \\
\hline H & CEREC locks & $\begin{array}{l}\text { Feldspathic } \\
\text { ceramic }\end{array}$ & $\begin{array}{l}\mathrm{SiO}_{2} 56-64 \%, \mathrm{Al}_{2} \mathrm{O}_{3} 20-23 \%, \mathrm{Na}_{2} \mathrm{O} \\
6-9 \%, \mathrm{~K}_{2} \mathrm{O} 6-8 \%, \mathrm{CaO} 0.3-0.6 \%, \mathrm{TiO}_{2} \\
0.0-0.1 \%\end{array}$ & $\begin{array}{l}\text { Sirona Dental Systems GmbH, } \\
\text { Bensheim, Germany }\end{array}$ \\
\hline
\end{tabular}

Abbreviations: Au: gold; Pt: platinum; Zn: zinc; Rh: rhodium, Fe: iron; Mn: manganese; Ta: tantalum; Cr: chromium; Co: cobalt; W: tungsten; Mo: molybdenum; Ni: nickel; Si: silicon; Bis-GMA: bisphenol A-glycidyl methacrylate; UDMA: urethane dimethacrylate; Bis-EMA: ethoxylated bisphenol A-glycol dimethacrylate; TEGDMA: triethylene glycol dimethacrylate; $\mathrm{SiO}_{2}$ : silicon dioxide; $\mathrm{ZrO}_{2}$ : zirconium dioxide; $\mathrm{Li}_{2} \mathrm{O}$ : lithium oxide; $\mathrm{B}_{2} \mathrm{O}_{3}$ : Boron trioxide; $\mathrm{P}_{2} \mathrm{O}_{5}$ : Phosphorus pentoxide; $\mathrm{Al}_{2} \mathrm{O}_{3}$ : aluminium oxide; $\mathrm{ZrO}_{2}$ : zirconium dioxide; $\mathrm{HfO}_{2}$ : hafnium dioxide, $\mathrm{Y}_{2} \mathrm{O}_{3}$ : yttrium Oxide; $\mathrm{F}_{2} \mathrm{O}_{3}$ : ferric oxide; $\mathrm{Na}_{2} \mathrm{O}$ : sodium oxide; $\mathrm{K}_{2} \mathrm{O}$ : potassium oxide; $\mathrm{CaO}$ : calcium oxide; $\mathrm{TiO}_{2}$ : titanium dioxide.

but metallurgically, considering the periodic table various elements can be used in dental alloys and they are even more complex materials. The intricacy and variety of these alloys complicate to understand their biocompatibility, since the body can be affected by any element released from the alloy [1]. According to the American Dental Association (ADA) (1986), dental cast alloys can be: (1) high noble alloys $(\geq 60 \%$ Gold $(\mathrm{Au})$, Platinum (Pt), Palladium (Pd) and $\geq 40 \% \mathrm{Au}$ ), (2) noble alloys ( $\geq 25 \% \mathrm{Au}, \mathrm{Pt}, \mathrm{Pd}$ ) and (3) predominantly base metal alloys ( $<25 \% \mathrm{Au})$ [3]. Dental alloys are defined by their composition, but composition can be explained in two ways, either as in the alloy percent of the number of atoms of each element (atomic percentage $=$ at $\%$ ) or percentage of weight (wt\%) of elements. Even though the alloy manufacturers and standards organizations describe an alloy's composition by weight percentage, atomic percentage of these materials determine their biological properties [1]. In recent decades, esthetic and durable restorations have been designed and produced with computer-aided design and computer-aided manufacturing (CAD/CAM) technology. Feldspathic ceramics, glass ceramics containing leucite and lithium disilicate or yttrium tetragonal zirconia polycrystals are the examples of CAD/ CAM high quality CAD/CAM ceramic materials. Recently, nano-hybrid ceramics, zirconia-reinforced lithium silicate ceramics, composites and glass-fiber composites have been added to the previous CAD/ CAM materials [4,5]. Glass-fiber-composite technology has been introduced to the dental practice for well over 20 years. Fiber reinforced composite materials like TRILOR are alternative materials for permanent and temporary dental restorations. Copings, substructures, frameworks for anterior or posterior crowns, bridges, telescopic restorations, bar attachments on implants and drilling guide for implant surgery are among the indications for these materials [6].

Since dental materials used in fixed prosthodontics are contact with oral tissues, the biocompatibility of these materials is very critical and dentists, especially prosthodontics, should focus on dental biomaterials [7]. The release of copper or nickel from cast alloys has been suggested as the main (toxic) cause of oral tissue reactions, such as gingival inflammation [8]. In order to study the cytotoxicity of restorative materials, various in vitro systems including organ cultures and cells in culture have been utilized. However, for in-vitro toxicity test of dental materials, the most commonly used biological system is the cell culture method. Two different types of cells are generally preferred; permanent cell lines derived from type-culture collections (L929 or 3T3 mouse fibroblasts), and primary cells derived from mucosal or gingival explants and established in each individual laboratory. However, permanent cell lines 


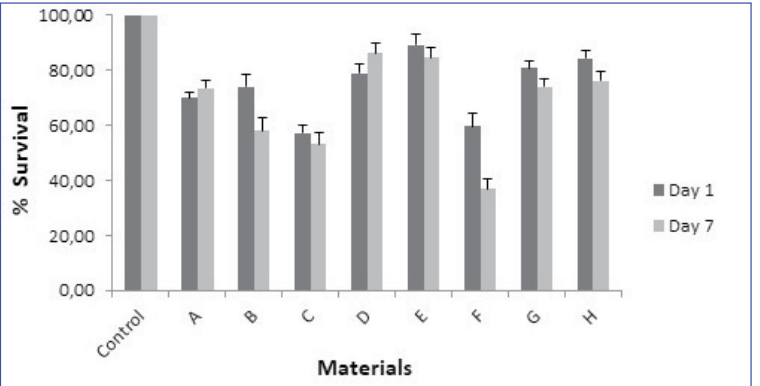

Figure 1. Mean and standard deviation (SD) values of cell viability comparison among the $1^{\text {st }}$ and $7^{\text {th }}$ day medium extracts of restorative materials obtained from XTT assay.

are preferred since they are well defined and easily available [9]. Prior to introduction to dental clinical practice, physical property and biocompatibility accuracy assessment of dental materials is imperative [7]. Within this context, restorative materials entail thorough evaluation with respect to their interaction with the vital tissues, because they may release substances resulting in allergic reactions and inflammation [8]. The aim of the study was to assess the cytotoxic and apoptotic effects of eight indirect restorative materials by using XTT cell proliferation assay, XCELLigence real-time cell analysis system and Annexin-V PI staining on fibroblast cells.

\section{MATERIALS AND METHODS}

Three metal framework restoration materials [Goldbased alloy (A), Chromium-Cobalt alloy (B) and Nickel-Chromium alloy $(C)$ ] and five metal-free $C A D /$ CAM materials [fiber-reinforced-resin-blocks (D), resin-nano-ceramic $(E)$, lithium-disilicate-reinforcedceramics (F), monolithic-zirconia (G) and feldspathicceramics $(\mathrm{H})$ ] were studied. They are shown in Table 1. 36 disc-shaped specimens $(h=2 \mathrm{~mm}, \varnothing=5 \mathrm{~mm})$ were prepared in accordance with ISO 10993-5: Tests for Cytotoxicity - In Vitro Methods [10] for each material group. For the $A, B$ and $C$ groups; the disc-shaped wax patterns $(2 \times 5 \mathrm{~mm})$ were produced with conventional lost-wax technique using an induction-casting machine (Argonocaster- $C$, Shofu, Japan). The casting method was performed under the pressure of argon gas and vacuum suction, and afterwards standard dental laboratory procedures were performed.

After casting, air particle abrasion with $100 \mu \mathrm{m}$ aluminum oxide particles ( $80 \mathrm{psi}=5.62 \mathrm{kgf} / \mathrm{cm}^{2}$ ) was applied to the discs. For polishing process, $400,600,1200$ and 2000 grit silicon carbide papers were utilized and the polishing was completed with diamond and aluminum oxide pastes. For the $D, E$, $F, G$, and $F$ groups, the CAD/CAM blocks were cut using a low-speed diamond saw (Mecatome T180; Presi, Grenoble, France). $F$ and $G$ discs were sintered according to the manufacturer's instructions. Then, OptraFine ceramic polishing system (Ivoclar Vivadent, Schaan, Liechtenstein) was used for polishing the surfaces of the specimens, complying

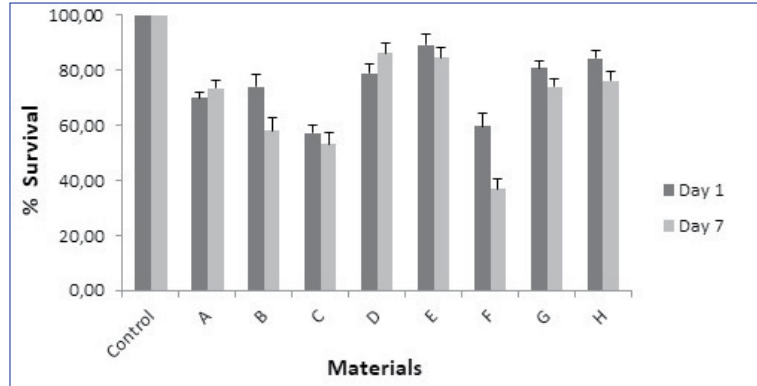

Figure 2. Mean and SD values of cell viability comparison among the $1^{\text {st }}$ and $7^{\text {th }}$ day medium extracts of restorative materials obtained from xCELLigence assay.

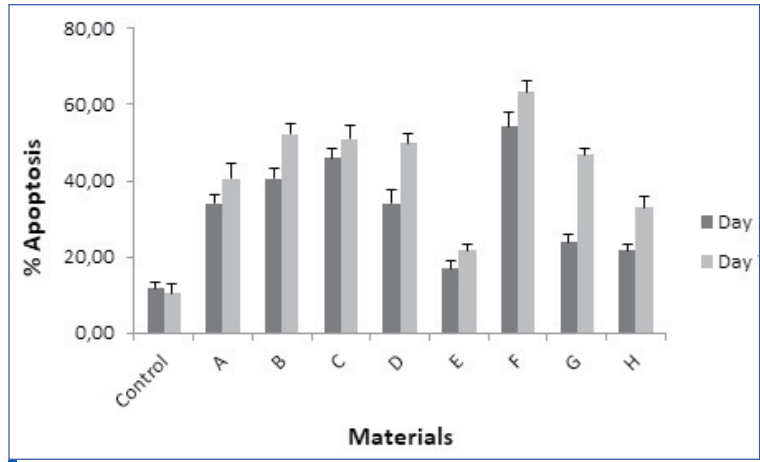

Figure 3. Apoptosis analysis for $1^{\text {st }}$ and $7^{\text {th }}$ day medium extracts of restorative materials. Bar graphs showing the percentage of cell populations (early apoptosis, late apoptosis and necrosis) in treated cells.

with the manufacturer's instructions. Subsequently, the specimens were placed into an ultrasonic water bath (Whaledent Biosonic Jr, Whaledent International, New York, NY) for 10 minutes and then dried. A total of 288 specimens ( $n=36$ per test material) were prepared. Each group was divided into three ( $n=12$ per group) randomly; two groups were assessed with the cytotoxicity assays, while the other group was used for the apoptosis assay.

\subsection{Preparation of medium extracts}

The sterilization process was made with 16 kGy gamma irradiation (Gamma-Pak Sterilization Ind. Tekirdag, Turkey). Then the sterilized disc samples were transferred into 96-well plate and each well was filled with $150 \mu \mathrm{L}$ Eagle's Minimum Essential Medium (EMEM) containing $10 \%$ fetal calf serum (FBS) with $100 \mathrm{U} / \mathrm{mL}$ of penicillin-streptomycin. In control group, there were no specimens in the well plate. All plates were incubated in a highly humidified atmosphere containing $5 \% \mathrm{CO}_{2}$ at $37^{\circ} \mathrm{C}$; medium extracts of the test materials were collected at $1 \mathrm{st}$ and 7 th days and were stored in $-20^{\circ} \mathrm{C}$ until cytotoxicity experiments.

\subsection{Cytotoxicity assay}

L929 cell line was obtained from the American Type Culture Collection (ATCC, Manassas, VA) and grown in EMEM culture medium that was supplemented with $10 \% \mathrm{FBS}$ and $1 \%$ penicillin-streptomycin in a humidified atmosphere with $5 \% \mathrm{CO}_{2}$ at $37^{\circ} \mathrm{C}$. XTT Cell Proliferation Kit (Roche Applied Science, Basel, Switzerland) and xCELLigence real-time cell analyzer 


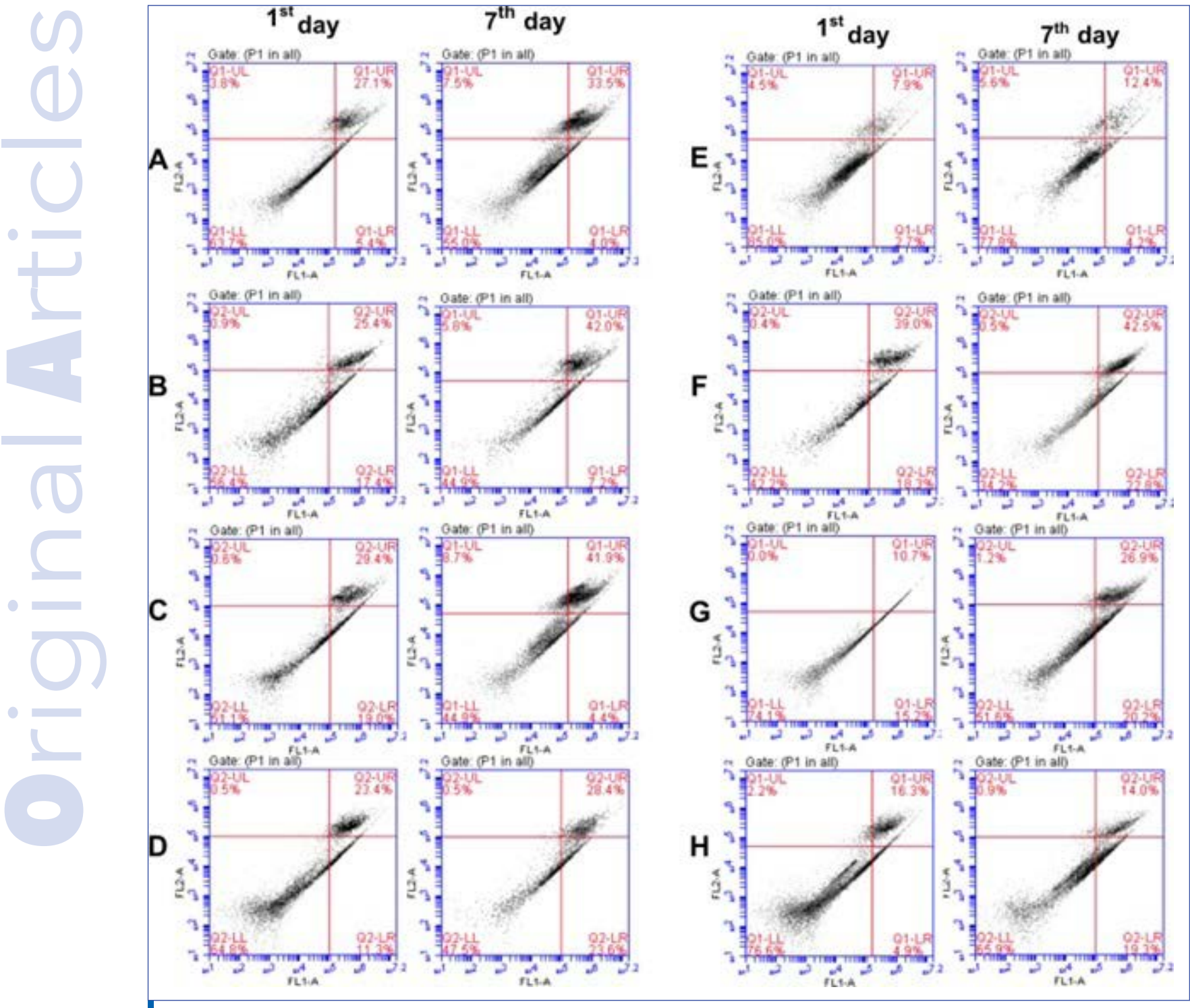

Figure 2. Annexin V/PI staining of indicated cell groups. Cells were treated with $1^{\text {th }}$, $3^{\text {rd }}$ and $7^{\text {th }}$ day medium extracts of restorative materials for $48 \mathrm{~h}$ and then subjected to flow cytometric analysis. (LL:Vital cells, LR: Early apoptosis, UR: Late apoptosis, UL: Necrosis).

(Roche Applied Science, Basel, Switzerland) were used to assess the cytotoxicity of the samples.

For the XTT assay; $3 \times 10^{4}$ cells/well were plated in a 96 -well plate for 24 hours. The next day, $100 \mu \mathrm{L}$ of culture medium extract of each test material was pipetted immediately into each well containing L929 cells. Formazan formation was quantified spectrophotometrically at $450 \mathrm{~nm}$ with a microplate reader (Thermo, Vantaa, Finland) following 48 hours of incubation. xCELLigence real-time cell analyzer measures electrical impedance across microelectrodes integrated on the bottom of tissue culture e-plates. $3 \times 10^{4}$ cells/well were seeded in 100 $\mu \mathrm{L}$ medium and incubated for 24 hours.

Next day, $100 \mu \mathrm{L}$ medium extracts of each test materials were added to the wells. Cell impedance was measured every 15 minutes for a period of 3 days. All experiments were applied in triplicate and the data was assessed with the xCELLigence software (ACEA Biosciences). In order to determine the cell viability, the classification used by Sjogren et al [11], was utilized. If cell viability was below $30 \%$, the material was accepted as severely cytotoxic. Moderately cytotoxic materials scored $30-59 \%$ cell viability, while slightly cytotoxic materials scored $60-90 \%$ and non-cytotoxic materials scored above $90 \%$ [11].

\subsection{Apoptosis assay}

L929 cells were seeded into 96-well plate at a density of $3 \times 10^{4}$ cells/well. Following 24 hours incubation period, $100 \mu \mathrm{L}$ of the medium was aspirated and the cells were treated with $100 \mu \mathrm{L}$ medium extracts of test materials. The cells were gathered after $48 \mathrm{~h}$ of the treatment, washed with phosphate buffered saline (PBS) and assessed with apoptosis detection kit (Annexin V FITC/PI, Roche Applied Science) using BD Accuri C6 Flow Cytometer (BD Biosciences, San Jose, CA). 


\subsection{Statistical analysis}

Three replicated spectrophotometric measurements of XTT assay were completed to calculate the cell viability rates of the samples. Real-time cell analyze data was evaluated with the XCELLigence software. The normality of the data distribution was tested by using the Kolmogorov-Smirnov test.

The data were normally distributed. One-way ANOVA and Tukey's multiple range tests were used with SPSS for Windows (22.0, SPSS Inc., Chicago, IL), $\mathrm{p}<0.05$ was considered significant.

\section{RESULTS}

The survival, early and late apoptosis, and necrosis cell rates of $1 \mathrm{st}$ and 7 th days medium extracts of eight different prosthetic restoration materials which were obtained by XTT, xCELLigence test (Figs. 1,2 ) and apoptosis analysis (Figs. 3, 4) are presented.

\subsection{Cytotoxic effects of prosthetic restoration materials} Regarding cell viability, among the material groups statistically significant differences were observed between the 1st day and 7th day medium extracts measurements $(p<0.05)$. The lowest cell viability was seen in $\mathrm{F}$ group both xCELLigence and XTT experiments $(\mathrm{p}<0.05)$.

On the 1st day, the highest cell viability values were observed in $\mathrm{E}$ and $\mathrm{H}$ groups, whereas $\mathrm{C}$ and $\mathrm{F}$ groups displayed the lowest cell viability with both $x C E L L i g e n c e$ and XTT tests $(p<0.05)$. No significant differences were observed between $A$ and $B$; and $D$ and $G$ groups ( $p>0.05$ ).

On the 7th day, the cell viability was significantly affected by the material type $(p<0.05)$. E group showed the highest viability value and had an enhanced effect on cell survival, while $F$ group displayed the lowest cell viability both with $x$ CELLigence and XTT tests $(p<0.05)$.

There were no substantial differences among $A$, $\mathrm{G}$ and $\mathrm{H} ; \mathrm{B}$ and $\mathrm{C}$ groups, respectively in all test methods ( $p>0.05)$.

The cell viability of $B, F, G$ and $H$ groups decreased over time both with XTT and xCELLigence tests $(p<0.05)$. However, no significant differences were discerned among $A, C, D$ and $E$ groups regarding time periods ( $p>0.05$ ).

Considering the 7-day observation period, among the tested materials $E$ group showed the highest cell survival values, whereas $\mathrm{F}$ group displayed the lowest cell viability, both with xCELLigence and XTT tests (Figs. 1, 2).

Throughout the entire test period, A, D, E, G and H groups continued to exhibit cell viability between $60-90 \%$. Hence, these materials were considered as slightly cytotoxic.

The $\mathrm{C}$ and $\mathrm{F}$ groups were moderately cytotoxic at all incubation periods (Figs. 1, 2). On the other hand; Group B was slightly cytotoxic on the 1st day but moderately cytotoxic on the 7th day.
3.2. Apoptotic effects of prosthetic restoration materials Within different incubation periods, apoptosis rates of the prosthetic restoration materials varied significantly $(p<0.05)$.

$\mathrm{F}$ group presented the highest apoptosis rates for both 1 st and 7 th days $(54.27 \pm 3.95 ; 63.27 \pm 2.96)$ whereas the lowest apoptosis rates were observed in $E(17.01 \pm 2.02 ; 21.73 \pm 1.55)$ and $H$ group $(21.80 \pm 1.71$; $33.03 \pm 2.66)$. C and B groups followed with the $45.97 \pm 2.59,40.53 \pm 2.83$ and $51.03 \pm 3.66,52.36 \pm 2.57$ apoptosis rates on the $1 \mathrm{st}$ and 7 th days, respectively (Figs. 3, 4).

\section{DISCUSSION}

Currently, wide ranges of restorative materials for fixed prosthodontics are available in the market for dental practitioners' use [7]. Dental casting alloys have played a major role in the restorative treatment of the patients, but this role has changed considerably in recent years due to the development of more durable resin-based composites and the improvement of all-ceramic restorations. Nevertheless, alloys will continue to be a commonly used material for fixed prosthetic restorations for the upcoming years [12], despite the fact that their mutual shortcoming remainis the long-term presence of all fixed prosthodontic materials in the oral cavity [7]. Considering that biocompatibility is one of the critical factors affecting the treatment outcome, the biomaterials that are used for partial or complete substitutions of tooth and/or oral tissues should be examined thoroughly before clinical applications [13-15]. Fortunately, increasing development of the innovative materials in dental applications has led to an improved awareness of the biological risks and restrictions of these materials. Monitoring the cell viability is crucial for biomedical study both from a systematic view to comprehend the biochemical and molecular pathways regulating cell viability, and from a therapeutic approach to acquire agents that modulate cell viability [16].

Cell culture method is considered as a coordinated, reproducible, and cost-effective technique to investigate the biocompatibility [17]. Dental materials' biocompatibility is commonly investigated with cytotoxicity and apoptosis tests [18]. In the present study, XTT and xCELLigence systems were used to assess the cytotoxicity. The xCELLigence system uses impedance as readout and provides dynamic and real-time monitoring of cellular phenotypic changes. By means of continuous monitoring, this system perceives between various disturbances of cell viability, for instance senescence, cell cycle arrest, and cell death. Additionally, the time perseverance of the xCELLigence system provides determination of the optimal time points to accomplish standard cell viability assays, alongside with other end-point assays to comprehend action mode [16]. XTT cell proliferation is a colorimetric 
assay system that measures formazan products produced by metabolically active cells and is used as a common cell culture method [19]. The programmed death of cells is apoptosis, and it is essential for the sustenance of homeostasis. The flow cytometric apoptosis assay is another method that specifies the cells that have started the apoptotic pathway $[20,21]$. Al-Hiyasat et al. [22], investigated the cytotoxicity of high-noble alloy and base-metal alloys by the diMethyl Thiazol diphenyl-Tetrazolium (MTT) method on Balb/C 3T3 fibroblasts, and revealed that the difference in the composition of alloys markedly affected their cytotoxicity potential. They stated that the high concentration of chromium $(\mathrm{Cr})$ and molybdenum (Mo) have reduced the cytotoxicity [22]. On the contrary, in the present study, the cell viability was lower in Group C with $11 \%$ Mo than Group B with 3.5\% Mo in the 1st day of the tests, and also, higher apoptosis rate was observed in Group C. Tai et al. [23], investigated both the corrosion rates and $\mathrm{Cr}$, nickel $(\mathrm{Ni})$ and beryllium $(\mathrm{Be})$ release of alloys in artificial oral environments. According to their study, nickel release was higher than that of chromium. Parallel to their findings, in the present study, on the 7th day tests, the decrease in the cell viability of Group C may be attributed to the $\mathrm{Ni}$ release. On the contrary, Schedle et al. [24], stated that Cobalt (Co) ions are more toxic than $\mathrm{Ni}$ ions, and the increase in Co content in an alloy would increase the toxicity of the material. In the present study, one of the highest apoptosis induced groups on the first day was the Ni-Cr-Mo alloy group (45.97\%). In a similar study where biocompatibility and apoptosis effects of Au, Titanium (Ti) and Ni-Cr alloy on $\mathrm{L} 929$ fibroblast cells were investigated, apoptosis was inducted via Caspase-3 and Caspase-9 mRNA expressions increase in $\mathrm{Ni}-\mathrm{Cr}$ material [25].

Wataha et al. [26], tested different gold alloys for element release into cell-culture medium, and reported that $\mathrm{Au}$ and $\mathrm{Pd}$ ions generally did not dissolve into the medium, but silver (Ag), copper (Cu) and zinc ( $\mathrm{Zn}$ ) ions were frequently dissolved. In another study, Sjörgen et al. [11], investigated the cytotoxicity of 15 different metals, dental alloys and ceramic materials, and reported that the Au alloy with $0.6 \% \mathrm{Zn}$ showed moderate cytotoxicity. In the present study, slight cytotoxicity was revealed for the Au alloy with $1.4 \% \mathrm{Zn}$ content.

Faria et al. [27], investigated the cytotoxicity of Ti6Al4V, CpTi, Ni-Cr and Co-Cr alloys on SCC-9 cell lines with cell viability and quantity. Surprisingly, they found that $\mathrm{Co}-\mathrm{Cr}$ alloy was cytotoxic but $\mathrm{Ni}-\mathrm{Cr}$ alloy was not. In the present study, $\mathrm{Cr}$-Co alloy was slightly cytotoxic, as well. Similarly, in-vitro cytotoxic effects of elements released from gold alloy are also reported [7]. Therefore, clinicians should be aware that Au alloy is not completely inert and biocompatible with oral tissues. The clinical relevance of these findings remains unclear and further in-vitro studies, as well as controlled clinical trials, are needed due to possible exceptions.

Although dental ceramics are known as chemically inert materials, a specific inert property of a ceramic cannot be attributed as a general feature to all ceramics since different ceramics have distinctive chemical configurations [28]. In addition to the diverse constituents and microstructures of the ceramics and the corrosive properties, the period and the temperature of the environment they are exposed to may negatively affect their chemical behavior [29]. Because of the structure and $\mathrm{pH}$ of saliva, $\mathrm{pH}$ of foods, plaque amount and the presence of abdominal acids, oral environment is considered corrosive. As a result of deterioration of chemical stability, release of potential toxic inorganic ions from dental ceramics may increase [28]. Milleding et al. [29], investigated the corrosive behaviors of crystal and oxide ceramics in liquid and acidic mediums, and reported that crystal ceramics like Empress was prone to corrosion more than oxide ceramics like zirconia and alumina. Nevertheless, massive loss of ceramics is very hard to investigate technically due to the oxidation of the released elements and the phenomenal precision of atomic absorption methods [30]. In their investigations concerning the cytotoxicity of disilicate materials, Messer et al. [30] and Bracket et al. [31], stated that, regardless of the materials fabrication methods and minor structural differences, Empress 2 is biologically precarious. In a previous study, IPS e.max CAD material was not found toxic [32]. Nevertheless, in the present study, lithium disilicate material Rosetta SuperMill was considered as moderately toxic. This contradiction may be attributed to the distinctive material compositions in different brands.

Y-TZP based materials produced by CAD/CAM systems are introduced to be utilized both in esthetic and load bearing areas. With superior esthetics and physical features, zirconia is the preferred material in current procedures [33]. Shin et al. [34] investigated the cytotoxicity of the zirconia posts cemented with different materials on L929 cells, and reported that zirconia posts alone did not reveal toxicity.

Frese et al. [35] declared that composites with fiber content exhibited minor toxicity. In the present study, fiber reinforced resin material exhibited less toxicity compared to the other materials tested. This finding may be attributed to the controlled polymerization of the CAD/CAM resin materials under optimum pressure and temperature during manufacturing process [32]. The major limitation of this study is that it is an in-vitro study accomplished in laboratory conditions, and the results cannot be directly valid for clinical practice. However, the results may provide additional information for clinicians during material selection. Permanent cell lines from mouse fibroblasts were used in this study, but in future studies primary cells (e.g., gingival fibroblasts) may be preferred due to their better mimicking ability of the oral environment. 


\section{CONCLUSIONS}

Within the limitations of this in vitro study, the following conclusions were drawn:

1) Rosetta SuperMill (Lithium disilicate ceramic material group (F)) revealed the highest apoptosis rate and the lowest cell viability at all incubation periods.

2) $\mathrm{Cr}$-Co alloy material group (B), $\mathrm{Ni}-\mathrm{Cr}$ alloy material group (C) and $\mathrm{F}$ group had moderate cytotoxic effects on the day 7.

3) Au alloy material group (A) showed similar cell viability result with $\mathrm{Cr}$-Co alloy material group (B) on the 1st day, whereas B group showed moderate cytotoxicity at the end of the 7th day.

4) $C A D / C A M$ restorative materials with fiber and resin content had favorable viability results.

5) All fixed restoration materials presented a variable degree of cytotoxicity potential.

\section{REFERENCES}

1. Wataha JC. Biocompatibility of dental casting alloys: a review. J Prosthet Dent. 2000;83(2):223-234. doi:10.1016/s00223913(00)80016-5.

[Full text links] [CrossRef] [PubMed] Google Scholar Scopus WoS 2. Wataha JC, Messer RL. Casting alloys. Dent Clin North Am. 2004;48(2):vii-512. doi:10.1016/j.cden.2003.12.010.

[Full text links] [CrossRef] [PubMed] Google Scholar Scopus 3. Classification system for cast alloys. Council on Dental Materials, Instruments, and Equipment. J Am Dent Assoc. 1984;109:766. doi:10.14219/jada.archive.1984.0185.

[Full text links] [CrossRef] [PubMed] Google Scholar Scopus 4. Aktas G, Yerlikaya H, Akca K. Mechanical failure of endocrowns manufactured with different ceramic materials: an in vitro biomechanical study. J Prosthodont. 2018;27(4):340-346. doi:10.1111/jopr.12499.

[Full text links] [CrossRef] [PubMed] Google Scholar Scopus WoS 5. Lauvahutanon S, Takahashi H, Shiozawa M, et al. Mechanical properties of composite resin blocks for CAD/CAM. Dent Mater J. 2014;33(5):705-710. doi:10.4012/dmj.2014-208.

[Full text links] [CrossRef] [PubMed] Google Scholar Scopus

6. Bioloren [Internet]. Website: https://bioloren.com/en/prodotti/ trilor-en/trilor-block/Accessed 20/05/2020.

7. Elshahawy W, Watanabe I. Biocompatibility of dental alloys used in dental fixed prosthodontics. Tanta Dental Journal 2014;11(2):150-159. doi:10.1016/j.tdj.2014.07.005.

[Full text links] [CrossRef] Google Scholar

8. Taylor TD, Morton TH Jr. Ulcerative lesions of the palate associated with removable partial denture castings. J Prosthet Dent. 1991;66(2):213-221. doi:10.1016/s0022-3913(05)80050-2. [Full text links] [CrossRef] [PubMed] Google Scholar Scopus WoS 9. Schmalz G. Use of cell cultures for toxicity testing of dental materials-advantages and limitations. J Dent. 1994; 22 Suppl 2:S6-S11. doi:10.1016/0300-5712(94)90032-9.

[Full text links] [CrossRef] [PubMed] Google Scholar Scopus WoS 10. . International Standards Organization (ISO) 10993-5:1992. Biological evaluation of medical devices - Part 5: Tests for in vitro cytotoxicity. International Standards Organization, Geneva Switzerland, 1992.

11. Sjogren G, Sletten G, Dahl JE. Cytotoxicity of dental alloys, metals, and ceramics assessed by millipore filter, agar overlay, and MTT tests. J Prosthet Dent. 2000;84(2):229-236. doi:10.1067/ mpr.2000.107227.

[Full text links] [CrossRef] [PubMed] Google Scholar Scopus WoS 12. Wataha JC. Alloys for prosthodontic restorations. J Prosthet Dent. 2002;87(4):351-363. doi:10.1067/mpr.2002.123817. [Full text links] [CrossRef] [PubMed] Google Scholar Scopus 13. Hondrum SO. A review of the strength properties of dental ceramics. J Prosthet Dent. 1992;67(6):859-865. doi:10.1016/00223913(92)90602-7.

[Full text links] [CrossRef] [PubMed] Google Scholar

14. Browne RM. The in vitro assessment of the cytotoxicity of dental materials-does it have a role? Int Endod J. 1988;21(2):5058. doi:10.1111/j.1365-2591.1988.tb00955.x.

[Full text links] [CrossRef] [PubMed] Google Scholar

\section{CONFLICT OF INTEREST}

The authors declare no conflict of interest.

\section{AUTHOR CONTRIBUTIONS}

AA: Data gathering, analysis and interpretation of the results, manuscript writing. VBC: experimental design, analysis and interpretation of the results. PG: Study design, manuscript proofreading. BBK: sample preparation. EC: Study and experimental design, analysis and interpretation of the results, manuscript proofreading.

\section{ACKNOWLEDGMENTS}

This study was supported by the Ege University, Scientific Research Project Coordination Unit (Project Number: Diş-022).

15. Scott A, Egner W, Gawkrodger DJ, et al. The national survey of adverse reactions to dental materials in the UK: a preliminary study by the UK Adverse Reactions Reporting Project. Br Dent J. 2004;196(8):471-477. doi:10.1038/sj.bdj.4811176.

[Full text links] [CrossRef] [PubMed] Google Scholar Scopus WoS 16. Ke N, Wang X, Xu X, et al. The xCELLigence system for realtime and label-free monitoring of cell viability. Methods Mol Biol. 2011;740:33-43. doi:10.1007/978-1-61779-108-6_6.

[Full text links] [CrossRef] [PubMed] Google Scholar Scopus WoS

17. Hensten-Pettersen A. Comparison of the methods available for assessing cytotoxicity. Int Endod J. 1988;21(2):89-99.

doi:10.1111/j.1365-2591.1988.tb00961.x.

[Full text links] [CrossRef] [PubMed] Google Scholar Scopus 18. Malkoc S, Ozturk F, Corekci B, et al. Real-time cell analysis of the cytotoxicity of orthodontic mini-implants on human gingival fibroblasts and mouse osteoblasts. Am J Orthod Dentofacial Orthop. 2012;141(4):419-426. doi:10.1016/j.ajodo.2011.12.009. [Full text links] [CrossRef] [PubMed] Google Scholar Scopus WoS 19. Shehata M, Durner J, Eldenez A, et al. Cytotoxicity and induction of DNA double-strand breaks by components leached from dental composites in primary human gingival fibroblasts. Dent Mater. 2013;29(9):971-979. doi:10.1016/j.dental.2013.07.007. [Full text links] [CrossRef] [PubMed] Google Scholar Scopus WoS 20. McCracken M. Dental implant materials: commercially pure titanium and titanium alloys. J Prosthodont. 1999;8(1):40-43. doi:10.1111/j.1532-849x.1999.tb00006.x.

[Full text links] [CrossRef] [PubMed] Google Scholar Scopus 21. Sedarat C, Harmand MF, Naji A, et al. In vitro kinetic evaluation of titanium alloy biodegradation. J Periodontal Res. 2001:36(5):269-274. doi:10.1034/j.1600-0765.2001.360501x. [Full text links] [CrossRef] [PubMed] Google Scholar Scopus WoS 22. Al-Hiyasat AS, Darmani H, Bashabsheh OM. Cytotoxicity of dental casting alloys after conditioning in distilled water. Int $J$

Prosthodont. 2003;16(6):597-601.

[PubMed] Google Scholar Scopus WoS

23. Tai Y, De Long R, Goodkind RJ, et al. Leaching of nickel, chromium and beryllium ions from base metal alloy in an artificial oral environment. J Prosthet Dent. 1992;68(4):692-697. doi:10.1016/0022-3913(92)90388-q.

[Full text links] [CrossRef] [PubMed] Google Scholar

24. Schedle A, Samorapoompichit P, Rausch-Fan XH, et al. Response of L-929 fibroblasts, human gingival fibroblasts and human tissue mast cells to various metal cations. J Dent Res. 1995;74(8):1513-1520. doi:10.1177/00220345950740081301. [Full text links] [CrossRef] [PubMed] Google Scholar Scopus WoS 25. Meng $\mathrm{H}$, Li XM, Xu YL, et al. [Effect of three dental alloys on cytotoxicity and apoptosis related gene expression in L929 cells]. Shanghai Kou Qiang Yi Xue. 2013; 22(1):30-34

[PubMed] Google Scholar Scopus

26. Wataha JC, Hanks CT, Craig RG. The in vitro effects of metal cations on eukaryotic cell metabolism. J Biomed Mater Res. 1991;25(9):1133-1149. doi:10.1002/jbm.820250907.

[Full text links] [CrossRef] [PubMed] Google Scholar Scopus WoS 
27. Faria $A C L$, Rosa $A L$, Rodrigues $R C$, et al. In vitro cytotoxicity of dental alloys and cpTi obtained by casting. J Biomed Mater Res Part B Appl Biomater. 2008;85(2):504-508. doi:10.1002/ jbm.b.30972.

[Full text links] [CrossRef] [PubMed] Google Scholar Scopus WoS 28. Jakovac M, Zivko-Babic J, Curkovic L, et al. Measurement of ion elution from dental ceramics. J Eur Ceram Soc.

2006;26(9):1695-1700. doi:10.1016/j.jeurceramsoc.2005.03.242.

[CrossRef] Google Scholar Scopus WoS

29. Milleding P, Haraldsson C, Karlsson S. Ion leaching from dental ceramics during static in vitro corrosion testing. J Biomed Mater Res. 2002;61(4):541-550. doi:10.1002/jbm.10109.

[CrossRef] [PubMed] Google Scholar Scopus WoS

30. Messer RL, Lockwood PE, Wataha JC, et al. In vitro cytotoxicity of traditional versus contemporary dental ceramics. J Prosthet Dent. 2003;90(5):452-458. doi:10.1016/s0022-3913(03)00533-x.

[Full text links] [CrossRef] [PubMed] Google Scholar Scopus WoS 31. Brackett MG, Lockwood PE, Messer RL, et al. In vitro cytotoxic response to lithium disilicate dental ceramics. Dent Mater. 2008;24(4):450-456. doi:10.1016/j.dental.2007.06.013.

[Full text links] [CrossRef] [PubMed] Google Scholar Scopus WoS
32. Atay A, Gürdal I, Bozok Cetıntas V, et al. Effects of new generation all-ceramic and provisional materials on fibroblast cells. J Prosthodont. 2019;28(1):e383-e394. doi:10.1111/ jopr.12915.

[Full text links] [CrossRef] [PubMed] Google Scholar Scopus WoS 33. Miyazaki T, Nakamura T, Matsumura H, et al. Current status of zirconia restoration. J Prosthodont Res. 2013;57(4):236261. doi:10.1016/j.jpor.2013.09.001.[Full text links] [CrossRef] [PubMed] Google Scholar Scopus WoS

34. Shin H, Ko H, Kim M. Cytotoxicity and biocompatibility of Zirconia (Y-TZP) posts with various dental cements. Restor Dent Endod. 2016:41(3):167-175. doi:10.5395/rde.2016.41.3.167. [Full text links] [CrossRef] [PubMed] Google Scholar 35. Frese C, Wolff D, Zingler S, et al. Cytotoxicity of coated and uncoated fibre-reinforced composites. Acta Odontol Scand. 2014;72(5):321-330. doi:10.3109/00016357.2013.826381.

[Full text links] [CrossRef] [PubMed] Google Scholar Scopus WoS

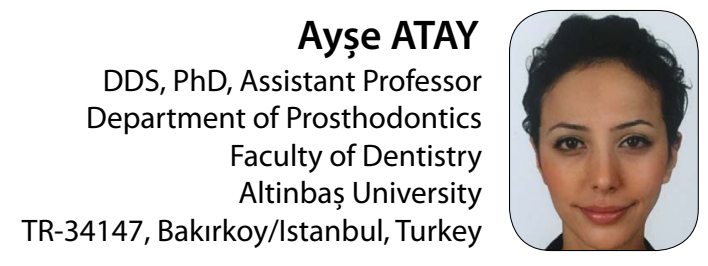

Ayşe Atay graduated from Ege University, Faculty of Dentistry, Izmir, Turkey in 2004. She enrolled on her PhD degree in 2006 and she was awarded her PhD degree by Ege University in 2010. Since 2014, she has been working as an assistant professor at the Department of Prosthodontics within the Faculty of Dentistry of the Altınbaș University.

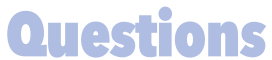

\section{Choose the content of the high noble alloys below:}

a. $<60 \% \mathrm{Au}, \mathrm{Pd}$

b. $\geq 60 \% \mathrm{Au}, \mathrm{Pt}, \mathrm{Pd}$ and $\geq 40 \% \mathrm{Au}$;

口c. $\geq 25 \% \mathrm{Au}, \mathrm{Pt}, \mathrm{Pd}$;

ad. $<25 \% \mathrm{Au}$.

2. Which of the following is the element released from cast alloys and shown as the main (toxic) cause of oral tissue reactions such as gingival inflammation?

口a. Au;

口b. Ni;

ac. Cr;

ad. Co.

3. Which of the following is a colorimetric assay that measures formazan products produced by metabolically active cells and is used as a common cell culture method?

口a. XTT assay;

口b. MTT assay;

$\square$ c. xCELLigence system;

$\square d$. Apoptosis assay.

\section{According to the results of this study, which materials showed favorable viability results?}

a. Cr-Co alloy;

$\square$ b. Lithium disilicate glass-ceramic;

ac. Fiber reinforced composite material;

ad. Ni-Cr alloy. 


\title{
INFLUENCE OF THE COVID-19 PANDEMIC ON DENTAL PRACTICE: WHY MEASURES SHOULD BE TAKEN - THE EXPERIENCE OF AN EUROPEAN UNIVERSITY HOSPITAL (PART 1)
}

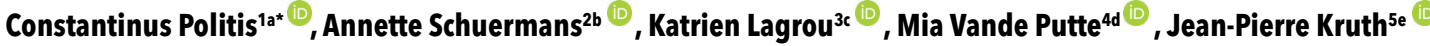 \\ 'Department OMFS, Department Imaging and Pathology, Faculty of Medicine, Leuven University Hospitals, Leuven, Belgium \\ 2Department of Hygiene, Infection Control and Epidemiology, Faculty of Medicine, Leuven University Hospitals, Leuven, Belgium \\ ${ }^{3}$ Department of Laboratory Medicine, Faculty of Medicine, Leuven University Hospitals, Leuven, Belgium \\ ${ }^{4}$ Hospital Hygiene and Infection Control Department, Faculty of Medicine, Leuven University Hospitals, Leuven, Belgium \\ ${ }^{5}$ Wet Engineering Department, Technical Service, Faculty of Medicine, Leuven University Hospitals, Leuven, Belgium
}

aMD, DDS, MM, MHA, PhD, Full Professor \& Chairperson OMFS; e-mail: constantinus.politis@uzleuven.be; ORCIDiD: https://orcid.org/0000-0003-4772-9897

${ }^{b} M D$, PhD, Professor; e-mail: annette.schuermans@uzleuven.be; ORCIDiD: https://orcid.org/0000-0002-0998-8241

'PharmD, PhD, Full Professor KU Leuven; e-mail: katrien.lagrou@uzleuven.be; ORCIDiD: https://orcid.org/0000-0001-8668-1350

dInfection Control Practitioner, Expert of the Higher Health Council; ICP; e-mail: mia.vandeputte@uzleuven.be;

ORCIDiD: https://orcid.org/0000-0003-0556-5345

eEng, Ir; e-mail: jean.kruth@uzleuven.be; ORCIDiD: https://orcid.org/0000-0003-0362-8875

ABSTRACT

d) https://doi.org/10.25241/stomaeduj.2020.7(3).art.2

Introduction The COVID-pandemic does not leave the dental practice unattended. The objective is to analyze why the COVID-19 pandemic urges changes in daily dental practice in the Belgian context.

Methodology The Leuven University Hospital's view is based on Belgian and Leuven University data and existing guidelines concerning hygiene measures in dental practices. The approach chosen is a narrative qualitative approach.

Results Although no transmission of COVID-19 has been reported in Belgian dental practices, the number of health care workers infected and deceased urges for safety measures.

Conclusions In the absence of a vaccine and of reliable data about the infectivity of droplet and droplet cores, dental procedures causing aerosol should be considered as possible sources of viral spread when treating contagious patients, symptomatic or asymptomatic.

\section{KEYWORDS}

COVID-19; Aerosol; SARS-2-COV; Personal Protective Equipment; Respirator.

\section{INTRODUCTION}

After the outbreak of COVID-19 in Wuhan, China, the virus spread to the rest of the world and on March $11^{\text {th }}, 2020$, the COVID-19 pandemic was formalized by the World Health Organization. On March $18^{\text {th }}$ 2020, the lock-down was decreed in Belgium and many dental practices decided to carry out only urgent treatments. A gradual reopening from 18.5.2020 was again possible thanks to guidelines from Sciensano concerning the organization of the dental practice. The government provided with an additional $20 €$ per treated patient up to maximal 200 patients per month as from March $1^{\text {st }}-$ December $31^{\text {st }} 2020$. This manuscript (in two parts) is intended to provide an answer to the question why measures should be taken by the dental community (part 1 of the manuscript) and which measures should be taken in the general dental practice based on the experience and the guidelines issued at Leuven University Hospitals (part 2 of the manuscript).

\section{METHODOLOGY}

In contrast to the flu, the COVID-pandemic has caused massive overload of the hospital system in different European countries (Italy, Spain). The disruptive nature of the pandemic urges an analysis of the chain of transmission and its translation into daily dental practice. There is a substantial differ-

(c) (1) (2) OPEN ACCESS This is an Open Access article under the CC BY-NC 4.0 license.

Peer-Reviewed Article

Citation: Politis C, Schuermans A, Lagrou K, Vande Putte M, Kruth JP. IInfluence of the COVID-19 pandemic on dental practice: why measures should be taken - the experience of an European University Hospital (part 1). Stoma Edu J. 2020;7(3):163-174.

Received: September 13, 2020; Revised: September 18, 2020; Accepted: September 20, 2020; Published: September 21, 2020

*Corresponding author: Prof. Dr. Constantinus Politis, MD, DDS, MM, MHA, PhD; Full Professor \& Chairperson Oral \& Maxillofacial Surgery

Kapucijnenvoer 33B, BE-3000 Leuven, Belgium

Tel. +32 16 341780; Fax: +32 16 332437; e-mail: Constantinus.Politis@uzleuven.be

Copyright: $\odot 2020$ the Editorial Council for the Stomatology Edu Journal. 


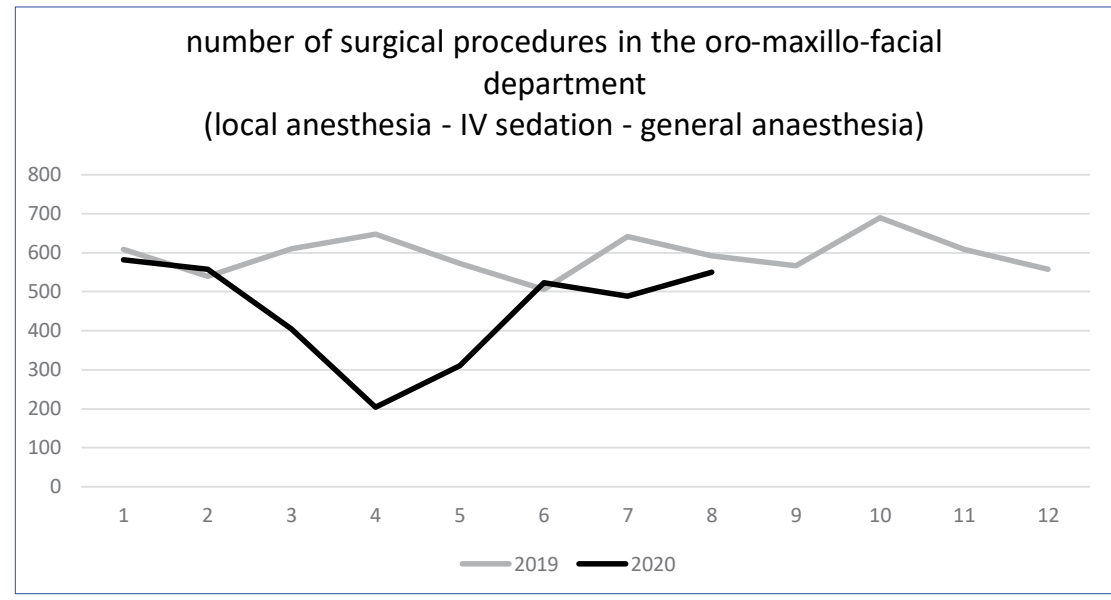

Figure 1. The guidelines issued at Leuven University Hospitals caused a significant impact on the number of executed oral and maxillofacial surgical procedures, during and after the lockdown.

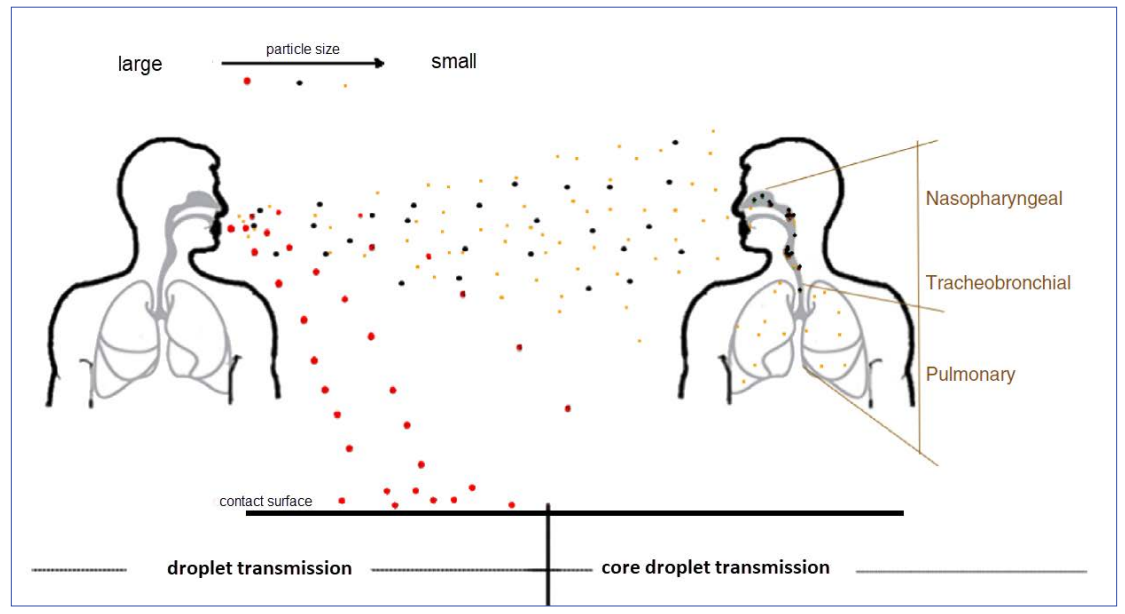

IFigure 2. The infectious chain in its simplest form in the COVID-19 virus: the source (the patient in the infectious phase) - the susceptible person (healthcare providers) - the transmission route (aerosol, direct and indirect contact). ence between hospitals and private dental practices both in guidelines and in exposure to infective micro-organisms. The chain of hygiene in hospitals offers an excellent framework of existing measures which might fit dental practices in an adapted form. The Belgian COVID-19 policy is based on a factsheet which is written by scientists from the Epidemiology of Infectious Diseases Unit of Sciensano, a Scientific Public Health Institute. This factsheet is regularly updated and integrates knowledge of over 4000 articles published on COVID-19 [1]. The existing guidelines for infection control in dental practice in Belgium date back to May $4^{\text {th }}, 2011$ and have not been revised since [2]. In Leuven University Hospitals the policy followed was to allow only treatments which could not be postponed during the lockdown period. Ever since the lockdown on Marcht 18th, every patient in need of an aerosol producing intervention or treatment was subjected to a COVID-19 RT-PCR test. If the test turned out negative, the planned procedure was carried out. In case of a positive RT-PCR test the procedure is postponed for 14 days without renewed taking of the RT-PCR test. In case of a positive RTPCR test and medical need for immediate or prompt treatment, this was carried out in an isolated facility with operating rooms having negative pressure and with maximal personal protective equipment including PAPR (Powered Air-Purifying Respirators). At all times measures of physical distancing, sanitizing and wearing of masks were made obligatory in the hospital setting and remained up to date.

\section{RESULTS}

As a result of these measures none of the health care providers in the oro-maxillo-facial nor dental department got infected with COVID-19. If a health care provider for one reason of another tested positive, contact-tracing was able to determine the source of the infection, never being a treated patient. These measures inflicted reduced revenue (Fig.1), while at the same time incurring new costs (FFP2 masks, RTPCR testing, sanitizing measures. The dental community and the dental alumni of the Catholic University of Leuven requested scientific substantiation of these measures (PART 1 of the manuscript) and their translation into daily dental practice (PART 2 of the manuscript).

\subsection{The disruptive nature of this pandemic}

There are 4 reasons why the COVID-19 pandemic has a disruptive effect on dental practice: the raising of public awareness through government measures on public health hygiene, the characterization of dental practice as an increased risk of transmission, the likelihood that the dentist himself may be infected, the likelihood of stigmatization in the event of a practicerelated epidemic. If a country decides to take little or 

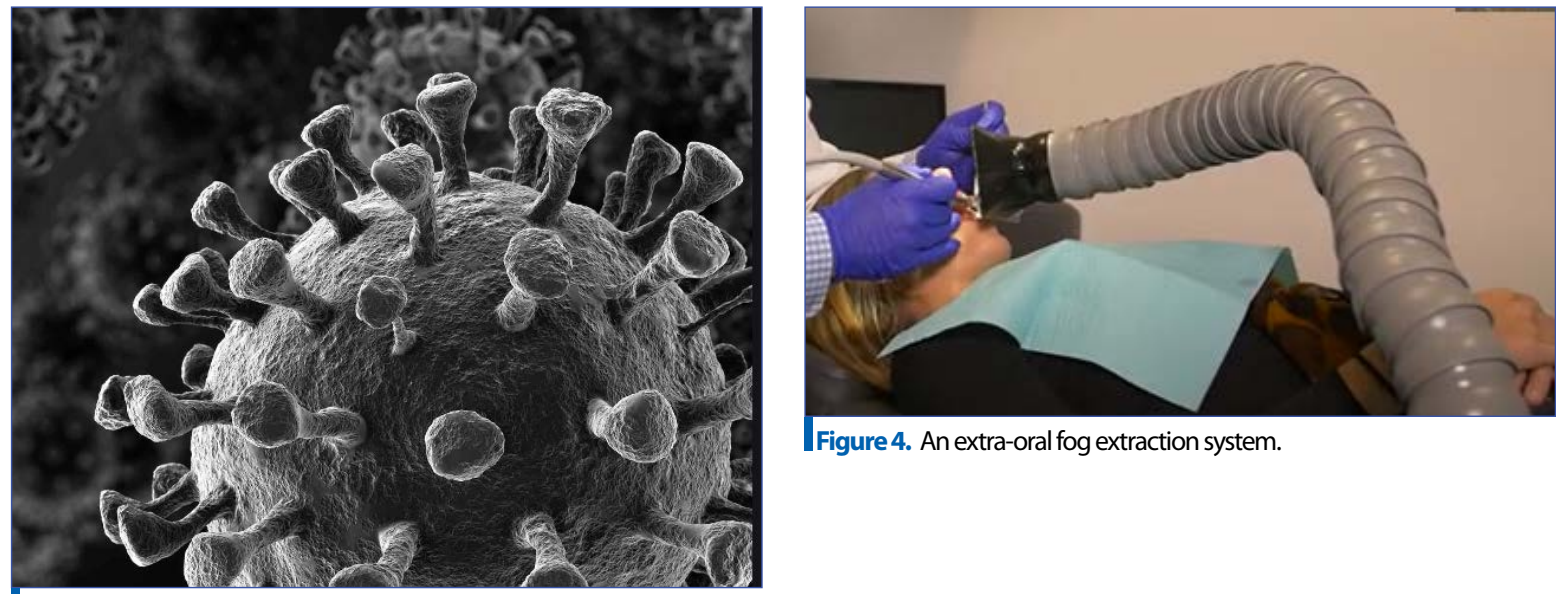

Figure 4. An extra-oral fog extraction system.

Figure 3. The COVID-19 virus has a two-layer phospholipid membrane containing glycoprotein antennae that allow the virus to vaccinate on the ACE-2 receptors of human cells (the ACE-2 receptor is expressed in lung tissue, the cardiovascular system, the renal and urogenital systems, the gastrointestinal system, the endocrine system, the nervous system).

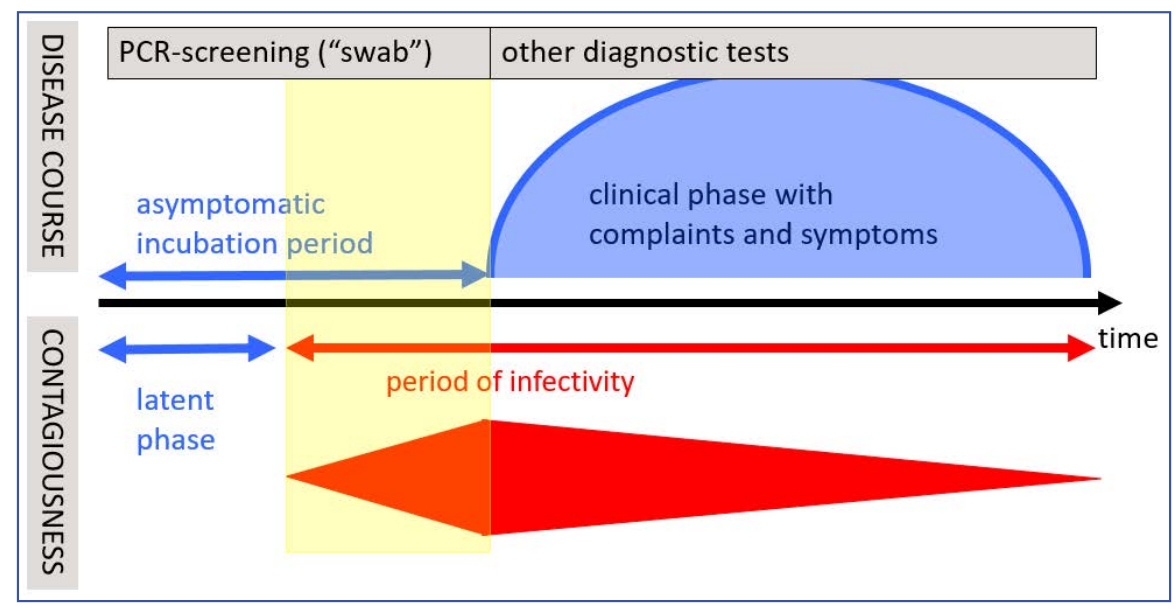

I Figure 5. COVID-19 infection and disease course: asymptomatic people can also be highly contagious during the incubation period of the virus.

no action against a growing epidemic in the hope of obtaining herd immunity, dentists are also not expected to change their daily practice routine. However, when a country quarantines itself, including the outpatient health sector, to prevent the spread of the epidemic, the dental practice is paralyzed, except for urgent treatment. Once all health concerns have been re-established, public opinion will be made aware of this infectious agent. For example, there has been no national or international public campaign on the flu virus and dental practice has not changed under the influence of the flu epidemics. If someone catches the flu in the waiting room of a dental or medical practice, it will not cause stigma to the practice. However, if several patients in the same practice are infected with HIV or hepatitis virus or MRSA or Legionella bacteria, this is very stigmatizing when this is publicly known. It is therefore not surprising that over the past few decades, possible contaminations through water, blood and surfaces have been brought under control through numerous hygiene, disinfection, sterilization and organizational measures. And certainly, when the dentist and the practice staff can themselves become victims of contamination. In the circles of ophthalmologists, ENT doctors, dentists and CMF doctors - disciplines that are in immediate proximity to the patient for more than a few minutes - it caused a sensation when ophthalmologist Li Wenliang from Wuhan alerted the Chinese authorities to the consequences of this "new" coronavirus, only to die of it himself on 7 February 2020 [3].

The COVID-19 virus will also have an impact on practice that goes beyond protection against the virus itself, but rather on its route of transmission, just as HIV, hepatitis and legionella have done previously with transmission via blood, surfaces and water. History shows that many of the measures that will affect outpatient medical or dental practice were implemented much earlier in the hospital sector [4].

This will not be different now. As the existing measures will not disappear, infection control in the dental practice will be extended again. Only this time, a pair of sterile gloves or a water filter will not suffice, even though - at present- no dental health professional working in a private practice in Belgium is known to have died in the line of duty from Covid-19.

\subsection{The chain of infection}

A three-pronged approach is necessary because three elements are inseparable: the chain of infec- 


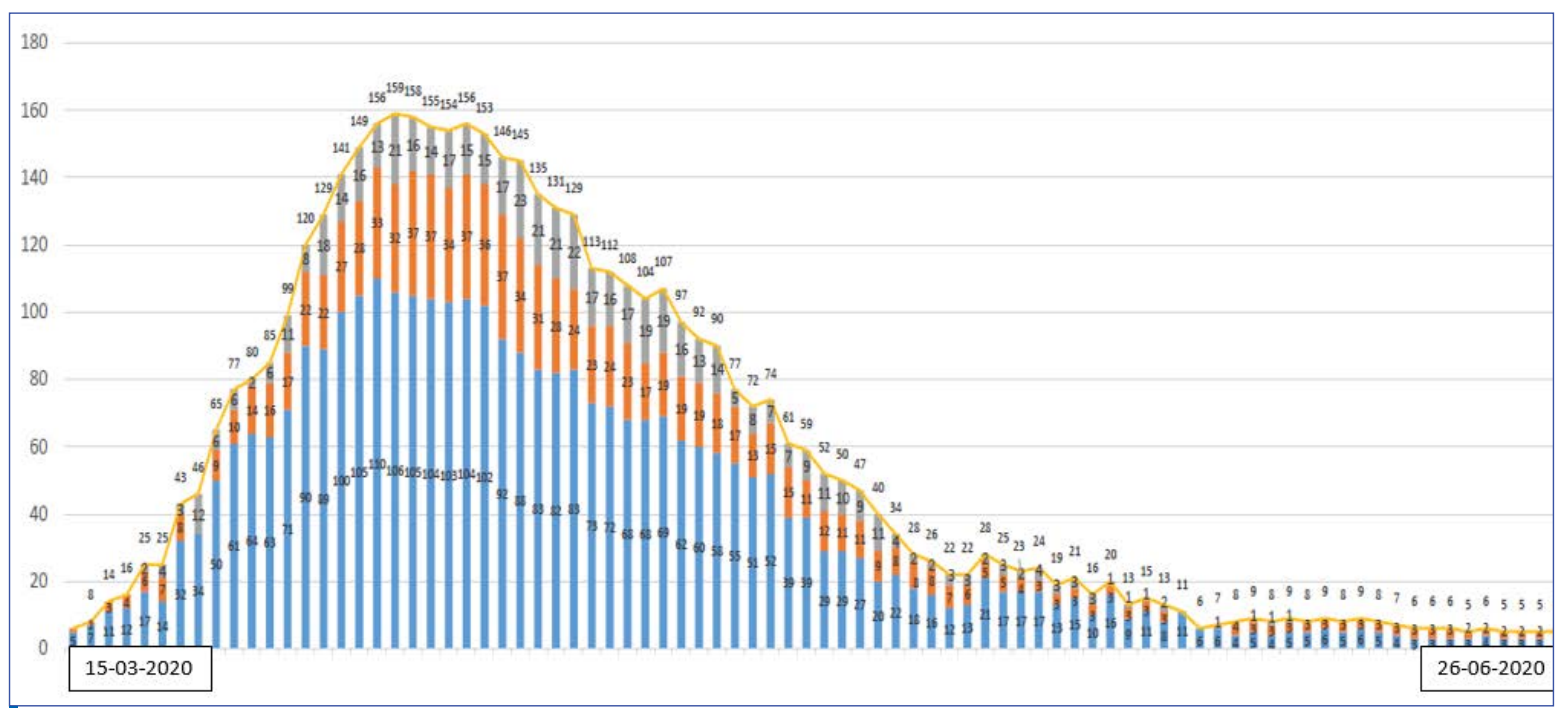

Figure 6a. Evolution of the situation in UZ Leuven between 14.03.2020 and 26.06.2020. The orange (ventilated) and grey (unventilated) bars show patients admitted to the intensive care unit; the blue bars show patients admitted to hospital wards. During this period COVID-19-positive patients are separated from COVID-19-negative patients for surgical interventions. Only urgent procedures can be performed on COVID-19-positive patients. For this purpose, all patients who qualify for surgery will be examined using PCR.

tion, measures to contain the risk of infection and the time factor throughout the epidemiological phases. In its simplest form, the chain of infection is characterized by three basic elements: the source - the route of transmission - the susceptible individual [5]. (Fig. 2) Measures to contain the risk of infection are classified according to a certain hierarchy, ranging from elimination of the source of infection to technical measures, from organizational measures to personal protection measures.

The epidemic has a bell-shaped progression with an accumulation phase until a peak and then a decline that never reaches zero and - in the absence of a vaccination programme - can lead to new local or generalized outbreaks [6]. Depending on the phase of the epidemic, the impact on dental practices varies. The health policy choices that the country makes throughout these phases also have a major influence on the overall picture.

\subsection{The virus}

There are 7 coronaviruses that can infect humans, with SARS-CoV-1, SARS-CoV-2 and MERS-CoV spreading worldwide. SARS-CoV-2 (severe acute respiratory syndrome coronavirus 2) is a respiratory single stranded RNA-virus and is responsible for the COVID-19 pandemic. Scientists in Hong Kong had already warned in 2007 about this "time bomb", which was triggered in 2020 [7,8].

The virus is relatively small, about $125 \mathrm{~nm}(0.125 \mu \mathrm{m})$ in diameter [9]. It is spherical and its mantle consists of a two-layered lipid membrane in which antennae of glycoproteins (so-called 'spike proteins') are anchored that protrude (Fig. 3) and allow them to connect to ACE-2 receptors in the respiratory epithelium (and other cells with ACE-2 receptors). Inside the casing is the viral RNA genome. The entry points are the respiratory epithelium and the oral epithelium, but the oral epithelium has a greater washing effect, so the viral load mainly affects the respiratory epithelium [10]. The ocular epithelium can also become infected with the virus. The virus is excreted through the faeces and faecal-oral transmission is theoretically possible, but infection through the digestive system has not been proven [11,12].

Blood-borne transmission has also not been proven [13]. The virus cannot do anything on its own and is inactive outside a host. The virus is carried by a drop and it is this drop that can be stopped by mouth masks. The virus therefore likes humidity and is believed to persist longer in humid conditions [14].

The virus is lipophilic and can be relatively easily deactivated with $75 \%$ ether and many disinfectants: alcohols (ethanol $70 \%$ or isopropanol $70-80 \%$ ), iodine $0.5 \%-1 \%$ (iodized alcohol, iodophors such as povidone-iodine), chlorinated compounds such as sodium hypochlorite $0.1 \%$ (bleaching javelin), peroxyacetic acid, hydrogen peroxide (hydrogen peroxide from 1\%) and also quaternary ammonium compounds such as ammonium chloride (deterioration of the lipid membrane) $[1,15]$.

Chlorhexidine digluconate is not suitable for the inactivation of the COVID-19 virus [16]. Chloroxylenol $0.12 \%-0.24 \%$ is only suitable for surfaces but not for the inactivation of viruses on the skin (Dettol wax gel) [17]. Benzalkonium chloride is not sufficiently effective against the corona virus [16].

Physical disinfectants are also suitable: a temperature of $56^{\circ} \mathrm{C}$ for 30 minutes, UV-C rays are all suitable for inactivation. Thorough hand washing with ordinary soap also dissolves the lipid mantle, which inactivates the virus, as the soap molecules trap the virus particles and form micelles [18].

The virus can only survive for a very limited time outside a host. It needs a host to survive, multiply and spread. The ideal host for an epidemic is a host that remains asymptomatic or does not become (too) sick, that does not develop antibodies and in which 


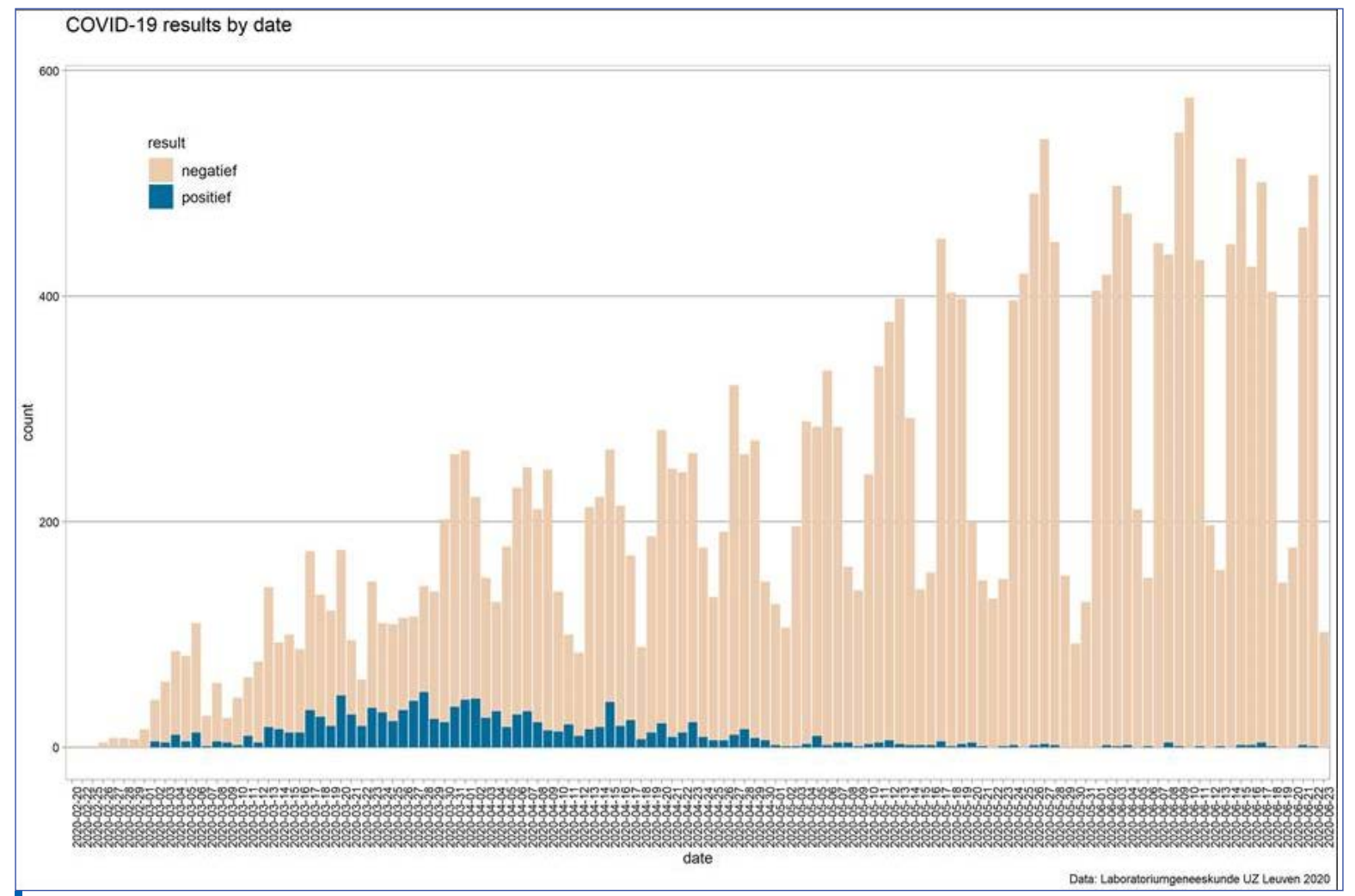

Figure 6 b. Daily overview of the number of positive and negative COVID-19 tests performed at UZ Leuven. In mid-June 2020, the number of positive PCR tests in asymptomatic patients fell to 1 positive in 1368 patients ( $(0.07 \%)$, at a cost of 46.80 euros per PCR test.

the virus can survive and multiply, after which the host continues to spread the virus; in short, a host that is a good carrier and super spreader.

\subsection{Route of transmission}

For dental practice, 3 situations are important in the transmission of the COVID-19 virus [19].

3.4.1. Transmission from the patient to the dentist and auxiliary personnel.

An infected person can infect the dentist and auxiliary personnel through direct contact (hands) or indirect contact (surfaces), through drip contamination (moisture particles) or through contaminated air (drip cores) when coughing, sneezing, talking. Contamination by droplets and droplet nuclei is also called aerosol contamination. The aerosol also contains contaminated water, blood, saliva and solid particles (pieces of scale). There is no transmission through blood splashes, needlestick injuries or tap water.

3.4.2. Patient transmission to the following patients Transmission between patients occurs through indirect contact with contaminated surfaces, materials and instruments and by holding contaminated aerosols in treatment rooms or through the dentist.

3.4.3. Transmission from dentist to patient

Transmission by an asymptomatic carrier dentist is possible by aerosol transfer, by direct or indirect contact, but it is more likely to be a dentist who still carries the viral load of a previous patient and transmits it by direct or indirect contact, not by aerosol transfer.

\subsection{Aerosol}

Aerosol is a fine suspension of liquid and solid particles. This suspension is responsible for the transfer of micro-organisms into the air. These particles consist of droplets or droplet cores. The droplets are by definition > $5 \mu \mathrm{m}$ ("Flügge" droplets) and are carried up to $1.5 \mathrm{~m}$ away when sneezing and coughing, but do not remain suspended in the air due to the heavy weight [20]. Droplet cores, on the other hand, are between 1 and $5 \mu \mathrm{m}$ in size, remain in the air for a long time and are transported over long distances. Coughing and sneezing can transport particles up to 9 meters. Droplets and droplet nuclei are both part of the aerosol and can contaminate surfaces [21]. In addition, an aerosol also contains contaminated water, blood, saliva and solid particles. Breathing also ensures air circulation when transporting the aerosol. An adult breathes 5 to 8 liters of air per minute. This can go up to 70-100 liters per minute with very great effort. The particle size determines the depth of the inhalation route through the nose or mouth. Large particles are captured by the mucous membranes of the nose, mouth and oropharynx. Particles $<10$ $\mu \mathrm{m}$ are inhalable and can reach the lungs. Finer particles $<2.5 \mu \mathrm{m}$ can penetrate the halves of the lungs (22). Ultrafine particles $<0.1 \mu \mathrm{m}(100 \mathrm{~nm})$ can be absorbed directly into the blood stream. COVID-19 viruses penetrate deep into the respiratory epithelium via the aerosol but cannot enter the bloodstream. Although no clinical studies are available, it is assumed that an aerosol containing the COVID-19 virus remains contagious for about 3 hours. Modifying fac- 


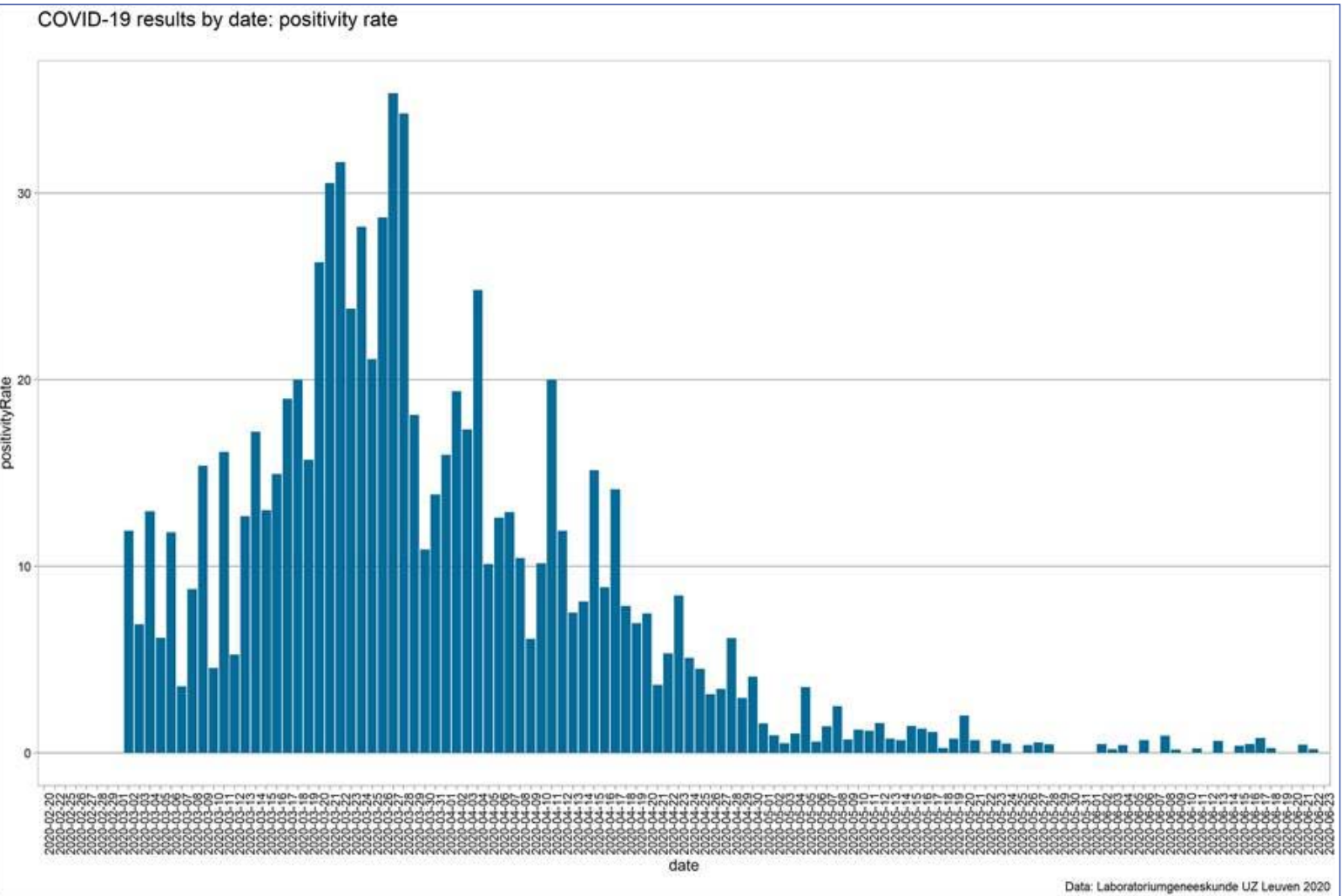

Figure 6c. Number of COVID-19: percentage of positive tests of all tests performed at UZ Leuven.

tors are the degree of aspiration of the aerosol, the number of air changes in the room, humidity, airflow characteristics and room temperature. As a high viral load in infected patients is more often associated with a more severe course of the disease, it is recommended to keep the aerosol viral load as low as possible. Super spreaders are asymptomatic patients with a high viral load during aerosol production. The fact that this issue is taken seriously in the medical world is demonstrated by modified resuscitation protocols where mouth-to-mouth resuscitation in adults is no longer allowed because the risk of infection is estimated to be almost $100 \%$. There is good experimental evidence that the COVID-19 virus survives in aerosol form for 3 hours on plastic and stainless steel for 72 hours, but less than 4 hours on copper surfaces [23]. This is little compared to the Coxsackie virus which survives more than 2 weeks on surfaces and the Hepatitis $B$ virus which can survive more than 14 days in a splash of dried blood on a surface. There is no clinical evidence or in vivo measurements of the COVID-19 virus in aerosols. There are no known numbers of COVID-19 viruses in aerosols, let alone whether they are "infectious". On the other hand, however, there is overwhelming clinical evidence of doctors, dentists, nurses who have treated COVID-19 patients without protection (and sometimes even protected) and have fallen ill to a much greater extent than the average population. For other viruses as well, serological monitoring shows that they have more antibodies against the cytomegal virus (CMV), the Epstein-Barr virus (EBV), but also against the Legionella bacteria than the general population. In short, aerosols can- not be considered a "fictitious" risk in the absence of hard evidence-based data on aerosols produced in dental practices. Aerosol-generating procedures include those in oro-maxillo-facial surgery and dental care : tracheotomy and tracheostomy care; airway suctioning; drainage of abscesses, wound irrigation; use of ultrasound scalers; use of piezotomy; use of turbines and high-speed hand and angle pieces; use of airway syringe ; use of electrocoagulation; inspection of the throat or base of the tongue using a tongue depressor; anterior rhinoscopy; endoscopic examinations of the naso- or oropharynx; all intubations of the nose or mouth; tooth extractions; all surgical procedures in the mouth, jaws or face [24, 25]. The possibilities of preventing contamination by aerosol production in the oro-maxillo-facial surgery practice are limited: prior rinsing of the patient with iodophoric water or hydrogen peroxide; use of osteotomes for extraction; use of self-tapping screws. In addition, air and smoke control systems must be used as usual; in hospital operating theatres: negative pressure in the operating theatre; \pm 60 air changes per hour in an operating theatre, smoke extraction systems, HEPA filtration and complete cleaning of the operating theatre between two patients. HEPA filtration stands for High Efficiency Particle Air Filter and is a filter that physically removes harmful microorganisms but does not inactivate them [26,27]. In dental practice, the use of the rubber dam simultaneously with the surgical aspiration allows a reduction of \pm $70 \%$ of aerosols $[28,29]$. Here too, it is advisable to rinse the patient beforehand with isobetadine or hydrogen peroxide. The use of osteotomes for dental 
extractions is a sensible measure. The use of a handpieces fitted with anti-retraction valves is recommended [30]. Ultrasound, piezoelectric and angle handpieces should be avoided if a good alternative is available. Here again, air treatment systems will be used in addition to extra-oral fog extraction systems for aerosols, although the latter penetrate the working field (Fig. 4). The systems that have been known for a long time in the hospital sector will be used as a basis for achieving germ reduction. It is not known how many COVID-19 viruses are contained in one $\mathrm{ml}$ of aerosol, but it is known that $1 \mathrm{ml}$ of saliva contains about 10 million bacteria and also that 15 minutes of unprotected operation corresponds to the inhalation of 0.014-0.12 $\mu$ l of saliva per aerosol. The use of atropine for dry mouth has been observed in patients who drool but not in healthy patients. Hypothetically, dry mouth should lead to a reduction in aerosols, but this is not supported anywhere.

\subsection{The patient as the source of COVID-19 virus}

As soon as the virus enters the patient and is anchoring its antenna-like glycoproteins on the ACE-2 receptor of the epithelial cells, the latent phase begins in which the virus must develop a whole production chain in order to replicate and release the newly formed viruses. The latent phase ranges from infection to the release of new infectious virus particles and the latent phase is immediately followed by the period of transmissibility or infectivity [31,32]. This phase is also known as the infectious phase. The exact duration of the latency phase of the COVID-19 virus cannot be determined precisely but varies between 1 and 4 days. The duration of the transmissibility period (contagious phase) is also not known with certainty, but as a guide, a 14-day contagious phase is maintained, with patients who present symptoms for the duration of clinical symptoms being considered contagious. The fact is that symptomatic patients are more contagious than asymptomatic. In some studies, PCR positivity has been established up to 37 days [33]. The patient's clinic does not strictly follow the path of virus replication and therefore does not follow the line between the latent and contagious phases. The patient clinically follows an incubation period (first asymptomatic phase) followed by either an asymptomatic or symptomatic evolution, identifying a diverse spectrum of diseases ranging from mild, moderate, severe, critical to fatal. The incubation period does not run parallel to the latent phase (Fig. 4). The patient starts to be contagious during the incubation period when he or she is not yet aware of a disease, in the asymptomatic phase. This means that simple questioning and examination of the patient's symptoms is not sufficient to detect infected patients $[34,35,36]$. The most important contagiousness is at the beginning of the disease course, during the period when symptoms are minimal to mild. During the incubation period, therefore, screening tests are used [37]. The incubation period of the CO-
VID-19 virus is estimated at 5-6 days, with a range of 1-14 days [38]. This is very different from the SARS-1 virus, which has an incubation period of 2-7 days, but where the person carrying the virus is infectious only after showing symptoms. In MERS, infectivity is present during the incubation period of 2-14 days, but human-to-human infection is relatively limited. SARS and MERS infection is mainly associated with nosocomial spread, while COVID-19 virus is transmitted by aerosol, contact and possibly fecal-oral transmission in the community (RNA for the virus has been found in the faeces of patients, but actual fecal-oral transmission has not been demonstrated yet). For all three coronaviruses (SARS, MERS, COVID-19), transmission on emergency health personnel has been detected $[39,40]$. It is completely unknown how many viral particles a person has to inhale in order to become infected. For the Ebola virus, one article on the virus is sufficient. For the noro-virus, 10 to 100 virus particles are sufficient. For the coronavirus, it is assumed that 100 to 1000 virus particles are required for an infection. A number of host-related factors also play a role (diffusion of receptors in the respiratory tract, advanced age of the patient, ...).

\subsection{Evolution of COVID-19 disease}

In general, it can be said that a large number of infected patients remain asymptomatical. Depending on the infected groups (cruise ships, aircraft carriers), it is known that between 20 and $60 \%$ of patients with a positive PCR test result were asymptomatic. For those with a symptomatic course, about $80 \%$ will mainly have a flu-like viral syndrome characterized by fever, dry cough, sore throat and some general symptoms. Prodromal symptoms are possible and consist mainly of a sudden loss of smell and taste [41]. The remaining fraction of patients with symptoms require hospitalization, with a significant fraction ending up in intensive care with a risk of death from pulmonary, cardiovascular, thromboembolic, renal complications and/or multi-organ failure. These complications are not so much considered as an effect of the virus, but rather as a host effect on the virus (excessive immune response with cytokine storm) [42]. Not everyone has the same risk of developing a serious illness. Advanced age, male sex, obesity, high blood pressure, cardiovascular disease, diabetes mellitus, smoking, chronic obstructive pulmonary disease, malignancies, chronic kidney disease, immune incompetence are considered to be patients at risk for serious disease progression. In some reports, health professionals are also referred to as "at-risk patients" because of the high incidence of infection with serious diseases and even death [43]. For the dental practice, the course of the disease is important in order to establish good questionnaires to detect potentially infected patients in time and to measure body temperature on arrival at the practice.

\subsection{RT-PCR screening}

As the patient may already be contagious during the 
asymptomatic incubation period, it is necessary, in addition to the questionnaire, to develop a screening test that can detect the presence of viral particles. In Belgium, a reverse transcriptase polymerase chain reaction test (RT-PCR screening test) has been chosen. A throat or nasopharyngeal swab is taken and the test can detect very small amounts of viral genetic material. The detection of viral material is not synonymous with infectivity. This test is not immediately readable, but requires a procedure in a clinical biology laboratory $[44,45]$. Under ideal circumstances, the sensitivity of this test is particularly high (over 95\%). However, in real life, it is assumed that false negative results of up to $30 \%$ are detected when testing upper respiratory tract wipers, for several reasons. Incorrect sampling is by far the main cause of a false negative result, followed by the quality of the wipers, transport problems, the margin of error of the test itself, and the presence of too few viruses $[46,47]$. It is assumed that these false negative (i.e. truly positive) patients have a low level of infectivity. A PCR test is a snapshot in which it is often assumed that the result is valid for about 48 hours. The guideline at Leuven University Hospitals states that a person with a positive PCR test is considered COVID-19 positive, a person with a negative PCR test is considered COVID-19 negative, and a person who had a positive PCR test 14 days ago and has been quarantined since then, and who has not had a fever for at least three days, may continue to be considered negative after those 14 days without a new PCR test. The reason why no new PCR test is recommended is that RNA can remain present for a very long time, allowing the PCR test to remain positive for a long time without proving infectivity [48]. In immunocompromised patients, and after a stay in intensive care with artificial respiration, it is necessary to wait 28 days after a positive PCR test and a new PCR test is subsequently recommended. PCR tests are logistically cumbersome for clinical biology laboratories, are expensive ( $€ 46.80$ in Belgium and $€ 60$ in Germany since the end of May 2020) and the testing capacity is limited per country and per hospital. PCR testing is particularly useful in communities where COVID-positive patients or healthcare providers are located (ships, camps, residential care centers, hospitals). Furthermore, the social cost is only justified in the phase of the epidemic when PCR testing actually influences local policy (Fig. 6 a, b, c). However, once the epidemic has passed its peak and a large number of tests are needed to find a positive test in an asymptomatic patient, the cost-benefit ratio becomes very unfavorable and, in addition to screening, general hygiene and prevention measures as well as contact tracing will be used. This has repercussions on dental practice. During a phase of national closure, it is justified to state that anyone requiring an aerosol production procedure must undergo a PCR test. In the event of a negative result, treatment can continue with the usual personal protection measures. If positive, treatment is carried out in health care facilities or care centers equipped to treat patients who are positive for COVID-19 or treatment is deferred for 14 days and the patient may undergo the aerosol production procedure if they are clinically completely cured. This policy can only be justified when the number of dental and oro-maxillo-facial surgery procedures is limited to emergencies. Once the lock is lifted and citizens are allowed to return to the dentist for dental care, the PCR test is no longer a tool that can be used in the event of a very low number of positive results. Figures from the health insurance funds show that about $40-50 \%$ of members go to the dentist every year and that more than half of the patients go to the dentist for curative care, mainly for the treatment of caries. However, there is also aerosol production during extractions, periodontal treatment and preventive dental care. In total, more than 2 million treatments can be carried out. Add to this more than 300,000 oro-maxillo-facial surgery operations per year and it soon becomes clear that a pre-operative test at 46.80 euros is not realistic, even if there were sufficient test capacity for it. At the Leuven University Hospital, as of March $11^{\text {th }} 2020$, every patient in need of an aerosol producing procedure, receives an RTPCR testing the day before the intervention. This policy has been continued and probably will be continued until cheaper reliable chair-side testing becomes available or an approved vaccine becomes available. Without a laboratory test, all that remains is a patient questionnaire. Interrogation does not conclusively detect an asymptomatic contagious patient, but may be indicative of recent contact with a person with a COVID-19 diagnosis. There are also a number of drawbacks to interrogation that allow both false positive and false negative conclusions to be drawn. In practice, the dentist will be faced with a situation in which he cannot be sure whether a patient is contagious or not with COVID-19. Unlike the influenza virus, which repeats itself every year, the dentist is forced to take the necessary measures against the transmission of a possible COVID-19 virus in the dental practice.

At least until a sufficient part of the population has been vaccinated against the COVID-19 virus.

\subsection{Chains of hygiene}

Just as there is a chain of infection, there is also a chain of hygiene to reduce the risk of exposure to germs. Here we identify a series of measures and a ranking of these measures. This set of measures is usually grouped by sector in guidelines or recommendations.

\subsubsection{Dentistry sector}

In 1997, a Belgian guideline for dentistry was developed under the title "Hygiene in Dental Practice" by the Ministry of Social Affairs, Public Health and the Environment [49]. It stated that "the spread of the Human Immunodeficiency Virus (HIV), the prevention of infections with the hepatitis viruses (HBV and $\mathrm{HCV}$ ) and the increase in cases of Therapy Resistant Tuberculosis (TB) are at the root of the greatly in- 
creased concern for the prevention of transmission of infections in medical procedures in hospitals. To date, there are no binding guidelines for measures to be applied in the dentist's office. In the absence of any form of external control, it is the duty of every dentist to assume his or her responsibility in this respect".

This publication was followed by the "Infection Control Recommendations during dental care" of 4 May 2011 issued by the High Council of Health (publication no. 8363) [2]. The prevention of airborne transmission of germs is explicitly mentioned, with attention being paid to the use of rubber dam, a nebuliser, a nasal mask and a face shield, as well as to rinsing the patient's mouth before any procedure. These recommendations are not legally binding. In the Netherlands, the "Guideline on Infection Control in Oral Care Practices" is regularly updated [50]. This is also based on the same concerns as above. In the 2016 edition of the Dutch Aerosol Directive it is also stated: "The amount of pathogenic micro-organisms in an aerosol is strongly diluted by water. Therefore, for most interventions, the risk of infection due to aerosol contamination is negligible". Perhaps this wording will be changed in a future edition. In the United States, the Center for Disease Control and Prevention has also updated the 2016 guidelines for infection control and prevention in dental offices, but states that "dental facilities are generally not designed to apply all transmission-based precautions (for example, airborne infection precautions for patients suspected of having tuberculosis, measles, or chickenpox) that are recommended for hospitals and other ambulatory care facilities." This is clearly a guideline that predates COVID-19 [5].

\subsubsection{Hospital sector}

As far as hospitals are concerned, there is no "no commitment" choice. Infection prevention and control manuals in hospitals are more than 1000 pages long and there are binding regulations and accreditation standards that are verified through internal and external audits of hospitals [51]. The well-known JCl audits and $\mathrm{JCl}$ hospital accreditations are an expression of this. Infection control is a set of procedures and policies to prevent or stop the spread of infections [52]. There are two types of measures: standard measures and transmission control measures.

3.9.2.1. Standard measures have been steadily expanded over the past several decades. They relate to hand hygiene, personal protective measures for the health care provider, respiratory hygiene, allocation of separate rooms for patients, prevention of the spread of infections inside and outside the health care facility ("environmental control"), safe injection techniques, prevention of needlestick injuries, cleaning and disinfection of instruments and surfaces. The standard measures apply to all patients, whether symptomatic or asymptomatic. Environmental control can be divided into several categories: waste control, animals in care facilities, washing and bedding, samples for control and monitoring, disinfection of premises, water and air quality control [4].

3.9.2.2. These standardization measures have long since been supplemented by measures to prevent transmission by direct or indirect contact, droplet and droplet core transmission (aerosol transmission). They applied only to patients with or suspected of having an infection.

These additional measures aim to prevent transmission and consist of isolating patients, defining and limiting patient pathways by providing separate routes for staff and visitors, limiting the number of contacts with the infected person, the use of disposable products and the application of personal protection measures also for the person suspected of infection, as well as strengthening cleaning and disinfection procedures for the environment and equipment (both frequency and products as indicated). It seems obvious that a number of measures which were generally designed for hospital use and related to the transmission of aerosols will have to be progressively translated into dental practice. It may be possible to progressively review each chapter of infection control, but it seems more appropriate to take an approach closer to the chain of infection described above.

\section{LIMITATIONS AND FUTURE AIMS}

The limitation of this paper is that it does not compare two patientgroups and health care providers, one following the guidelines and the other not following the guidelines. Future research should determine the number of COVID-19 virus particles in dental aerosols and in the air of the dental practice in order to quantify the risk of contracting COVID-19 through droplets and droplet cores.

\section{CONCLUSION}

The COVID-19 pandemic highlighted aerosol transmission in the chain of infection bringing both health professional and patients at risk. Implementation of adequate measures in the general dental practice can be achieved by returning to solutions that have already existed for some time in the hospital environment and, where possible and feasible, integrating them into daily practice.

\section{CONFLICT OF INTEREST}

The authors declare no conflict of interest.

\section{AUTHOR CONTRIBUTIONS}

All authors contributed to this paper. CP: contributed to concept and writing. AS and MVP: contributed to protocol. KL: contributed to data gathering and analysis. JK: contributed to critically revising the manuscript. ACKNOWLEDGMENTS

None. 


\section{REFERENCES}

1. Sciensano. COVID-19 disease (SARS-CoV-2 virus)[Internet]. 2020 (updated June 14th, 2020; version 5; cited 2020 September 12th 2020). Available from: https://covid-19.sciensano.be/sites/ default/files/Covid19/COVID-19_fact_sheet_ENG.pdf. 2. Superior Belgian Health Council. Recommendations for infection control in dental care. (May 2011; report $n^{\circ} \mathrm{CSS} 8363$ ). [Internet]. (2011; cited September 12th, 2020). Available from: https://www.health.belgium.be/sites/default/files/uploads/ fields/fpshealth theme_file/19069789/Aanbevelingen\%20 met $\% 20$ betrekking\%20tot $\% 20$ de $\% 20$ infectiebeheersing $\% 20$ bij\%20tandheelkundige\%20zorgverlening\%20\%28mei\%20 2011\%29\%20\%28HGR\%208363\%29.pdf

3. Ing EB, Xu QA, Salimi A, Torun N. Physician deaths from corona virus (COVID-19) disease. Occup Med (Lond). 2020;70(5):370-374. doi:10.1093/occmed/kqaa088.

[Full text links] [CrossRef] [PubMed] Google Scholar

4. Meehan P, Mishler O.P. Infection control in the dental office: standard precautions. In: DePaola LG, Grant LE (eds.). Infection control in the dental office. ISBN 978-3-030-30085-2, 2020; 77-90. https://doi.org/10.1007/978-3-030-30085-2_6

Google Scholar

5. Centers of Disease Control and Prevention. Guidelines for environmental infection control in health-care facilities [Internet].[2003, Updated: July 2019; cited September 12th, 2020]. Available from: https://www.cdc.gov/infectioncontrol/ quidelines/environmental/index.html

6 . Hens N, Vranck P, Molenberghs G. The COVID-19 epidemic, its mortality, and the role of non-pharmaceutical interventions. Eur Heart J Acute Cardiovasc Care. 2020;9(3):204-208. doi:10.1177/2048872620924922.

[Full text links] [CrossRef] [PubMed] Google Scholar Scopus WoS 7. Ortolon K. The SARS time bomb. Tex Med. 2004;100(7):57-59. [PubMed] Google Scholar Scopus

8. Cheng VC, Lau SK, Woo PC, Yuen KY. Severe acute respiratory syndrome coronavirus as an agent of emerging and reemerging infection. Clin Microbiol Rev. 2007;20(4):660-694. doi:10.1128/ CMR.00023-07.

[Full text links] [CrossRef] [PubMed] Google Scholar Scopus WoS 9. Scheller C, Krebs F, Minkner R, et al. Physicochemical properties of SARS-CoV-2 for drug targeting, virus inactivation and attenuation, vaccine formulation and quality control. Electrophoresis. 2020;41(13-14):1137-1151. doi:10.1002/ elps.202000121

[Full text links] [CrossRef] [PubMed] Google Scholar Scopus WoS 10. Wölfel R, Corman VM, Guggemos W, et al. Virological assessment of hospitalized patients with COVID-2019. Nature. 2020;581(7809):465-469. doi:10.1038/s41586-020-2196-x. [Full text links] [CrossRef] [PubMed] Google Scholar Scopus WoS 11. Gupta S, Parker J, Smits S, et al. Persistent viral shedding of SARS-CoV-2 in faeces - a rapid review. Colorectal Dis. 2020;22(6):611-620. doi:10.1111/codi.15138.

[Full text links] [CrossRef] [PubMed] Google Scholar Scopus WoS 12. Ding S, Liang TJ. Is SARS-CoV-2 also an enteric pathogen with potential fecal-oral transmission? A COVID-19 virological and clinical review. Gastroenterology. 2020;159(1):53-61.

doi:10.1053/j.gastro.2020.04.052.

[Full text links] [CrossRef] [PubMed] Google Scholar

13. Corman VM, Rabenau HF, Adams O, et al. SARS-CoV-2

asymptomatic and symptomatic patients and risk for transfusion transmission. Transfusion. 2020;60(6):1119-1122. doi:10.1111/ trf.15841.

[Full text links] [CrossRef] [PubMed] Google Scholar Scopus WoS 14. Fallahi HR, Keyhan SO, Zandian D, Kim SG, Cheshmi B. Being a front-line dentist during the Covid-19 pandemic: a literature review. Maxillofac Plast Reconstr Surg. 2020;42(1):12. doi:10.1186/ s40902-020-00256-5.

[Full text links] [CrossRef] [PubMed] Google Scholar WoS 15. Fathizadeh $\mathrm{H}$, Maroufi $\mathrm{P}$, Momen-Heravi $\mathrm{M}$, et al. Protection and disinfection policies against SARS-CoV-2 (COVID-19). Infez Med. 2020:28(2):185-191.

[Full text links] [PubMed] Google Scholar

16. Kampf G, Todt D, Pfaender S, Steinmann E. Persistence of coronaviruses on inanimate surfaces and their inactivation with biocidal agents [published correction appears in J Hosp Infect. 2020 Jun 17;:]. J Hosp Infect. 2020;104(3):246-251. doi:10.1016/j. jhin.2020.01.022

[Full text links] [CrossRef] [PubMed] Google Scholar Scopus WoS 17. Wood A, Payne D. The action of three antiseptics/disinfectants against enveloped and non-enveloped viruses. J Hosp Infect. 1998;38(4):283-295. doi:10.1016/s0195-6701(98)90077-9.

[Full text links] [CrossRef] [PubMed] Google Scholar Scopus WoS
18. Smith ML, Gandolfi S, Coshall PM, Rahman PKSM Biosurfactants: a Covid-19 perspective. Front Microbiol. 2020;11:1341. doi:10.3389/fmicb.2020.01341.

[Full text links] [CrossRef] [PubMed] Google Scholar Scopus WoS 19. Patel KP, Vunnam SR, Patel PA, et al. Transmission of SARSCoV-2: an update of current literature [published online ahead of print, 2020 Jul 7]. Eur J Clin Microbiol Infect Dis. 2020;1-7. doi:10.1007/s10096-020-03961-1.

[Full text links] [PubMed] Google Scholar

20. Lo Giudice R. The severe acute respiratory syndrome coronavirus-2 (SARS CoV-2) in dentistry. Management of biological risk in dental practice. Int J Environ Res Public Health. 2020;17(9):3067. doi:10.3390/ijerph17093067.

[Full text links] [PubMed] Google Scholar WoS

21. Jayaweera M, Perera H, Gunawardana B, Manatunge J. Transmission of COVID-19 virus by droplets and aerosols: a critical review on the unresolved dichotomy. Environ Res. 2020;188:109819. doi:10.1016/j.envres.2020.109819.

[Full text links] [CrossRef] [PubMed] Google Scholar Scopus 22. Qian H, Zheng X. Ventilation control for airborne transmission of human exhaled bio-aerosols in buildings. $J$ Thorac Dis. 2018;10(Suppl 19):S2295-S2304. doi:10.21037/jtd.2018.01.24 [Full text links] [CrossRef] [PubMed] Google Scholar Scopus WoS 23. van Doremalen N, Bushmaker T, Morris DH, et al. Aerosol and surface stability of SARS-CoV-2 as compared with SARS-CoV-1. N Engl J Med. 2020;382(16):1564-1567. doi:10.1056/NEJMc2004973. [Full text links] [CrossRef] [PubMed] Google Scholar Scopus WoS 24. Société Française de Stomatologie, Chirurgie Maxillo-Faciale et Chirurgie Orale (SFSCMFCO). [Practitioners specialized in oral health and coronavirus disease 2019: Professional guidelines from the French society of stomatology, maxillofacial surgery and oral surgery, to form a common front against the infectious risk]. J Stomatol Oral Maxillofac Surg. 2020;121(2):e3-e6. doi:10.1016/j. jormas.2020.03.012.

[Full text links] [CrossRef] [PubMed] Google Scholar 25. Zimmermann M, Nkenke E. Approaches to the management of patients in oral and maxillofacial surgery during COVID-19 pandemic. J Craniomaxillofac Surg. 2020;48(5):521-526.

doi:10.1016/j.jcms.2020.03.011.

[Full text links] [CrossRef] [PubMed] Google Scholar Scopus WoS 26. Nazarenko Y. Air filtration and SARS-CoV-2. Epidemiol Health 2020;42:e2020049. doi:10.4178/epih.e2020049.

[Full text links] [PubMed] Scopus WoS

27. Rebmann T. Management of patients infected with airbornespread diseases: an algorithm for infection control professionals. Am J Infect Control. 2005;33(10):571-579. doi:10.1016/j. ajic.2005.05.015

[Full text links] [CrossRef] [PubMed] Google Scholar Scopus WoS 28. Li Y, Ren B, Peng X, et al. Saliva is a non-negligible factor in the spread of COVID-19. Mol Oral Microbiol. 2020;35(4):141-145. doi:10.1111/omi.12289

[Full text links] [CrossRef] [PubMed] Google Scholar 29. Cochran MA, Miller $\mathrm{CH}$, Sheldrake MA. The efficacy of the rubber dam as a barrier to the spread of microorganisms during dental treatment. J Am Dent Assoc. 1989;119(1):141-144. doi:10.14219/jada.archive.1989.0131.

[Full text links] [CrossRef] [PubMed] Google Scholar Scopus WoS 30. Epstein JB, Rea G, Sibau L, et al. Assessing viral retention and elimination in rotary dental instruments. J Am Dent Assoc. 1995;126(1):87-92. doi:10.14219/jada.archive.1995.0028. [Full text links] [CrossRef] [PubMed] Google Scholar Scopus WoS 31. Dos Santos WG. Natural history of COVID-19 and current knowledge on treatment therapeutic options. Biomed Pharmacother. 2020;129:1 10493. doi:10.1016/j biopha.2020.110493

[Full text links] [CrossRef] [PubMed] Google Scholar Scopus 32. Romagnoli S, Peris A, De Gaudio AR, Geppetti P. SARS-CoV-2 and COVID-19: from the bench to the bedside. Physiol Rev. 2020;100(4):1455-1466. doi:10.1152/physrev.00020.2020. [Full text links] [CrossRef] [PubMed] Google Scholar WoS 33. Zhou F, Yu T, Du R, et al. Clinical course and risk factors for mortality of adult inpatients with COVID-19 in Wuhan, China: a retrospective cohort study [published correction appears in Lancet. 2020 Mar 28;395(10229):1038] [published correction appears in Lancet. 2020 Mar 28;395(10229):1038]. Lancet. 2020;395(10229):1054-1062. doi:10.1016/S0140-6736(20)30566-3 [Full text links] [CrossRef] [PubMed] Google Scholar Scopus WoS 34. Macera M, De Angelis G, Sagnelli C, et al. Clinical presentation of COVID-19: case series and review of the literature. Int J Environ Res Public Health. 2020;17(14):5062. doi:10.3390/ijerph17145062. [Full text links] [CrossRef] [PubMed] Google Scholar Scopus WoS 
35. Müller O, Neuhann F, Razum O. [Epidemiology and control of COVID-19]. Dtsch Med Wochenschr. 2020;145(10):670-674. doi:10.1055/a-1162-1987.

[Full text links] [PubMed]

36. Tang D, Comish $P$, Kang R. The hallmarks of COVID-19 disease. PLoS Pathog. 2020;16(5):e1008536. doi:10.1371/journal. ppat. 1008536.

[Full text links] [CrossRef] [PubMed] Google Scholar

37. Fang B, Meng QH. The laboratory's role in combating COVID-19. Crit Rev Clin Lab Sci. 2020;57(6):400-414. doi:10.1080/1 0408363.2020.1776675.

[Full text links] [PubMed] Google Scholar

38. Cevik M, Bamford CGG, Ho A. COVID-19 pandemic-a focused review for clinicians. Clin Microbiol Infect. 2020;26(7):842-847. doi:10.1016/j.cmi.2020.04.023.

[Full text links] [PubMed] Google Scholar Scopus

39. Wilson NM, Norton A, Young FP, Collins DW. Airborne transmission of severe acute respiratory syndrome coronavirus-2 to healthcare workers: a narrative review. Anaesthesia. 2020;75(8):1086-1095. doi:10.1111/anae.15093.

[Full text links] [CrossRef] [PubMed] Google Scholar Scopus WoS 40. Raboud J, Shigayeva A, McGeer A, et al. Risk factors for SARS transmission from patients requiring intubation: a multicentre investigation in Toronto, Canada. PLoS One. 2010;5(5):e10717. doi:10.1371/journal.pone.0010717.

[Full text links] [PubMed] Google Scholar Scopus WoS

41. Giacomelli A, Pezzati L, Conti F, et al. Self-reported olfactory and taste disorders in patients with severe acute respiratory Coronavirus 2 infection: a cross-sectional study. Clin Infect Dis. 2020;71(15):889-890. doi:10.1093/cid/ciaa330.

[Full text links] [CrossRef] [PubMed] Google Scholar Scopus 42. Ragab D, Salah Eldin H, Taeimah M, et al. The COVID-19 cytokine storm; what we know so far. Front Immunol. 2020;11:1446. doi:10.3389/fimmu.2020.01446.

[Full text links] [CrossRef] [PubMed] Google Scholar Scopus WoS 43. Wolff D, Nee S, Hickey NS, Marschollek M. Risk factors for Covid-19 severity and fatality: a structured literature review. Infection. 2020;10.1007/s15010-020-01509-1. doi:10.1007/ s15010-020-01509-1.

[Full text links] [CrossRef] [PubMed] Google Scholar Scopus WoS 44. Venter M, Richter K. Towards effective diagnostic assays for COVID-19: a review. J Clin Pathol. 2020;73(7):370-377. doi:10.1136/jclinpath-2020-206685.

[Full text links] [CrossRef] [PubMed] Google Scholar Scopus WoS 45. Esbin MN, Whitney ON, Chong S, et al. Overcoming the bottleneck to widespread testing: a rapid review of nucleic acid testing approaches for COVID-19 detection. RNA. 2020;26(7):771783. doi:10.1261/rna.076232.120.

[Full text links] [CrossRef] [PubMed] Google Scholar Scopus WoS 46. Vankrunkelsven P, Finoulst $M, G o o s s e n s ~ H$. [What is the reallife sensitivity of PCR-testing in detecting SARS-CoV-2?]. Tijdschr voor Geneeskunde. 2020;76(10):1-5. doi: 10.2143/

TVG.76.10.2003069.

47. Afzal A. Molecular diagnostic technologies for COVID-19: limitations and challenges. J Adv Res. 2020;10.1016/j. jare.2020.08.002. doi:10.1016/j.jare.2020.08.002.

[Full text links] [CrossRef] [PubMed] Google Scholar Scopus 48. Medical Letter on the CDC \& FDA; Atlanta COVID-19/SARSCoV-2 News from Preprints; At what times during infection is $S A R S-C o V-2$ detectable and no longer detectable using RT-PCR based tests?: A systematic review of individual participant data [Internet] (publication date Aug 2, 2020; updated 2020-07-

29; cited September 12th 2020). Available from: https://

search-proquest-com.kuleuven.ezproxy.kuleuven.be/ docview/2428105985?accountid=17215

49. High Council of Health. Hygiene in the dental practice. (HGR 5303-12). [Internet] (March 1997; cited September 12th 2020). Available from: https://www.health.belgium.be/sites/ default/files/uploads/fields/fpshealth theme file/4394403/ Hygi\%C3\%ABne\%20in\%20de\%20tandheelkundige\%20 praktijk\%20\%28maart\%201997\%29\%20\%28HGR\%205303$12 \% 29 . p d f$

50. KNMT. Infection Prevention Directive in Oral Care Practices. 2016 (cited 2020 September 12th ). Available from: https:// www.knmt.nl/sites/default/files/richtlijn infectiepreventie autorisatiefase 23.pdf

51. Wattal C, Khardori N. Hospital Infection Prevention. New Delhi: Springer; 2014. ISBN 978-81-322-1607-0. doi: 10.1007/978-81322-1608-7.

52. JCI. Joint Commission International Accreditation Standards for Hospitals. 6th Edition | Effective 1 July 2017 Including Standards for Academic Medical Center Hospitals. [Internet] (cited: 2020 September 12th) Available from: https://www. jointcommissioninternational.org/-/media/jci/jci-documents accreditation/hospital-and-amc/jci-standards-only 6th-edhospital.pdf

\author{
Constantinus POLITIS \\ MD, DDS, MM, MHA, PhD \\ Full Professor \& Chairperson \\ Oral and Maxillofacial Surgery Department \\ Faculty of Medicine \\ University Hospitals Leuven, KU Leuven \\ Leuven, Belgium
}

Dr. Politis is an Oral and Maxillo-Facial Surgeon. He is currently a Full Professor and Chairperson of the Department of OMFS at Leuven University Belgium. He is an invited Lecturer at EHSAL in Brussels. He graduated from the Catholic University of Leuven in medicine (MD) and dentistry (DDS), also specializing in oral and maxillofacial surgery at the same university. He defended his doctor's thesis on the subject of complications of orthognathic surgery $(\mathrm{PhD})$. He followed additional postgraduate training in Arnhem (Stoelinga), Aachen (Koberg), Copenhagen (Pindborg), Göteborg (Bränemark) and San Francisco (Marx). He also holds a master degree in management (MM) and a master degree in Hospital Management (MHM). He is Secretary General of the Professional Union of Belgian Oral and Maxillofacial Surgeons. He is acknowledged trainer of OMFS trainees. Clinical research projects include prevention and repair of iatrogenic trigeminal nerve injury, transplantation of teeth and orthognathic surgery. 


\section{Ouestions}

\section{The COVID-19 virus is $a(n)$ :}

$\square$ a. Enveloped virus;

ab. Non-eveloped virus;

ac. DNA-virus;

ad. Double-stranded RNA virus.

\section{The least probable route of transmission is:}

Da. Contaminated aerosol;

ab. Contaminated respiratory droplets;

uc. Contaminated fomites;

Dd. Blood of COVID-19 patients.

\section{PC-R testing for COVID-19:}

$\square$ a. Allows results to be read in 30 minutes;

$\square$ b. Has less false positive than false negative results;

uc. Has hardly ever false negative results;

$\square d$. Is only positive in COVID-19 symptomatic patients.

\section{The following is not suitable for the inactivation of the COVID-19 virus:}

Da. Ethanol 70\%;

ab. Sodium hypochlorite $0.1 \%$;

uc. Hydrogen peroxide from $1 \%$;

ad. Chlorhexidine biguanide.

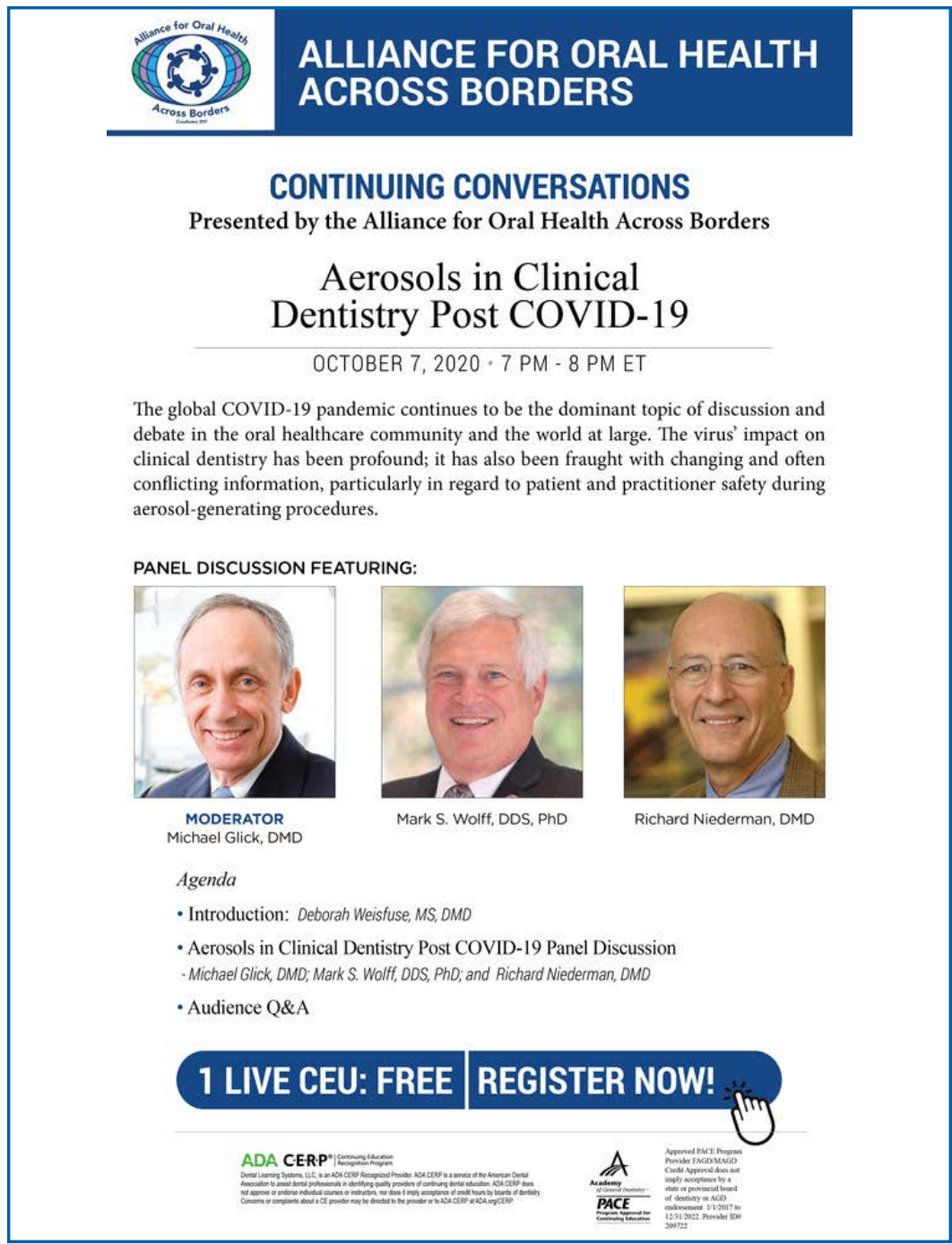




\title{
KNOWLEDGE ABOUT DENTIN HYPERSENSITIVITY: A QUESTIONNAIRE-BASED SURVEY AMONG DENTAL STUDENTS AND YOUNG DENTISTS
}

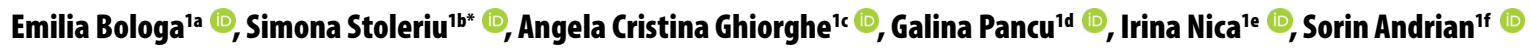 \\ 'Department of Odontology, Periodontology and Fixed Prosthodontics, Faculty of Dental Medicine, Grigore T. Popa University of Medicine and Pharmacy \\ of Jassy, Jassy, Romania
}

\begin{abstract}
aDDS, PhD Student; e-mail: bologa.emilia@umfiasi.ro; ORCIDiD: https://orcid.org/0000-0002-0091-8765
bDDS, PhD, Associate Professor; e-mail: stoleriu_simona@yahoo.com; ORCIDiD: https://orcid.org/0000-0001-5427-6027

'DDS, PhD, Lecturer; e-mail: cristina.ghiorghe@umfiasi.ro; ORCIDiD: https://orcid.org0000-0002-1636-6686

dDDS, PhD, Lecturer; e-mail: galina.pancu@umfasi.ro; ORCIDiD: https://orcid.org/0000-0001-9593-1884

eDDS, PhD, Assistant Professor; e-mail: irina.nica@umfiasi.ro; ORCIDiD: https://orcid.org/0000-0003-1189-0785

fDDS, PhD, Professor; e-mail: sorin.andrian@umfiasi.ro; ORCIDiD: https://orcid.org/0000-0002-9271-6123
\end{abstract}

\section{ABSTRACT}

d. https://doi.org/10.25241/stomaeduj.2020.7(3).art.3

Introduction Continued education is a fundamental characteristic of one's working life, especially in the medical field. Keeping up to date should be a mandatory element of dental practice. Dentin hypersensitivity (DH) has been a long-term significant challenge for practitioners due to the uncertainties around its diagnosis and treatment. The aim of this study is to assess the knowledge of senior dental students and young doctors with respect to this dental pathology.

Methodology A total of 632 self-administered questionnaire were distributed to dental students and doctors for data collection. The 10 questions investigated the knowledge about the description of pain in $\mathrm{DH}$, triggering and predisposing factors, treatment strategies, preventive and treatment measures, remineralization products, etiological factors of dental wear, and main characteristics of $\mathrm{DH}$. The data were analyzed using SPSS 20.0. Standard descriptive statistics were computed and analytical statistical analysis was performed using Pearson's chi-square test.

Results The response rate for dental students was $87.87 \%$ and $10.2 \%$ for young doctors. Most respondents revealed a good level of knowledge regarding pain characterization, triggering factors, and predisposing factors of dentin hypersensitivity, and a satisfactory level for the disease management strategies. The average score of the questionnaire recorded at group level was 42.253.

Conclusion Young dentists had better knowledge of $\mathrm{DH}$ compared to 6th-year dental students. The information obtained from this study revealed that there is a need to provide better theoretical but also clinical teaching opportunities to students, as well as continued educational programs to young doctors.

\section{KEYWORDS}

Dentin Hypersensitivity; Knowledge; Dental Students; Dentists; Questionnaire.

\section{INTRODUCTION}

Dentin hypersensitivity $(\mathrm{DH})$ is a condition that has often been encountered in dental practice in recent decades [1-3], however, the historical reporting of this symptomatology goes as far back as the 16 th century $[4,5]$. Holland et al. [6] described this pathology as a short, sharp pain arising when dentin is exposed to different stimuli (typically thermal, evaporative, tactile, osmotic or chemical) and the pain cannot be ascribed to any other form of dental defect or disease. The prevalence of $\mathrm{DH}$ ranges from $1.34 \%$ to $92.1 \%$ in the adult population [1-4,7-11]. This discrepancy occurs due to the differences in the methods used for diagnosis and in the selection criteria of the subjects.

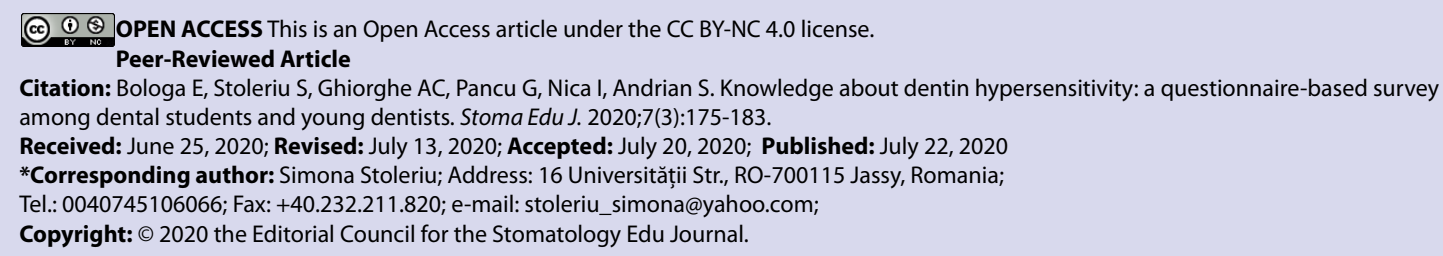




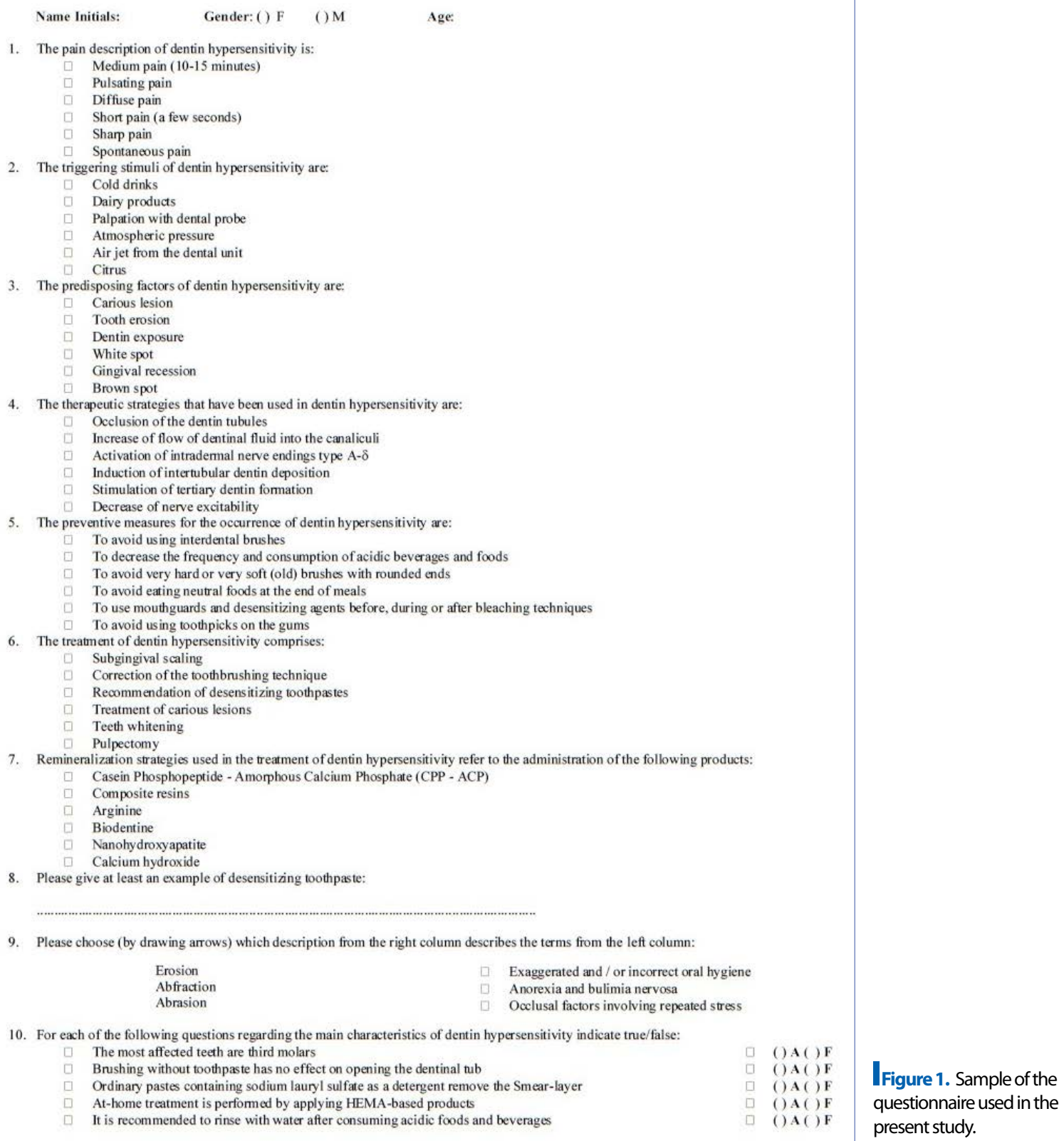

10. For each of the following questions regarding the main characteristics of dentin hypersensitivity indicate true/false: The most affected teeth are third molars

Brushing without toothpaste has no effect on opening the dentinal tub

Patients with sensitive teeth experience discomfort while eating, drinking, and brushing their teeth, all of them being considered activities that affect the quality of life $[2,12]$. The academic curricula include clinical training for students to diagnose and to treat patients with different dental diseases under supervision, and therefore they are expected to have adequate knowledge about these conditions. Dental students and beginner young dentists that no longer have a supervisor to check their work quality must be acquainted with $\mathrm{DH}$ and must have the skills to correctly manage the disease $[3,9]$.

There are limited data available regarding dental students' and young dentists' understanding of $\mathrm{DH}$, especially in Romania, where no studies have been conducted on this topic.

Questionnaires are objective tools that researchers can use to collect information about people's knowledge, beliefs, attitudes, and behavior [13]. Cross-sectional studies can be based on questionnaires, providing descriptive data on the entire population being studied. In scientific literature, several self-reported questionnaire studies assess students' or dentists' knowledge about dentin hypersensitivity $[1-4,8,9,14,15]$.

Those surveys evaluated the clinical practice of the subjects in patients with $\mathrm{DH}$ and did not assess the theoretical knowledge that they possess about this disease.

The theoretical educational processes represent the base for developing clinical skills. For this reason, we conducted a study to evaluate the knowledge of dental students and young dentists about dentin hypersensitivity regarding pain description, triggering factors, predisposing factors, diagnosis, preventive and treatment measures. The null hypothesis of the present study is that there are no differences in the evaluation of the level of knowledge between young dentists and dental students. 


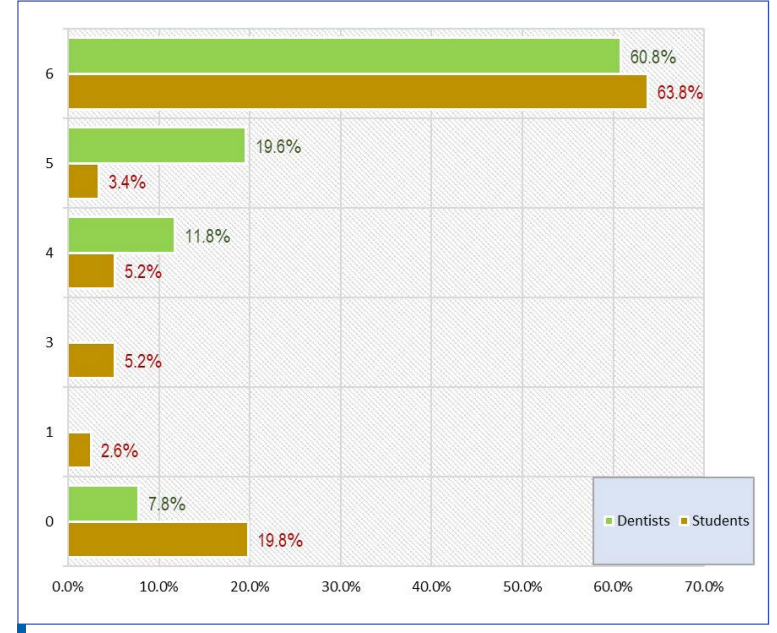

Figure 2. The distribution of scores obtained by students and dentists for Q1 (regarding the pain characteristics of DH).

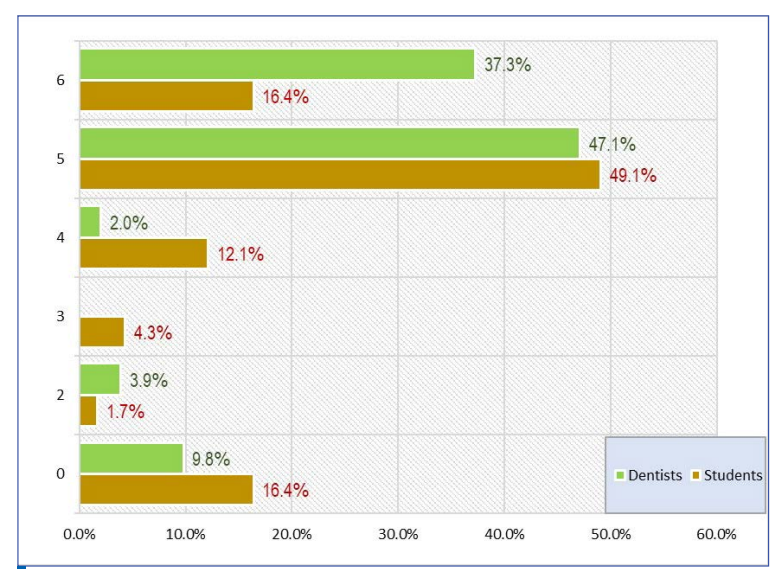

Figure 4. The distribution of scores obtained by students and dentists for Q3 (regarding the predisposing factors of DH).

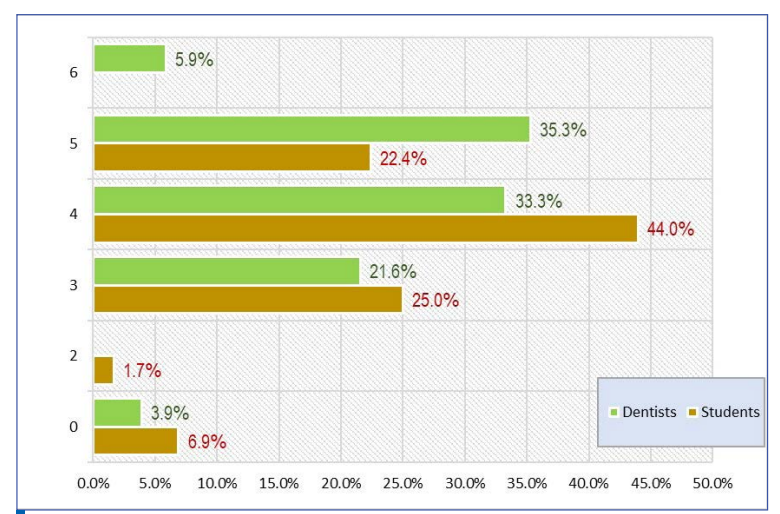

Figure 6. The distribution of scores obtained by students and dentists for Q6 (regarding the treatment of DH).

\section{MATERIAL AND METHODS}

This cross-sectional study was conducted since November 2018 till May 2019. A total of 632 questionnaires were distributed among senior dental students (6th year of study) at the Faculty of Dental Medicine - "Grigore T. Popa" University of Medicine and Pharmacy lași, Romania, and among alumni who graduated in the last five years.

All participants were informed about the purpose and the objective of this study and signed a consent form of agreement. One hundred thirty-

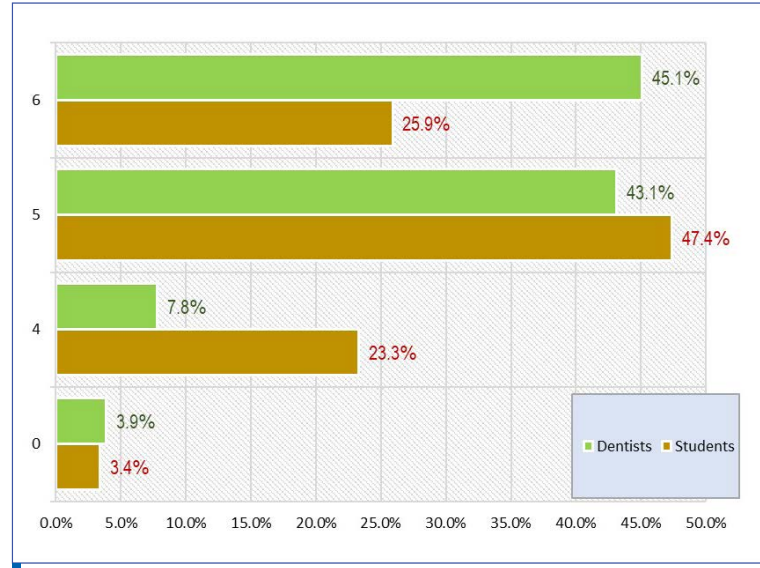

Figure 3. The distribution of scores obtained by students and dentists for Q2 (regarding the triggering factors of $\mathrm{DH}$ ).

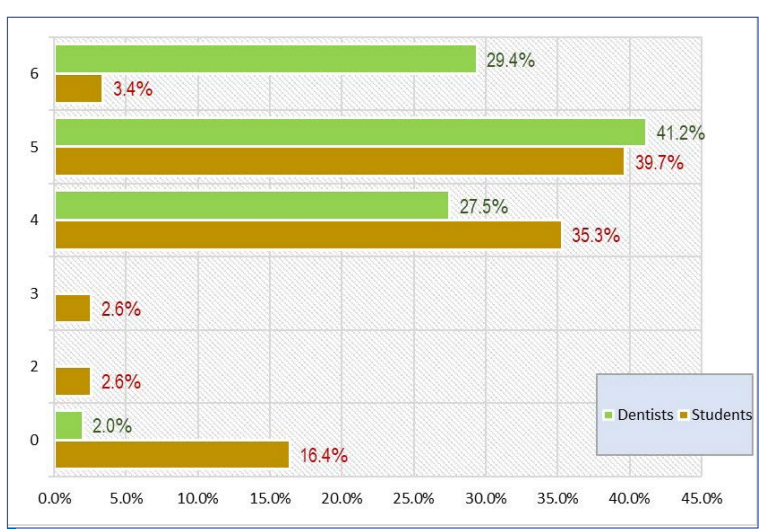

Figure 5. The distribution of scores obtained by students and dentists for Q5 (regarding the preventive measures of DH).

two dental students were asked to respond to the self-administered questionnaire at the end of their Cariology classes. Also, 500 young dentists were randomly chosen from the alumni database and received the questionnaire online. No reminder was given to those participants who did not return the questionnaire.

A literature search was performed on readily available questionnaires that measure the knowledge of dental students and young dentists about dentin hypersensitivity. None of them met the criteria to be followed in this study, so a new questionnaire was developed.

The process of developing the new questionnaire followed the recommendations of Tsang et al. [16]. The first step was to establish the expert committee, that was comprised of cariology professors, and then identify the dimensionality of the construct. It was decided that the questionnaire will be selfadministered because in this way the respondents will answer more truthfully.

The items used specific medical terminology because all the participants were trained in the dentistry field, hence being familiar with such terms. The questionnaire was constructed based on nine close-ended questions (seven multiple choice questions, one true/false question, one matrix question) and one open-ended item (Fig. 1). 
I Table 1. The qualitative assessment for the 7 multiple choice questions.

\begin{tabular}{|c|c|c|c|c|}
\hline Question & Group & Good & Satisfactory & Insufficient \\
\hline \multirow{2}{*}{$\begin{array}{r}\text { Q1 - description of the } \\
\text { pain in } \mathrm{DH}\end{array}$} & students & $67.2 \%$ & $10.3 \%$ & $22.4 \% *$ \\
\hline & dentists & $80.4 \%$ & $11.8 \%$ & $7.8 \% *$ \\
\hline \multirow{2}{*}{ Q2 - triggering factors } & students & $73.3 \% *$ & $23.3 \% *$ & $3.4 \%$ \\
\hline & dentists & $88.2 \% *$ & $7.8 \% *$ & $3.9 \%$ \\
\hline \multirow{2}{*}{ Q3 - predisposing factors } & students & $65.5 \% *$ & $16.4 \% *$ & $18.1 \%$ \\
\hline & dentists & $84.3 \% *$ & $2.0 \% *$ & $13.7 \%$ \\
\hline \multirow{2}{*}{ Q4 - treatment strategies } & students & $32.8 \% *$ & $32.8 \%$ & $34.5 \% *$ \\
\hline & dentists & $60.8 \% *$ & $31.4 \%$ & $7.8 \% *$ \\
\hline \multirow{2}{*}{$\begin{array}{r}\text { Q5 - preventive } \\
\text { measures }\end{array}$} & students & $43.1 \% *$ & $37.9 \%$ & $19.0 \% *$ \\
\hline & dentists & $70.6 \% *$ & $27.5 \%$ & $2.0 \% *$ \\
\hline \multirow{2}{*}{ Q6 - treatment measures } & students & $22.4 \% *$ & $69.0 \%$ & $8.6 \%$ \\
\hline & dentists & $41.2 \% *$ & $54.9 \%$ & $3.9 \%$ \\
\hline \multirow{2}{*}{$\begin{array}{r}\text { Q7 - remineralization } \\
\text { products }\end{array}$} & students & $12.9 \% *$ & $57.8 \%$ & $29.3 \%$ \\
\hline & dentists & $39.2 \% *$ & $45.1 \%$ & $15.7 \%$ \\
\hline
\end{tabular}

* statistically significant differences between students and dentists for each category

ITable 2. The qualitative assessment for the 7 multiple choice questions.

\begin{tabular}{|c|c|c|c|c|c|c|}
\hline \multirow{2}{*}{$\begin{array}{l}\text { Q4: therapeutic strategies } \\
\text { Pearson's chi-square test }=16.720 \text {, } \\
P=.010^{*}\end{array}$} & \multicolumn{2}{|c|}{ Students } & \multicolumn{2}{|c|}{ Dentists } & \multicolumn{2}{|l|}{ Total } \\
\hline & $n$ & $\%$ & $\mathbf{n}$ & $\%$ & $\mathbf{n}$ & $\%$ \\
\hline 0 & 37 a & $31.9 \% *$ & $4_{b}$ & $7.8 \% *$ & 41 & $24.6 \%$ \\
\hline 1 & $1_{a}$ & $0.9 \%$ & $0_{a}$ & $0.0 \%$ & 1 & $0.6 \%$ \\
\hline 2 & $2 a$ & $1.7 \%$ & $0_{a}$ & $0.0 \%$ & 2 & $1.2 \%$ \\
\hline 3 & $9_{a}$ & $7.8 \%$ & $3 a$ & $5.9 \%$ & 12 & $7.2 \%$ \\
\hline 4 & $29 a$ & $25.0 \%$ & $13_{a}$ & $25.5 \%$ & 42 & $25.1 \%$ \\
\hline 5 & $33 a$ & $28.4 \% *$ & $26_{b}$ & $51.0 \% *$ & 59 & $35.3 \%$ \\
\hline 6 & $5_{a}$ & $4.3 \%$ & $5_{\mathrm{a}}$ & $9.8 \%$ & 10 & $6.0 \%$ \\
\hline Total & 116 & $100.0 \%$ & 51 & $100.0 \%$ & 167 & $100.0 \%$ \\
\hline
\end{tabular}

* statistically significant differences between students and dentists for each category

Items were simple, short, and written in the native language of the respondents. It was considered that a 10-item questionnaire was short enough to avoid respondents experiencing fatigue or loss of motivation during completion. The experts reviewed the items in order to make sure they were accurate, free of item construction problems, and grammatically correct. Minor modifications were made to the instrument to achieve the objectives of the study.

Content and face validation were obtained by circulating the questionnaire to 15 senior dental students and five young dentists (others than the ones we recruited for the study). They concluded that the questionnaire items were clear, easy, valid, and covered all the main subjects regarding the knowledge of $\mathrm{DH}$.

The survey instrument recorded the respondent's gender and age. The subjects were asked to respond
7 multiple choice questions about the description of the pain in $\mathrm{DH}$, triggering factors, predisposing factors, treatment strategies, preventive measures, treatment measures, and remineralization products. The matrix question was about the etiological factors of dental wear (abrasion, abfraction, and erosion), and the true/false question had subscales about the main characteristics of $\mathrm{DH}$.

The open-ended question asked the participants to give an example of desensitizing toothpastes that participants may have knowledge of being efficient in $\mathrm{DH}$ treatment.

We used a quantitative evaluation by scoring each response between 0-6 points according to the number of correct answers identified, first 7 questions had between 2-4 correct answers (for each incorrect answer given or correct answer missed 1 point was deducted; a single answer given scored 0 points). Question no.8 scored 0 or 6 , for question 
ITable 3. Results obtained by students and dentists at Q7.

\begin{tabular}{|c|c|c|c|c|c|c|}
\hline \multirow{2}{*}{$\begin{array}{l}\text { Q7: Remineralization strategies } \\
\text { Pearson's Chi-square Test }=39.981 \text {, } \\
P=.000^{* *}\end{array}$} & \multicolumn{2}{|c|}{ Students } & \multicolumn{2}{|c|}{ Dentists } & \multicolumn{2}{|l|}{ Total } \\
\hline & $\mathbf{n}$ & $\%$ & $\mathbf{n}$ & $\%$ & $\mathbf{n}$ & $\%$ \\
\hline 0 & $31_{a}$ & $26.7 \% *$ & 2 & $3.9 \% *$ & 33 & $19.8 \%$ \\
\hline 1 & $0_{a}$ & $0.0 \%$ & $1_{a}$ & $2.0 \%$ & 1 & $0.6 \%$ \\
\hline 2 & $3 a$ & $2.6 \%$ & $5_{b}$ & $9.8 \%$ & 8 & $4.8 \%$ \\
\hline 3 & $44_{a}$ & $37.9 \%$ & $11_{b}$ & $21.6 \%$ & 55 & $32.9 \%$ \\
\hline 4 & $23 a$ & $19.8 \%$ & $12_{a}$ & $23.5 \%$ & 35 & $21 \%$ \\
\hline 5 & 8 a & $6.9 \% *$ & $19_{b}$ & $37.3 \% *$ & 27 & $16.2 \%$ \\
\hline 6 & 7 a & $6.0 \%$ & $15_{a}$ & $2.0 \%$ & 8 & $4.8 \%$ \\
\hline Total & 116 & $100.0 \%$ & 51 & $100.0 \%$ & 167 & $100.0 \%$ \\
\hline
\end{tabular}

* statistically significant differences between students and dentists for each category

ITable 4. Global score obtained of each group.

One-Sample Kolmogorov-Smirnov Test $p=.000^{*}$

Mann-Whitney $U=1466.500, p=.000^{* *}$

\begin{tabular}{|c|c|c|c|c|c|c|}
\hline Group & $\mathbf{N}$ & Mean & $\begin{array}{c}\text { Standard } \\
\text { deviation }\end{array}$ & $\begin{array}{c}\text { Standard } \\
\text { error of the } \\
\text { mean }\end{array}$ & Minimum & Maximum \\
\hline student & 116 & 40.471 & 7.8261 & .7266 & 8.0 & 52.8 \\
\hline dentist & 51 & 46.306 & 7.1557 & 1.0020 & 8.4 & 54.6 \\
\hline Total & 167 & 42.253 & 8.0697 & .6245 & 8.0 & 54.6 \\
\hline
\end{tabular}

no.9 each correct association scored 2 points, and for question no. 10 each correct answer scored 1.2 points. The maximum overall score of the questionnaire was 60 points. For the qualitative assessment, each response was evaluated as follows:

- from 0-2 points = Insufficient,

- 3-4 points $=$ Satisfactory,

- 5-6 points $=$ Good.

The participants' overall knowledge was categorized using modified Bloom's cut-off point, as good if the score was between 80 and 100\% (48-60 points), satisfactory if the score was between 50 and $79 \%$ (30-47 points), and insufficient if the score was less than $50 \%$ ( $<30$ points).

\subsection{Statistical Analysis}

The data obtained were fed into Microsoft Excel (Microsoft Inc., USA). The statistical software SPSS 20.0 (IBM Inc., USA) was used for data analysis. The standard descriptive methods were applied to determine the characteristics of the sample. Pearson's Chi-square test was applied to compare categorical variables between the groups.

We used nonparametric Mann-Whitney $U$ and OneSample Kolmogorov-Smirnov tests to evaluate the differences in the distribution of the age data set and data from the true/false question.
The confidence interval was set to $95 \%$ and p-values less than 0.05 were considered statistically significant.

\section{RESULTS}

The response rate for dental students was $87.87 \%$ (116 questionnaires returned from 132), and for young doctors this was $10.2 \%$ (51 questionnaires returned from 500). The mean age of the participants was $26.34 \pm 3.635$ years. Most participants were students $(69.5 \%)$ and $30.5 \%$ were doctors. The results showed that $61.1 \%$ were female participants and $38.9 \%$ males.

The qualitative assessment for the seven multiple choice questions is presented in Table 1. The percentage of young doctors having a good level of knowledge was statistically significantly higher than the one of dental students (Pearson's Chi-square Test, $\mathrm{p}<0.05)$.

Regarding the characterization of dentin hypersensitivity, 27 out of all subjects (16.2\%) did not know the correct answer, while the majority of subjects (105 subjects - 62.9\%) obtained the maximum score. The comparative study of the results obtained by students and doctors revealed statistically significant differences (Pearson's Chi-square Test, $p=0.001$ ). 
The percentage of students who did not know how to characterize dentin hypersensitivity was significantly higher than the doctors' percentage as seen in Figure 2.

For the question regarding the triggering factors of $\mathrm{DH}, 31.7 \%$ of all respondents obtained the maximum score. There was a statistically significant difference (Fig. 3) between the percentage of doctors (45.1\%) and that of students (25.9\%) who obtained a maximum score of 6 (Pearson's Chi-square Test, $p$ $=0.032$ ).

The third question analyzed the knowledge of the predisposing factors that determine the appearance of $\mathrm{DH}$. Figure 4 shows that a significantly higher percentage of doctors $(37.7 \%)$ than of students (16.4\%) scored a maximum of 6 points, while a significantly higher percentage of students $(12.1 \%)$ than of doctors scored 4 points.

Table 2 shows the scores obtained by students and dentists for question no. 4 regarding the therapeutic strategies.

The fifth item looked into the knowledge regarding the preventive measures for $\mathrm{DH}$. The comparative evaluation of doctors and students showed statistically significant differences (Pearson's Chisquare Test, $p=0.001$ - Fig. 5).

Analyzing the results of the sixth question regarding the treatment measures of $\mathrm{DH}$ we identified statistically significant differences (Pearson's chisquare Test, $\mathrm{p}=0.040$ ) between the $5.9 \%$ of the young doctors that obtained the maximum score compared with none of the students (Fig. 6).

The results obtained for the seventh question about remineralization strategies are shown in Table 3.

On the open-ended question, namely question eight, 160 participants (95.8\%) were able to give examples of desensitizing toothpastes. There were no statistically significant differences (Pearson's Chisquare Test, $p=0.340$ ) between the answers given by the students compared with the doctors.

Item number nine analyzed the knowledge about the etiology of different types of dental wear (abrasion, abfraction, and erosion). Most participants (63.5\%) obtained the maximum score, and $7.8 \%$ of the subjects failed to make any correct association. There were no statistically significant differences (Pearson's Chi-square Test, $\mathrm{p}=0.052$ ) between the answers given by the students compared with the doctors.

The last question evaluated the knowledge of some of the main characteristics of the $\mathrm{DH}$. The average score recorded was $3.959 \pm 1.2037$, and no statistically significant differences (One-Sample Kolmogorov-Smirnov Test $p=.000^{*}$, Mann-Whitney $U=2689.500, p=0.328$ ) were obtained between students and doctors.

The subjects' answers to the questionnaire were also quantified using an overall score, with values between 8 and 54.6. The average score recorded at the level of the whole group was $42.253 \pm 8.0697$ - a value that proved subjects had average knowledge of dentin hypersensitivity, as seen in Table 4. There were statistically significant differences between the performances of doctors and students in this questionnaire, indicating that doctors had a higher level of knowledge than students on the investigated subject.

\section{DISCUSSION}

The current research is one of the first studies that aimed to establish whether the knowledge of young doctors differs from the knowledge of senior dental students regarding their theoretical information about the dentin hypersensitivity. The high students' response rate can be due to the setting in which the questionnaires were collected, as soon as they were filled. We observe a similar response rate $(75.7$ $-78.7 \%)$ to the one reported in other studies that analyzed dental students $[3,9]$. The doctors' response rate was lower, mainly because the interaction with the participants was on-line. Additionally, the lack of knowledge and understanding of the subject might have prevented them from filling in and returning the questionnaire [17]. These data (response rate of $10.2 \%$ in the current study) are also in line with the low response rate $(7 \%)$ reported by the Canadian Advisory Board on Dentin Hypersensitivity in a similar study regarding the practitioners' understanding and clinical management of $\mathrm{DH}[8]$.

Our study revealed that most participants knew that the short and sharp pain is characteristic for $\mathrm{DH}$, which is an important step in correctly diagnosing this disease. The first clinical data that a practitioner must collect cover the history of the patient's pain $[8,18]$.

In the present study, most participants had a good performance on the evaluation of all triggering factors (thermal, tactile, evaporative, chemical stimuli) of $\mathrm{DH}$, but young doctors had a significantly better performance than students. In other studies, $92 \%$ of the surveyed dentist identified chemical and thermal stimuli as the main triggering factors for $\mathrm{DH}$ [2]. Amarasena et al. [19] observed that cold stimuli were the most frequently cited trigger of $\mathrm{DH}(67.5 \%)$. An earlier study reported the participants' lack of knowledge because the doctors had identified bruxism and malocclusion as triggers of $\mathrm{DH}$ even though neither has been recognized as a major causative factor [8].

Most participants had a good performance when asked to identify multiple predisposing factors (tooth erosion, dentin exposure, gingival recession) of DH. Comparatively, young doctors performed better than the senior dental students on this specific item. The data are consistent with other studies that have reported abrasion and gingival recession as the most important predisposing factor for $\mathrm{DH}[1,19]$. The dental professional should identify and remove predisposing factors as a first step approach when 
treating patients with $\mathrm{DH}[18]$. Less than half of the respondents knew the therapeutic strategies for $\mathrm{DH}$. One-third of the dental students and four doctors obtained a null score on this question, which means an insufficient level of knowledge. This question did not appear in other questionnaire-based studies that we found in our scientific literature search.

The preventive measures were identified by twothirds of the young doctors and more than onethird of the students, and half of all respondents performed well on this item. This is in agreement with the studies of Benoist et al. [2] (where 78\% of the dentists recognized the preventive measures) and Nazir et al. [3] where the most common preventive strategy $(74.1 \%)$ used by dental students and interns was the proper education on toothbrushing technique.

As to identifying the correct treatment of $\mathrm{DH}$, the data revealed that less than one-third of all participants obtained a good performance score, most of them having only satisfactory results. The mostly recognized treatment strategies were the correction of toothbrushing technique and the use of desensitizing toothpastes, which is consistent with other studies $[2,3,9,19]$. Less than ten percent of all respondents failed to answer this item correctly. This is in agreement with the result obtained by Cunha-Cruz et al. [20].

Half of all participants had satisfactory knowledge about the remineralization strategies used in the treatment of $\mathrm{DH}$, but one-third of them did not know the answer.

Almost all of the participants had knowledge of and could mention at least one brand of desensitizing toothpaste. That is in conformity with the findings of Benoist et al. [2], but as different from another study which has shown that fifty percent of the dentists reported incorrectly that the most popular desensitizing ingredients in desensitizing toothpastes are fluoride compounds [8].

Almost two-thirds of the participants in our study were able to recognize the etiology of different types of dental wear (as abrasion, abfraction, and erosion). Less than half of the young dentists and almost half of the dental students obtained a good result in identifying some of the main characteristics of $\mathrm{DH}$.

The mean global score of the questionnaire proved that subjects had an overall average level of knowledge of dentin hypersensitivity. No participant obtained the maximum score or a score zero.

The null-hypothesis was rejected. There were multiple results with statistically significant differences $(p<$ 0.05 ) between the two groups. This demonstrates that young dentists have a higher level of knowledge of $\mathrm{DH}$ when comparing to the students. We believe that the differences between groups are explained by the higher practical experience that doctors accumulate in time, although dental students studied DH more recently. This demonstrates that theoretical knowledge needs to be completed by practice and vice-versa.

Given the high prevalence of $\mathrm{DH}$ and its complexity, the results of this study point to the stringent need to provide better theoretical, but also clinical teaching opportunities to students and good access to continued educational programs to young doctors. These will contribute to a better quality of care for patients having this pathology. To date, there is no evidence of such an observational study being undertaken in dentistry, but it is our belief that such a design would lead to interesting and significant insights for the field. The limitations of the study are the decreased overall response rate obtained and the restricted population of undergraduate students belonging to the same university. Further multicenter studies are required in order to allow for these results to be confidently generalized into a wider population of general dental practitioners and senior dental students.

\section{CONCLUSION}

The findings of this study indicate that dentists under five-years' working experience have significantly better knowledge as compared to 6th-year dental students. Both groups of participants were far better informed regarding $\mathrm{DH}$ pain characterization, triggering factors, and predisposing factors of this condition, and less about its treatment.

\section{CONFLICT OF INTEREST}

The authors declare no conflict of interest.

\section{AUTHOR CONTRIBUTIONS}

EB: conception and design of the study, acquisition of data, analysis and interpretation of data, drafting the article, final approval of the version to be submitted. SS: drafting the article, revising the article critically for important intellectual content. AG: acquisition of data, analysis and interpretation of data. IN: acquisition of data, analysis and interpretation of data. GP: acquisition of data, analysis and interpretation of data. SA: conception and design of the study, revising the article critically for important intellectual content, final approval of the version to be submitted.

\section{ACKNOWLEDGMENTS}

The authors would like to thank all participants in the study who provided their fullest cooperation. 


\section{REFERENCES}

1. Kopycka-Kedzierawski DT, Meyerowitz C, Litaker MS, et al. Management of Dentin Hypersensitivity by National Dental Practice-Based Research Network practitioners: Results from questionnaire administered prior to initiation of a clinical study on this topic. BMC Oral Health. 2017:17:41. doi: 10.1186/s12903017-0334-0

[Full text links] [PubMed] Google Scholar Scopus WoS

2. Benoist FL, Ndiaye FG, Faye B, et al. Knowledge of and management attitude regarding dentin hypersensitivity among dentists from a West African country. J Contemp Dent Pract. 2014;15(1):86-91. doi: 10.5005/jp-journals-10024-1493 [Full text links] [PubMed] Google Scholar Scopus

3. Nazir MA, Almas K, Majeed MI, Majeed A, Ahmed SZ. A cross sectional study of dentin hypersensitivity among dental students and interns. J Int Dent Med Res. 2018;11(2):376-382.

[Full text links] Google Scholar Scopus

4. Amarasena N, Spencer J, Ou Y, Brennan D. Dentine hypersensitivity in a private practice patient population in Australia. J Oral Rehabil. 2011;38(1):52-60. doi: 10.1111/j.13652842.2010.02132x

[Full text links] [PubMed] Google Scholar Scopus WoS 5. West NX. Dentine hypersensitivity: Preventive and therapeutic approaches to treatment. Periodontol 2000. 2008;48(1):31-41. doi: 10.1111/j.1600-0757.2008.00262.x

[Full text links] [PubMed] Google Scholar Scopus WoS 6. Holland GR, Narhi MN, Addy M, Gangarosa L, Orchardson R. Guidelines for the design and conduct of clinical trials on dentine hypersensitivity. J Clin Periodontol. 1997;24(11):808-813. doi: 10.1111/j.1600-051x.1997.tb01194x

[Full text links] [PubMed] Google Scholar Scopus WoS

7. Gillam DG, Seo HS, Bulman JS, Newman HN. Perceptions of dentine hypersensitivity in a general practice population. J Oral Rehabil. 1999;26(9):710-714. doi: 10.1046/j.13652842.1999.00436x.

[Full text links] [PubMed] Google Scholar Scopus WoS 8. Canadian Advisory Board on Dentin Hypersensitivity. Consensus-Based Recommendations for the Diagnosis and Management. J Can Dent Assoc. 2003;69(4):221-226.

[Full text links] [PubMed] Google Scholar Scopus

9. Majeed A, Alshwaimi E, Nazir MA, Almas K. Dental Students' Perception of Dentine Hypersensitivity and Awareness about its Management. J Clin Diagnostic Res. 2019;13(8):ZC15-ZC19.

[Full text links]

10. Lima TC, Vieira-Barbosa NM, Grasielle de Sá Azevedo C, et al. Oral Health-Related Quality of Life Before and After Treatment of Dentin Hypersensitivity With Cyanoacrylate and Laser. J Periodontol. 2017:88(2):166-172 doi: 10.1902/jop.2016.160216 [Full text links] [PubMed] Google Scholar Scopus WoS
11. Machado AC, Rabelo FEM, Maximiano V, et al. Effect of inoffice desensitizers containing calcium and phosphate on dentin permeability and tubule occlusion. J Dent. 2019;86:53-9. doi: 10.1016/j.jdent.2019.05.025

[Full text links] [PubMed] Google Scholar Scopus

12. Bekes K, John MT, Schaller HG, Hirsch C. Oral health-related quality of life in patients seeking care for dentin hypersensitivity. J Oral Rehabil. 2009;36(1):45-51. doi: 10.1111/j.13652842.2008.01901.x

[Full text links] [PubMed] Google Scholar ScopusWoS 13. Boynton PM, Greenhalgh T. Hands-on guide to questionnaire research: Selecting, designing, and developing your questionnaire. BMJ. 2004;328(7451):1312-1315. doi: 10.1136/ bmj.328.7451.1312

[Full text links] [PubMed] Google Scholar Scopus WoS

14. Schuurs AHB, Wesselink PR, Eijkman MAJ, Duivenvoorden $H J$ Dentists' views on cervical hypersensitivity and their knowledge of its treatment. Dent Traumatol. 1995;11(5):240-244. doi:

10.1111/j.1600-9657.1995.tb00496.x

[Full text links] [PubMed] Google Scholar Scopus WoS

15. Gillam DG, Bulman JS, Eijkman MAJ, Newman HN. Dentists' perceptions of dentine hypersensitivity and knowledge of its treatment J Oral Rehabil 2002·29(3):219-225 doi: 10.1046/j.1365-2842.2002.00812.x

[Full text links] [PubMed] Google Scholar Scopus WoS

16. Tsang S, Royse CF, Terkawi AS. Guidelines for developing, translating, and validating a questionnaire in perioperative and pain medicine. Saudi J Anesth. 2017;11(5):80-9. doi: 10.4103/sja. SJA 20317

[Full text links] [PubMed] Google Scholar Scopus WoS

17. Pereira R, Gillam D, Bapatla S, Satyamurthy P. Awareness of Dentine Hypersensitivity among General Dental Practitioners in Mumbai, India. J Odontol. 2018:2(1):1-6.

[Full text links] Google Scholar

18. Gillam DG. Treatment Modalities for Dentin Hypersensitivity. In: Taha S, Clarkson BH, editors. Clinician's Guide to the Diagnosis and Management of Tooth Sensitivity. First ed. Heidelberg: Springer; 2014. doi:10.1007/978-3-642-45164-5 Google Scholar

19. Amarasena N, Spencer J, Ou Y, Brennan D. Dentine hypersensitivity - Australian dentists' perspective. Aust Dent J. 2010;55(2):181-187. doi: 10.1111/j.1834-7819.2010.01223.x [Full text links] [PubMed] Google Scholar Scopus WoS

20. Cunha-cruz J, Wataha JC, Manning W, et al. Treating Dentin Hypersensitivity: Therapeutic Choices Made by Dentists of the Northwest PRECEDENT Network. JADA. 2010;141(9):1097-1105. doi: 10.14219/jada.archive.2010.0340

[Full text links] [PubMed] Google Scholar Scopus WoS
Emilia BOLOGA

DDS, PhD Student Department of Odontology Periodontology and Fixed Prosthodontics Faculty of Dental Medicine "Grigore T. Popa" University of Medicine and Pharmacy of Jassy Jassy, Romania

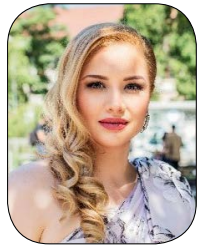

Emilia Bologa, DDS, received her degree in dentistry in 2014 from the „Gr. T. Popa” University of Medicine and Pharmacy, Jassy. Dr. Bologa is currently a PhD student at the Department of Odontology, Periodontology and Fixed Prosthodontics, Faculty of Dental Medicine, "Grigore T. Popa” University of Medicine and Pharmacy of Jassy, Jassy, Romania. She is a young researcher whose area of interest includes dentin hypersensitivity and remineralization strategies. 


\section{Ouestions}

\section{Dentin hypersensitivity is described as:}

$\square$ a. A diffuse pain;

b. A pulsating pain;

ac. A short, sharp pain;

$\square d$. An aching pain.

\section{Patients with sensitive teeth experience discomfort while:}

口a. Flossing;

ab. Jogging;

ac. Sleeping;

d. Brushing their teeth.

3. According to the results of this study, which percentage of participants have been able to give examples of desensitizing toothpastes?

口a. $88.5 \%$;

口b. $95.8 \%$;

ac. $15.8 \%$;

ad. None.

\section{What did the mean global score of the questionnaire prove?}

a. Subjects had a very good level of knowledge;

ab. Subjects had a good level of knowledge;

uc. Subjects had an average level of knowledge;

ad. Subjects had an insufficient level of knowledge.

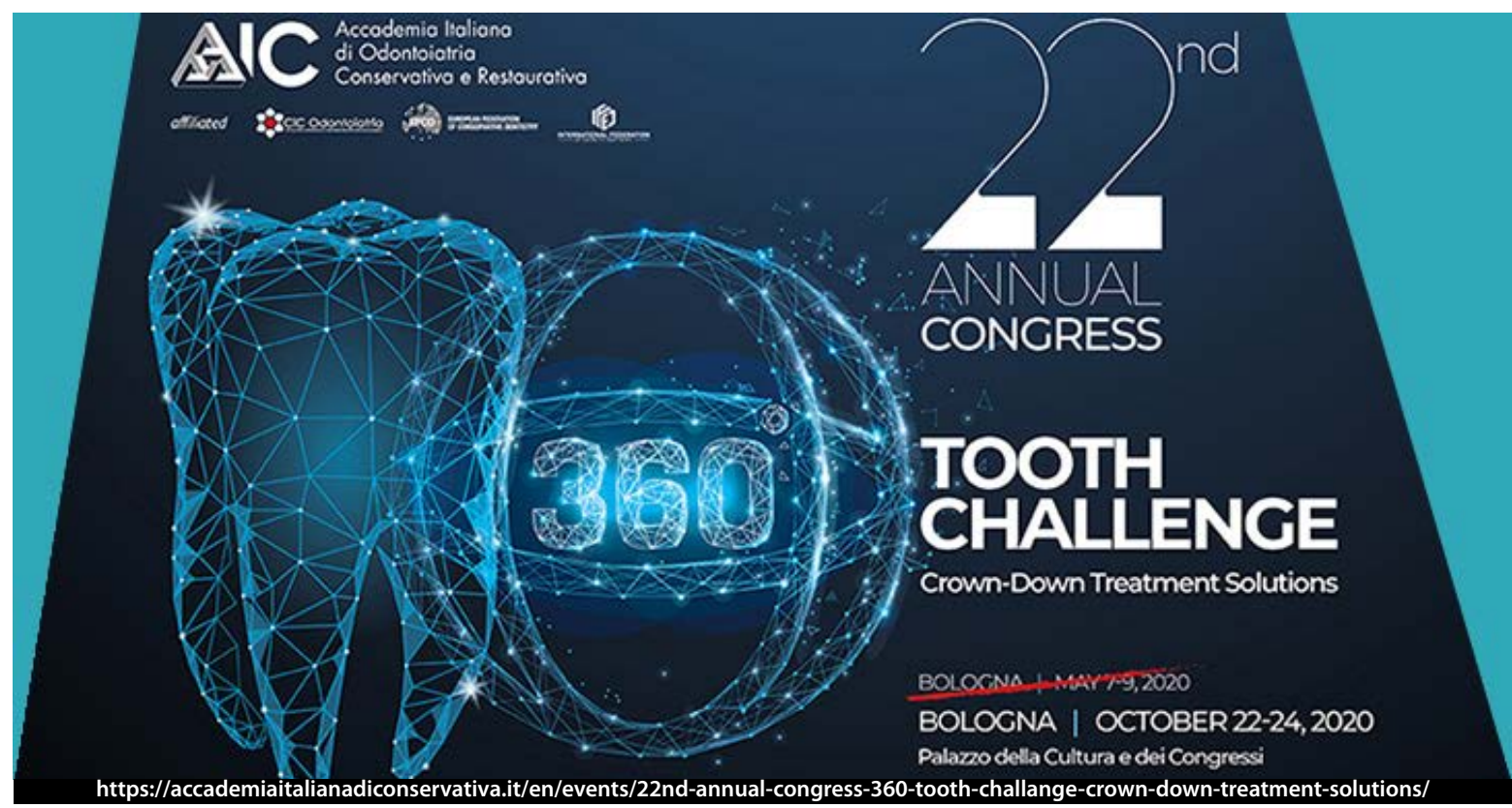




\title{
EVALUATION OF UPPER ARCH CHANGES IN PATIENTS WITH UNILATERAL CLEFT LIP AND PALATE AFTER MAXILLARY EXPANSION USING DIGITAL DENTAL CASTS
}

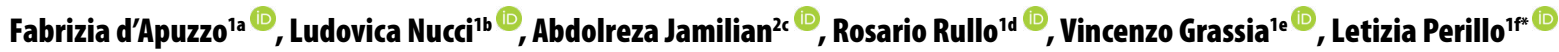 \\ ${ }^{1}$ Multidisciplinary Department of Medical-Surgical and Dental Specialties, University of Campania Luigi Vanvitelli, Naples, Italy \\ ${ }^{2}$ Department of Orthodontics, Islamic Azad University, Tehran, Iran
}

a DDS, MS, PhD, Research fellow; e-mail: fabriziadapuzzo@gmail.com; ORCIDiD: https://orcid.org/0000-0003-0291-9339

${ }^{b} D D S$, PhD student; e-mail: ludortho@gmail.com; 0RCIDiD: https://orcid.org/0000-0002-7174-7596

' DDS, MSc, OMFS, Full professor; e-mail: info@jamilian.net; ORCIDiD: https://orcid.org/0000-0002-8841-0447

${ }^{d}$ MD, MS, Associate professor; e-mail: rosario.rullo@unicampania.it; ORCIDiD: https://orcid.org/0000-0002-5418-8171

eDDS, MS, PhD, Lecturer; e-mail: grassiavincenzo@libero.it; ORCIDiD: https://orcid.org/0000-0002-6671-2380

fMD, MS, PhD, Professor, Head, Dean; e-mail: letizia.perillo@unicampania.it; ORCIDiD: https://orcid.org/0000-0001-6175-7363

ABSTRACT

d) https://doi.org/10.25241/stomaeduj.2020.7(3).art.4

Objective To compare the upper arch dimensions of young patients with unilateral cleft lip and palate (UCLP) before and after treatment with bonded maxillary expander and hybrid activation protocol using digital dental casts.

Methods Sixteen subjects with UCLP, aged between 7 and 14 years (mean age $10.9 \pm 2.7$ years) consecutively treated with bonded maxillary expander and hybrid activation were included. The dental casts before and after treatment were digitalized using a 3Shape scanner. Intercanine, interpremolar and intermolar widths (at cusp and gingival levels) and arch perimeters were measured. The significance level for statistical analyses was set as $p<0.05$.

Results The total treatment time using the hybrid expansion protocol lasted $12 \pm 1.9$ months while the active expansion time lasted $4 \pm 0.2$ months. Patients with UCLP showed significant differences in all transverse upper arch dimensions both at cusp and gingival level.

Conclusion The use of a bonded maxillary expander with a hybrid activation protocol during growth may be efficient to improve all transverse upper arch widths in patients affected by UCLP.

KEYWORDS

Cleft Lip and Palate; Maxillary Expansion; Bonded Expander; Hybrid Expansion Protocol; Digital Dental Casts.

\section{INTRODUCTION}

Cleft Lip and Palate (CLP) is one of the most common types of congenital craniofacial birth anomalies due to environmental, genetic and epigenetic risk factors interacting among them [1-3].

They can occur between the fourth and twelfth week of gestation due to the failure of fusion between the medial nasal and maxillary processes in the primary palate or the palatal units in the secondary palate [4]. Affected patients need interdisciplinary care since birth until adulthood and evince higher morbidity and mortality throughout life compared to noncleft subjects [5]. Oral rehabilitations usually require complex and challenging interdisciplinary treatments since the first post-birth weeks do not allow the most adequate early recovery of vital functions $[5,6]$

Craniofacial growth harmony in patients with unilateral or bilateral CLP is affected in all 3 dimensions (3D). Previous studies showed that it can be only partially improved after surgery during childhood [7-9]. Lip surgery is usually performed at 6 months of age using the Delaire technique, soft 
ITable 1. Age, treatment time and sex ratio of the UCLP patients.

\begin{tabular}{|l|c|c|}
\hline Variable & Mean & SD \\
\hline Initial age (years) & 10,9 & 2,7 \\
\hline Total Treatment time (months) & 12,0 & 1,9 \\
\hline Active Treatment time (months) $\quad$ Female & 4,0 & 0,2 \\
\hline \multirow{2}{*}{ Sex Male } & 10 & \\
\cline { 2 - 3 } & 6 & \\
\hline
\end{tabular}

Table 2. Random and systematic errors of the measurements performed on the digital dental models.

\begin{tabular}{|l|c|c|c|c|}
\hline & \multicolumn{2}{|c|}{ T0 } & \multicolumn{2}{c|}{ T1 } \\
\hline Measurements & D Dahlberg & $\begin{array}{c}\text { Systematic } \\
\text { error P level }\end{array}$ & D Dahlberg & $\begin{array}{c}\text { Systematic } \\
\text { error P level }\end{array}$ \\
\hline 3-3 cusp & 1.30 & NS & 1.55 & NS \\
\hline 3-3 gingival & 1.24 & NS & 0.78 & NS \\
\hline 4-4 cusp & 0,89 & NS & 1.56 & NS \\
\hline 4-4 gingival & 1.50 & NS & 1.34 & NS \\
\hline 5-5 cusp & 1.45 & NS & 2,01 & NS \\
\hline 5-5 gingival & 1.67 & NS & 1.34 & NS \\
\hline 6-6 cusp & 1.07 & NS & 1.67 & NS \\
\hline 6-6 gingival & 0.98 & NS & 0.87 & NS \\
\hline AP & 4.06 & NS & 1.81 & \\
\hline
\end{tabular}

${ }^{*} p<0.05,{ }^{* *} p<0.005$

palate surgery at 12 months and hard palate surgery at 18 months, whereas secondary alveolar bone graft is usually planned when the patient is around 9 to 12 years old [10-12]. When the surgical protocol for the hard palate closure is delayed, the occlusion is even more affected [12].

During the early mixed dentition, the maxillary arch linear dimensions significantly differ between the unilateral cleft lip and palate (UCLP) group and the noncleft group, [13] while the intercanine width seems to be more reduced in bilateral complete clefts due to scars resulting from palatal surgery [14]. It has been also demonstrated that children with UCLP usually suffer from a nasomaxillary complex deficiency which continues worsening until the end of their growth and have maxillary dental arches constricted in width and length [15].

Thus, it is suggested to ideally start to perform an early dentofacial orthopedic treatment protocol during the mixed dentition [16]. In the light of these findings, an interceptive treatment with a palatal expander is usually proposed as a first approach [1719]. The palatal expander allows to correct transverse skeletal maxillary constriction and dental posterior crossbite [20]. There are several different maxillary expansion modalities based on the appliance design [21] or the type of activation and no differences were found between slow or rapid expansion protocols in children with bilateral CLP $[17,22]$. Thus, the positive effects on the occlusion are undeniable in patients with CLP modifying the upper arch diameters and stimulating the transversal skeletal growth, even without leading to the same amount of bone formation, as reported in normal patients [23]. However, to the best of our knowledge, there are no studies treating subjects affected by CLP using a bonded maxillary expander with a hybrid activation [24-27]. The bonded expander seems to have some advantages such as better control of vertical growth, reduced interocclusal interferences and less dental tipping due to acrylic splints covering both occlusal, buccal and palatal surfaces of teeth [28-30]. Many papers conducted the palatal analysis of patients with CLP as compared to controls using novel threedimensional (3D) technologies [31-33]. Nowadays, the use of digital models is considered useful for treatment planning and outcome evaluations and the reliability of measurements from $3 \mathrm{D}$ dental casts as compared to those obtained directly from plaster models is evidence-based [34]. Thus, the purpose of this study was to evaluate upper arch dimensions on digital dental casts in young patients with UCLP before and after treatment using a bonded maxillary expander with a hybrid activation.

\section{METHODOLOGY}

This retrospective observational study was based on the analysis of data collected from patients with UCLP who had completed an orthodontic treatment with maxillary expansion at the Orthodontic Program of the University of Campania Luigi Vanvitelli, Naples, Italy. The research was carried out in accordance with the Declaration of Helsinki and approved by the ethics committee of the University of Campania Luigi Vanvitelli, Naples, Italy (Prot. $N^{\circ} 147$ ). An 


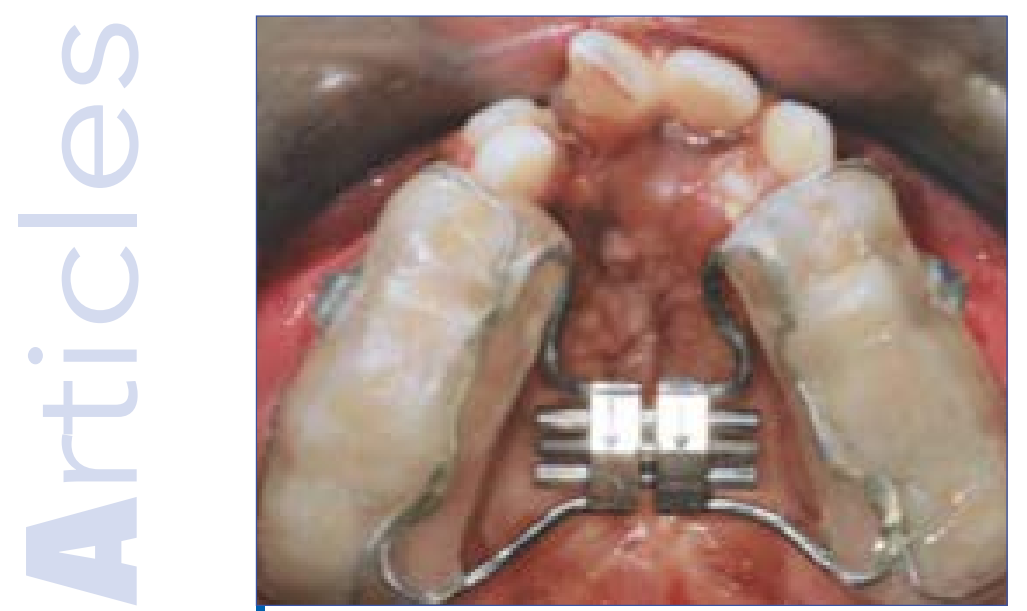

Figure 1. Intraoral photograph of bonded maxillary expander in a patient with UCLP.

informed consent was obtained from the parents of each patient. Here are the inclusion criteria: patients affected by UCLP, age ranging between 7 and 14 years, constricted upper arch, cervical vertebral maturation between CS1 and CS4 and treatment protocol including a bonded maxillary expander with hybrid activation $[24,26]$. Subjects with other craniofacial syndromes, previous orthodontic treatment or incomplete documentation were excluded.

All patients had been previously treated at the Division of Maxillofacial Surgery at the University of Campania Luigi Vanvitelli, Naples, Italy, by the same surgeon, using the same protocol and method as follows: lip surgery at 6 months, soft palate surgery at 12 months and hard palate surgery at 18 months. No infant orthopaedics was carried out prior to surgery. The initial (T0) and after expansion (T1) plaster models of each patient were collected to be digitalized and then analyzed [35].

The treatment was performed with a bonded palatal expander (Fig.1) [16] applied on the upper lateral teeth. The activation started after the appliance onset and ended when overcorrection was achieved. The protocol used had two phases: the initial phase started at the chair side and included three steps with four, two and one turn, respectively; the second one followed at home with one turn every 3 days [24, 26]. During the active expansion phase depending on the degree of maxillary constriction, the patients were monitored every 2 weeks.

After the active expansion phase, the screw of the appliance was closed with acrylic composite and the expander was used as a retainer for about 8 months. The expander was removed after about 1 year and a second plaster model was realized. Both dental casts were scanned using the 3shape TRIOS $^{\circ}$, with a reported manufacturing accuracy of less than 20 microns (www.3shape.com), by the same trained operators. The digital models were exported in STL surface mesh then imported in Viewbox 4 (dHal Software, Kifissia, Greece). A total of nine linear measurements of the upper dental

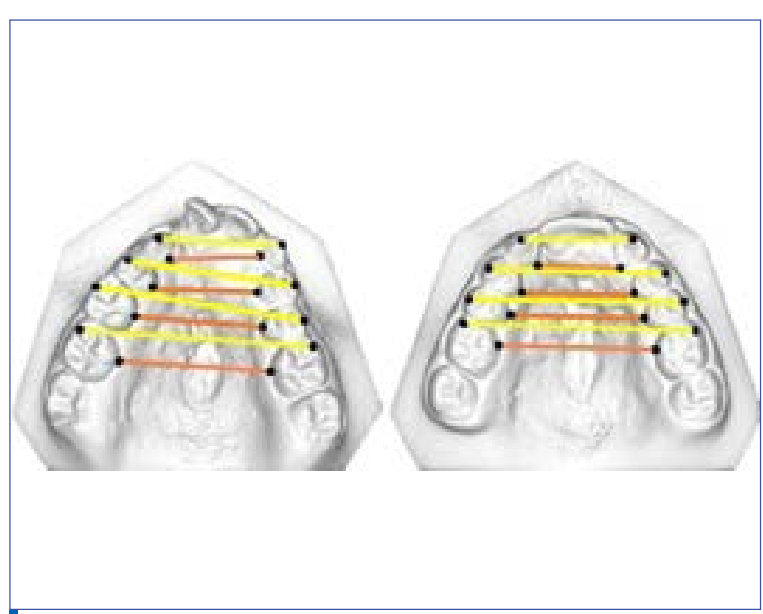

Figure 2. Assessment on the digital model of arch widths: at the cusp (yellow lines) and gingival (orange lines) level.

arch were considered: transverse intercanine (3-3), interpremolar or interdeciduous molar (4-4 and 5-5) and intermolar (6-6) distances at both cusp tips and gingival levels, and arch perimeter (AP) calculated as circumference of the dental arch, measured from the distal surface of the maxillary permanent first molars on the right side to the distal surface of the contralateral ones.

\subsection{Statistical analysis}

The reliability of the measurements was determined by randomly selecting five dental casts before and after the expansion treatment. They were measured twice after a two-week interval. Dahlberg's formula was used to quantify the measurement error. An Intraclass Correlation Coefficient was also calculated to assess test/retest reliability. An unpaired t-test and a Wilcoxon signed-rank test were utilized to evaluate any significant difference before and after treatment. The statistical significance was set at $p<0.05$.

All statistical analyses were performed with SPSS software (Statistical Package for the Social Sciences, SPSS, Version 12, Chicago, IL, USA).

\section{RESULTS}

The total sample included 16 patients, 10 females and 6 males. The initial mean age was $10.9 \pm 2.7$ years. The total treatment phase with the bonded expander (T0-T1) lasted $12.0 \pm 1.9$ months while the active expansion phase was $4.0 \pm 0.2$ months (Table 1 ). The statistical analysis confirmed that there were no systematic measurement errors before and after treatment, as shown in (Table 2).

Comparing measurements at T0 and T1 showed statistically significant differences in all transverse arch widths while arch perimeter values revealed no differences (Table 3).

As to the difference arch diameters at both cusp tips and gingival levels (Table 4), data showed statistically significant differences only for the diameter 3-3 measured at cusp level. 
ITable 3. Measurements before (T0) and after maxillary expansion (T1).

\begin{tabular}{|l|c|c|c|c|c|}
\hline \multicolumn{1}{|c|}{ Variable } & $\begin{array}{c}\text { T0 mean value } \\
(\mathbf{m m})\end{array}$ & $\begin{array}{c}\text { T1 mean value } \\
(\mathbf{m m})\end{array}$ & STD Error & t & S \\
\hline 3-3 cusp & 26,72 & 31,36 & 1,59 & $0,01^{*}$ & $0,01^{*}$ \\
\hline 3-3 gingival & 21,72 & 24,81 & 1,38 & $0,04^{*}$ & $0,04^{*}$ \\
\hline 4-4 cusp & 34,18 & 40,05 & 1,73 & $0,004^{* *}$ & $0,006^{*}$ \\
\hline 4-4 gingival & 23,08 & 28,43 & 1,51 & $0,003^{* *}$ & $0,007^{*}$ \\
\hline 5-5 cusp & 40,68 & 46,40 & 1,92 & $0,009^{*}$ & $0,01^{*}$ \\
\hline 5-5 gingival & 26,94 & 33,16 & 1,82 & $0,004^{* *}$ & $0,005^{* *}$ \\
\hline 6-6 cusp & 49,90 & 55,79 & 1,65 & $0,003^{* *}$ & $0,002^{*}$ \\
\hline 6-6 gingival & 32,76 & 38,65 & 1,55 & $0,002^{* *}$ & $0,003^{* *}$ \\
\hline AP & 88,76 & 88,41 & 3,18 & 0,91 & 0,61 \\
\hline
\end{tabular}

${ }^{*} p<0.05,{ }^{* *} p<0.005$

Table 4. Mean differences between measurements at the cusp and gingival level of arch widths, before and after maxillary expansion.

\begin{tabular}{|c|c|c|c|c|}
\hline Variable & $\begin{array}{c}\text { Mean } \\
\text { difference } \\
\text { T1-T0 (mm) }\end{array}$ & STD Error & t & S \\
\hline $3-3$ & $-1,54$ & 0,41 & $0,002^{* *}$ & $0,004^{* *}$ \\
\hline $4-4$ & $-0,52$ & 0,48 & 0,29 & 0,53 \\
\hline $5-5$ & 0,50 & 0,59 & 0,41 & 0,77 \\
\hline $6-6$ & 0,00 & 0,39 & 0,98 & 0,95 \\
\hline
\end{tabular}

${ }^{*} p<0.05,{ }^{* *} p<0.005$

\section{DISCUSSION}

Several previous studies showed significant different maxillary morphologies in patients with CLP in mixed or permanent dentition when compared to matched controls before any orthopedic/orthodontic treatment [31-33,36]. In particular, the upper intercanine widths significantly decreased both at cusp and gingival levels $[13-15,37]$. Therefore, there is a complete agreement on the need to expand the maxillary arch in patients affected by CLP. The reasons to use an expander in the orthodontic treatment plan are manifold. Iwasaki et al. [38] found that the nasal airway flow significantly improved after rapid maxillary expansion in patients with UCLP increasing both the quantity of airflow and nasal cross-sectional area on the cleft side. Also, speech and deglutition enhance after expansion due to wider space for the tongue, $[6,33]$ but, above all, the occlusal relationships result improved by widening the palatal dimensions [18].

Many investigations focused on dental and alveolar changes in patients with BCL and UCLP using different appliances and protocols. Our results have shed light on a different expansion appliance and protocol in patients with UCLP. Pugliese et al. [21] found that the maxillary expansion with Hyrax, Quad-helix and Expander with Differential Opening (EDO), in bilateral CLP patients, had similar changes in arch size, whereas only Quad-helix expander and EDO were associated with a greater shape at the intercanine area. Other researchers, comparing slow and rapid activation through Quad-helix and Hyrax expanders, respectively, in children with bilateral CLP, showed differences only with respect to the treatment time. Specifically, the expansion active phase ranged from 4 to 21 months in the slow protocol and from 7 to 14 days in the rapid one [17,22]. Façanha et al. [20] assessing the effects achieved with the Haas and Hyrax expanders using a rapid protocol in patients with UCLP, highlighted similar increases of the transverse dimensions. Ayub et al. [39] performing the expansion with a rapid protocol, found significant increases of all maxillary measurements including arch perimeter probably due to the sample selection based on patients with a posterior crossbite. Conversely, in our study, this parameter did not change significantly. However, a direct comparison of our findings with other studies was only partially possible due to the differences in cleft features and size, patients' age, dentition period, expansion appliance and protocol as well as the data analyses performed. Nevertheless, our treatment outcomes may add a missing piece in the puzzle about maxillary arch changes after expansion treatment, underlying the possibility to achieve similar effects in a reduced time with a different type of expander and activation [16,24-26]. Our results confirmed the need for orthodontic treatment during the development of the permanent dental occlusion and showed increases in all transverse upper arch dimensions. Moreover, the bonded expander seemed to exert a more homogeneous lateral pressure on the two halves of the maxilla avoiding any possible interference of the lower arch due to the smooth acrylic splints covering the occlusal surface. Thus, the bonded expander along with the hybrid activation protocol should be suggested in UCLP as a procedure to achieve an efficient maxillary expansion with arch widths homogeneous increase avoiding buccal tipping of premolars and molars maintaining an adequate active treatment time, of about 4 months, in the middle between the slow and rapid protocol $[17,22]$. This investigation, of course, had some limitations such as the retrospective nature of the study design 
with short-term outcomes, currently lacking longterm data [23]. Moreover, some subjects with UCLP had some permanent teeth missing in the dental arch on one or both sides.

The elimination of these patients, however, may have introduced higher selection bias eliminating more severely affected subjects with smaller arch widths which is actually a common clinical frame of CLP anomalies.

Future studies should be planned with an increased sample size, even to compare, with multicentric randomized clinical trials, this novel approach with the other conventional maxillary expansion protocol in patients with UCLP.

\section{CONCLUSION}

Growing patients with UCLP showed significant differences in all transverse upper arch dimensions after orthodontic treatment with a bonded maxillary expander and a hybrid activation protocol.

\section{REFERENCES}

1. Cobourne MT. The complex genetics of cleft lip and palate. Eur J Orthod. 2004;26(1):7-16. doi: 10.1093/ejo/26.1.7. [Full text link][CrossRef][PubMed][Google Scholar][Scopus] 2. Grassia V, Lombardi A, Kawasaki H, et al. Salivary microRNAs as new molecular markers in cleft lip and palate: a new frontier in molecular medicine. Oncotarget. 2018;9(27):18929-18938. doi:10.18632/oncotarget.24838.

[Full text link][CrossRef][PubMed][Google Scholar][Scopus] 3. Zhao J, Zhang B, Yang S, et al. Maternal exposure to ambient air pollutant and risk of oral clefts in Wuhan, China. Environ Pollut. 2018;238:624-630. doi:10.1016/j.envpol.2018.03.053.

[Full text link][CrossRef][PubMed][Google Scholar][Scopus] [WoS]

4. Mossey PA, Little J, Munger RG, et al. Cleft lip and palate. Lancet.

2009;374(9703):1773-1785. doi: 10.1016/S0140-6736(09)60695-4. [Full text link][CrossRef][PubMed][Google Scholar][Scopus]

5. Rullo R, Festa VM, Rullo R, et al. Prevalence of dental anomalies in children with cleft lip and unilateral and bilateral cleft lip and palate. Eur J Paediatr Dent. 2015;16(3):229-232.

[Full text link][PubMed][Google Scholar][Scopus] [WoS]

6. Rullo R, Di Maggio D, Addabbo F, et al. Speech outcome in unilateral complete cleft lip and palate patients: a descriptive study. Eur J Paediatr Dent. 2014;15(3):293-296.

[Full text link][PubMed][Google Scholar][Scopus] [WoS] 7. Fudalej PS, Urbanova W, Klimova I, et al. The Slavcleft: a three-center study of the outcome of treatment of cleft lip and palate. Part 2: dental arch relationships. J Craniomaxillofac Surg. 2019;47(7):1092-1095. doi: 10.1016/j.jcms.2019.03.023. [Full text link][CrossRef][PubMed][Google Scholar][Scopus] 8. Heliövaara A, Skaare P, Küseler A, et al. Scandcleft randomized trials of primary surgery for unilateral cleft lip and palate. Dental arch relationships in 8 year-olds. Eur J Orthod. 2020;42(1):1-7. doi: 10.1093/ejo/cjz067.

[Full text link][CrossRef][PubMed][Google Scholar][Scopus] 9. Küseler A, Mølsted K, Marcusson A, et al. Scandcleft randomized trials of primary surgery for unilateral cleft lip and palate: maxillary growth at eight years of age. Eur J Orthod. 2020;42(1):24-29. doi: 10.1093/ejo/cjz078.

[Full text link][Cross Ref][Pubmed][Google Scholar][Scopus] 10. Scalzone A, Flores-Mir C, Carozza D, et al. Secondary alveolar bone grafting using autologous versus alloplastic material in the treatment of cleft lip and palate patients: systematic review and meta-analysis. Prog Orthod. 2019;20(1):6. doi: 10.1186/s40510018-0252-y.

[Full text link][CrossRef][PubMed][Google Scholar][Scopus]

\section{CONFLICT OF INTEREST}

The authors declare no conflict of interest.

\section{AUTHOR CONTRIBUTIONS}

Made substantial contributions to conception and design of the study and performed data analysis and interpretation: FdA, VG, LP. Performed data acquisition, as well as provided administrative, technical, and material support: LN, AJ, RR.

\section{FINANCIAL SUPPORT AND SPONSORSHIP}

None.

\section{ETHICAL APPROVAL AND CONSENT TO PARTICIPATE}

Research was performed in accordance with the Declaration of Helsinki and approved by the ethics committee of the University of Campania Luigi Vanvitelli, Naples, Italy (Prot. N 147).

An informed consent to participate in the study was obtained.

\section{CONSENT FOR PUBLICATION}

A written informed consent for publication was obtained.
11. Yang CJ, Pan XG, Qian YF, Wang GM. Impact of rapid maxillary expansion in unilateral cleft lip and palate patients after secondary alveolar bone grafting: review and case report. Oral Surg Oral Med Oral Pathol Oral Radiol. 2012;114(1):e25-e30. doi: 10.1016/j.tripleo.2011.08.030. [Full text link][CrossRef][PubMed][Google Scholar][Scopus] [WoS]

12. Botticelli S, Küseler A, Marcusson A, et al. Do infant cleft dimensions have an influence on occlusal relations? A subgroup analysis within an RCT of primary surgery in patients with unilateral cleft lip and palate. Cleft Palate Craniofac J. 2020;57(3):378-388. doi: 10.1177/1055665619875320. [Full text link][Crossref][PubMed][Google Scholar][Scopus] 13. Garrahy A, Millett DT, Ayoub AF. Early assessment of dental arch development in repaired unilateral cleft lip and unilateral cleft lip and palate versus controls. Cleft Palate Craniofac J. 2005:42(4):385-391. doi:10.1597/03-159.1.

[Full text link][CrossRef][PubMed][Google Scholar][Scopus] 14.Loomans N, Decombel O, Goethals K, Mommaerts MY. Transverse maxillary development in complete cleft patients: comparison of 2 treatment strategies by longitudinal and crosssectional model analysis. Cleft Palate Craniofac J. 2019;56(5):610618. doi: 10.1177/1055665618802539.

[Full text link][CrossRef][PubMed][Google Scholar][Scopus] 15. Gopinath VK, Samsudin AR, Mohd Noor SNF, Mohamed Sharab HY. Facial profile and maxillary arch dimensions in unilateral cleft lip and palate children in the mixed dentition stage. Eur J Dent. 2017;11(1):76-82. doi: 10.4103/ejd.ejd_238_16. [Full text link][CrossRef][PubMed][Google Scholar][Scopus] 16. Perillo L, Vitale M, d'Apuzzo F, et al. Interdisciplinary approach for a patient with unilateral cleft lip and palate. Am $J$ Orthod Dentofacial Orthop. 2018;153(6):883-894. doi: 10.1016/j. ajodo.2016.12.035.

[Full text link][CrossRef][PubMed][Google Scholar][Scopus] 17. de Medeiros Alves AC, Garib DG, Janson G, et al. Analysis of the dentoalveolar effects of slow and rapid maxillary expansion in complete bilateral cleft lip and palate patients: a randomized clinical trial. Clin Oral Investig. 2016;20(7):1837-1847. doi: 10.1007/s00784-015-1675-1.

[Full text link][CrossRef][PubMed][Google Scholar][Scopus] [WoS]

18. Pan X, Qian Y, Yu J, et al. Biomechanical effects of rapid palatal expansion on the craniofacial skeleton with cleft palate: a threedimensional finite element analysis. Cleft Palate Craniofac J. 2007:44(2):149-154. doi: 10.1597/05-161.1.

[Full text link][CrossRef][PubMed][Google Scholar][Scopus] 
19. Bejdová S, Krajíček V, Peterka M, et al. Variability in palatal shape and size in patients with bilateral complete cleft lip and palate assessed using dense surface model construction and 3D geometric morphometrics. J Craniomaxillofac Surg. 2012;40(3):201-208. doi: 10.1016/j.jcms.2011.04.013.[Full text link][CrossRef][PubMed][Google Scholar][Scopus] 20. Façanha AJ, Lara TS, Garib DG, da Silva Filho OG. Transverse effect of Haas and Hyrax appliances on the upper dental arch in patients with unilateral complete cleft lip and palate: a comparative study. Dental Press J Orthod. 2014;19(2):39-45. doi: 10.1590/2176-9451.19.2.039-045.oar.

[Full text link][CrossRef][PubMed][Google Scholar][Scopus] 21. Pugliese F, Palomo JM, Calil LR, et al. Dental arch size and shape after maxillary expansion in bilateral complete cleft palate: a comparison of three expander designs. Angle Orthod. 2020;90(2):233-238. doi: 10.2319/020219-74.1.

[Full text link][CrossRef][PubMed][Google Scholar][Scopus] 22. de Almeida AM Ozawa TO, Alves ACM et al. Slow versus rapid maxillary expansion in bilateral cleft lip and palate: a CBCT randomized clinical trial. Clin Oral Investig. 2017;21(5):1789-1799. doi: 10.1007/s00784-016-1943-8.

[Full text link][CrossRef][PubMed][Google Scholar][Scopus] [WoS] 23. Al-Gunaid T, Asahito T, Yamaki M, et al. Relapse tendency in maxillary arch width in unilateral cleft lip and palate patients with different maxillary arch forms. Cleft Palate Craniofac J. 2008;45(3):278-283. doi: 10.1597/07-053.

[Full text link][CrossRef][PubMed][Google Scholar][Scopus] 24. Grassia V, D'Apuzzo F, Ferrulli VE, et al. Dento-skeletal effects of mixed palatal expansion evaluated by postero-anterior cephalometric analysis. Eur J Paediatr Dent. 2014;15(1):59-62. [Full text link][PubMed][Google Scholar][Scopus]

25. Perillo L, De Rosa A, laselli F, et al. Comparison between rapid and mixed maxillary expansion through an assessment of dentoskeletal effects on posteroanterior cephalometry. Prog Orthod. 2014;15(1):46. doi: 10.1186/s40510-014-0046-9.

[Full text link][CrossRef][PubMed][Google Scholar][Scopus] 26. Grassia V, d'Apuzzo F, DiStasio D, et al. Upper and lower arch changes after Mixed Palatal Expansion protocol. Eur J Paediatr Dent. 2014:15(4):375-380.

[Full text link][PubMed][Google Scholar][Scopus] [WoS] 27. Grassia V, d'Apuzzo F, Jamilian A, et al. Comparison between rapid and mixed maxillary expansion through an assessment of arch changes on dental casts. Prog Orthod. 2015;16:20. doi: 10.1186/s40510-015-0089-6.

[Full text link][CrossRef][PubMed][Google Scholar][Scopus] [WoS] 28. Lione R, Brunelli V, Franchi L, et al. Mandibular response after rapid maxillary expansion in class II growing patients: a pilot randomized controlled trial. Prog Orthod. 2017;18(1):36. doi: 10.1186/s40510-017-0189-6.

[Full text link][CrossRef][PubMed][Google Scholar][Scopus] [WoS] 29. Ngan P. Biomechanics of maxillary expansion and protraction in Class III patients. Am J Orthod Dentofacial Orthop. 2002;121(6):582-583. doi: 10.1067/mod.2002.124168.

[Full text link][CrossRef][PubMed][Google Scholar][Scopus] [WoS]
30. D'Apuzzo F, Grassia V, Quinzi V, et al. Paediatric Orthodontics. Part 4: SEC III protocol in Class III malocclusion. Eur J Paediatr Dent. 2019;20(4):330-334. doi: 10.23804/ejpd.2019.20.04.14. [Full text link][PubMed][Google Scholar][Scopus]

31. Generali C, Primozic J, Richmond S, et al. Three-dimensional evaluation of the maxillary arch and palate in unilateral cleft lip and palate subjects using digital dental casts. Eur J Orthod. 2017;39(6):641-645. doi: 10.1093/ejo/cjx019.

[Full text link][CrossRef][PubMed][Google Scholar][Scopus] [WoS] 32. Smahel Z, Velemínská J, Trefný P, Müllerová Z. Threedimensional morphology of the palate in patients with bilateral complete cleft lip and palate at the stage of permanent dentition. Cleft Palate Craniofac J. 2009;46(4):399-408. doi: 10.1597/07-199.1.

[Full text link][CrossRef][PubMed][Google Scholar][Scopus] 33. Smahel Z, Trefný P, Formánek P, et al. Three-dimensional morphology of the palate in subjects with isolated cleft palate at the stage of permanent dentition. Cleft Palate Craniofac J. 2003;40(6):577-584. doi: 10.1597/1545-1569_2003_040_0577_ tmotpi_2.0.co_2.

[Full text link][CrossRef][PubMed][Google Scholar][Scopus] 34. De Luca Canto G, Pachêco-Pereira C, Lagravere MO, et al. Intra-arch dimensional measurement validity of laser-scanned digital dental models compared with the original plaster models: a systematic review. Orthod Craniofac Res. 2015;18(2):65-76. doi: 10.1111/ocr.12068.

[Full text link][CrossRef][PubMed][Google Scholar][Scopus] [WoS] 35. Shahen S, Carrino G, Carrino R, et al. Palatal volume and area assessment on digital casts generated from cone-beam computed tomography scans. Angle Orthod. 2018;88(4):397-402. doi: 10.2319/091117-611.1.

[Full text link][CrossRef][PubMed][Google Scholar][Scopus] [WoS] 36. Smahel Z, Trefný P, Formánek P, et al. Three-dimensional morphology of the palate in subjects with unilateral complete cleft lip and palate at the stage of permanent dentition. Cleft Palate Craniofac J. 2004;41 (4):416-423. doi: 10.1597/03-053.1. [Full text link][CrossRef][PubMed][Google Scholar][Scopus] 37. Lewis BR, Stern MR, Willmot DR. Maxillary anterior tooth size and arch dimensions in unilateral cleft lip and palate. Cleft Palate Craniofac J. 2008;45(6):639-646. doi: 10.1597/07-078.1.

[Full text link][CrossRef][PubMed][Google Scholar][Scopus] 38. Iwasaki T, Yanagisawa-Minami A, Suga H, et al. Rapid maxillary expansion effects of nasal airway in children with cleft lip and palate using computational fluid dynamics. Orthod Craniofac Res. 2019:22(3):201-207. doi: 10.1111/ocr.12311.

[Full text link][CrossRef][PubMed][Google Scholar][Scopus] Ayub PV, Janson G, Gribel BF, et al. Analysis of the maxillary 39. dental arch after rapid maxillary expansion in patients with unilateral complete cleft lip and palate. Am J Orthod Dentofacial Orthop. 2016;149(5):705-715. doi: 10.1016/j.ajodo.2015.11.022. [Full text link][CrossRef][PubMed][Google Scholar][Scopus] [WoS]

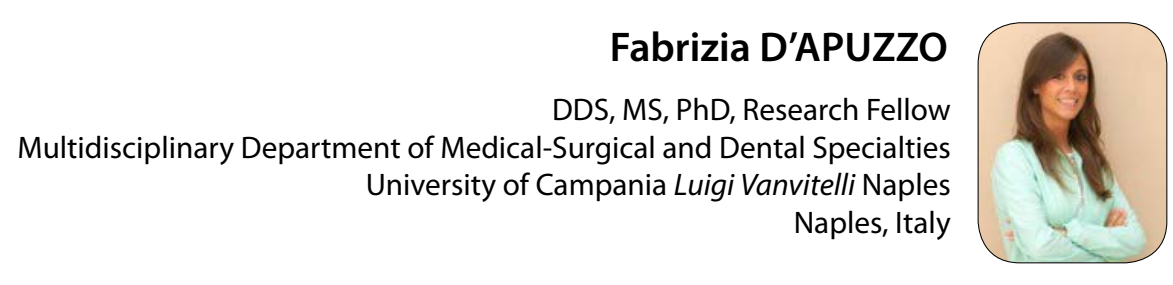

\section{Fabrizia D'APUZZO}

DDS, MS, PhD, Research Fellow University of Campania Luigi Vanvitelli Naples Naples, Italy 


\section{Ouestions}

\section{Cleft lip and palate is a?}

Da. Congenital craniofacial birth anomaly;

ab. Congenital dental disorder;

ac. Nosocomial infection;

Dd. Acquired disorder.

\section{What is the etiology of cleft lip and palate?}

Da. Environmental;

ab. Genetic;

口c. Epigenetic;

ud. All of the aforementioned.

\section{What is the first surgery performed in CLP patients?}

$\square$ a. Alveolar bone graft;

口b. Lip;

口c. Soft palate;

口d. Hard palate.

\section{Patients with cleft lip and palate can have}

$\square$ a. Skeletal maxillary constriction;

ab. Dental posterior crossbite;

uc. Reduced intercanine widths;

ud. All of the aforementioned.

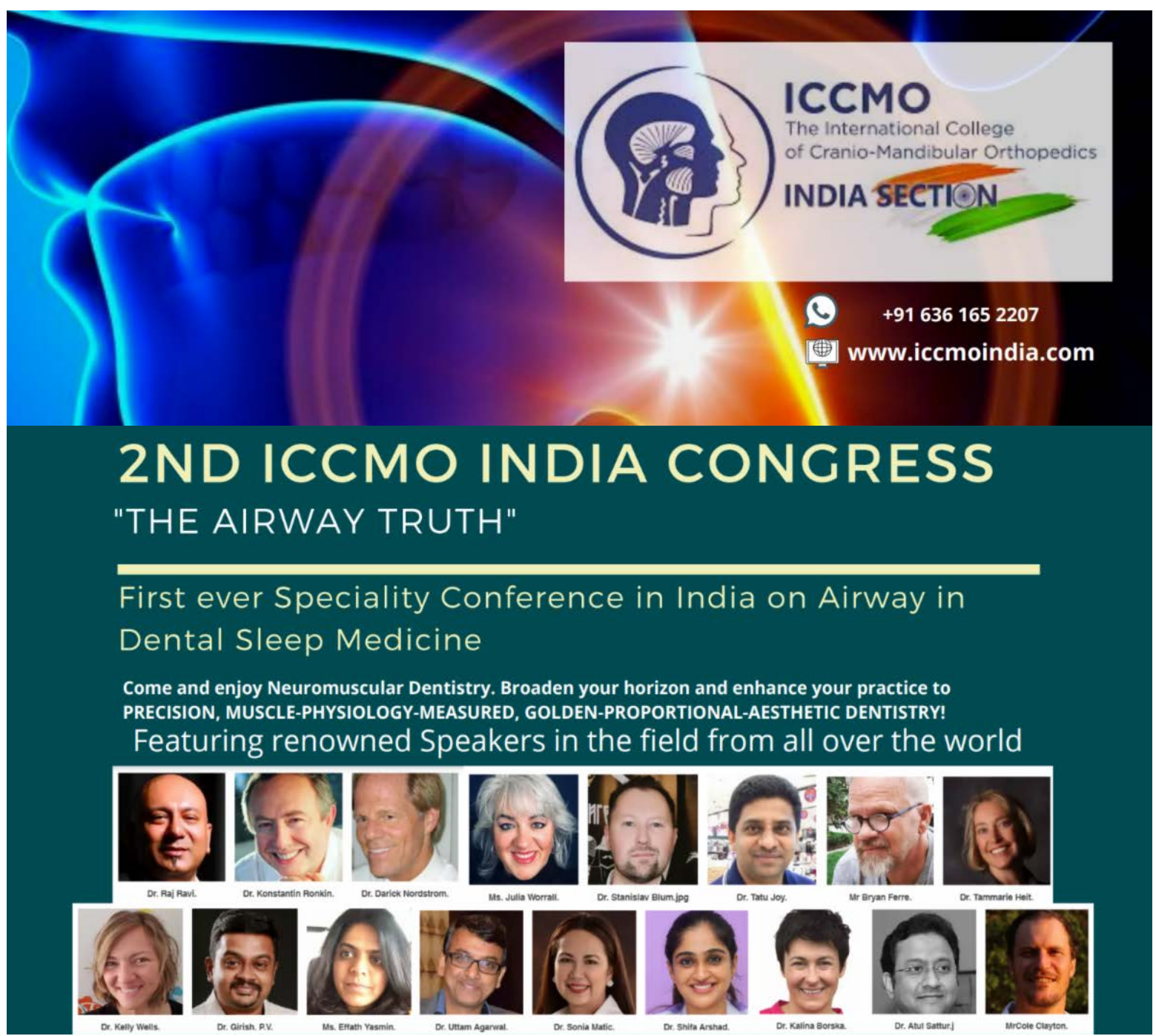




\title{
UNMET DENTAL TREATMENT NEED IMPAIRS QUALITY OF LIFE IN HEPATITIS C VIRUS-INFECTED PATIENTS
}

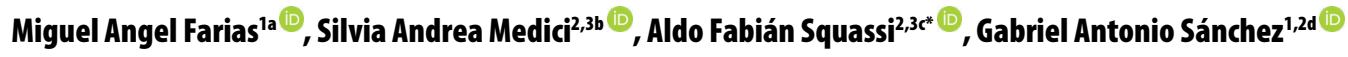 \\ 'Cátedra de Biofísica y Bioestadística, Facultad de Odontología, Universidad de Buenos Aires, Buenos Aires, Argentina \\ ${ }^{2}$ Clínica para la Atención de Pacientes de Alto Riesgo I, Facultad de Odontología, Universidad de Buenos Aires, Buenos Aires, Argentina \\ ${ }^{3}$ Cátedra de Odontología Preventiva y Comunitaria, Facultad de Odontología, Universidad de Buenos Aires, Buenos Aires, Argentina \\ aDDS, Senior Faculty; e-mail: miguel.farias@odontologia.uba.ar; ORCIDiD: https://orcid.org/0000-0002-3881-0258 \\ bDDS, Assistant Professor; e-mail: silvia.medici@odontologia.uba.ar; ORCIDiD: https://orcid.org/0000-0001-5370-2709 \\ 'DDS, MSc, PhD, Head Professor; e-mail: aldo.squassi@odontologia.uba.ar; ORCIDiD: https://orcid.org/0000-0001-7687-5805 \\ dDDS, MD, MSc, PhD, Head Professor; e-mail: gabriel.sanchez@odontologia.uba.ar; ORCIDiD: https://orcid.org/0000-0002-2358-4622
}

\section{ABSTRACT}

d) https://doi.org/10.25241/stomaeduj.2020.7(3).art.5

Introduction The hepatitis C virus (HCV) infection is a health condition affecting $3 \%$ of the world population, which oral manifestations and associated factors interest both physicians and dentists. The aim of this work was to describe the dental treatment need and the impact of the perception of the oral component of health on the quality of life in $\mathrm{HCV}+$ patients.

Methodology Descriptive study on a convenience sample. $45 \mathrm{HCV}+$ patients (46 \pm 5 y.o.) completed the OHIP-14 questionnaire, which consists of 14 questions grouped in 7 domains (D1 functional limitation, D2 physical pain, D3 psychological discomfort, D4 physical disability, D5 psychological disability, D6 social disability and D7 general disability). The participants indicated their responses using a Likert-type frequency scale. The Community Caries Index of Treatment Need (CCITN) was determined for each patient. The proportion and $\mathrm{C} 195 \%$ of the social impact on the quality of life were calculated. The association between CCITN and the quality of life was assessed by $\mathrm{Chi}^{2}(\mathrm{p}<0.05)$. Results The CCITN was 11 (8-14). The overall social impact was 38\% (24-52\%). The increasing order relationship of the impact on each of the domains was D1, D7, D6, D4, D5, D2, D3. A significant association between oral health-related quality of life and CCITN was observed $\left(\mathrm{Chi}^{2}=7.57, \mathrm{p}=0.006\right)$, showing greater impairment of the quality of life as the treatment need increased.

Conclusion The association between CCITN and quality of life becomes evident using OHIP-14 during dental appointments. The results suggest the need for comprehensive interventions during the provision of oral health care to $\mathrm{HCV}+$ patients.

\section{KEYWORDS}

Dental Care; Hepatitis C; Medical Risk; Oral Medicine; Quality of Life.

\section{INTRODUCTION}

The hepatitis $C$ (HCV) viral infection affects 175 million subjects over the world, that is, $3 \%$ of its population; and, three millions of new infections are reported each year [1]. Chronic liver pathology consequent to HCV has been reported in eighty percent of the infected patients. If no treatment is administered, close to $25 \%$ of patients progresses to liver cirrhosis [2]. Once cirrhosis has been diagnosed, the incidence of hepatocellular carcinoma, one of the main indications of liver transplant, is 3-5\% per year [3]. In Latin America and the Caribbean region HCV infected patients are estimated at 7.8 million [4]. In Argentina HCV is considered a low prevalence infection, with an approximate value of $1.2 \%$, which increases in overcrowded dwelling conditions up to $3.6 \%$. Males (3.4\%) are more affected than females (2.5\%) [5]. The infection risk rate has also been studied in South American countries. The

(c) (1) (2) OPEN ACCESS This is an Open Access article under the CC BY-NC 4.0 license. Peer-Reviewed Article

Citation: Farias MA, Medici SA, Squassi AF, Sánchez GA. Unmet dental treatment need impairs quality of life in Hepatitis C Virus-infected patients. Stoma Edu J. 2020;7(3):191-196.

Received: May 08, 2020; Revised: July 13, 2020; Accepted: August 06, 2020; Published: August 07, 2020

*Corresponding author: Professor Aldo Fabián Squassi; Cátedra de Odontología Preventiva y Comunitaria, Facultad de Odontología, Universidad de Buenos Aires; MT de Alvear 2142, 5th floor, Suite B; CP 1122, Buenos Aires, Argentina

Tel.: / Fax: +54 115287 6253, e-mail: aldo.squassi@odontologia.uba.ar

Copyright: $\odot 2020$ the Editorial Council for the Stomatology Edu Journal. 
ITable 1. Description of the Community Caries Index of Treatment Need (CCITN).

\begin{tabular}{|c|c|c|}
\hline Health condition & Score & Needed treatment \\
\hline $\begin{array}{l}\text { Healthy mouth with preventive } \\
\text { treatment }\end{array}$ & 00 & No treatment needed \\
\hline $\begin{array}{l}\text { Healthy mouth without preventive } \\
\text { treatment }\end{array}$ & 01 & Basic preventive plan \\
\hline $\begin{array}{l}\text { Healthy mouth with dental white } \\
\text { spots/ deep grooves }\end{array}$ & 02 & $\begin{array}{l}\text { Additional preventive plan including the sealing of dental } \\
\text { grooved and fissures }\end{array}$ \\
\hline $\begin{array}{l}\text { Amelo-dentinal tooth decay in } 1 \\
\text { quadrant of the mouth }\end{array}$ & 03 & Additional preventive plan + restorative treatment in 1 quadrant \\
\hline $\begin{array}{l}\text { Amelo-dentinal tooth decay in } 2 \\
\text { quadrant of the mouth }\end{array}$ & 04 & $\begin{array}{l}\text { Additional preventive plan }+ \text { restorative treatment in } 2 \\
\text { quadrants }\end{array}$ \\
\hline $\begin{array}{l}\text { Amelo-dentinal tooth decay in } 3 \\
\text { quadrant of the mouth }\end{array}$ & 05 & $\begin{array}{l}\text { Additional preventive plan + restorative treatment in } 3 \\
\text { quadrants }\end{array}$ \\
\hline $\begin{array}{l}\text { Amelo-dentinal tooth decay in } 4 \\
\text { quadrant of the mouth }\end{array}$ & 06 & $\begin{array}{l}\text { Additional preventive plan }+ \text { restorative treatment in } 4 \\
\text { quadrants }\end{array}$ \\
\hline $\begin{array}{l}\text { Pulp disease in } 1 \text { quadrant of the } \\
\text { mouth }\end{array}$ & 07 & $\begin{array}{l}\text { Additional preventive plan }+ \text { pulp treatment in } 1 \text { quadrant of the } \\
\text { mouth }+ \text { restorations }\end{array}$ \\
\hline $\begin{array}{l}\text { Pulp disease in } 2 \text { quadrants of the } \\
\text { mouth }\end{array}$ & 08 & $\begin{array}{l}\text { Additional preventive plan + pulp treatment in } 2 \text { quadrants of } \\
\text { the mouth + restorations }\end{array}$ \\
\hline $\begin{array}{l}\text { Pulp disease in } 3 \text { quadrants of the } \\
\text { mouth }\end{array}$ & 09 & $\begin{array}{l}\text { Additional preventive plan + pulp treatment in } 3 \text { quadrants of } \\
\text { the mouth + restorations }\end{array}$ \\
\hline $\begin{array}{l}\text { Pulp disease in } 4 \text { quadrants of the } \\
\text { mouth }\end{array}$ & 10 & $\begin{array}{l}\text { Additional preventive plan + pulp treatment in } 4 \text { quadrants of } \\
\text { the mouth + restorations }\end{array}$ \\
\hline $\begin{array}{l}\text { Missed teeth in } 1 \text { quadrant of the } \\
\text { mouth }\end{array}$ & 11 & $\begin{array}{l}\text { Additional preventive plan }+ \text { pulp treatment }+ \text { tooth removal }+ \\
\text { prosthesis rehabilitation in } 1 \text { quadrant of the mouth }\end{array}$ \\
\hline $\begin{array}{l}\text { Missed teeth in } 2 \text { quadrants of the } \\
\text { mouth }\end{array}$ & 12 & $\begin{array}{l}\text { Additional preventive plan }+ \text { pulp treatment }+ \text { tooth removal }+ \\
\text { prosthesis rehabilitation in } 2 \text { quadrant of the mouth }\end{array}$ \\
\hline $\begin{array}{l}\text { Missed teeth in } 3 \text { quadrants of the } \\
\text { mouth }\end{array}$ & 13 & $\begin{array}{l}\text { Additional preventive plan }+ \text { pulp treatment }+ \text { tooth removal }+ \\
\text { prosthesis rehabilitation in } 3 \text { quadrant of the mouth }\end{array}$ \\
\hline $\begin{array}{l}\text { Missed teeth in } 4 \text { quadrants of the } \\
\text { mouth }\end{array}$ & 14 & $\begin{array}{l}\text { Additional preventive plan }+ \text { pulp treatment }+ \text { tooth removal }+ \\
\text { prosthesis rehabilitation in } 4 \text { quadrant of the mouth }\end{array}$ \\
\hline
\end{tabular}

nosocomial infection risk was the highest (45.3\%), followed by sexual transmission (18.8\%), unknown causes (12.5\%), use of intravenous drugs (4.7\%) and occupational exposure (4.7\%) [6].

Extra hepatic manifestations of HCV infection include depression (25\%) and diabetes $(15 \%)$ as the most frequent ones, along with chronic renal disease, B-cells lymphoma, cutaneous porphyria and rheumatoid arthritis [7]. The oral manifestations of hepatic dysfunction include oral mucosa jaundice and petechiae, blood coagulation disorders, gingivitis and gum bleeding, perioral rash, atrophic tongue and hepatic halitosis. Xerostomia has been reported as a frequent symptom of HCV infection and Sjögren disease, and sialadenitis and oral lichen planus are more likely to occur $[8,9]$. Dry eye and mouth symptoms have been reported in $20-30 \%$ of $\mathrm{HCV}$ infected patients. However, less than $5 \%$ of Sjögren patients are also HCV patients [10]. As for the periodontal conditions of patients suffering from hepatic diseases, there are no updated reports focused on their association, but the development of specific research lines has been encouraged [11].
In this regard, the affected oral status described above may result in predisposing conditions for the development of periodontal disease and oral carcinogenesis. For this reason, the existence of an immunological link between HCV and periodontal health is being studied [12].

The health care of HCV infected patients is a matter of concern of both, physicians and dentists. The inclusion of the dental examination and treatment in the routine medical health care protocol for these patients has been proposed and the interdisciplinary collaboration between physicians and dentists has also been pointed out as mandatory [13]. However, little is known about the oral component of health in HCV patients.

This lack of updated knowledge motivated this investigation aimed at determining the need for dental treatment in HCV positive patients and the social perception they have of the oral component of health on their quality of life. Our hypothesis states that oral health conditions derived from HCV infection impair the quality of life of the affected subjects. 


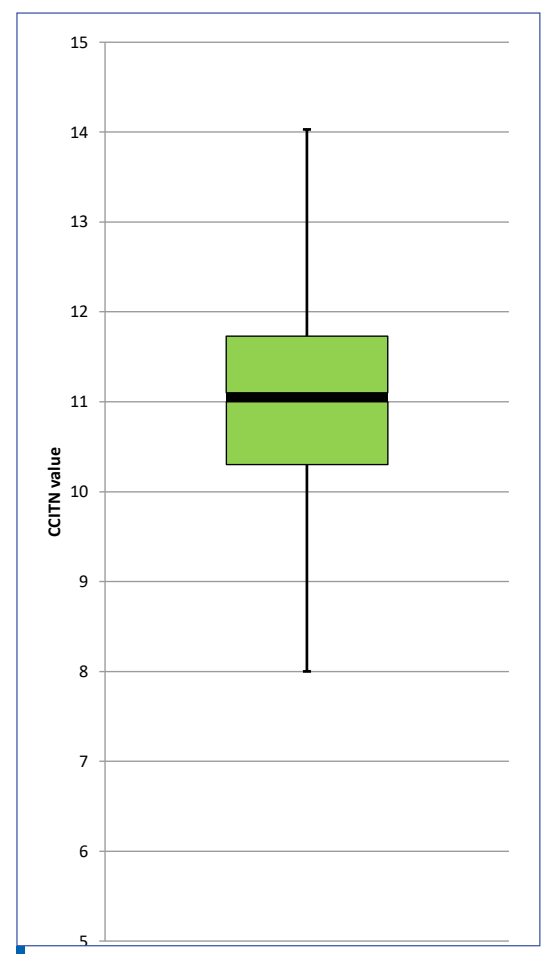

Figure 1. CCITN in $\mathrm{HCV}+$ patients. Box plot of the distribution of the index obtained values showing median and range of the need for dental treatment in a sample of 45 infected subjects.

\section{METHODOLOGY}

The investigation was planned as a descriptive observational study including some preliminary analytical work regarding the prevalence of the need for dental treatment and its associated social impact on the quality of life of $\mathrm{HCV}+$ patients. From this study population, a sample consisting of 45 patients was obtained through the non-probabilistic convenience sampling method. Thirty patients were males and 15 were females, with a mean age of $46 \pm 5$ y.o. Participants were recruited from patients with chronic moderate HCV infection referred to this Unit by their treating hepatologists for oral check-up. The reported time course of the infection was for all of them three years and the drug therapy they had received was interferon and rivabirin. All of the referred patients had health insurance, a formal employment, middle income and were high school graduates.

Patients coinfected with HIV, users of nasal drugs, smokers and users of intravenous drugs (except for those rehabilitated five years prior to recruitment) were not included in this study. Recruitment was done at the High Risk Patients Dental Care Unit (CLAPAR I), an oral health care clinic at the Dental School of the University of Buenos Aires, between April 2014 and July 2015. All participants gave their written informed consent for free and voluntary participation in the study.

The research protocol was reviewed and approved by the Ethics Committee of the Dental School of the University of Buenos Aires (Acceptance number:

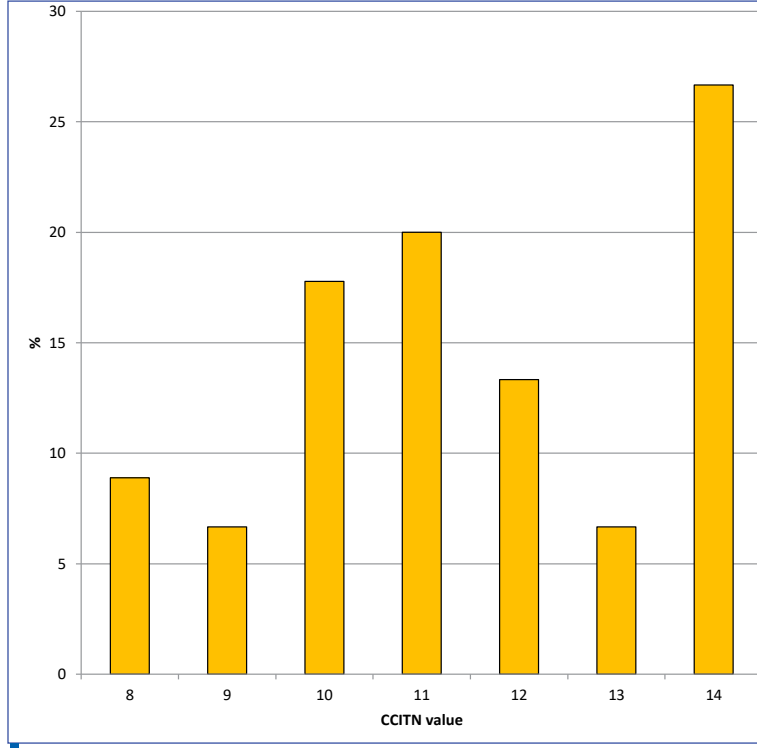

Figure 2. $\mathrm{HCV}+$ patients need for dental treatment. Bar chart of the percent distribution of patients according to CCITN values $(n=45)$.

CETICAFOUBA20020120100324BA/13). The need for dental treatment was assessed through the Community Caries Index of Treatment Need (CCITN) [14] during the clinical routine examination of the oral cavity performed by three previously calibrated operators (Kappa's coefficient=0.92). The CCITN was designed to determine the oral health condition of populations in terms of health and disease. It indicates the recommended treatment to achieve a healthy oral condition, and it also estimates the amount of appropriate resources to provide the corresponding oral health care. The index is determined within an ordinal number scale from 0 to 14 following the criteria shown in the Table 1.

The social impact of the oral health condition on the quality of life was measured using the validated questionnaire Oral Health Impact Profile (OHIP-14) [15], which consists of 14 questions grouped in 7 domains; namely, D1: functional limitation, D2: physical pain, D3: psychological discomfort, D4: physical disability, D5: psychological disability, D6: social disability and D7: general disability. Participants indicated their responses using a Likert-type frequency scale: never, hardly ever, sometimes, frequently and very frequently, coded as 0, 1, 2, 3 and 4 respectively. The total score was obtained as the sum of the coded score numbers given to each of the questions. This procedure allows the calculation of 0 as the minimal score and 56 as the maximal one, indicating greater impact as the score value increases.

The descriptive statistical data analysis included the calculation of median and range for the CCITN and the frequency distribution determination for each category of the index. The assessment of the social impact included the calculation of the percent proportion of the impact along with the 95\% confidence interval. The inferential statistical analysis evaluated through $\mathrm{Chi}^{2}$ test the association 


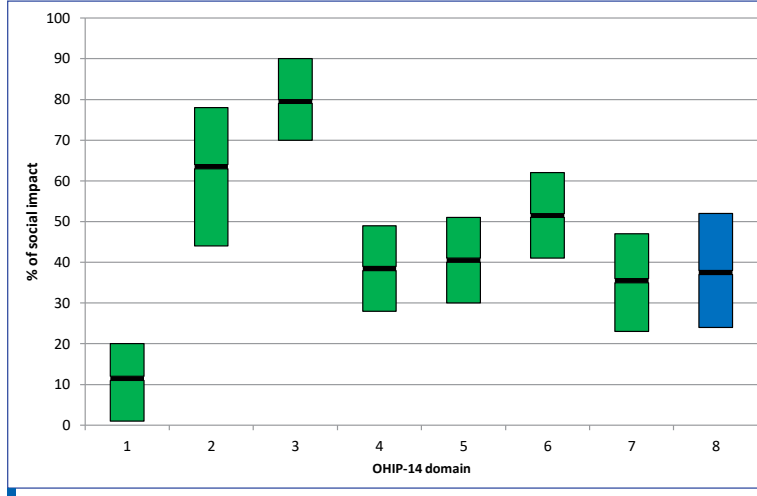

Figure 3. Social impact of the oral component of health in $\mathrm{HCV}+\mathrm{pa}-$ tients. Box plot of the distribution of the social impact expressed as $\%$. The proportion and $\mathrm{Cl} 95 \%$ obtained in 45 patients are shown. The numbers on the $x$ axis indicate the OHIP-14 domains: 1 functional limitation, 2 physical pain, 3 psychological discomfort, 4 physical disability, 5 psychological disability, 6 social disability and 7 general disability. Number 8 indicates the overall impact value.

between CCITN score and OHIP-14 percent of impact distributions according to their corresponding median and mean values, respectively. The level of significance used to determine the association was $\mathrm{p}<0.05$.

\section{RESULTS}

The need for dental treatment found in HCV+ patients in this investigation was great. The obtained median value of CCITN was 11 and its range was 8-14, as shown in Fig. 1 and Fig. 2. There were no patients with healthy oral conditions and no patients with only amelo-dentinal tooth decay either. In all cases, tooth decay involved dental pulp in different extent. The frequency distribution of CCITN values found in male patients was not significantly $\left(\mathrm{Chi}^{2}=0.21, \mathrm{p}=\right.$ 0.96) different from those determined for female patients (data not shown).

The social impact of the oral component of health self-reported through the use of OHIP-14 revealed a $38 \%$ of impact (C195\%: $24-52 \%)$ in $\mathrm{HCV}+$ patients included in the convenience sample studied in the present research and no significant differences $\left(\mathrm{Chi}^{2}\right.$ $=0.34, p=0.88$ ) were found between male and female patients (data not shown).

Fig. 3 shows this finding along with the differential impact recorded for each single domain of the questionnaire. The social impact showed the increasing order D1 $<\mathrm{D} 7<\mathrm{D} 4<\mathrm{D} 5<\mathrm{D} 6<\mathrm{D} 2<$ D3, being D3 (78\%, IC95 90-66\%) and D2 (62\%, IC95 $48-76 \%)$, the domains revealing the highest social impact of the oral component of health on the quality of life.

To assess the association between CCITN and OHIP14 , the distribution of patients was determined in two categories according to the value of 11 for the dental treatment need, and according to the value of $38 \%$ for the social impact. Fig. 4 shows $52 \%$ of the $\mathrm{HCV}+$ patients reporting social impact above $38 \%$ if their CCITN value is found above 11, revealing a

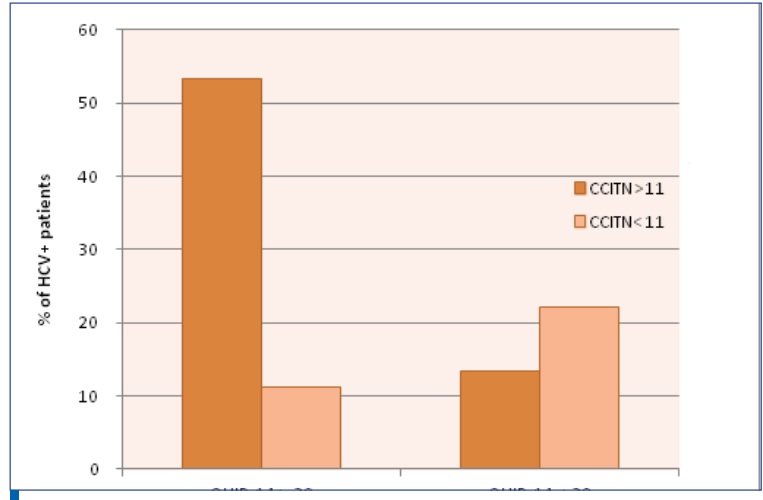

Figure 4. Association between Community Caries Index of Treatment Need (CCITN) values and Oral Health Impact Profile (OHIP-14) score. Bar plot of the distribution of $\mathrm{HCV}$ + patients $(n=45)$ grouped according median CCITN and mean \% of social impact reported through OHIP-14.

significant association between those two variables $\left(\mathrm{Chi}^{2}=7.57, \mathrm{p}=0.006\right)$.

\section{DISCUSION}

This is the first study investigating the need for dental treatment in $\mathrm{HCV}+$ subjects in association with the quality of life of this patient population. The results reported herein interest both physicians and dentists and provide new evidence for the successful interdisciplinary approach of this viral infection. Up to now, most studies have focused exclusively on the oral manifestations of the HCV infection and on the haemostatic associated complications. For instance, oral lichen planus is clinically diagnosed by dentists [16] and it has been reported as involved in oral carcinogenesis [17].

Another well-known systemic disorder of HCV infection involves haemostatic complications leading to oral bleeding during dental procedures [8], especially in the acute stage of the disease, but fewer complications have been reported in asymptomatic chronic patients [18]. It is also known that the viral infection may alter the metabolism of certain drugs. That is why the current clinical challenge includes the prediction and treatment of hemorrhage and the careful evaluation of drugs interactions in $\mathrm{HCV}$ infected patients [19].

The results reported in this study show a clear social impact of the oral component of health which impairs the quality of life of the studied HCV+ patients, who mainly experience physical pain and psychological discomfort because of their dental status consequent to the course of the liver disease as we hypothesize. Given that the study design used herein lacks a control group studied in parallel, data of CCITN and OHIP-14 previously reported in other groups of patients may be useful for a comparative discussion. Compared to non-medically compromised patients, the CCITN largely exceed the reported value of 6 [20] in healthy subjects and the social impact on 
the quality of life regarded as intermediate [21]. As compared to other viral infections, HIV+ patients showed also social impact of the oral conditions on the quality of life with similar percentage $(36 \%)$ and similar CCITN values [14].

These results are in line with previous findings of hepatologists, surgeons and psychologists reporting that HCV infection negatively changes the patients' quality of life in the analysis of the psychological component of health [22]. Increased levels of anxiety and depression have been reported to impair the quality of live [23].

The results obtained in this investigation provide evidence to support the early referral to oral health care of HCV + patients, which will benefit the patients since the beginning of the medical treatment if they are referred to the dentist during the first medical visit, a professional decision that we strongly recommend.

Although the sample size we analyzed may appear small, it was large enough to perform the planned statistical analysis meeting the criteria of optimal sample size.

The future perspective of this research includes the extension of the study variables such as the Community Periodontal Index, dental plaque index, $\mathrm{HCV}$ viral load in blood, routine hepatic enzymes laboratory values and the time course of the viral infections which will be interesting to perform a multivariate analysis of factors.

\section{REFERENCES}

1. Lauer GM, Walker BD. Hepatitis C virus infection. N Engl J Med. 2001;345(1):41-52. doi:10.1056/NEJM200107053450107. [Full text link] [Pubmed] [Google Scholar] [Publons]

2. Sharma $P$, Lok A. Viral hepatitis and liver transplantation. Semin Liver Dis. 2006;26(3):285-297. doi:10.1055/s-2006-947298.

[Full text link] [Pubmed] [Google Scholar] [Publons]

3. Brown RS. Hepatitis $C$ and liver transplantation. Nature. 2005;436(7053):973-978. doi:10.1038/nature04083.

[Full text link] [Pubmed] [Google Scholar]

4. Soto-Ramirez LE. World hepatitis day. Fighting hepatitis $C$ in Latin America and the Caribbean; an urgent call. J Int AIDS Soc. 2017;20(1):22183. doi:10.7448/IAS.20.1.22183.

[Full text link] [Pubmed] [Google Scholar] Scopus WoS

5. Angeleri P, Sotelo J, Orlando M, et al. [Prevalence of HIV, syphilis, viral hepatitis and tuberculosis in persons confined in units of the Federal Penitentiary Service]. Boletín sobre el VIH, sida e ITS en la Argentina. 2017;34(20):12-24.

\section{[Full text link]}

6. Dirchwolf M, Marciano S, Mauro E, et al. Clinical epidemiology of acute hepatitis C in South America. J Med Virol. 2017;89(2):276283. doi:10.1002/jmv.24588

[Full text link] [Pubmed] [Google Scholar] [Publons] Scopus WoS 7. Younossi Z, Park H, Henry L, et al. Extrahepatic manifestations of hepatitis C: a meta-analysis of prevalence, quality of life, and economic burden. Gastroenterology. 2016;150(7):1599-1608. doi:10.1053/j.gastro.2016.02.039.

[Full text link] [Pubmed] [Google Scholar] Scopus WoS

8. ADA Science Institute. Oral Health Topics. Hepatitis Viruses - Key Points [Internet]. Chicago (IL); [Topic updated: March 26, 2019; cited 2020 Apr 6]. Available from: URL: https://www.ada.org/en/ member-center/oral-health-topics/hepatitis-viruses [Full text link]

\section{CONCLUSION}

On the basis of the features of this convenience sample showing moderate chronic viral infection, it can be concluded that the need for dental treatment in $\mathrm{HCV}+$ patients is high and impairs the quality of life of the subjects, a fact detectable during the routine dental visit through the use of the OHIP-14 Questionnaire. Our results suggest that oral preventive measures should be necessarily reinforced in the oral health care of this group of patients.

\section{CONFLICT OF INTEREST}

The authors declare no conflict of interest.

\section{AUTHOR CONTRIBUTIONS}

MF: participated in the research goal proposal, research protocol design, and scientific writing of the manuscript. SM: participated in the clinical examinations and data collection procedures.

AS: participated in the research plan design and critical revision of the manuscript. GS: participated in the clinical examinations, data collection, statistical analysis and scientific writing of the manuscript.

\section{ACKNOWLEDGMENTS}

This research work was performed with a grant from the Universidad de Buenos Aires, Grant UBACyT 20020120100324BA.
9. Cruz-Pamplona M, Margaix-Muñoz M, Gracia Sarrión-Pérez MG. Dental considerations in patients with liver disease. J Clin Exp Dent. 2011;3(2):127-134. doi:10.4317/jced.3.e127

[Full text link] [Google Scholar] Scopus

10. Cacoub P, Comarmond C, Domont F, et al. Extrahepatic manifestations of chronic hepatitis $C$ virus infection. Ther Adv Infect Dis. 2016;3(1):3-14. doi:10.1177/2049936115585942. [Full text link] [Pubmed] [Google Scholar]

11. Han P, Sun D, Yang J. Interaction between periodontitis and liver diseases. Biomed Rep. 2016;5(3):267-276. doi:10.3892/ br.2016.718

[Full text link] [Pubmed] [Google Scholar] Scopus WoS

12. Gheorghe DN, Foia L, Toma V, et al. Hepatitis C infection and periodontal disease: is there a common immunological link?. J Immunol Res. 2018;2018:8720101. doi:10.1155/2018/8720101 [Full text link] [Pubmed] [Google Scholar] [Publons]

13. Wu IJ, Chang TS, Hwang SL, Chen MY. Effects of oral hygiene programme and home phone counselling for hepatitis $C$ patients receiving antiviral treatment. J Adv Nurs. 2019;75(5):1010-1017. doi:10.1111/jan.13896.

[Full text link] [Pubmed] [Google Scholar] Scopus WoS

14. Sánchez GA, D'Eramo LR, Lecumberri R, Squassi AF. Impact of oral health care needs on health-related quality of life in adult HIV+ patients. Acta Odontol Latinoam. 2011;24(1):92-97.

[Full text link] [Pubmed] [Google Scholar] [Publons] Scopus

15. Montero-Martín J, Bravo-Pérez M, Albaladejo-Martínez A, et al. Validation the Oral Health Impact Profile (OHIP-14sp) for adults in Spain. Med Oral Patol Oral Cir Bucal. 2009;14(1):E44-E50. [Full text link] [Pubmed] [Google Scholar] [Publons]

16. Mester A, Lucaciu O, Ciobanu L, et al. Clinical features and management of oral lichen planus (OLP) with emphasis on the management of hepatitis C virus (HCV)-related OLP. Bosn J Basic 
Med Sci. 2018;18(3):217-223. doi:10.17305/bjbms.2018.3133. [Full text link] [Pubmed] [Google Scholar] [Publons] WoS 17. Carrozzo M, Scally K. Oral manifestations of hepatitis C virus infection. World J Gastroenterol. 2014;20(24):7534-7543. doi:10.3748/wjg.v20.i24.7534

[Full text link] [Pubmed] [Google Scholar] [Publons] 18. Chen G, Cheung R, Tom JW. Hepatitis: sedation and anesthesia implications. Anesth Prog. 2017;64(2):106-118. doi:10.2344/anpr-64-02-13

[Full text link] [Pubmed] [Google Scholar] Scopus

19. Lisman T, Kwaan HC. Hemostatic dysfunction in liver diseases. Semin Thromb Hemost. 2015;41(5):445-446. doi:10.1055/s-0035-1550441

[Full text link] [Pubmed] [Google Scholar] Scopus WoS 20. Capurro MA, Bordoni N, Squassi A, Mendez CF. [Analysis of spontaneous demand in an urban dental service using georeferential systems]. In: Susana Molgatini; Abstract book of the 50th Annual Scientific Meeting of the Argentine Society for Dental Research. Buenos Aires (AR): $1^{\text {a }}$ ed. Ciudad Autónoma de Buenos Aires: AR Soluciones gráficas S.R.L.; 2017.

[Full text link]
21. Toledo M, Cotello L, Damoso G, et al. [Oral health-related quality of life in spontaneous demand services]. In: Susana Molgatini; Abstract book of the 50th Annual Scientific Meeting of the Argentine Society for Dental Research. Buenos Aires (AR): $1^{\text {a }}$ ed. Ciudad Autónoma de Buenos Aires: AR Soluciones gráficas S.R.L.; 2017.

[Full text link]

22. Golfieri L, Gitto S, Morelli MC, et al. Impact of hepatitis $C$ virus infection on health-related quality of life before and after liver transplantation: a multidisciplinary point of view. Expert Rev Anti Infect Ther. 2017;15(8):759-765. doi: 10.1080/14787210.2017.1362334.

[Full Text link] Google Scholar

23. Kesen O, Kani HT, Yanartaş Ö, et al. Evaluation of depression, anxiety and quality of life in hepatitis $C$ patients who treated with direct acting antiviral agents. Turk J Gastroenterol. 2019;30(9):801806. doi:10.5152/tjg.2019.18679.

[Full Text link]

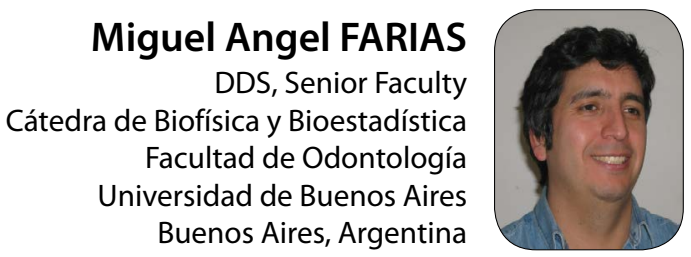

Miguel Angel Farias, DDS specialized in periodontics, is currently a PhD fellow at the University of Buenos Aires. His research work in the field of Preventive Dentistry and Dentistry for medically compromised patients has been recognized by scientific research associations both locally and regionally (Argentine Divison of the International Association for Dental Research -IADR- and the Brazilian Division of said world association). He was also presented with Research Awards as an undergraduate research fellow of the University of Buenos Aires, such as the Argentine Dental Schools Association Award. He is an active participant and presenter of IADR Divisional meetings and he has published seven abstracts of his research oral communications in the last five years in the widely known online version of the abstracts date base of the Journal of Dental Research.

\section{Ouestions}

\section{Which of the following oral manifestations could be found in HCV infected patients?}

$\square$ a. Mucosa jaundice and petechiae, blood coagulation disorders;

b. Gingivitis and gum bleeding, perioral rash, atrophic tongue and hepatic halitosis;

ac. Xerostomia;

ad. All of them are correct.

\section{What is the ideal dental treatment approach for HCV positive patients?}

$\square$ a. Interdisciplinary approach;

b. No specific approach;

ac. Approach does not matter if patients receive medical treatment;

$\square$ d. Interdisciplinary approach is not required.

\section{What is the need for dental treatment in HCV infected patients?}

a. No need;

b. Low;

ac. Moderate;

$\square$ d. High.

\section{What it the relationship between unmet oral health care needs and the quality of life in HCV positive patients?}

口a. Impairs quality of life;

b. Improves quality of life;

ac. Quality of life is not affected;

$\square d$. There is no relation between oral health and quality of life. 


\title{
THE INFLUENCE OF OCCLUSION ON MASTICATORY EFFICIENCY CONSIDERING RELEVANT INFLUENCING FACTORS
}

\author{
Gregor Slavicek ${ }^{1,2, a^{*}} \odot$ \\ 1Steinbeis Transfer Institute Biomedical Interdisciplinary Dentistry, Steinbeis University Berlin, DE-12489 Berlin, Germany \\ 20REHAB-Minds GmbH, DE-70567 Stuttgart, Germany \\ aMD, DDS, MSc, Director and Head, CE0 and Head; e-mail: gregor.slavicek@stw.de; ORCIDiD: https://orcid.org/0000-0003-2454-4048
}

Introduction The role of the occlusal quality as a relevant factor for mastication is controversially discussed. This paper aims to determine the role of the occlusion given the influencing factors. The correlation between the subjective evaluation of treatment needs and objective chewing test results are assessed.

Methodology 842 participants (female $n=460,54.5 \%$; male $n=382,45.4 \%$ ) performed a standardized chewing test. The participants' occlusal quality, angle classification, age, gender, treatment needs and intraoral status were recorded. The participants were instructed to break down the standardized chewing tests units. The particles were collected in a sieve and placed on a calibrated acquisition board. Standardized images were analysed, measuring the areas of each particles in $\mathrm{mm}^{2}$. Null Hypotheses were tested with the Kruskal-Wallis tests and post hoc tests with Bonferroni correction, to be rejected at $p \leq 0.01$.

Results The occlusion quality has a significant impact on the chewing efficiency ( $p \leq 0.001$ ), but angle classification only to some extent. Age $(p \leq 0.001)$ and gender $(p \leq 0.001)$ are important intrinsic factors. Fixed prosthodontics do not reach the chewing performance of natural occlusion $(p \leq 0,01)$. The subjective clinical assessment of treatment needs correlates in categories with strong differentiations $(p \leq 0,001)$, but not if only minor differences are asserted ( $p \leq 0,515)$.

Conclusion The occlusion quality has a significant impact on the chewing efficiency. Masticatory performance is highly dependent on the natural or artificial chewing surface morphology. Age, gender and the intraoral status are important intrinsic factors. The maintenance of a sufficient functional oral status is a crucial task in the care of the aging population.

\section{KEYWORDS}

Chewing Efficiency; Chewing Surface Morphology; Dental Occlusion; Mastication; Standardized Chewing Test.

\section{INTRODUCTION}

\subsection{Aim of mastication}

The aim of a masticatory process is to comminute food as homogeneously as possible, to moisten the food bolus with saliva and to prepare it for swallowing. The principle of the mechanical processing of food is found in all mammals, including humans. From an evolutionary perspective, it is an advantage to comminute food prior to digestion in the gastrointestinal tract. This mechanical fragmentation makes digestion more efficient [1]. The provision of energy and essential nutrients can be guaranteed by the regular intake of smaller, but mechanically processed amounts of foods. The masticatory process poses a major functional challenge to the stomatognathic system for its whole lifetime [2]. Mastication exerts a substantial effect on human health [3]. Food, inserted in the mouth, is normally known. So, an expectation 


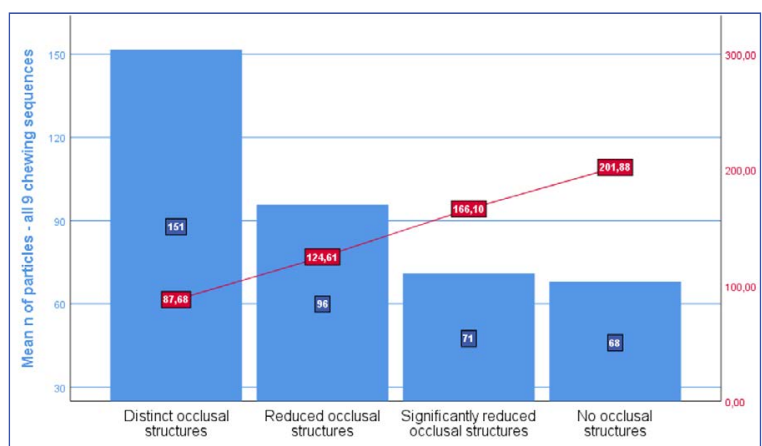

Figure 1a. Overall chewing efficiency vs. occlusal quality.

exists, reinforced by visual, olfactory, and gustatory sensations. Based on this preliminary information, patterns can be retrieved from memory that are optimally adapted to the food. If the feedback from the intra- and extraoral proprioceptors differs from the expectations, the masticatory pattern will be adapted [4]. These feed-back mechanisms react to the so-called mouth feel of food (Tab.1).

\subsection{Teeth are highly specialized tools}

Teeth are used as highly specialised tools when food needs to be comminuted. Teeth have adapted over the course of evolution to the needs of the mammalian species in an astonishing variety of forms [5]. A food bolus positioned between the dental arches is broken down mechanically. The structures of the occlusal surface of the teeth tend to be flat with prominent enamel ridges in many mammals, so the masticatory forces have an optimal effect on food [6]. The huge variety in the morphology of the masticatory surfaces can be explained by adaptation to extrinsic factors [7].

Just like tooth morphology, the shape of the occlusal surfaces, and the spatial arrangement of the teeth differ considerably in many species, oversimplified traceable on the carnivores-herbivores differences. The teeth of carnivores (meat-eaters) are completely different from the teeth of herbivores (plant-eaters) [8]. Catching and retaining prey are tasks that require considerable strength and robustness of the carnivores stomatognathic system. The teeth of carnivores chisel off large pieces, which are then swallowed entirely. The actual process of digestion is performed in the digestive tract. Herbivores have totally different demands on teeth and the chewing organ. Leaves and twigs can be grasped easily. Excessive mechanical processing is performed in the oral cavity. The tooth surfaces are moved against one another in a distinct direction - so plant fibres are mechanically comminuted. The direction of chewing movements is adapted to the structure of the tooth surfaces [4].

Unphysiological chewing movements may have serious effects on teeth, periodontium, and the neuromuscular system [9]. The relationship with craniomandibular dysfunctions (CMD) is also a subject of discussion [10]. A preferred chewing side

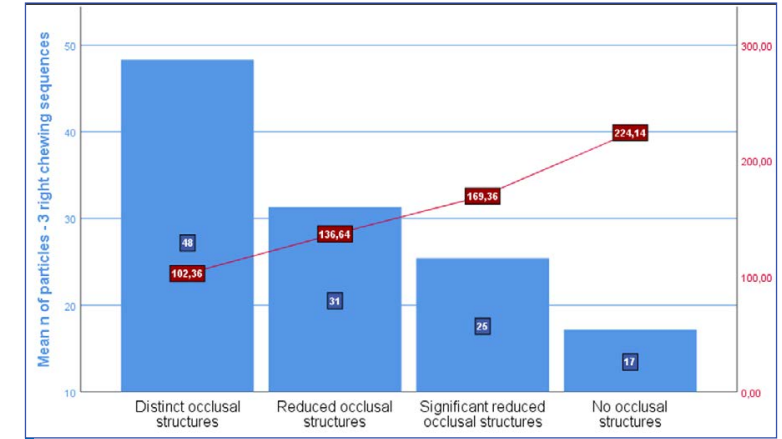

Figure 1b. Right side chewing efficiency vs. occlusal quality of the right side.

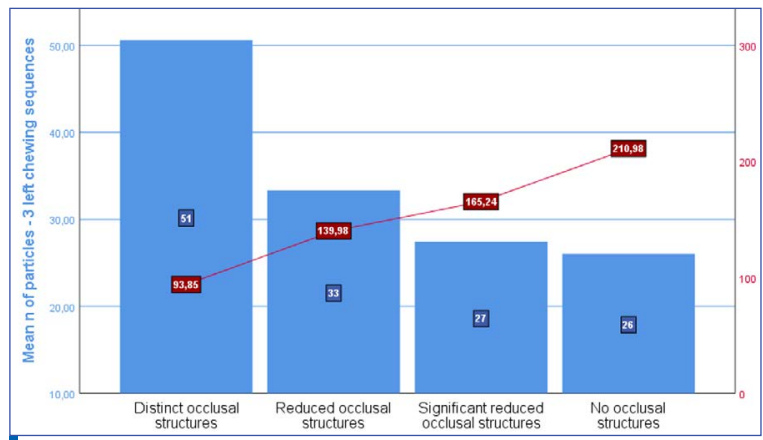

Figure 1c. Left side chewing efficiency vs. occlusal quality of the left side.

and a reduced chewing ability is reported more often in patients with CMD symptoms [11]. The masticatory patterns of children with deciduous teeth are characterised by wide lateral movements to the working side on opening and a more inwardly directed path during the closing phase of the masticatory cycle. In adults, on the other hand, the opening movement are performed in the median-sagittal plane. The closing movement is characterised by a wide lateral movement to the working side. The closing paths of the molars on the working side move from a retrusive, inferior and lateral position forward, upward, and inward [12,13,14]. In children, occlusion is approached directly from an opened mandibular position in the median sagittal plane. The movements of molar cusps on working and nonworking sides follow different paths in children and adults [15].

\subsection{Gender differences}

Women's and men's dietary habits differ considerably [16]. If the dynamics of the masticatory process are considered and correlated with gender, males perform faster and wider chewing cycles. The duration of a single chewing cycle is extended in females [17]. Obviously, males develop higher masticatory forces than women. What is noteworthy, however, is that it is not possible to infer any direct correlation between the masticatory force and muscle activity [18]. Nevertheless, many other factors such as age, dental status, prosthetic status overlap genderspecific differences in chewing [19]. In addition, health conditions, such as facial osteoporosis, may impair masticatory muscles patterns and performance [20]. 


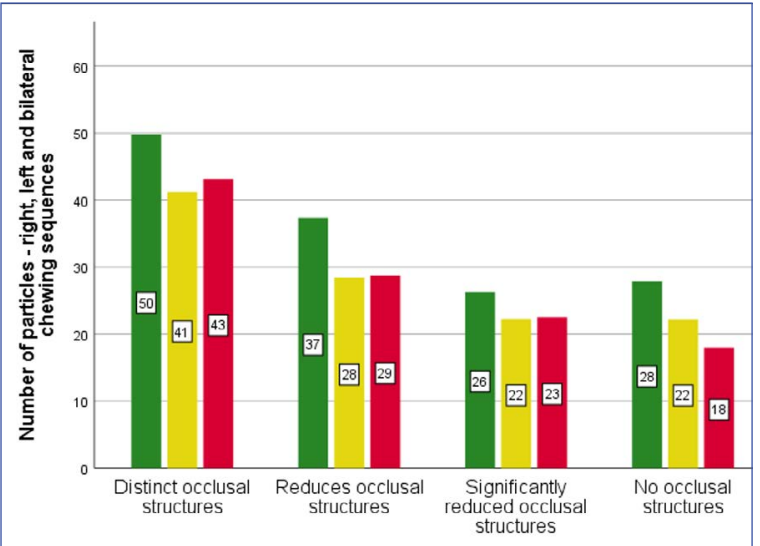

Figure 2a. Soft, medium and hard standard chewing test unit vs. overall occlusal quality.

\subsection{Chewing tests - requirements to be fulfilled}

A clinical test measuring chewing ability must consider extrinsic and intrinsic factors. Extrinsic parameters include food properties. Intrinsic parameters are among others age, gender, dental status. In addition, chewing tests units must be chosen that pose a similar challenge on the masticatory organ as natural foods.

1.4.1. Fragmentation methods as the golden standard

Significantly different methods to measure chewing ability are described in the specialized literature. Bearing in mind that mastication is intended to reduce food to as many equally sized particles as possible, methods that determine the degree of comminution are the methods of choice. SCTU is chewed within a defined time span and then spat out $[5,27]$. The number, area and distribution of the particles can be determined for analysis. An alternative method is to measure the time span required to achieve a certain degree of comminution. However, this requires several masticatory series of increasing duration to check when the degree of comminution is in line with the expectations $[12,27,28]$. The degree of comminution can be determined in various ways, among which the sieving method has become established as a valid model. Sieving methods are used to determine the distribution of the particle sizes of a granular material. This involves arranging several test sieves with decreasing mesh widths on top of one another. The quantity of the test material in each sieve can then be determined - for example by weighing the dried mass per sieve. In this way, conclusions can be drawn about the efficiency of the comminution process and hence the masticatory efficiency from the homogeneity of the particle size. This involves a consideration of the number of particles, the size of the particles and the ratio of the particle sizes in the food bolus. The methods for determining the masticatory ability based on the sieving technique principle are also referred to as fragmentation procedures [29]. Sieving methods are time consuming and not appropriate for routine

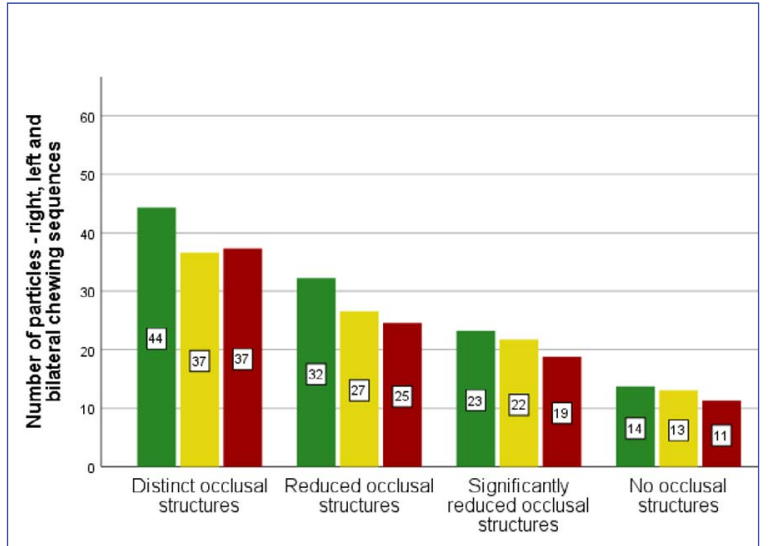

Figure 2b. Soft, medium and hard standard chewing test unit vs. overall occlusal quality in females.

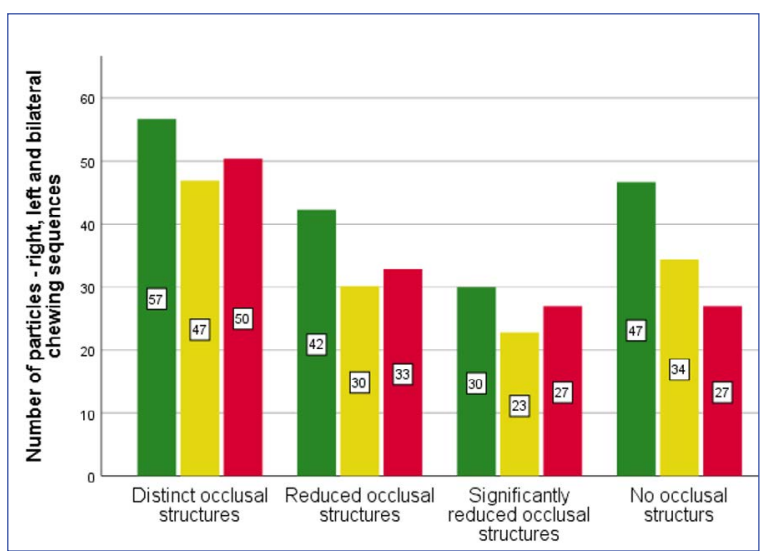

Figure 2c. Soft, medium and hard standard chewing test unit vs. overall occlusal quality in males.

clinical practice. Modern technologies such as optical scanning and/or imaging techniques can be used to overcome such burdens. The comparison of sieving with optical methods validates both methods and demonstrates comparable reliability and accuracy of information technology-based chewing fragmentation test procedures with sieving methods [30].

\subsection{Factors influencing chewing efficiency}

How well food is comminuted depends on many factors. Manifold parameters such as dental status, quality of chewing surface morphology, chewing forces, harmony of mandibular movements and co-ordination capacity of the neuromuscular system must be considered. These parameters are commonly subdivided into intrinsic (e.g. demographic attributes) and extrinsic (e.g. food properties) factors.

1.5.1. Intrinsic factors

Salivation and saliva quality affect the outcome of the masticatory sequence [31]. The degree of moisture of the food and in some cases additional fluid intake during mastication contribute to a change in the masticatory performance [32]. Age and gender are intrinsic modulators as well. All these factors affect mastication [33]. On the other hand, the effect of age may not be as pronounced as initially assumed. The number of masticatory cycles 


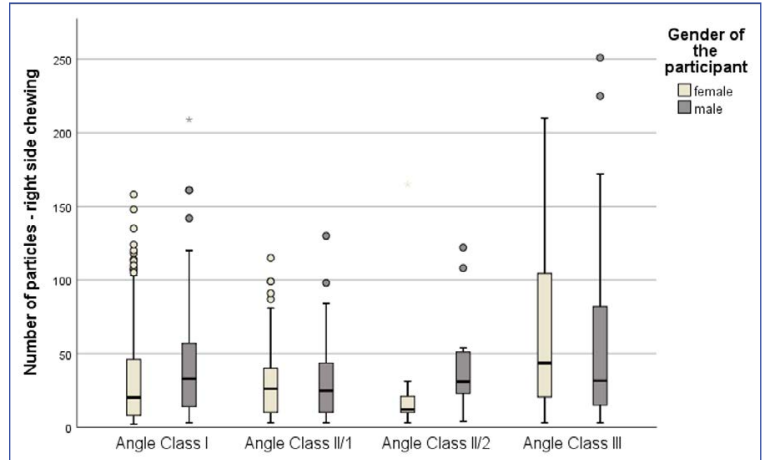

Figure 3a. Rigt side chewing efficiency vs. Angle classification on the right side; female vs. male.

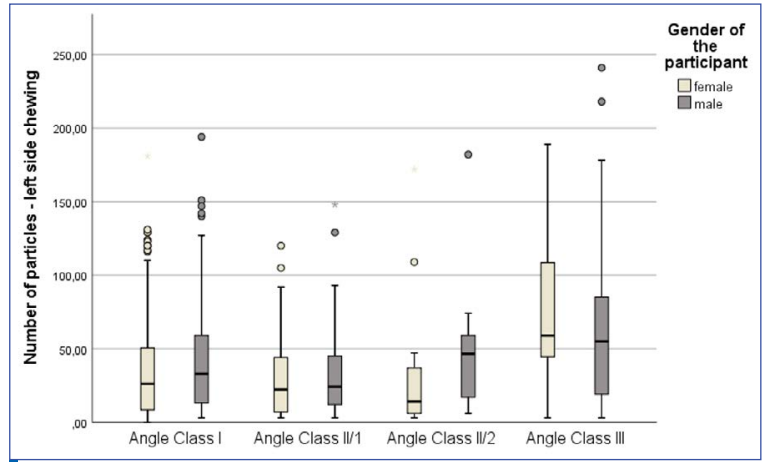

Figure 3b. Left side chewing efficiency vs. Angle classification on the left side; female vs. male.

Table 1. Overview of the perceived properties of food that have a significant influence on subjective perception and the so-called mouthfeel. The subjective taxation of food ingested in the mouth is by no means constant from the time it is placed in the mouth until it is swallowed, but can change considerably during a chewing sequence.

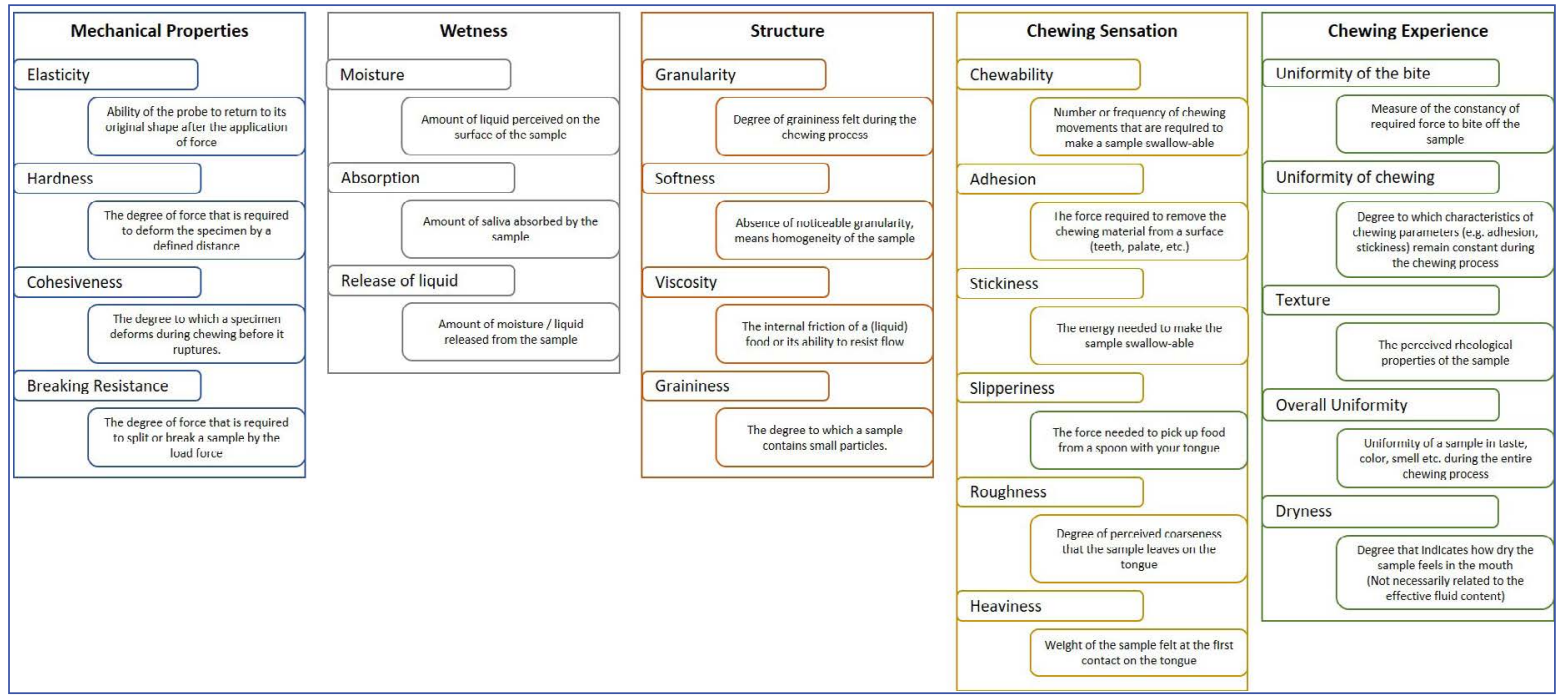

required to comminute a standardised food unit increases with age, but the capacity for individual adaptation to the properties of the food persists even in elderly subjects. The stomatognathic system remains relatively well preserved if people retain their dentition. This contrasts with other areas of the locomotor apparatus, which may be because the stomatognathic apparatus is used every day, even in people who already have difficulties walking [28]. 1.5.2. Extrinsic factors

Like the parameters attributable to the individual, food has a considerable effect on the process of mastication. The masticatory force, the vertical and lateral excursions of the masticatory movements, the rate of individual masticatory cycles and the frequency of mastication are parameters affected by food properties. The rheological properties of food are controlled by mechanisms localised in the brainstem $[2,21,22,24,34,35,36]$. Varying food textures can be used to influence dietary habits, such as more rapid or slower mastication, but in this case, hardness is not the most critical factor. Food properties such as plasticity, elasticity, and size have a direct effect on the afferent input signal in the central nervous system. Instead, parameters such as elasticity, springiness, texture, chewability and cohesiveness cause changes in masticatory behaviour. By changing food texture, it is possible to alter masticatory behaviour. The timespan, until a food bolus is swallowed, can be varied by food properties. Slower eating, which can be induced by a change in texture, thus produces a reduction in energy intake without affecting post-meal satisfaction [35].

Consensus exists to define the task of the masticatory process as the oral fragmentation of food to form a semi-liquid bolus for swallowing, a SCT should reflect on this: SCTU to be comminuted into as much and as equally sized particles as possible within a predefined length of the chewing sequence. Chewing media that do not degrade, such as chewing gum, do not meet this fundamental requirement [18]. Additionally, understanding chewing efficiency is not possible with one chewing sequence only (preferred chewing side problem). Intra-individual comparisons such as right vs. left vs. bilateral or soft vs. medium vs. hard based on several chewing sequences provides an in-depth review for clinicians and a better understanding for laypersons (patients and relatives). 


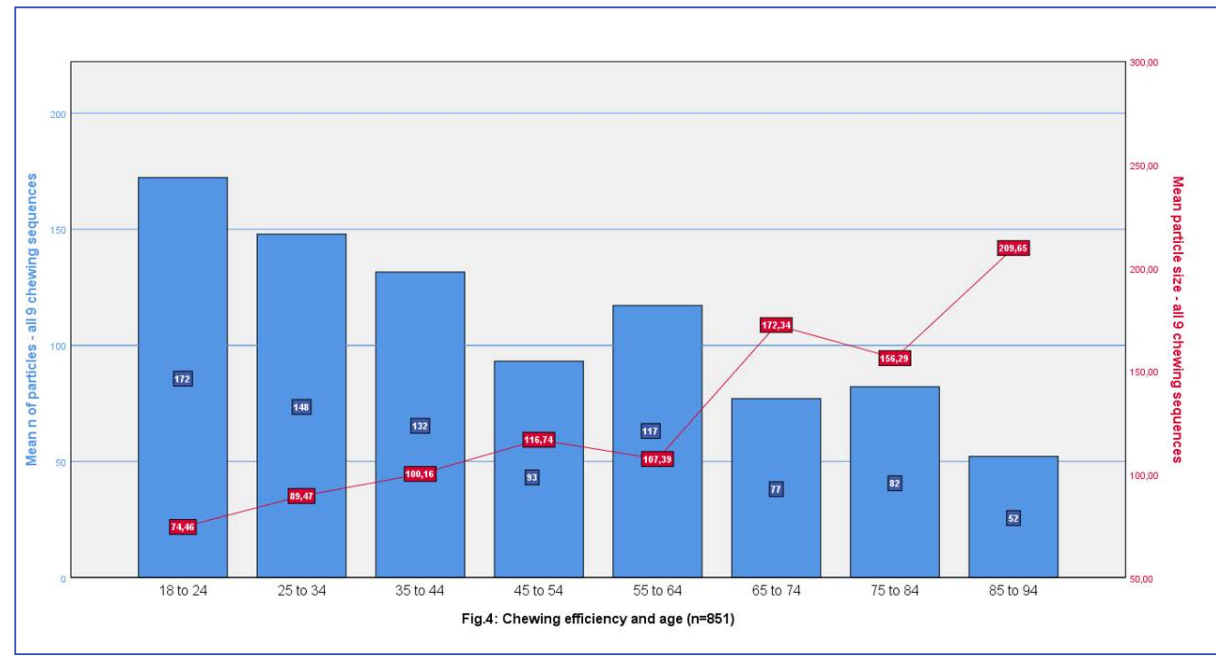

I Figure 4. Chewing efficiency and age $(n=851)$.

ITable 2. The categories to assess occlusal quality, using photo's for classification: no to distinct occlusal structures. The evaluation was performed per quadrant.

\begin{tabular}{|c|c|}
\hline Reference & Judgement \\
\hline \hline & no occlusal structures \\
\hline
\end{tabular}

\begin{tabular}{|l|l|}
\hline & $\begin{array}{c}\text { significantly reduces } \\
\text { occlusal structures }\end{array}$ \\
\hline
\end{tabular}

\begin{tabular}{|c|c|}
\hline & $\begin{array}{c}\text { reduced occlusal } \\
\text { structures }\end{array}$ \\
\hline & $\begin{array}{c}\text { distinct occlusal } \\
\text { structures }\end{array}$ \\
\hline
\end{tabular}

\subsection{Research question}

The role of the quality of occlusion as an influencing factor of masticatory efficiency is controversially discussed in the dental community. The aim of this article is to contribute to a better understanding of whether occlusion significantly influences chewing efficiency or not and to highlight possible cofounders such as angle classification, age, gender, treatment needs and intraoral status.

The null hypotheses tested are:

$\mathrm{H}_{0}$ 1: The distribution of number of particles (or mean area of particles, respectively) is the same across categories occlusal quality.

$\mathrm{H}_{0}$ 2: The distribution of number of particles (or mean area of particles, respectively) is the same across categories Angle classifications.

$\mathrm{H}_{0} 3$ : The distribution of number of particles (or mean area of particles, respectively) is the same across age groups.

$\mathrm{H}_{0}$ 4: The distribution of number of particles (or mean area of particles, respectively) is the same for females and males.

$\mathrm{H}_{0}$ 5: The subjective assessment of treatment needs by the investigator correlates with the distribution of number of particles (or mean area of particles, respectively).

$\mathrm{H}_{0} 6$ : The distribution of number of particles (or mean area of particles, respectively) is independent from the maxillary and mandibular status.

\section{METHODOLOGY}

The participants were instructed to try to break down the standardized chewing tests units (SCTU) into as many small pieces as possible. After 30 seconds the participants spited out the particles into a sieve. The particles were placed on a acquisition board with calibration elements. Standardised images are then taken and analysed using a validated software application. The surface areas of each of the particles are measured and displayed in $\mathrm{mm}^{2}$. The a priori determined Null Hypotheses were tested with the Kruskal-Wallis test followed by an applicable post hoc test with Bonferroni correction for repeated tests, to be rejected if $p \leq 0,01$. Data are collected as part of the BID-11400 study, multicentre and multinational clinical trial to evaluate masticatory functionality and quality of life. The study is approved by the Ethic Committee of University Cologne, Nr. 16-082, 15. May 2017. This evaluation includes data form projects which were recorded within the BID-11400 study, but solely by students as part of the Master of Science curriculum - Biomedical Interdisciplinary Dentistry at Steinbeis University Berlin. The data were collected between 2017-2019. A total of 851 data sets were used for these analyses.

Occlusal quality was judged by the investigator, using reference pictures, and determining occlusal quality for each quadrant (Tab. 2). The overall occlusal quality and the quality of occlusion on the right and left side were consolidated for the analytic process. Gender and year of birth were recorded for each participant. The age was calculated, and each 


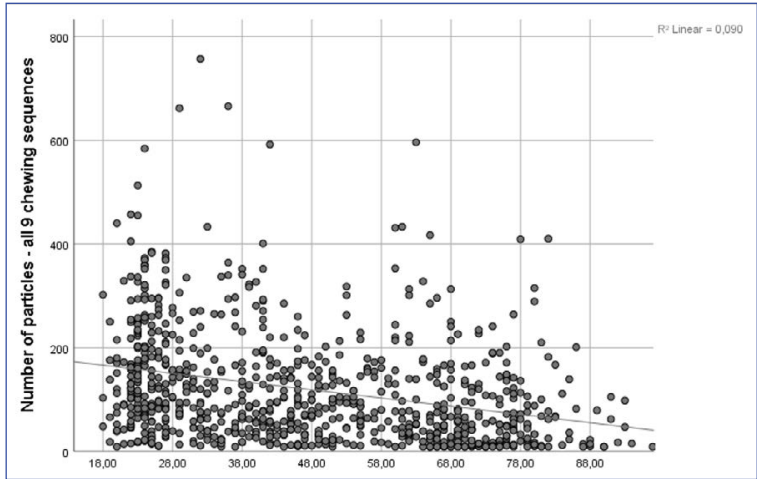

Figure 5a. Overall chewing efficiency vs. age; females vs. males.

participant was assigned to one age group: 18-24y; 25-34y; 35-44y; 45-54y; 55-64y; 65-74y; 75-84y. The treatment needs were assessed by the investigator. Theassessment was made in the following categories: clear indication for treatment; average treatment indication; minor treatment indication; no treatment indication. The maxillary and mandibular status was captured, for this analysis, only 3 categories have been used: Prevalence of natural teeth with minimal presence of restorations; Prevalence of natural teeth with the presence of fillings and partial crowns; Fixed prosthesis with bridges and crowns including implants. The chosen procedure should reflect the real clinical situation.

The standardized chewing test (SCT) was performed as follows: The patient is instructed on how to carry out the required nine masticatory sequences, each lasting 30 seconds. SCTU are used with tree different types of hardness. The basic mass for the SCTU is a standard formula used and approved commercially for fruit gum. The difference in hardness is achieved by the amount of gelatin added. Three different colors are used - algae extract for the green/soft, carrot/pumpkin extract for the yellow/medium and elder for the red/hard. The SCTU are equally flavored with strawberry essence. The chosen shape of the SFM is slightly cylindrical, with a diameter of $2 \mathrm{~cm}$ and a height of $1 \mathrm{~cm}[5,37]$.

The instruction to the patient is: "Try to break down the test item into as many small pieces as you can". The patient should chew in a concentrated way and should not be or get distracted while chewing. After 30 seconds the patient spits out the particles into a sieve. The particles per chewing sequence are placed on a recording plate with calibration elements and spread out so that the particles are at least $1 \mathrm{~mm}$ apart. Standardised images are then taken and analysed using a software application. The surface areas of each of the particles are measured and displayed in $\mathrm{mm}^{2}$. From this information the following key data can be determined: number $n$, area, and ratio of the particle sizes.

\section{RESULTS}

A sample of $n=842$ participants (female $n=460$, $54,6 \%$; male $n=382,45,4 \%$ ) performed a standardized

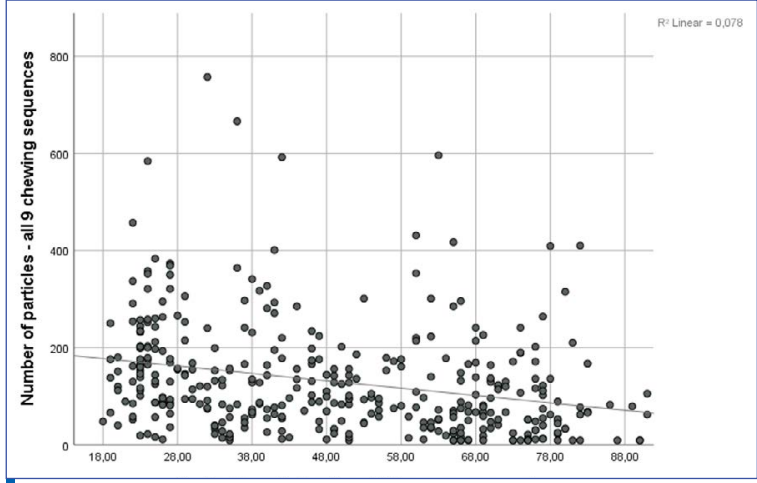

Figure 5b. Overall chewing efficiency vs. age; females.

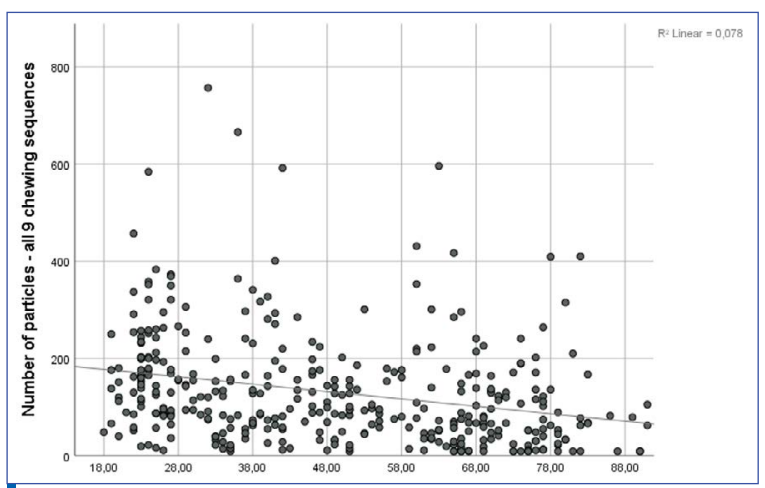

Figure 5c. Overall chewing efficiency vs. age; males.

chewing test (SCT). In addition, data on the participant's occlusal quality, angle classification, age, gender, treatment needs and intraoral status were recorded. The age distribution was as follows: $18-24 y(n=124,14,7 \%$; 26-34y $(n=160,19 \%) ; 35-44 y$ $(\mathrm{n}=126,15 \%) ; 45-54 \mathrm{y}(\mathrm{n}=110,13,1 \%) ; 55-64 \mathrm{y}(\mathrm{n}=84$, $10 \%) ; 65-74 y(n=131,15,6 \%) ; 75-84 y(n=85,10,1 \%)$, $>85 y(n=22,2,5 \%)$. Age group $>85 y$ was excluded for this analysis due to the low percentage.

\subsection{Quality of occlusion and Chewing efficiency}

The $\mathrm{H}_{0} 1$ "The distribution of number of particles (or mean area of particles, respectively) is the same across categories occlusal quality" was tested with a Kruskal-Wallis test followed by a post hoc test with Bonferroni correction for repeated tests. The difference between the occlusal categories was significant $(p<0,001)$. The post hoc analysis shows the marked difference between all four occlusal categories. This applies to overall chewing efficiency as well as for the right and left sides, where only the masticatory test results for that side were used for the analysis (Fig.1a,1b,1c). Considering occlusal quality, an almost linear reduction of the numbers of particles can be seen in especially in females, but not in males (Fig. 2a,2b,2c).

\subsection{Influence of Angle's classification on masticatory efficiency}

The $\mathrm{H}_{0} 2$ "The distribution of number of particles (or mean area of particles, respectively) is the same across categories Angle classifications" was tested using a Kruskal-Wallis test followed by a post hoc test 


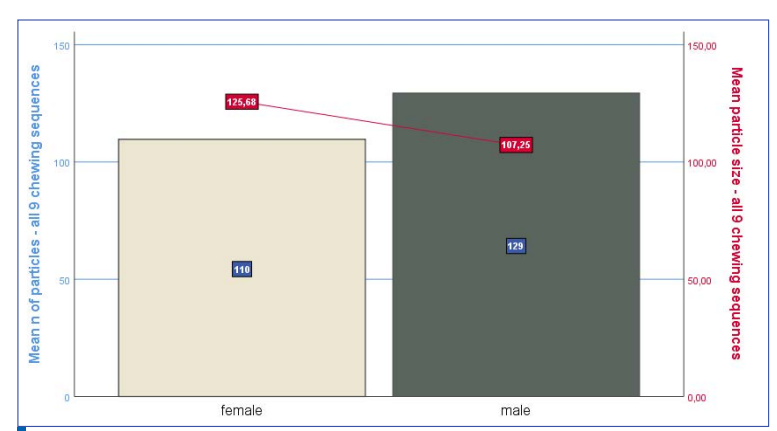

Figure 6. Overall chewing efficiency vs. gender.

with Bonferroni correction for repeated tests. The differences between the Angle classifications were significant $(p<0,001)$. The post hoc analysis showed that dental classes I, II/1 and II/2 do not differ. Angle's class III differs significantly from the other dental classes. This applies to both the right and left sides, where only the masticatory test results for that side were used for the analysis (Fig. 3a,3b). However, the results should be interpreted cautious since class II malocclusions were underrepresented in the study sample. Hence it cannot be confirmed that Angle's classification has a major impact on masticatory performance.

\subsection{Influence of Age on masticatory efficiency}

The $\mathrm{H}_{0} 3$ "The distribution of number of particles (or mean area of particles, respectively) is the same across age groups" was tested with a Kruskal-Wallis test $(p<0.001)$ followed by a post hoc test with Bonferroni correction for repeated tests. The results are presented in Table 3. The influence of age quoted in the literature can be confirmed based on the results of this study. It can be inferred that intraoral factors, especially in the elderly, significantly exceed the influencing factors age on chewing efficiency and should be taken into consideration in treatment strategies of an elderly population.

\subsection{Gender-specific differences}

The $\mathrm{H}_{0} 4$ "The distribution of number of particles (or mean area of particles, respectively) is the same for females and males" was tested with a MannWhitney-U test $(p<0.001)$. A SCT test based on nine chewing sequences shows that men generate markedly more (male 129 vs. female 110) and smaller particles (male $107.25 \mathrm{~mm}^{2}$ vs. female $125.68 \mathrm{~mm}^{2}$ ) than women (Fig.6). The difference is significant $(p=0.002$ for the number of particles, $p<0.001$ for the particle area). This overall difference between males and females can also be seen for soft and hard SCTU (Fig.7).

\subsection{Assessment of treatment needs and chewing efficiency}

The $\mathrm{H}_{0} 5$ "The subjective assessment of treatment needs by the investigator correlates with the distribution of number of particles (or mean area of

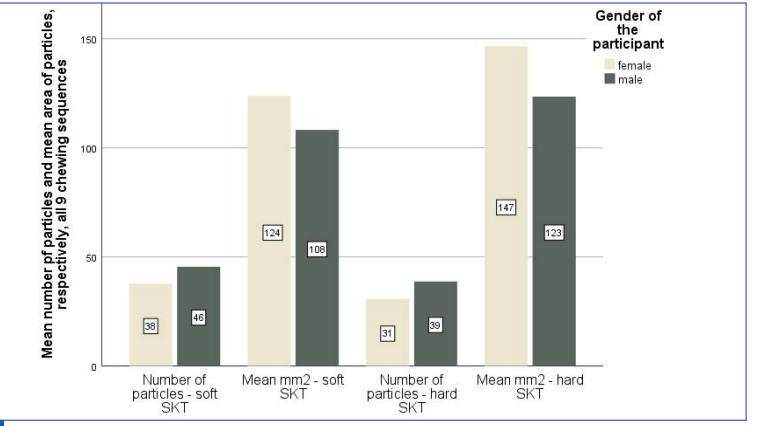

Figure 7. Influence of soft and hard standard chewing test units on chewing efficiency, per gender.

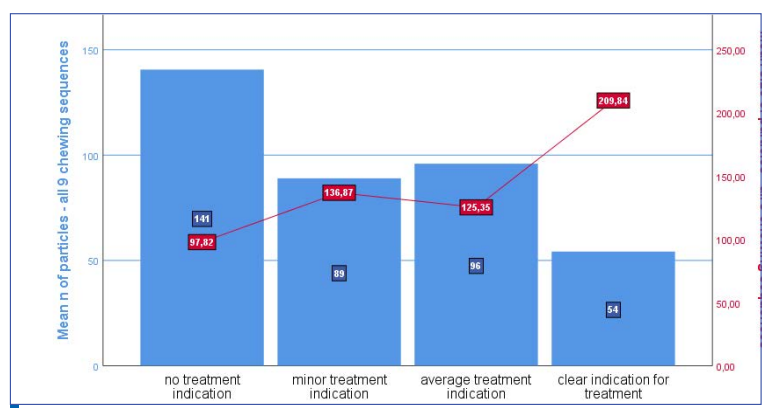

Figure 8. Chewing efficiency vs. assessment of treatment needs by investigators.

particles, respectively)" was tested with a KruskalWallis test $(p<0.001)$ followed by post hoc test with Bonferroni correction for repeated tests. The results are presented in Fig.8. The post hoc analysis showed that objective masticatory efficiency coincides with the assessment of treatment need for the extreme categories "no treatment indication" and "clear indication for treatment" only, while no significant difference $(p=0.515)$ was found between the "average" and "minor" treatment indication groups.

\subsection{Maxillary and mandibular status and masticatory efficiency}

The categories "Prevalence of natural teeth with minimal presence of restorations (upper jaw: $n=475$; lower jaw: $n=494)$ ), "Prevalence of natural teeth with the presence of fillings and partial crowns (upper jaw $\mathrm{n}=90$; lower jaw $\mathrm{n}=103$ )" and "Fixed prosthesis with bridges and crowns including implants (upper jaw $n=178$; lower jaw $n=155$ )" are incorporated in this analysis. The analysis was done separately for the upper and lower jaws. The $\mathrm{H}_{0} 6$ "The distribution of number of particles (or mean area of particles, respectively) is independent from the maxillary and mandibular status" was tested. The highest masticatory performance is achieved by natural teeth with minimal presence of restorations, followed by natural teeth with fillings and partial crowns. The results apply for upper (Fig.9a) and lower jaw (Fig.9b). Fixed prosthetic restorations such as crowns and bridges, including implant-supported fixed dentures, do not reach the results of natural occlusion. The Mann-Whitney- $U$ test was used to test for significance. For maxillary status no significant difference was found between "Prevalence of natural 


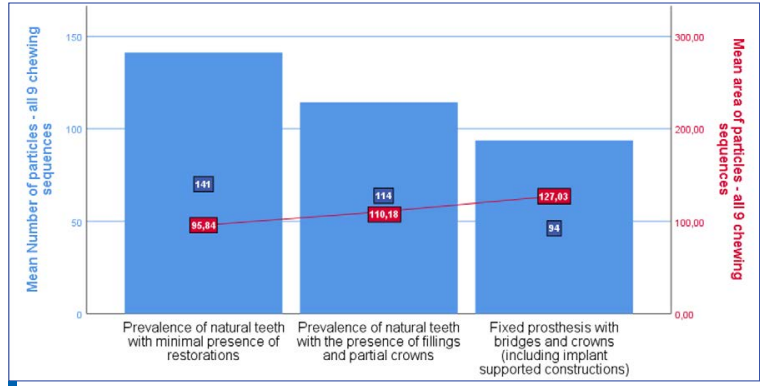

Figure 9a. Overall chewing efficiency vs. current status of the upper jaw (natural occlusal and fixed prosthesis only).

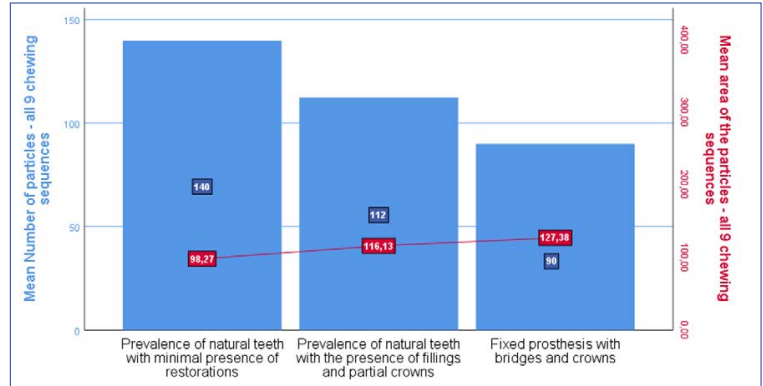

Figure 9b. Overall chewing efficiency vs. current status of the lower jaw (natural occlusal and fixed prosthesis only).

ITable 3. Results of a one-way ANOVA on ranks (Kruskal-Wallis test) followed by a post hoc test with Bonferroni correction for repeated tests to test whether chewing efficiency is different in age groups. In elderly, the age-related decline of chewing performance seems to be altered by other influencing intrinsic factors.

\begin{tabular}{|c|c|c|c|c|c|c|c|c|}
\hline $18-24$ years & $18-24$ years & & & & & & & \\
\hline $25-34$ years & 1,000 & $25-34$ years & & & & & & \\
\hline $35-44$ years & 0,023 & 1,000 & $35-44$ years & & & & & \\
\hline $45-54$ years & $<0,001$ & 0,005 & 1,000 & $45-54$ years & & & & \\
\hline $55-64$ years & 0,004 & 0,425 & 1,000 & 1,000 & $55-64$ years & & & \\
\hline $65-74$ years & $<0,001$ & $<0,001$ & $<0,001$ & 0,040 & 1,000 & $65-74$ years & & \\
\hline $75-84$ years & $<0,001$ & $<0,001$ & 0,012 & 1,000 & 0,413 & 1,000 & $75-84$ years & \\
\hline $85-94$ years & $<0,001$ & $<0,001$ & 0,013 & 0,094 & 0,384 & 1,000 & 1,000 & $85-94$ years \\
\hline
\end{tabular}

teeth with minimal presence of restorations" and "Prevalence of natural teeth with the presence of fillings and partial crowns". A significant difference was found between "Prevalence of natural teeth with minimal presence of restorations" and "Fixed prosthesis with bridges and crowns including implants" $(p<0.001)$. A significant difference was found between "Prevalence of natural teeth with the presence of fillings and partial crowns" and "Fixed prosthesis with bridges and crowns including implants" $(p<0.039)$.

\section{DISCUSSION}

The chewing surface morphology is admirably adapted to the food of each species $[1,4,8]$. Individuals with compromised occlusion have an impaired chewing efficiency compared to those with satisfactory occlusion $[2,10,37]$. Categorizing occlusion into four groups-distinct occlusal structures; reduced occlusal structures; significantly reduces occlusal structures; no occlusal structures - and correlating these groups with the masticatory performance reveals the significant impact of occlusal morphology on masticatory efficiency (Fig.1a). These results support the influence of occlusion on the function of mastication and the chewing efficiency. A well-formed and distinctly shaped occlusal morphology significantly increases masticatory efficiency.

The angle's classification is usually applied to describe occlusion. And, although critical and noncoherent, the Angle classification is often used to deduce functional conditions. In addition, the terms norm-occlusion and malocclusion are often used equated to functional or dysfunctional occlusion.
Maxillary and mandibular teeth are best aligned with each other in a class I occlusion, assuming regular tooth shapes. What is known as a class II or class III malocclusion does not exist in primates - this would obviously be a distinct disadvantage in the search for food and consumption of food. Malocclusion seems to conflict with the evolutionary concept of survival of the fittest. In humans, malocclusion has ceased to be a selection criterion because hunting and cutting tools are available and fire allows to preprocess meals.

The masticatory performance diminishes with age $[19,28]$. In particular, the length of the masticatory sequence required to produce the same particle size increases. Peyron et al. [28] quantified this increase of the required time for chewing with three masticatory cycles per ten years of life on average. Consequently, a $50 \%$ increase in numbers of chewing cycles needed to reach the same size of the particles between 25years and 75years [28]. These data can, to a certain extent, be transferred to the result of a chewing test based on fragmentation procedures. As the masticatory sequences are always the same length of 30 seconds, the number of chewed particles decreases with age.

Coincidentally, the mean particle size of chewed particles increases with age. The results show a continuous decrease in number of particles produced by elderly (Fig. 4). The decrease in 10 years can be calculated with approximately $15 \%$. Undoubtedly, the decrease in masticatory performance is no longer linear from the age of about 50 years. A possible explanation for this finding is a progressively intraoral alteration - including an increasing number of missing teeth, more and extended dentures and reduced structures of occlusal surfaces. The decline 
in the masticatory performance with age follows a similar path for both genders (Fig. 5). Gender-specific differences are described in the literature [16,18,32]. Forces during chewing are higher in males than females. The masticatory movements of men are also executed with greater vertical and transverse amplitude $[6,12,13,14]$. The overall results confirm the difference in masticatory efficiency between men and women that is quoted in the literature. But, as the difference is similar for soft and hard SCTU, it cannot be inferred that males are much more effective in chewing the hard SCTU than females. This result only partly confirms the fundamental assumption that, because of higher physical force, males are better able to masticate than women.

The clinical occlusal appearance is often used as treatment indicator. The subjective assessment of treatment needs and an objective measure of masticatory performance should coincide. This required the researchers to make a subjective assessment of treatment need without using further tests or other data. The assessment was made in the following categories: clear indication for treatment; average treatment indication; minor treatment indication; no treatment indication. The post hoc analysis showed that the objective masticatory efficiency coincides with the assessment of treatment need for the extreme categories "no treatment indication" and "clear indication for treatment" only, while no significant difference $(p=0.515)$ was found between the "average" and "minor" treatment indication groups. Therefore, the purely subjective assessment of treatment need cannot be considered to be adequate in individual decision making.

The aim of oral rehabilitation is to maintain and restore all functions of the masticatory organ. A clear relationship between intraoral status and masticatory efficiency can be deduced by the scientific literature $[2,10,11,19,25,27,32]$. It is still unclear what prosthetic rehabilitation best restores the individual's masticatory function.

The masticatory performance is often debriefed only via questionnaires and self-reporting by patient. The question arises if prosthetic rehabilitation can reach the chewing efficiency of natural occlusion? In this particular analysis, only natural occlusion and fixed prosthodontics are included. Based on the analysed tests of the SCT, it can be concluded, that fixed prosthodontic rehabilitation are not capable to reach the functional efficiency of natural occlusion.

\section{CONCLUSION}

The better the masticatory performance, the more particles will be found in the lower size ranges. Conversely, it can be concluded that few and large particles denote insufficient masticatory performance. The golden standard for testing chewing performance is the sieve technique. But, the clinical efforts in performing a chewing test based on the sieving method exceed the resources in daily practice. Therefore, contemporary IT-technologies including optical methods may be implemented in clinical routine, as such techniques have been demonstrated to be reliable and accurate to analyse chewing fragmentation test procedures comparably with sieving methods. Within the limitations of this study, it can be concluded:

- The quality of occlusion has a significant impact of chewing efficiency. The masticatory performance depends on the natural and/or artificial chewing surface morphology.

- Angle classification explains chewing efficiency only to some extent. A reasoning of an individual functional status just from Angle's classification is critical.

- Age is an important intrinsic factor which influences masticatory performance. But, at least in the age groups above 60 years, the intraoral status seems to overrule the influence of age. The maintenance of a sufficient functional oral status is a crucial task in care of the aging population.

- Gender differences in chewing outcomes, as described in the literature, can be confirmed by the results of this study. It can be added that the quality of occlusion affects both genders in a similar way. Higher muscle forces in males are not able to compensate poor occlusal quality.

- The assessment of treatment needs by the clinician based on a clinical inspection correlates with the masticatory performance in clear conditions only - either no treatment needs or clear indication for treatment. If the judgement of the treatment needs is unclear - minor or average treatment indications - the chewing efficiency is not correlated.

- Fixed prosthodontics, including implant supported construction, do not reach the chewing performance of natural occlusion with minor restorations.

\section{CONFLICT OF INTEREST}

There is a conflict of interest: The author is Founder and CEO of OREHAB-Minds GmbH, DE-70567 Stuttgart, Germany.

\section{AUTHOR CONTRIBUTIONS}

GS contributed to the concept, protocol, data gathering and analysis, their interpretation and critically revising the manuscript.

\section{ACKNOWLEDGMENTS}

None. 


\section{REFERENCES}

1. Lucas PW, Luke DA. Chewing it over: basic principles of food breakdown. In: Chivers DJ, Wood BA, Bilsborough A. (eds) Food acquisition and processing in primates. Boston, MA: Springer Since; 1984. https://doi.org/10.1007/978-1-4757-5244-1_12

Google Scholar

2. Slavicek G. Human mastication. J Stomat Occ Med. 2010;3:29-

41. https://doi.org/10.1007/s12548-010-0044-6.

3. Geissler CA, Bates JF. The nutritional effects of tooth loss. Am J

Clin Nutr. 1984;39(3):478-489. doi:10.1093/ajcn/39.3.478.

Google Scholar

4. Ungar PS. Mammalian dental function and wear: a review. Biosurf Biotribol. 2015;1(1):25-41. https://doi.org/10.1016/j.

bsbt.2014.12.001.

[Crossref] Google Scholar

5. Slavicek G, Soykher M, Soykher M, et al. Relevance of a standard food model in combination with electronic jaw movement recording on human mastication pattern analysis. $A d v$ Biosci Biotechnol. 2010;1(2):68-78. doi:10.4236/abb.2010.12011.

[Crossref] Google Scholar

6. Gibbs $\mathrm{CH}$, Mahan $\mathrm{PE}$, Lundeen $\mathrm{HC}$, et al. Occlusal forces during chewing-influences of biting strength and food consistency.

J Prosthet Dent 1981:46(5):561-567. doi:10.1016/0022

3913(81)90247-x

[Full text links] [Crossref] [PubMed] Google Scholar Scopus WoS

7. Butler PM. Evolution and mammalian dental morphology. J Biol

Buccale. 1983;11(4):285-302.

[PubMed] Google Scholar Scopus WoS

8. Orthlieb JD. The curve of Spee: understanding the sagittal

organization of mandibular teeth. Cranio. 1997;15(4):333-340. doi

$: 10.1080 / 08869634.1997 .11746028$

[Full text links] [Crossref] [PubMed] Google Scholar Scopus WoS

9. Bortun CM, Rusu LC. Recording mastication angels by Planas's laws. Stoma Edu J. 2014;1 (2):86-91. https://doi.org/10.25241/ stomaeduj.2014.1(2).art.1

[Crossref]

10. Meyer GB, Bernhardt O, Constantinescu MV. Fundamentals of occlusion and masticatory function. Stoma Edu J. 2014;1(2):116122. https://doi.org/10.25241/stomaeduj.2014.1(2).art.6.

[Crossref]

11. Tandetzki J. [Development of a practical test to measure chewing efficiency on patients]. Masterthese Department for Interdisziplinary Dentristry and Technologie University of Continuing Education Krems, 2011.

12. Gibbs CH, Wickwire NA, Jacobson AP, et al. Comparison of typical chewing patterns in normal children and adults. J Am Dent Assoc. 1982;105(1):33-42. doi:10.14219/jada. archive.1982.0073.

[Full text links] [Crossref] [PubMed] Google Scholar Scopus WoS 13. Julien KC, Buschang PH, Throckmorton GS, Dechow

PC. Normal masticatory performance in young adults and children. Arch Oral Biol. 1996;41(1):69-75. doi:10.1016/00039969(95)00098-4

[Full text links] [Crossref] [PubMed] Google Scholar Scopus WoS 14. Gibbs CH, Lundeen HC, Mahan PE, Fujimoto J. Chewing movements in relation to border movements at the first molar. J Prosthet Dent. 1981;46(3):308-322. doi:10.1016/00223913(81)90220-1.

[Full text links] [Crossref] [PubMed] Google Scholar Scopus

15. Gibbs $\mathrm{CH}$, Mahan PE, Lundeen $\mathrm{HC}$, et al. Occlusal forces during chewing--influences of biting strength and food consistency. J Prosthet Dent. 1981;46(5):561-567. doi:10.1016/0022-3913(81)90247-x.

[Full text links] [Crossref] [PubMed] Google Scholar Scopus WoS 16. Shiga H, Kobayashi Y, Katsuyama H, et al. Gender difference in masticatory performance in dentate adults. J Prosthodont Res. 2012;56(3):166-169. doi:10.1016/j.jpor.2012.02.001.

[Full text links] [Crossref] [PubMed] Google Scholar Scopus WoS 17. Uesugi H, Shiga H. Relationship between masticatory performance using a gummy jelly and masticatory movement. J Prosthodont Res. 2017:61(4):419-425. doi:10.1016/j. jpor.2017.01.001.

[Full text links] [Crossref] [PubMed] Google Scholar Scopus WoS 18. Youssef RE, Throckmorton GS, Ellis E 3rd, Sinn DP. Comparison of habitual masticatory patterns in men and women using a custom computer program. J Prosthet Dent. 1997;78(2):179-186. doi:10.1016/s0022-3913(97)70123-9.

[Full text links] [Crossref] [PubMed] Google Scholar Scopus WoS 19. Mishellany-Dutour A, Renaud J, Peyron MA, et al. Is the goal of mastication reached in young dentates, aged dentates and aged denture wearers?. Br J Nutr. 2008;99(1):121-128. doi:10.1017/ S0007114507795284.

[Full text links] [Crossref] [PubMed] Google Scholar

20. Siéssere $S$, Sousa LG, Lima Nde A, et al. Electromyographic activity of masticatory muscles in women with osteoporosis. Braz Dent J. 2009·20(3):237-342 doi:10.1590/s0103-

64402009000300012

[Full text links] [Crossref] [PubMed] Google Scholar Scopus 21. Woda A, Foster K, Mishellany A, Peyron MA. Adaptation of healthy mastication to factors pertaining to the individual or to the food. Physiol Behav. 2006;89(1):28-35. doi:10.1016/j. physbeh.2006.02.013.

[Full text links] [Crossref] [PubMed] Google Scholar Scopus 22. Kohyama K, Sasaki T, Hayakawa F. Characterization of food physical properties by the mastication parameters measured by electromyography of the jaw-closing muscles and mandibular kinematics in young adults. Biosci Biotechnol Biochem. 2008;72(7):1690-1695. doi:10.1271/bbb.70769.

[Full text links] [Crossref] [PubMed] Google Scholar Scopus WoS

23. van der Bilt A, Olthoff LW, van der Glas HW, et al. A

mathematical description of the comminution of food

during mastication in man. Arch Oral Biol. 1987;32(8):579-586.

doi:10.1016/0003-9969(87)90067-7.

[Crossref] [PubMed] Google Scholar Scopus WoS

24. Peyron MA, Mishellany A, Woda A. Particle size distribution of food boluses after mastication of six natural foods. J Dent Res. 2004:83(7):578-582. doi:10.1177/154405910408300713.

[Full text links] [Crossref] [PubMed] Google Scholar Scopus WoS 25. Slagter AP, Olthoff LW, Steen WH, Bosman F. Comminution of food by complete-denture wearers. J Dent Res. 1992;71(2):380386. doi:10.1177/00220345920710020601.

[Full text links] [PubMed] Google Scholar

26. Woda A, Nicolas E, Mishellany-Dutour A, et al. The masticatory normative indicator. J Dent Res. 2010;89(3):281-285. doi:10.1177/0022034509357022.

Google Scholar

27. Helkimo E, Carlsson GE, Helkimo M. Chewing efficiency and state of dentition. A methodologic study. Acta Odontol Scand. 1978;36(1):33-41. doi:10.3109/00016357809026364.

[Full text links] [Crossref] [PubMed] Google Scholar Scopus 28. Peyron MA, Blanc O, Lund JP, Woda A. Influence of age on adaptability of human mastication. J Neurophysiol. 2004:92(2):773-779. doi:10.1152/jn.01122.2003.

[Full text links] [Crossref] [PubMed] Google Scholar Scopus WoS 29. Schneider G, Senger B. Clinical relevance of a simple fragmentation model to evaluate human masticatory performance. J Oral Rehabil. 2002:29(8):731-736. doi:10.1046/ j.1365-2842.2002.00967.x

[Full text links] [Crossref] [PubMed] Google Scholar Scopus WoS 30. Mowlana F, Heath MR, Van der Bilt A, Van der Glas HW. Assessment of chewing efficiency: a comparison of particle size distribution determined using optical scanning and sieving of almonds. J Oral Rehabil. 1994;21(5):545-551. doi:10.1111/j.1365-2842.1994.tb01168.x.

[Full text links] [Crossref] [PubMed] Google Scholar Scopus WoS 31. van der Bilt A, Engelen L, Pereira LJ, et al. Oral physiology and mastication. Physiol Behav. 2006;89(1):22-27. doi: 10.1016/j. physbeh.2006.01.025

Google Scholar

32. Pereira LJ, Gavião MB, Engelen L, Van der Bilt A. Mastication and swallowing: influence of fluid addition to foods. J Appl Oral Sci. 2007;15(1):55-60. doi:10.1590/s1678-77572007000100012. [Full text links] [Crossref] [PubMed] Google Scholar Scopus WoS 33. van der Bilt A. Assessment of mastication with implications for oral rehabilitation: a review. J Oral Rehabil. 2011;38(10):754780. doi:10.1111/j.1365-2842.2010.02197.x.

[Full text links] [Crossref] [PubMed] Google Scholar Scopus WoS 34. Foster KD, Woda A, Peyron MA. Effect of texture of plastic and elastic model foods on the parameters of mastication. $J$ Neurophysiol. 2006;95(6):3469-3479. doi:10.1152/jn.01003.2005. [Full text links] [Crossref] [PubMed] Google Scholar Scopus WoS 35. Wee MSM, Goh AT, Stieger M, Forde CG. Correlation of instrumental texture properties from textural profile analysis (TPA) with eating behaviours and macronutrient composition for a wide range of solid foods. Food Funct. 2018;9(10):5301-5312. doi:10.1039/c8fo00791h.

[Full text links] [Crossref] [PubMed] Google Scholar WoS 36. Witt T, Stokes JR. Physics of food structure breakdown and bolus formation during oral processing of hard and soft solids. Curr Opin Food Sci. 2015;(3):110-117. https://doi.org/10.1016/j. cofs.2015.06.011.

Google Scholar

37. Slavicek G, Soykher M, Gruber H. et al. A novel standard food model to analyze the individual parameters of human mastication. J Stomat Occ Med. 2009;2:163-174. https://doi. org/10.1007/s12548-009-0029-5.

[Crossref] Google Scholar 


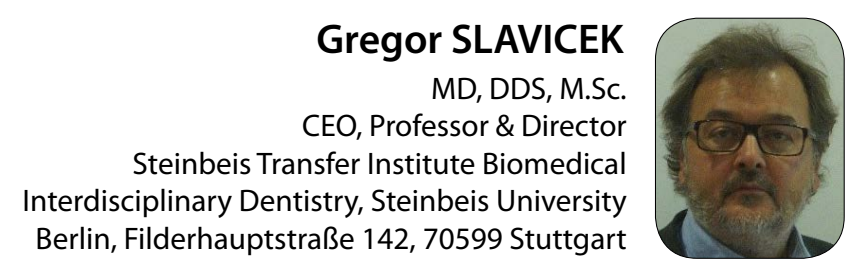

Dr. Slavicek is an MD, specialized in Dentistry. He is currently Director of the Steinbeis Transfer Institute Biomedical Interdisciplinary Dentistry, Steinbeis University Berlin. Since 2019, he has been CEO of Orehab Minds GmbH in Stuttgart, Germany. He graduated from the University Vienna (medicine and dentistry), also specializing in Clinical Research at the same university (Master of Science). He attended additional postgraduate orthodontic training at University Aarhus (Denmark), Prof. B. Melsen, and postgraduate gnathological training at University of Florida (USA), Prof. H. Lundeen and Prof. C. Gibbs. He is an honorary member of the Italian Gnathological Society. He received an honorary professorship from the Ukrainian Dental Society. He is an honorary member of the Italian Gnathological Society. He was visiting professor at the first medical state University in Moscow Sechenov (2014-2018).

\title{
Questions
}

\section{Which of the following statement is incorrect?}

$\square$ a. Chewing efficiency is related to angle classification only to a certain extent;

ab. Chewing efficiency increases with age;

ac. Chewing efficiency with males and females is significantly different;

$\square d$. Chewing efficiency is dependent on the prosthetic rehabilitation.

\section{Which of the following parameters can influence chewing efficiency?}

\author{
$\square$ a. Chewing surface morphology; \\ ab. Gender; \\ ac. Age; \\ d. Answers 1-3 are correct.
}

\section{A subjective assessment of treatment needs by the clinician?}

$\square$ a. Can be considered as a sufficient method to understand individual masticatory functions;

b. Is able to distinguish even small differences in treatment needs;

ac. Is not possible to distinguish even in extreme situations of treatments needs (not treatment indication vs. clear treatment indication);

$\square$ d. A subjective assessment should be proven by suitable tests.

\section{An adequate chewing function test for clinical use?}

$\square$ a. Is based on the principles of the sieving method;

b. Considers the ability of the stomatognathic system to fragment food;

ac. Contemporary IT-supported methods based on the evaluation of standardized photos are qualitatively equivalent to the sieving method;

$\square$ d. Answers 1-3 are correct. 


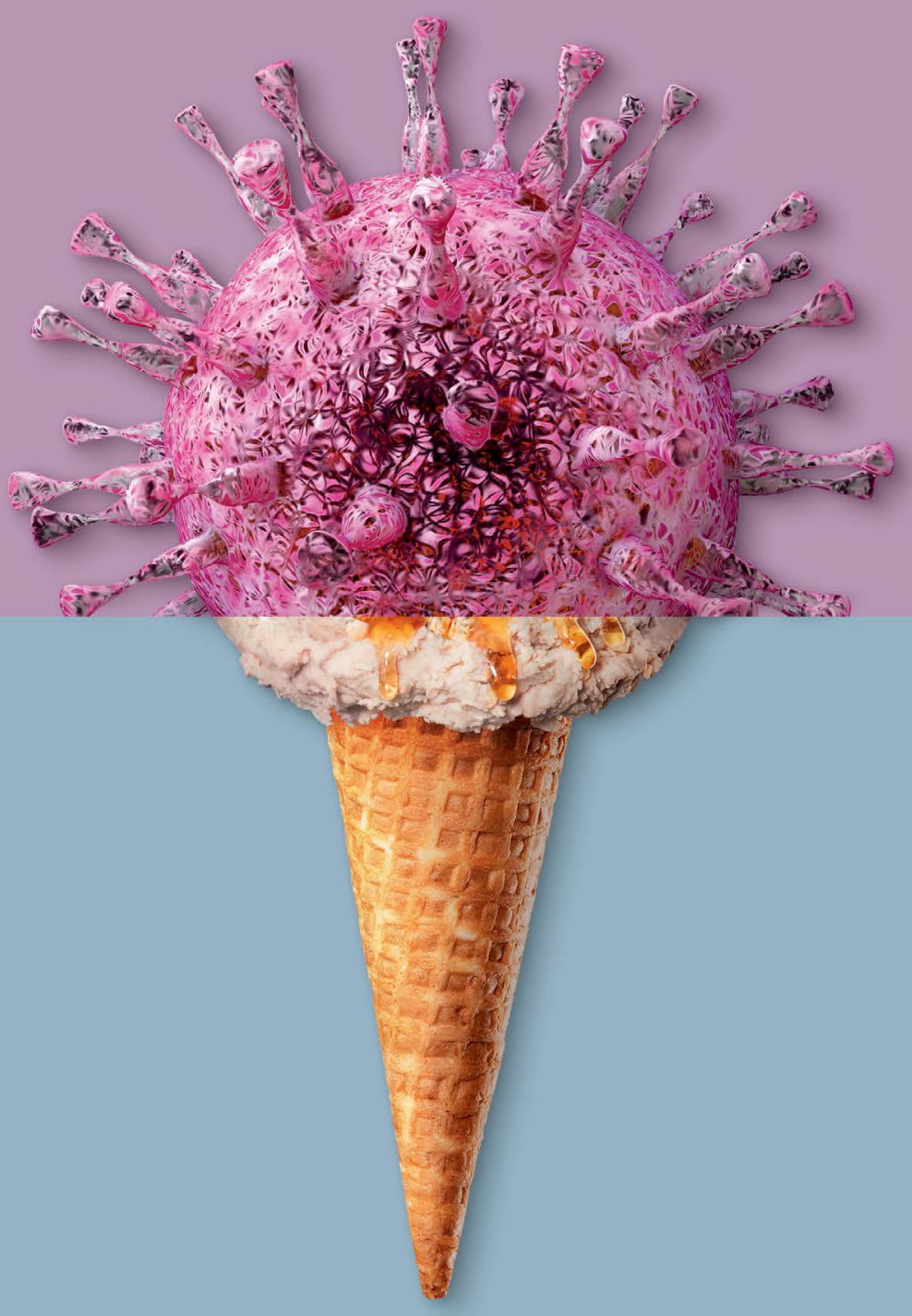

DAC Universal S

\section{Hazards turned harmless.}

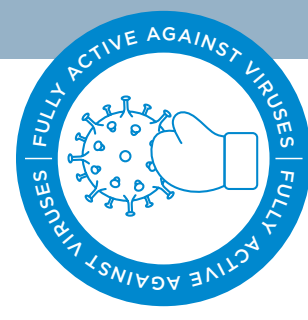

You think you will never win the fight against germs but Dentsply Sirona turns hygiene risks into manageable maintenance. With DAC Universal S you'll benefit from an automated and quick way of cleaning, lubricating and sterilizing dental instruments. The process takes approx. 21 minutes making it possible to comply with hygiene requirements by simply pressing a button. Your patients and your team can fully rely on our comprehensive protection against hazards.

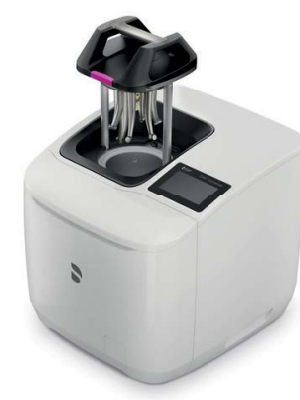




\title{
RETURNING TO THE ORTHODONTIC PRACTICE AMID COVID-19 CRISIS
}

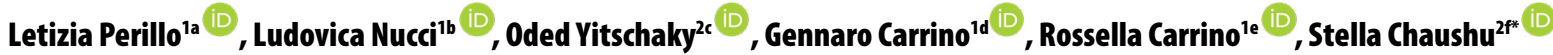 \\ ${ }^{1}$ Multidisciplinary Department of Medical-Surgical and Dental Specialties, School of Dentistry, University of Campania Luigi Vanvitelli, Naples, Italy \\ ${ }^{2}$ Department of Orthodontics, Faculty of Dental Medicine, Hebrew University-Hadassah, Jerusalem, Israel \\ aMD, MS, PhD, Professor, Head, Dean; e-mail: letizia.perillo@unicampania.it; ORCIDiD: https://orcid.org/0000-0001-6175-7363 \\ bDDS, PhD Student; e-mail: ludortho@gmail.com; ORCIDiD: https://orcid.org/0000-0002-7174-7596 \\ 'DMD, MA; e-mail: oyits76@gmail.com; ORCIDiD: https://orcid.org/0000-0002-5732-532X \\ dMD, MS, PhD; e-mail: gencarrino@gmail.com; ORCIDiD: https://orcid.org/0000-0002-9179-0751 \\ eDDS, Postgraduate Student; e-mail: rossella.carrino1@gmail.com; ORCIDiD: https://orcid.org/0000-0003-0417-5791 \\ fDMD, MSc, PhD; e-mail: drchaushu@hadassah.org.il; ORCIDiD: https://orcid.org/0000-0001-9571-8338
}

\section{ABSTRACT}

de) https://doi.org/10.25241/stomaeduj.2020.7(3).art.7

Background The coronavirus disease (COVID-19), caused by the novel severe acute respiratory virus syndrome (SARS)-CoV-2, was defined as pandemic on March 11, 2020. All health care providers are at risk of a COVID-19 infection; however, dentists pose the highest risk since SARS-CoV-2 is transmitted through breathing and aerosol, coughing and droplets and direct or indirect contact with infected skin and surfaces. Guidelines for minimizing the risk of transmission in general dental clinics have been published and are regularly updated. Objective The present article aims to specifically address the concerns of the orthodontic profession amid the COVID-19 crisis, and suggest recommendations for orthodontic care settings, infection prevention measures and delivery of clinical procedures.

Data Sources An electronic search was conducted via PubMed/MEDLINE, Google and health organization websites from two independent data abstractors.

Study Selection All kinds of manuscripts describing guidelines for health care providers to follow during the COVID-19 pandemic were included. No language restrictions were considered. Any disagreements on study inclusion were resolved by discussion between the two reviewers.

Data Extraction Information on guidelines and suggestions on the management of clinical orthodontic practice were extracted from studies identified for inclusion in the review.

Data Synthesis Orthodontists are at a very high risk for COVID-19 infection and all published guidelines should be followed for the patient and DHCPs safety. The care settings, the infection protocols, and the delivery of AGP clinical procedures must be continuously revised and modified to overcome the threat of the SARS-CoV-2 infection in the orthodontic practice.

\section{KEYWORDS}

COVID-19; Saliva; Aerosol; Orthodontists; Clinical Practice.

\section{INTRODUCTION}

The coronavirus disease 2019 (COVID-19) is a clinical syndrome caused by the novel Severe Acute Respiratory Syndrome Coronavirus 2 (SARS-CoV-2), a pathogen closely related to the Severe Acute Respiratory Syndrome Coronavirus (SARS-CoV) and Middle East Respiratory Syndrome Related Coronavirus (MERS-
CoV). SARS-CoV-2 mainly attacks the respiratory system, due to its affinity to angiotensin-converting enzyme 2 (ACE2) cell receptor, highly expressed in the lungs and the heart [1]. COVID-19 appears to have a lower case-fatality rate (3.4\%) as compared to SARSCoV (10\%) and MERS-CoV (3.4\%) [2], but is more transmissible, therefore posing a major public health threat. Most people infected by COVID-19 present

Received: July 03, 2020; Revised: July 20, 2020; Accepted: July 21, 2020; Published: July 23, 2020

*Corresponding author: Prof. Dr. Stella Chaushu, Professor and Chair, Department of Orthodontics, Faculty of Dental Medicine, Hebrew UniversityHadassah, Jerusalem, Israel, Address: PO Box 12272

Tel.: 972-2-6776184; Fax: 972-2-6427613; e-mail: drchaushu@hadassah.org.il

Copyright: $\odot 2020$ the Editorial Council for the Stomatology Edu Journal. 
mild, inconsequential respiratory symptoms. However, a minority of often aged individuals with other medical conditions, develop a severe disease, clearly distinct from the well-known acute respiratory distress syndrome. The disease is caused by a cytokine storm, a form of systemic unrestrained inflammatory response featured by the abundant release of proinflammatory cytokines [3].

This leads to alveolar injury, increased vascular permeability and extravascular accumulation of edema fluid, culminating in respiratory and heart failure, thromboembolism and death [4]. COVID-19 was declared as a pandemic by the World Health Organization (WHO) on March 11, 2020.

The current approaches to treatment include vaccine development and discovering new or re-proposed anti-viral and immunosuppressive medicines [5]. Unfortunately, pharmacologic treatments and vaccines are not yet available and it is likely that a high number of asymptomatic carriers [6] contribute to the spread of the virus. Currently, isolation and social distancing seem to be the most effective weapons against the virus and its widespread [7].

In this gruesome scenario, health care providers are extremely vulnerable and among them, dentists are considered to be at the highest risk [8], although the exact risk is still unknown. SARS-CoV-2 is transmitted by droplets loaded with viral particles emitted from the respiratory tract of an infected individual.

Dentists come in close contact with the oral cavity and are exposed to aerosol from breathing and coughing. Furthermore, droplets land on surfaces and can spread infection in the dental office by direct or indirect contact [9].

Dental care procedures may also aerosolize viral particles from saliva during treatment in the same way as sneezing or coughing. Dental aerosol generating procedures (AGPs) are associated with the use of ultrasonic instruments, air/water syringe and handpieces [10]. They have been charged to be responsible for the virus transmission and infection for healthy patients, but at the same time, they also represent a high risk for the dental health care personnel (DHCP) [11].

AGPs can generate droplets having a diameter ranging from $0.1 \mu \mathrm{m}$ to $900 \mu \mathrm{m}$. Liu Y, et al classified the droplets in five groups, with the largest group ranging from $0.25 \mu \mathrm{m}$ to $1 \mu \mathrm{m}$ [12]. The particles with this diameter can reach the alveoli. Droplets $<0.25 \mu \mathrm{m}$, loaded with pathogenic microorganisms, can travel up to 20 feet [13], so the 1-2-meter distance advised by WHO is not always enough to prevent cross infection between patients and DHCP.

The minimal aerosol viral load necessary for infection is still unknown; However, in vitro experiments show that aerosol contains viable virus for up to 16 hours [14]. Infectiveness of aerosol finds the evidence when COVID-19 gave an outbreak in buses and conference rooms [15]. Treatment sessions on the dentist chair should be divided into two risk categories: with AGP and without AGP. Each of them must be faced with proper Personal Protective Equipment (PPE) [13]. The Centers for Disease Control and Prevention (CDC) recommended using N95 respirators and not surgical face masks, whenever AGPs are performed [7].

Moreover, if AGP are needed for patients who have or are suspected of having COVID-19, airborne precautions should be strictly followed in addition to adequate PPE and a room with negative pressure, relative to the surrounding area, becomes mandatory [16]. Unfortunately, at this moment, there is still no reliable and efficient test to identify asymptomatic carriers, therefore everybody should be suspected to be infective. Caprioglio et al. published an interesting editorial article on the management of orthodontic emergencies during the initial quarantine period, of COVID-19 pandemics [17].

Recently, the American Dental Association (ADA) has published interim guidelines for minimizing the risk of COVID-19 transmission [18]. There are essential recommendations for all dental practitioners and clearly they should be followed by orthodontists. However, orthodontic treatment is different, since emergency service is seldom required [17], and many orthodontic procedures do not generate AGP.

Moreover, many treatment protocols can be modified to decrease droplets production and thus minimize the risk of cross contamination in the orthodontic office.

The aim of this article is to focus on the orthodontic profession and suggest specific recommendations for care settings, infection control and treatment delivery amid the COVID-19 crisis. The article was written as an international cooperation between the University of Campania Luigi Vanvitelli, Naples, Italy, and the Hebrew University-Hadassah Faculty of Dental Medicine, Jerusalem, Israel.

\section{ORTHODONTIC PRACTICE AND COVID-19}

\subsection{Before orthodontic treatment}

- An orthodontic practice usually has a high patient turnover, including a mixture of children and adults. Scheduling of appointments should allow appropriate "social distancing" in the waiting room.

Adults should be instructed to come without companions; however, children are usually accompanied by guardians. In this case, pretreatment triage for signs and symptoms of COVID-19 should be performed for both children and guardians.

DHCP will collect the medical history and check temperature to identify suspect patients until reliable chairside tests for SARS-CoV-2 are developed [19]. Since the virus has been found on shoes, a shoe wrapping machine can be installed at the entrance. Toys, books and other items which may carry the virus have to be removed from the waiting room.

- The recall orthodontic appointments are usually short. Due to the time needed for room cleaning and disinfection, working on a single chair is extremely 
inefficient, whereas working on at least 2 chairs, alternating working and disinfection, is preferred. The minimal distance between the chairs is 2 meters and a separation box is needed as a physical barrier to minimize aerosol spreading [20].

- Implementing tele dental applications can be particularly advantageous in this period. Records assessment and proposed treatment plans can be shared virtually online with the patients and discussed using modern web-based communication tools [21]. All communication with patients through virtual tools should be documented in the patients' file for medicolegal protection, as any physical appointment.

- ADA recommended antibacterial mouth rinses ( $1.5 \%$ hydrogen peroxide) before treatment, to reduce the viral load, but there are no clinical studies to support it. Mouth rinses containing $\beta$-cyclodextrins combined with flavonoids agents have been proposed for COVID-19 [22]. Children should rinse only under adult supervision.

\subsection{During the orthodontic treatment}

The CDC divides patient-care items in 3 categories: critical, semi critical, and noncritical, depending on the potential risk for infection. Critical items have the greatest risk for transmitting infection and should always be sterilized using heat [23].

This classification takes in consideration the risk of bloodborne contamination. However, the transmission modes of SARS-CoV-2 are respiratory droplets and physical contact [10]. Under these circumstances, each item that has been in contact with the patient or maybe contaminated by aerosol, becomes critical. 2.2.1. Records collection

- Extraoral radiographs, such as panoramic views, should be preferred whenever possible since intraoral radiographs may cause saliva secretion and coughing [19].

- Clinical photos should be taken wearing clean gloves, masks, and glasses, since cameras are difficult to clean and disinfect. Double gloving allows handling the camera with the inner gloves, after discarding the outer gloves.

Anti-fog treatment of mirrors should be done with warm water and not with air. Assistants should handle the plastic retractor and the mirror, thus fourhanded orthodontics is mandatory [24]. The plastic retractor and the mirror should be autoclaved after use. An antibacterial cloth can be used for cleaning the camera surface.

- Dental impressions are potential sources of contamination through the adhered blood or saliva. ADA [19], CDC [24] require impression disinfection to prevent contamination. Irreversible hydrocolloid impressions are effectively treated with 1:10 dilution of sodium hypochlorite for a ten-minute immersion [25]. Disposable impression trays should not be reprocessed since they are manufactured for a single use or for the use of one patient only, and not designed or intended for reuse [26].
- Intraoral scanning should be preferred whenever possible, especially for study models. Scanning does not reduce chair-time, but is more comfortable for the patient, minimizing gag reflex and difficulties in breathing associated with conventional impressions [27]. Moreover, the intraoral tip of the scanner is autoclavable.

\subsubsection{Multibracket appliances}

- Bonding requires etching of the enamel. Air/water syringe is used to wash and dry the enamel after etching, as well as to spread the bonding resin into a thin layer before light curing. ADA is advocating the use of a rubber dam for AGPs, to help minimize aerosol or splatter, as the saliva is washed away from teeth and aspirated with high power suction, before drying with the air syringe [11].

The use of a rubber dam in orthodontics has been already proposed for bracket bonding in general anesthesia [28] and can be also adopted in the routine orthodontic practice. Conversely, a rubber dam can introduce errors in bracket positioning, which can be avoided by using indirect bonding techniques or drawing marks on the teeth.

- Self-etching primer, which eliminates the need for air/water spray washing and drying, is an excellent alternative to the two-step conventional bonding techniques.

The bond strength with self-etching primers is clinically acceptable and bonding duration is also slightly reduced [29].

- Indirect bonding is an additional option which can significantly shorten chair-time, by up to $30 \mathrm{~min}$ for both arches [30] and reduce the DHCP exposure.

Thus, a combination of self-etching primer and indirect bonding significantly decreases the risk of aerosol contamination during bonding procedures.

- Visible-light curing units are a potential source of transmission due to contamination of the light curing tip, which directly contacts oral structures, and the handle, which becomes contaminated with blood and saliva from the DHCP gloves.

Different infection control techniques, that meet the CDC-recommended standards, include sterilization of curing tips, disposable barriers, or single-use plastic wrapping tip [31].

\subsubsection{Removable appliances}

Managing removable appliances in the clinic creates a low risk for the transmission of SARS-CoV-2 [17]. Impressions for appliances should be delivered to the lab after proper disinfection [see above] and returned from the lab after ultraviolet (UV) sterilization [32] in a plastic bag sealed with a label.

\subsubsection{Other orthodontic procedures}

Inserting, tying, and removing archwires and/or miniscrews are not AGPs and may be performed with the conventional ADA interim precautions [18].

\subsubsection{Aligners}

Compared with fixed appliances, aligners offer the advantage of shorter chair-time and fewer overall appointments in the office, therefore decreasing the 
risk for airborne transmission. Whenever possible, treatment progress can be assessed, and further instructions can be given through online virtual meetings. Attachments can be bonded with the aid of self-etching primers similarly to bracket bonding [33] and refined manually. On the contrary, attachment removal, like bracket debonding, is riskless only if a rubber dam is utilized.

\subsubsection{Interproximal enamel reduction}

Instruments used to slenderize teeth usually include diamond disks or air rotor burs [34,35]. These methods inevitable create aerosol.

Manual interproximal enamel reduction with handoperated abrasive strips is more time consuming and harder to use in posterior teeth, however it creates less aerosol and should be preferred in this period. Strip holders may aid in manual interproximal reduction [36].

\subsubsection{Auxiliaries}

Elastomeric ligatures, coils or other auxiliaries can be cut in small pieces, inserted in pouches before treatment and delivered to the doctor by the dental assistant. However, in case they are mistakenly contaminated, the unused parts can be sterilized via cold sterilization. Disinfection of these materials in a $2 \%$ glutaraldehyde solution for 10 minutes has no effect on strength and distention [38].

\subsubsection{Band application and removal}

No particular restriction is advised for these procedures, except for the use of air/water syringe. If used and tried on in the mouth, bands should be sterilized in autoclave. When bands are removed, cement breaks away and there is no need to use a handpiece.

\subsection{End of orthodontic treatment}

\subsubsection{Bracket debonding}

Debonding and enamel cleanup is the orthodontic procedure which produces the highest amount of aerosol and splatters [39]. Usually, brackets are debonded with special task pliers, but the adhesive remnants are removed with high speed or low speed burs, discs, or ultrasonic scalers [40]. Dental dam can prevent aerosol creation [10]. Remnants of bonding material can also be removed manually, using adhesive removing pliers, although this method is more time consuming and less efficient, leaving more adhesive remnants on the teeth [41]. The use of ceramic brackets should be restrained for their frequent fracture during debonding and the consequent need to use a turbine handpiece.

\subsubsection{Retainers}

Previous articles reported the bonding of retainers with a rubber dam in order to prevent failures [42]. During the current period, the rubber dam is even more recommended. Self-etching primers and indirect bonding [43] can further shorten chair-time and lower the risk of aerosol exposure, as explained above. Alternatively, clear retainers can be performed using intraoral scans and fixed retainer bonding postponed at this stage.

\section{STERILIZATION OF ORTHODONTIC PLIERS}

Orthodontic pliers touch patients' mucosa/skin and therefore become critical items in the COVID-19 era, and must be sterilized by autoclave. Pliers should be maintained in sterile envelopes, opened just before their use.

A larger supply of instruments is thus mandatory and if a plier is heat-sensitive, it should be replaced by a heat-tolerant item. On the other hand, heat sterilization leads to less corrosion than cold disinfection [37].

\section{CONCLUSIONS}

Similarly to other dental professions, orthodontists are at a very-high-risk for COVID-19 infection, and all published guidelines should be followed for the patient's and DHCP's safety. In the past, DHCP protection measures mostly addressed bloodborne infections. Presently, protection from COVID-19, which is highly transmissible through aerosol, droplets, and contact, is the main global concern.

In this period, the care settings, the infection protocols, and the delivery of AGP clinical procedures must be revised and modified to overcome the threat of SARS-CoV-2 infection in the orthodontic practice.

\section{List of abbreviations}

COVID-19 - Coronavirus disease 2019

(SARS-CoV-2) - Severe Acute Respiratory Syndrome Coronavirus 2 SARS-CoV - Severe Acute Respiratory Syndrome Coronavirus MERS-CoV - Middle East Respiratory Syndrome Related Coronavirus

ACE2 - angiotensin-converting enzyme 2

WHO - World Health Organization

AGP - dental aerosol generating procedure

DHCP - dental health care personnel

PPE - Personal Protective Equipment

CDC - Centers for Disease Control and Prevention

ADA - American Dental Association

UV - ultraviolet

Declarations

- Ethical Approval and Consent to participate - not applicable - Consent for publication - all authors read and approved the final version of the manuscript.

- Availability of supporting data - not applicable

- Competing interests - the authors declare that they have no competing interests.

- Funding - not applicable

- Acknowledgements not applicable

\section{CONFLICT OF INTEREST}

The authors declare no conflict of interest.

\section{AUTHOR CONTRIBUTIONS}

LP, SC and GC conceived the protocol, wrote, and revised the manuscript. LN, RC and OY revised the literature and collected the references. 


\section{REFERENCES}

1. Vaduganathan $\mathrm{M}$, Vardeny $\mathrm{O}$, Michel $\mathrm{T}$, et al. Renin-angiotensinaldosterone system inhibitors in patients with Covid-19. N Engl J Med. 2020;382(17):1653-1659. doi:10.1056/NEJMsr2005760. [Full text links] [CrossRef] [PubMed] [Google Scholar] [Scopus] 2. World Health Organization. Coronavirus disease (Covid-2019) situation reports. Available from: https://www.who.int/ emergencies/diseases/novel-coronavirus-2019/situation-reports [Internet]

3. McGonagle D, Sharif K, O'Regan A, Bridgewood C. The role of cytokines including interleukin-6 in Covid-19 induced pneumonia and macrophage activation syndrome-like disease. Autoimmun Rev. 2020;19(6):102537. doi:10.1016/j. autrev.2020.102537

[Full text links] [CrossRef] [PubMed] [Google Scholar] [Scopus] 4. Driggin E, Madhavan MV, Bikdeli B, et al. Cardiovascula considerations for patients, health care workers, and health systems during the Covid-19 pandemic. J Am Coll Cardiol. 2020;75(18):2352-2371. doi:10.1016/j.jacc.2020.03.031. [Full text links] [PubMed] [Google Scholar] [Scopus] 5. Stebbing J, Phelan A, Griffin I, et al. Covid-19: combining antiviral and anti-inflammatory treatments. Lancet Infect Dis. 2020;20(4):400-402. doi:10.1016/S1473-3099(20)30132-8. [Full text links] [CrossRef] [PubMed] [Google Scholar] [Scopus] 6. Yu X, Yang R. Covid-19 transmission through asymptomatic carriers is a challenge to containment. Influenza Other Respir Viruses. 2020;14(4):474-475 doi:10.1111/irv 12743. [Full text links] [CrossRef] [PubMed] [Google Scholar] 7. Forrester JD, Nassar AK, Maggio PM, Hawn MT. Precautions for operating room team members during the Covid-19 pandemic. J Am Coll Surg. 2020;230(6):1098-1101. doi:10.1016/J. jamcollsurg.2020.03.030.

[Full text links] [CrossRef] [PubMed] [Google Scholar] [Scopus] 8. OSHA. Guidance on Preparing Workplaces for Covid-19. Available from: https://www.osha.gov/Publications/OSHA3990. pdf [Internet]

9. Lai CC, Shih TP, Ko WC, et al. Severe acute respiratory syndrome coronavirus 2 (SARS-CoV-2) and coronavirus disease-2019 (COVID-19): the epidemic and the challenges. Int J Antimicrob Agents. 2020;55(3):105924. doi:10.1016/j. ijantimicag.2020.105924

[Full text links] [CrossRef] [PubMed] [Google Scholar] 10. Harrel SK, Molinari J. Aerosols and splatter in dentistry: a brief review of the literature and infection control implications. J Am Dent Assoc. 2004;135(4):429-437. doi:10.14219/jada. archive.2004.0207.

[Full text links] [CrossRef][PubMed] [Google Scholar] [Scopus] [WoS]

11. Morawska L, Cao J. Airborne transmission of SARS-CoV-2: the world should face the reality. Environ Int. 2020;139:105730. doi:10.1016/j.envint.2020.105730.

[Full text links] [CrossRef] [PubMed] [Google Scholar] [Scopus] 12. Liu Y, Ning Z, Chen Y, et al. Aerodynamic analysis of SARSCoV-2 in two Wuhan hospitals. Nature. 2020;582(7813):557-560. doi:10.1038/s41586-020-2271-3.

[Full text links] [CrossRef] [Google Scholar]

13. Froum S, Strange M. Covid-19 and the problem with denta aerosols. Perio-Implant Adv. Published 2020, April 7th. Available from: https://www.perioimplantadvisory.com/periodontics/ oral-medicine-anesthetics-and-oral-systemic-connection/ article/14173521/covid19-and-the-problem-with-dental-aerosols [Full text links]

14. Fears AC, Klimstra WB, Duprex $P$, et al. Comparative dynamic aerosol efficiencies of three emergent coronaviruses and the unusual persistence of SARS-CoV-2 in aerosol suspensions. Preprint. medRxiv. 2020;2020.04.13.20063784. doi:10.1101/2020. 04.13.20063784.

[Full text links] [CrossRef] [PubMed] [Google Scholar] 15. Shen Y, Li C, Dong H, et al. Airborne transmission of Covid-19: epidemiologic evidence from an outbreak investigation. Preprin April 2020. Available at SSRN: https://ssrn.com/abstract= or http://dx.doi.org/10.2139/ssrn.3567505 doi: 10.13140/ RG.2.2.3665.38881

[Full text links] [CrossRef] [Google Scholar]

16. Banaee S, Claiborne DM, Akpinar-Elci M. Use of negative pressure isolation in the provision of dental care. Decisions in Dentistry. Published 2020, April 13. Available from: https:// decisionsindentistry.com/2020/04/use-of-negative-pressureisolation-in-the-provision-of-dental-care/. [Full text links]
17. Caprioglio A, Pizzetti GB, Zecca PA, et al Management of orthodontic emergencies during 2019-NCOV. Prog Orthod. 2020;21(1):10. doi:10.1186/s40510-020-00310-y. [Full text links] [CrossRef] [PubMed] [Google Scholar] [Scopus] 18. Versaci MB. ADA releases interim guidance on minimizing Covid-19 transmission risk when treating dental emergencies. Resources discuss how to proceed before, during, after treatment. ADA News. Published 2020, April 01. Available from: https://www.ada.org/en/publications/adanews/2020-archive/april/ada-releases-interim-guidanceon-minimizing-covid-19-transmission-risk-when-treatingemergencies [Internet]

19. Sri Santosh T, Parmar R, Anand H, et al. A review of salivary diagnostics and its potential implication in detection of Covid-19. Cureus. 2020;12(4):e7708 doi:10.7759/cureus.7708.

[Full text links] [CrossRef] [PubMed] [Google Scholar] 20. Vilarinho Oliveira AMA, de Alencar RM, Santos Porto JC, et al. Analysis of fungi in aerosols dispersed by high speed pens in dental clinics from Teresina, Piaui, Brazil. Environ Monit Assess. 2018;190(2):56. doi:10.1007/s10661-017-6436-y. [Full text links] [CrossRef] [PubMed] [Google Scholar] [Scopus] [WoS

21. Patel RN, Antonarakis GS. Factors influencing the adoption and implementation of teledentistry in the UK, with a focus on orthodontics. Community Dent Oral Epidemiol. 2013;41(5):424431. doi:10.1111/cdoe.12029. [Full text links] [CrossRef] [PubMed] [Google Scholar] [Scopus] [WoS]

22. Carrouel F, Conte MP, Fisher J, et al. Covid-19: a recommendation to examine the effect of mouthrinses with $\beta$-cyclodextrin combined with Citrox in preventing infection and progression. J Clin Med. 2020;9(4):1 126. doi:10.3390/jcm9041126. [Full text links] [CrossRef] [PubMed] [Google Scholar]

23. Centers for Disease Control and Prevention. Guide to infection prevention for outpatient settings: minimum expectations for safe care. Available from: https://www.cdc.gov/ hai/settings/outpatient/outpatient-care-guidelines.html. Internet

24. Modi PD, Nair G, Uppe A, et al. Covid-19 awareness among healthcare students and professionals in Mumbai metropolitan region: a questionnaire-based survey. Cureus. 2020;12(4):e7514. doi:10.7759/cureus.7514.

25. Schwartz RS, Bradley DV Jr, Hilton TJ, Kruse SK. Immersion disinfection of irreversible hydrocolloid impressions. Part 1: Microbiology. Int J Prosthodont. 1994;7(5):418-423. [Full text links] [PubMed] [Google Scholar] [Scopus] 26. OSAP. FAOIE2018. FAO-Instruments \& Equipment. Available from: https://www.osap.org/page/FAQIE2018 [Internet]

27. Glisic O, Hoejbjerre L, Sonnesen L. A comparison of patient experience, chair-side time, accuracy of dental arch measurements and costs of acquisition of dental models. Angle Orthod. 2019;89(6):868-875. doi:10.2319/020619-84.1.

[Full text links] [CrossRef] [PubMed] [Google Scholar] [Scopus] 28. Chaushu S, Zeltser R, Becker A. Safe orthodontic bonding for children with disabilities during general anaesthesia. Eur $J$ Orthod. 2000;22(3):225-228. doi:10.1093/ejo/22.3.225

[Full text links] [CrossRef] [PubMed] [Google Scholar] [Scopus] [WoS]

29. Fleming PS, Johal A, Pandis N. Self-etch primers and conventional acid-etch technique for orthodontic bonding: a systematic review and meta-analysis. Am J Orthod Dentofacial Orthop. 2012;142(1):83-94. doi:10.1016/j.ajodo.2012.02.023. [Full text links] [CrossRef] [PubMed] [Google Scholar] [Scopus] [WoS]

30. Yıldırım K, Saglam-Aydinatay B. Comparative assessment of treatment efficacy and adverse effects during nonextraction orthodontic treatment of Class I malocclusion patients with direct and indirect bonding: a parallel randomized clinical trial. Am J Orthod Dentofacial Orthop. 2018;154(1):26-34.e1. doi:10.1016/j.ajodo.2017.12.009.

[Full text links] [CrossRef] [PubMed] [Google Scholar] [Scopus] [WoS]

31. Khode RT, Shenoi PR, Kubde RR, et al. Evaluation of effect of different disposable infection control barriers on light intensity of light-curing unit and microhardness of composite - An in vitro study. J Conserv Dent. 2017;20(3):180-184. doi:10.4103/JCD. JCD 17116

[Full text links] [CrossRef] [PubMed] [Google Scholar] [Scopus] 
32. Darnell ME, Taylor DR. Evaluation of inactivation methods for severe acute respiratory syndrome coronavirus in noncellular blood products. Transfusion. 2006;46(10):1770-1777. doi:10.1111/ j.1537-2995.2006.00976.x

[Full text links] [CrossRef] [PubMed] [Google Scholar] [Scopus] [WoS]

33. Gange P. The evolution of bonding in orthodontics. Am J Orthod Dentofacial Orthop. 2015;147(4 Suppl):S56-S63. doi:10.1016/j.ajodo.2015.01.011.

[Full text links] [CrossRef] [PubMed] [Google Scholar] [Scopus] [WoS]

34. Zachrisson BU. Interdental papilla reconstruction in adult orthodontics. World J Orthod. 2004;5(1):67-73.

[Full text links] [PubMed] [Google Scholar] [Scopus]

35. Chudasama D, Sheridan JJ. Guidelines for contemporary airrotor stripping. J Clin Orthod. 2007:41(6):315-320.

[Full text links] [PubMed] [Google Scholar] [Scopus]

36. Sharma NS, Shrivastav SS, Hazarey PV. Mastering

interproximal stripping: with innovations in slenderization. Int J Clin Pediatr Dent. 2012;5(2):163-166. doi:10.5005/jpjournals-10005-1159.

[Full text links] [CrossRef] [PubMed] [Google Scholar]

37. Wichelhaus A, Brauchle G, Mertmann M, Sander FG. Corrosion of orthodontic pliers using different sterilization procedures. $J$ Orofac Orthop. 2004;65(6):501-511. doi:10.1007/s00056-004-

0417-9.

[CrossRef] [PubMed] [Google Scholar] [Scopus]

38. Jeffries $\mathrm{CL}$, von Fraunhofer JA. The effects of $2 \%$ alkaline gluteraldehyde solution on the elastic properties of elastomeric chain. Angle Orthod. 1991;61(1):26-30. doi:10.1043/00033219(1991)061<0026:TEOAGS>2.0.CO;2.

[Full text links] [PubMed] [Google Scholar] [Scopus] [WoS]

39. Day CJ, Price R, Sandy JR, Ireland AJ. Inhalation of aerosols produced during the removal of fixed orthodontic appliances: a comparison of 4 enamel cleanup methods. $A m$ J Orthod Dentofacial Orthop. 2008;133(1):11-17. doi:10.1016/j. ajodo.2006.01.049.

[CrossRef] [PubMed] [Google Scholar] [WoS]

40. Cochrane NJ, Ratneser S, Woods MG, Reynolds EC. Effect of different orthodontic adhesive removal techniques on sound, demineralized and remineralized enamel [published correction appears in Aust Dent J. 2014 Jun;59(2):278. Woods, MG [added]. Aust Dent J. 2012;57(3):365-372. doi:10.1111/j.18347819.2012.01713.x

[Full text links] [CrossRef] [PubMed] [Google Scholar]

41. Miksić M, Slaj M, Mestrović S. Stereomicroscope analysis of enamel surface after orthodontic bracket debonding. Coll Antropol. 2003;27 Suppl 2:83-89.

[Full text links] [PubMed] [Google Scholar] [Scopus] [WoS] 42. Arnone R. Bonding orthodontic lower 3 to 3 retainers with a rubber dam: a second generation step-by-step procedure. $A m$ J Orthod Dentofacial Orthop. 1999:116(4):432-434 doi:10.1016/ s0889-5406(99)70229-5.

[CrossRef] [PubMed] [Google Scholar] [Scopus] [WoS

43. Egli F, Bovali E, Kiliaridis S, Cornelis MA. Indirect vs direct bonding of mandibular fixed retainers in orthodontic patients: comparison of retainer failures and posttreatment stability. A 2-year follow-up of a single-center randomized controlled trial. Am J Orthod Dentofacial Orthop. 2017;151(1):15-27. doi:10.1016/j. ajodo.2016.09.009.

[Full text links] [CrossRef] [PubMed] [Google Scholar] [Scopus] [WoS]

\section{Letizia PERILLO}

MD, MS, PhD, Professor, Head, Dean Multidisciplinary Department of Medical-Surgical and Dental Specialties School of Dentistry University of Campania Luigi Vanvitelli Naples, Italy

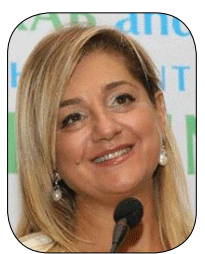

Letizia Perillo is full Professor and Dean of the School of Dentistry, University of Campania Luigi Vanvitelli, Naples (Italy). She is Visiting Professor at the University of Alabama (USA) and of Alexandria (Egypt). She was elected President of the Italian Society of Orthodontics (2021), of the Mediterranean Orthodontic Integration Project (2022), and International Ambassador of the American Association of Orthodontists (2018-2020). She is a member of many international dental organizations and of the Editorial Board of several journals. She graduated in Medicine and Surgery and specialized in Orthodontics at the University of Naples Federico II. She completed a postgraduate fellowship at the University of Michigan and a PhD in Interceptive Orthodontics at the University of Florence. She is authored several publications and she is speaker at international courses and congresses. 


\section{Questions}

\section{Dental aerosol generating procedures (AGPs) are associated with:}

$\square$ a. The use of ultrasonic instruments;

ab. Air/water syringe;

ac. Handpieces;

ud. All of them.

\section{When was Covid-19 declared a pandemic by the World Health Organization (WHO)?}

Da. On January 31th, 2020;

ab. On February 11th, 2020;

Dc. On March 11th, 2020;

ad. On April 12th, 2020.

3.Which dilution of sodium hypochlorite is effective for the disinfection of irreversible hydrocolloid impressions?

Da. 1:10;

Db. 2:10;

ac. 3:10;

ad. 4:10.

\section{Which is the diameter of particles that can reach the alveoli?}

Da. From $0.1 \mu \mathrm{m}$ to $1 \mu \mathrm{m}$;

ab. From $1 \mu \mathrm{m}$ to $10 \mu \mathrm{m}$;

ac. From $10 \mu \mathrm{m}$ to $100 \mu \mathrm{m}$;

口d. $>100 \mu \mathrm{m}$.

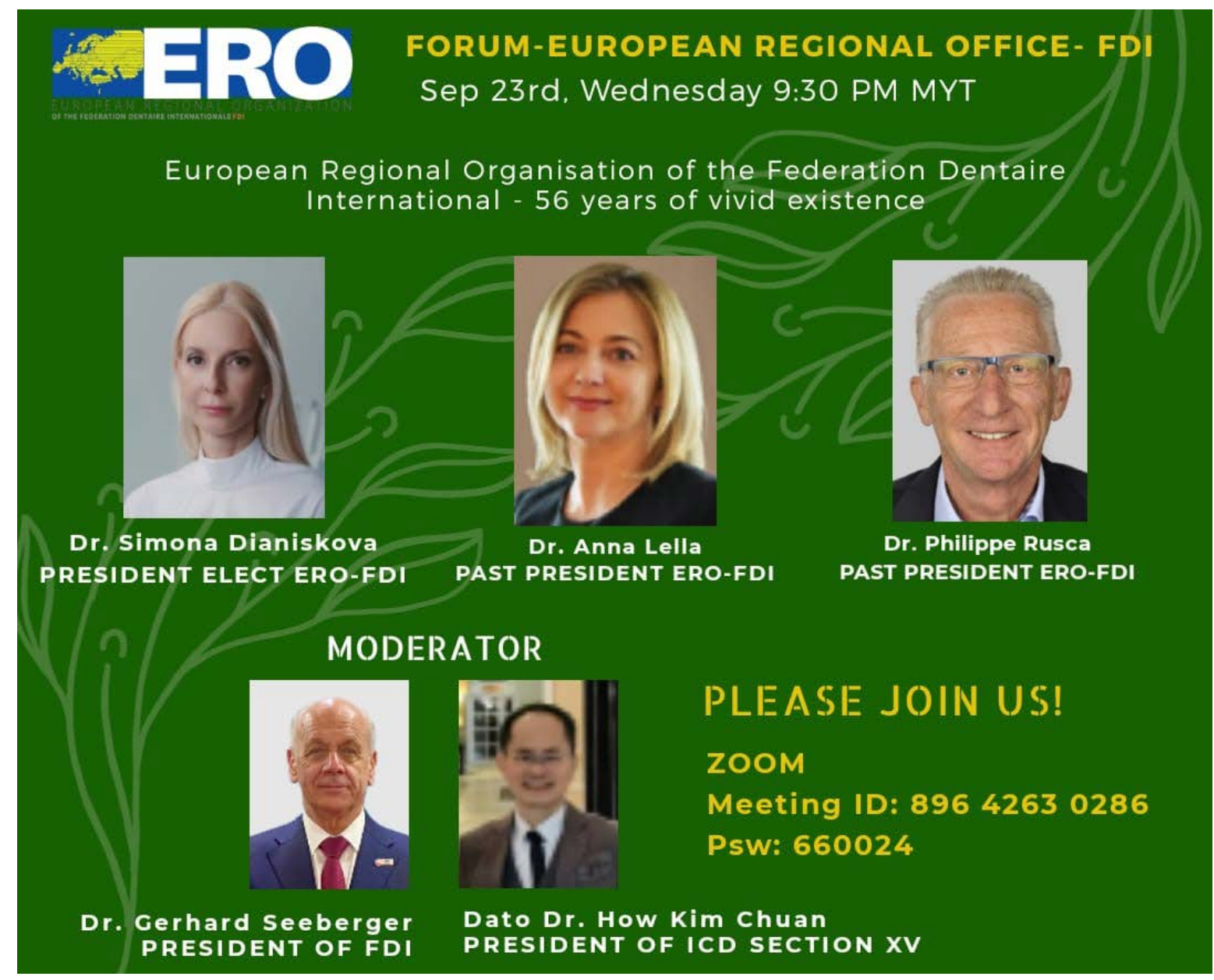




\section{MAILLEFER}

\section{WaveOne ${ }^{\circledR}$ Gold}

\section{Time savings}

for you, safety for your patients.

\section{WaveOne Gold}

The WaveOne Gold solution brings together proven products designed to work together into one endodontic system for efficiency and confidence in a variety of cases.

\section{Infection prevention with WaveOne Gold}

Single patient use. One patient, One use

1. No risk of cross contamination, for patients, for your staff and for you

2. Saves time for reprocessing, changing and organizing files

3. Better control of the risk of file breakage

4. Stable high cutting efficiency

\section{Learn more about WaveOne Gold}

https://www.dentsplysirona.com/en/explore/endodontics/

waveone-gold-reciprocating-files.html

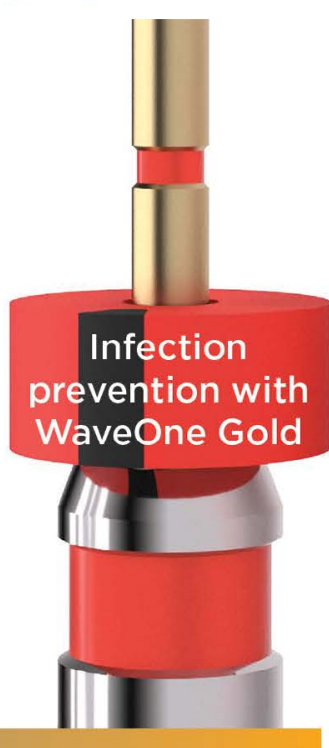




\section{Degranulation kit by Strauss \& Co: ensuring optimal mechanical debridement of the inflammatory tissue}

In dentistry, over time, various practitioners have introduced various tool kits bearing their name to have a more ergonomic therapeutic act. Thus, in my own practice I have successfully used a series of tool kits, such as: the kit for preparing the contour of the prosthetic reconstructions of Prof. Mario Martignoni, TDA Kit Martignoni (North Bel International SRL, Italy), the kit for predictable and precise tooth preparation techniques for porcelain laminate veneers (PLV) by Dr. Galip Gürel (Komet, Germany), preparation set for modified chamfer according to Dr. Domenico Massironi (Komet, Germany), a kit of coordinated diamond instruments for conservative, controlled preparation of ceramic veneers, called "Keramik-Veneers.de" by Dr. Oliver Ahlers (Komet, Germany) or TPS2 Set for inlay, crown and bridge preparation according to Dr. Bernard Touati (Komet, Germany).

Lately I have been focusing on complex dentoperiodontal treatments. To streamline the therapeutic act of debridement of the inflammatory tissue, we have successfully used the method of mechanical debridement to eliminate elements that may inhibit healing or promote infection.

The mechanical debridement method can be practiced with good results using the degranulation kit designed by Dr. Efraim Kfir produced by Strauss \& Co., Ra'Anana, Israel.

The kit comes with four specially designed $31 \mathrm{~mm}$ long burs with heads of different sizes $(1 \mathrm{~mm}, 2.5 \mathrm{~mm}$, $3.1 \mathrm{~mm}, 3.5 \mathrm{~mm}$ ), a cleaning brush and a suction tube. After tooth extraction the degranulation kit is used to biologically clean the empty socket from debris, inflamed soft tissues, remnants or roots of teeth and loose bone fragments, which all can impede the healing process.

The use of the degranulation kit is contraindicated in patients whose dental implantation is contraindicated.

The manufacturer makes a series of recommendations regarding the use of the degranulation kit:

- The kit is to be used only by qualified and trained professionals.

- It is recommended to read the instructions for use before using the kit.

- It is mandatory to sterilize the cutters and the suction tube before the initial use and between patients.

- It is not recommended to exceed the maximum speed indicated by the manufacturer.

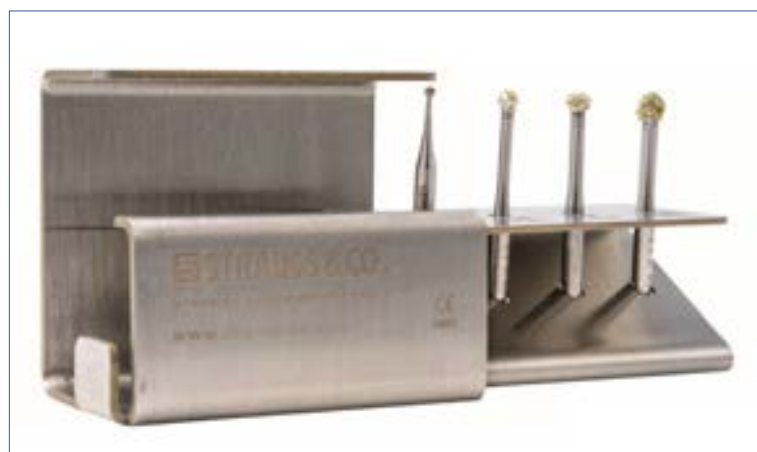

Degranulation Kit designed by Dr. Efraim Kfir Strauss \& Co., 19, Hayezira St. Industrial Zone, P.O.Box 2521 Ra'Anana, 4366363, Israel email: info@strauss-co.com https://strauss-co.com/

- Check the complete insertion of the chuck and the correct fixing in the head of the handpiece before use.

- Instruments are handled with sterile gloves.

- Eye protection with goggles or Full Face Protective Shield Visor against discharged particles is recommended.

- The surgical mask must be worn to avoid inhalation of aerosols or generated dust.

Following the use of the degranulation kit, I myself and any practitioner have found the undeniable advantages it offers:

- Provides good results in oral implantology, periodontal surgery, endodontic surgery and root removal.

- Tear off all remnants of soft tissue firmly attached to the bone and remove them without affecting the walls of the alveolar bone.

- An optimal debridement of the inflammatory tissue is achieved, which cannot be done manually with the surgical spoon curette.

- Ensures a fast and efficient debridement procedure. - Diamond cutters are more precise and do not catch the bone compared to tungsten cutters.

- The cutters are driven by the physio-dispenser working in a sterile environment.

- Adjustable working speed depending on the type of procedure performed.

- Single suction with multiple uses designed exclusively for direct viewing of the infected area to ensure optimal debridement.

- Ensures maximum safety when working near anatomical structures. 


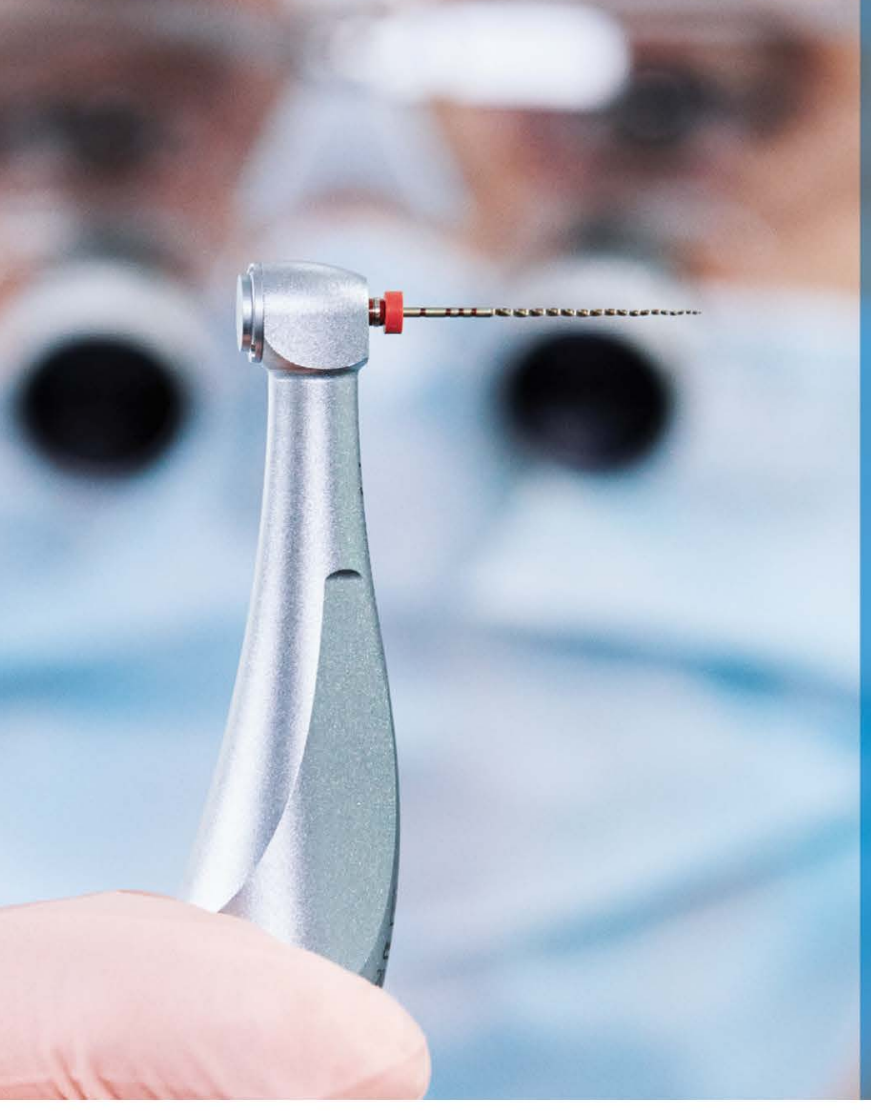

\section{MAILLEFER \\ TruNatomy ${ }^{\mathrm{TM}}$}

\section{Natural dentin preservation}

\section{TruNatomy}

TruNatomy is a complete clinical solution that's designed to respect the true, natural anatomy of the root canal system-featuring an intuitive file system with an Orifice Modifier, a Glider, and a single shaping file. For smaller or larger canals, there are also two additional shaping files available, all complemented by corresponding paper points, Gutta-Percha points, and GuttaCore obturators, as well as a flexible irrigation needle.

\section{Infection prevention with TruNatomy}

Single patient use. One patient, One use

1. No risk of cross contamination, for patients, for your staff and for you

2. Saves time for reprocessing, changing and organizing files

3. Better control of the risk of file breakage

4. Stable high cutting efficiency

Learn more about TruNatomy

https://www.dentsplysirona.com/en/explore/endodontics/trunatomy.html

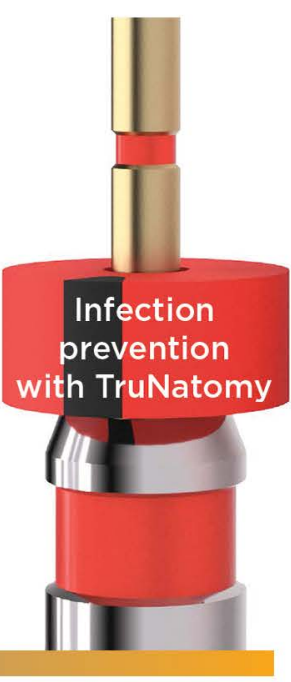

Office \& Showroom

98A Vulturilor Street, 030857, Bucharest, Romania

Tel.: +40 774074094

e-mail: office.romania@dentsplysirona.com

https://www.dentsplysirona.com/ro-ro

http://facebook.com/dentsplysirona.romania

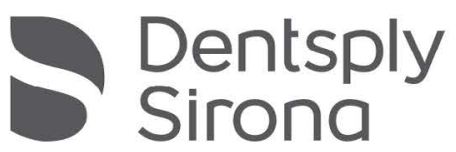




\section{Advances in \\ Esthetic Implant Dentistry}

Author: Abdelsalam Elaskary

Publisher:Wiley-Blackwell, Hoboken, NJ, USA

Language: English

ISBN: 978-1-119-28667-7

Edition: $1 / \mathrm{e}$

Publish Year: 2019

Pages: 392, illustrated

Price: $€ 141.30$

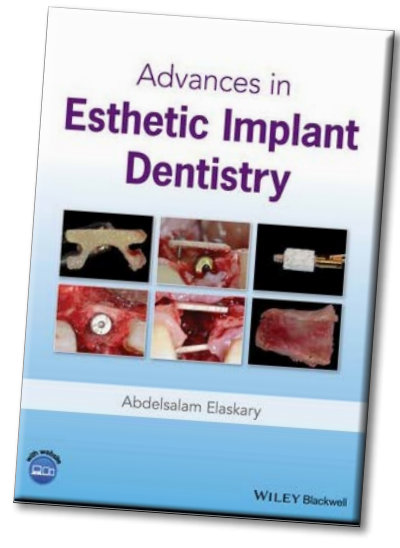

Marian-Vladimir

Constantinescu

DDS, MSc, PhD

Holistic Dental \& Medical Institute

of Bucharest-ROPOSTURO

Bucharest, Romania

e-mail:

dr.vladimir.constantinescu@gmail.com

Dr. Abdelsalam Elaskary, owner of the Elaksary \& Associates Institute and Clinic for Dental Implants and Oral Reconstruction in Alexandria, Egypt and a visiting lecturer at the University of New York (NYU) presents his extensive experience in dental implantology in the book entitled Advances in Esthetic Implant Dentistry.

The book has nine chapters and an index.

Chapter 1 discusses the predictability of aesthetic implant therapy and how to fulfill patient expectations in this type of therapy.

Chapter 2 evaluates the integration of smile-related facial components in the treatment plan in terms of smile reflection from the perspective of personal and social well-being.

Chapter 3 discusses the physiology and stability of immediate implant placement.

Chapter 4 describes the personal clinical protocol, a synthesis of old and current methods.

Chapter 5 presents implant-related gingival recession as a clinical dilemma of practitioners detailing its etiology and describes a novel guide scoring template to measure the degree of treatment success and proposes a treatment protocol for each recession category.

Chapter 6 addresses different surgical protocols regarding the aesthetic area meant to obtain free soft tissue in any regeneration procedure.

Chapter 7 describes the dental CAD/CAM technology protocol for immediate implant placement loading concept with a one-day teeth delivery.

Chapter 8 defines the magnitude and means to optimize the restorative space in horizontal and vertical dimensions to obtain a rational unpredictability treatment.

Chapter 9 talks about the long-term evaluation of regenerative techniques available in oral implantology. Each chapter is accompanied by photographs and radiographs as well as a website in which videos of the treated cases are presented. It is an indispensable guide for practitioners and students in periodontics, prosthodontics, oral and maxillofacial surgery, and general dentistry in aesthetic rehabilitation by dental implants.

de) http://www.stomaeduj.com 10.25241/stomaeduj.2020.7(3).bookreview.1

The Books Review is drafted in the reviewer's sole wording and illustrates his opinions. 
Alexandra Popa

Holistic Dental \& Medical Institute of Bucharest - ROPOSTURO,

Bucharest, Romania

e-mail: alesandra17popa@gmail.com

\section{Levison's Textbook for Dental Nurses}

Author: Carole Hollins

Publisher: Wiley-Blackwell, Hoboken, NJ, USA

Language: English

ISBN: 978-1-119-40134-6

Edition: 12/e

Publish Year: 2019

Pages: 784, illustrated

Price: $€ 32.80$

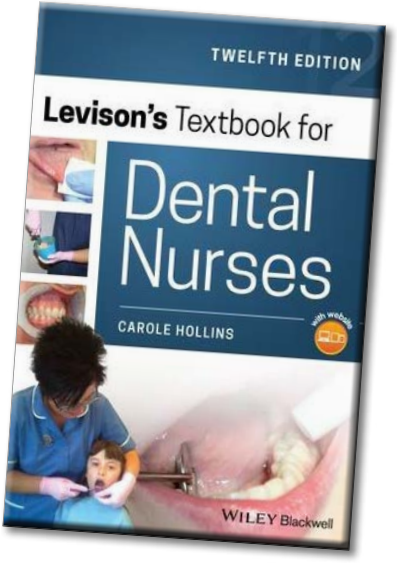

Dr. Carole Hollins, author of the $\mathbf{1 2}^{\text {th }}$ edition of Levison's Textbook for Dental Nurses is a General Dental Practitioner, member of the British Dental Association and has been a dental nurse trainer for the National Examining Board for Dental Nurses (NEBDN) qualifications for 23 years and Examiner for the City \& Guilds Level 3 Diploma in Dental Nursing.

The book is divided into 18 chapters, each chapter being accompanied by key learning points to help readers, and also an index.

The first chapters present the Structure of the Dental Profession, The Dental Nurse and Legal and Ethical Issues. After presenting the criteria for Health and Safety at Work Act (1974) and the role of the Dental Nurse, the Control of Substance Hazardous to Health (2002), and Health and Safety Regulation (1992) are described. We are then informed on the General Anatomy and Physiology, Medical Emergencies, Microbiology and Pathology, Infection Control and Cleanliness, Head and Neck Anatomy and Physiology, Oral Anatomy and Physiology. With the basic information provided, there follow presentations of Oral Disease, Oral Health Assessment and Diagnosis, Oral Health Promotion and Disease Prevention, Pain and Anxiety Control.

The involvement of dental care in the therapeutic, prosthetic and minor oral surgery acts is described in the last chapters. The book is an indispensable resource for the NEBDN Diploma in Dental Nursing, summing up recent developments in dental nursing practice and education, according to the latest General Dental Council standards, and also a great benefit to dental nurses studying for the City \& Guilds Diploma in Dental Nurses, Level 3.

The manual contains representative images in each chapter, and a website to test knowledge through interactive MCQs and EMQs. Although this book was intended to be a source of information for dentists in the UK, the book is recommended as a guide for any dentist anywhere.

\section{d) http://www.stomaeduj.com 10.25241/stomaeduj.2020.7(3).bookreview.2}

\section{Dental Reception and Supervisory Management}

Author: Glenys Bridges

Publisher: Wiley-Blackwell, Hoboken, NJ, USA

Language: English

ISBN: 978-1-119-51308-7

Edition: 2/e

Publish Year: 2019

Pages: 784, illustrated

Price: $€ 45.20$

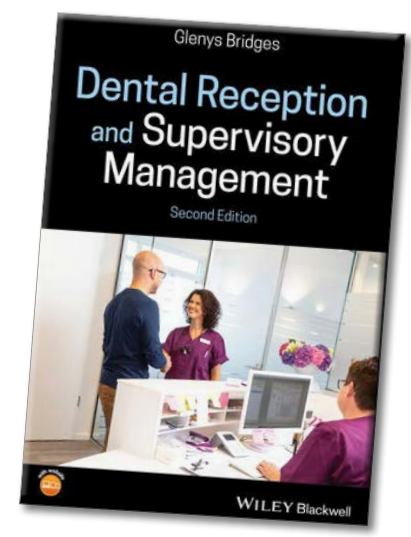

Dental Reception and Supervisory Management, $2^{\text {nd }}$ edition, by Glenys Bridges, an experienced management and administration trainer, covers the area of knowledge needed for receptionists and supervisory managers to provide effective activity and a patient-friendly approach.

The book has 12 chapters which define the role and tasks of dental reception and supervisory management, and then establish their administrative role, informing the reader on marketing, financial aspects of patient consent, staff selection, quality management, the role of management and leadership, team meetings, safety and well-being, customer care strategy, treatment coordination and aspects of computer technology required for each member of the dental team. Dental Reception and Supervisory Management, $2^{\text {nd }}$ edition is intended for dental receptionist practice, but is also a working tool for dental nurses, dental hygienists, and dentists. The book is accompanied by a companion website, which facilitates learning the basics within the constant items that a dental receptionist must accumulate.

\section{d) http://www.stomaeduj.com 10.25241/stomaeduj.2020.7(3).bookreview.3}


Oral and Maxillofacial Radiology: A Diagnostic Approach

Editor: David MacDonald

Publisher:Wiley-Blackwell, Hoboken, NJ, USA

Language: English

ISBN: 978-1-119-21870-8

Edition: 2/e

Publish Year: 2019

Pages: 656, illustrated

Price: $€ 171.00$

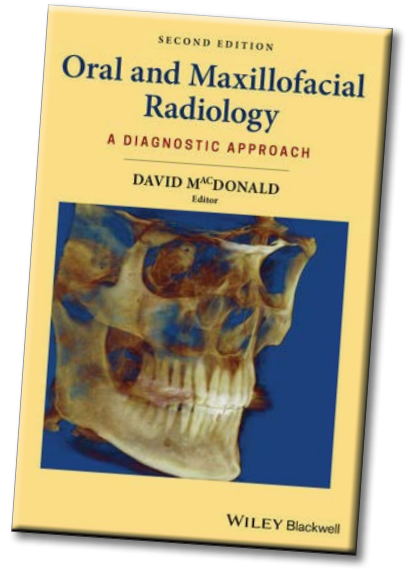

Florin-Eugen

Constantinescu

DMD, PhD Student

Holistic Dental \& Medical Institute

of Bucharest-ROPOSTURO

Bucharest, Romania

e-mail:

dr.florin.constantinescu@gmail.com

David MacDonald, BDS, BSc, LLB, MSc (Lond.), DDS (Edin.), DDRRCR (UK), FDSRCPS, FRCDC, Professor and Chair of Oral and Maxillofacial Radiology at the University of British Columbia, Vancouver, Canada together with his 9 contributors offers the reader a textbook to guide him in the imaging diagnosis of lesions affecting the face and jaws.

The book is divided in 5 parts and contains 20 chapters.

Part I, Introduction, has 3 chapters which present the basic notions on radiological diagnosis, physiological phenomena and radiological interpretation and evidence-based radiology.

Part II, Advanced imaging modalities, describes and illustrates in its 5 chapters computed tomography, conebeam computed tomography, magnetic resonance imaging, positron emission tomography, and basics of ultrasound.

Part III, Radiological pathology of the jaws, has 8 chapters which present and eloquently illustrate radiolucencies, radiopacities, maxillary sinus, lesions within the soft tissues, imaging of the salivary glands, oral and maxillofacial vascular lesions, fractures of the face and jaws and temporomandibular joint diseases.

Part IV, Extragnathic lesions, describes extragnathic, benign and malignant lesions in its 3 chapters.

Part V, Osseointegrated implants, makes an extensive presentation on dental implants.

To clarify the text, each chapter is accompanied by numerous figures and the latest references in the field.

Oral and Maxillofacial Radiology: A Diagnostic Approach, $\mathbf{2}^{\text {nd }}$ Edition is an essential support for medical radiologists, oral and maxillofacial radiologists, functional imaging specialists, radiation oncologists, oral and maxillofacial surgeons, head and neck surgeons, general dentists and radiologists, and residents in these fields. 


\section{Alexandra Popa}

Holistic Dental \& Medical Institute of Bucharest - ROPOSTURO,

Bucharest, Romania

e-mail: alesandra17popa@gmail.com

\section{Dental Management of the Pregnant Patient}

Editor: Christos A. Skouteris

Publisher:Wiley-Blackwell, Hoboken, NJ, USA

Language: English

ISBN: 978-1-119-28656-1

Edition: $1 / \mathrm{e}$

Publish Year: 2018

Pages: 192, illustrated

Price: $€ 88.90$

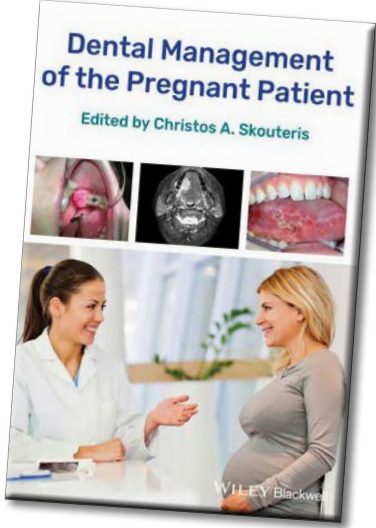

The physiological changes that occur during pregnancy must be known to the dental practitioner for him to know how to plan and treat pregnant patients. Dr. Christos A. Skouteris (University of Michigan School of Medicine in Ann Arbor, USA) and the 6 contributors, draft their first book, Dental Management of the

Pregnant Patient, on how to approach such patients. The book is divided into 9 chapters, plus a series of appendices, a Self-Assessment Quiz and an Index. The presentation of the ethical issues in the treatment of the pregnant patient is followed by the physiologic changes and their implications in the dental management of pregnant patients: cardiovascular, respiratory, hematologic, gastrointestinal, genitourinary, endocrine, immunologic, dermatologic, musculoskeletal, psychologic and behavioral changes. There follows a presentation of the general principles for the comprehensive treatment of pregnant patients, including prenatal counseling and prevention. A special place is occupied by the dental, oral, and maxillofacial diseases and conditions and their treatment. The book includes a description of each treatment of dental diseases, odontogenic oral and maxillofacial infections, benign diseases and conditions management of oral and maxillofacial malignancy and management of oral and maxillofacial trauma. The book tackles known postnatal considerations on medical contraindications, infant oral health and procedures and medications during breastfeeding, Basic Life Support (BLS) and Advanced Cardiac Life Support (ACLS) in pregnancy and obstetric gynecologic emergencies. The book provides information on emergency medical and gynecological issues in pregnant patients, and is an indispensable guide for any practitioner who is treating a pregnant woman.

d) http://www.stomaeduj.com 10.25241/stomaeduj.2020.7(3).bookreview.5

\section{Basic Guide to \\ Dental Sedation Nursing}

Author: Nicola Rogers

Language: English

ISBN: $978-1-119-52577-6$

Edition: $2 / \mathrm{e}$

Publish Year: 2020

Pages: 200, illustrated

Price: $€ 45.20$
Publisher:Wiley-Blackwell, Hoboken, NJ, USA

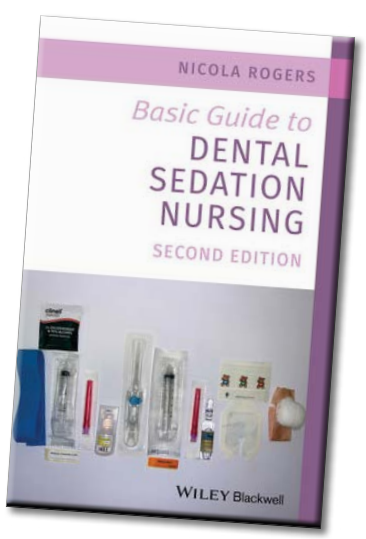

Nowadays, more and more patients request dental treatments under sedation. In the book entitled Basic Guide to Dental Sedation Nursing, 2nd Edition, Nicola Rogers, dental nurse tutor for pre and post-registration qualification training at Bristol Dental Hospital in Bristol, UK presents the basic information that any dental nurse needs to know in order to be able to help the treatments performed under dental sedation. The book is divided into seven chapters, accompanied by an index. It presents the most important aspects of sedation one by one, such as the definition of conscious sedation, medico-legal aspects of dental sedation, the role of the dental nurse and equipment, patient selection, types of sedation, medical emergencies and finally essential anatomy regarding the blood, the heart, and the respiratory system. The book is accompanied by clear images and diagrams so that the reader could understand the information presented much faster and easier. It provides good support for any dental nurse who wants to participate in treatments performed under sedation and is also a very good manual for sedation nurses undertaking any of the current National Examining Board of Dental Nurses (NEBDN) sedation qualifications, including the NEBDN Diploma in Dental Nursing, City and Guilds or CACHE Dental Nursing qualifications, as well as for dental hygienists and therapists.

The Books Review is drafted in the reviewer's sole wording and illustrates his opinions. 
The Stomatology Edu Journal (Stoma Edu J) is one of the first Green Open Access journals in the field of dental medicine publishing well-established authors, but equally committed to encouraging early career researchers and professionals alike to publish their work after a non-partisan, objective, double-blind rigorous peer-reviewed process. Our aim is to publish in the shortest possible time frame and ensure the rapid dissemination of your work via our journal page, but also through our indexing partners (Dimensions, EBSCO, KUDOS, Google Scholar, Scilit) which reach the vast mass of denta researchers, professionals and practitioners across the world This journal fully adheres and complies to the policies and principles of the Committee on Publication Ethics (COPE).

\section{Submission Instructions}

The Stomatology Edu Journal (Stoma Edu J) publishes articles written only in English. All articles will be accompanied by the signed copyright form which can be returned by e-mail, fax (as scanned documents). All the responsibility for the originality of the material sent belongs to the author(s) alone. Each article will be evaluated by the peer-review committee composed of two independent peer-reviewers, in a blinded fashion, according to the peer-review protocol. All manuscripts must be original and exclusive. The Stomatology Edu Journal Editor will consider only articles that are original, have not been published elsewhere and have been submitted exclusively to the Stomatology Edu Journal. The manuscripts should be submitted online at wWw. ManuscriptManager.net/stom.

\section{Ethics in publishing}

The Stomatology Edu Journal (Stoma Edu J) and its editorial board fully adhere and comply to the policies and principles of Committee on Publication Ethics (COPE) (https://publicationethics.org/files/2008CodeofConduct.pdf). Your manuscript should not contain any information that has already been published. If you include already published figures or images, please obtain the necessary permission from the copyright holder to publish under the CC-BY license. Plagiarism, data fabrication and image manipulation are not tolerated. Plagiarism is not acceptable in the Stomatology Edu Journal (Stoma Edu J) submissions. Plagiarism includes copying text, ideas, images, or data from another source, even from your own publications, without giving any credit to the origina source. Reuse of text that is copied from another source must be between quotes and the original source must be cited. If a study's design or the manuscript's structure or language has been inspired by previous works, these works must be explicitly cited.

If plagiarism is detected during the peer review process, the manuscript may be rejected. If plagiarism is detected after publication, we may publish a correction or retract the paper. Image files must not be manipulated or adjusted in any way that could lead to misinterpretation of the information provided by the original image. To verify the originality of content submitted to our journals, we use iThenticate (www.ithenticate com) to check submissions against previous publications All submitted manuscripts will be checked for any possible duplication or plagiarism with iThenticate (www.ithenticate com). Nevertheless, corresponding authors are responsible for any fraud, intentional or unintentional malpractice.

\section{Articles sent for publishing}

The Stomatology Edu Journal (Stoma Edu J) publishes: origina articles; reviews; case reports; technical procedures; consensus declaration coming from an association or from a group of specialists; letters to the editor. All articles must be up to 3,000 and 5,000 words for meta- analysis (the word count is for the manuscript text only). Letters to the editor must not exceed 400 words of text and have no more than 3 authors. Letters to the editor can be related to an article already published in the journal or it can represent original scientific contributions or events news/presentations etc. of interest for the reader.

\section{Permissions and Ethics}

For citations, tables, figures etc. which are not original, these must be accompanied by the written permission for their use and the full reference must be provided. Photographs of identifiable persons must be sent alongside the written permission of the person(s) and all regions that may allow the identification of the subject must be covered. The author must have obtained, for all studies including human subjects, the permission of the subjects to be part of the study whilst keeping their anonymity. By sending the article, the author declares that he obtained this permission from all his subjects. All studies must respect the Helsinki Declaration (2013). For human and animal studies, the authors must have obtained the approval of the ethics committee from the University/Institute/etc. where the study was done. Consent for publication is required for studies involving human subjects - ALL case reports, letters that describe cases and some original articles. Cohort studies are exempt; instead evidence of IRB approval (name of IRB, date of approval and approval code/reference number) must be provided.

\section{Manuscript preparation}

The article must be written in conformity with the general recommendations of the International Committee of Medical Journal Editors.

http://www.icmje.org/icmje-recommendations.pdf

The Stomatology Edu Journal (Stoma Edu J) uses doubleblind review, which means that both the reviewer and author name(s) are not allowed to be revealed to one another for a manuscript under review. The identities of the authors are concealed from the reviewers, and vice versa. To facilitate this, please include the following separately:

Title page (with author details): This should include the title, authors' names and affiliations, and a complete address for the corresponding author including an e-mail address, Author Contributions, Acknowledgements and Curriculum Vitae. Blinded manuscript (no author details): The main body of the paper (including the references, figures, and tables) should not include any identifying information, such as the authors' names or affiliations.The articles must be sent either as a Microsoft Word 2000 document (*.doc) or as a Microsoft Word 2003 document $\left({ }^{*}\right.$.docx). The article will be written using Times New Roman font, size 12 for the characters with one and half $(11 / 2)$ spaces between paragraphs. The manuscript must be sent in its final form. The pages will be numbered with the manuscript containing the following sections: title, authors, abstract, keywords, the text of article, contributions, acknowledgments, references, the figures and the tables legend.

A. The title of the manuscript will have a maximum of 100 characters without spaces, written in title case, centered capitals, and in 12 point bold Times New Roman font at the top of page. Abbreviations should be avoided within the title.

B. The author(s) will send their full name(s) and surname(s) the highest academic position, their full titles and their affiliations. All names are listed together and separated by commas. Provide exact and correct author names as these will be indexed in official archives. Affiliations should be keyed to the author's name with superscript numbers and be listed as follows: Laboratory, Department, Institute, Organization, City, State abbreviation (USA, Canada, Australia), and Country (without detailed address information such as city zip codes or street names).

The correspondent author will send his/her full name and surname, the highest academic position, his/her full title, his/ her affiliation, his/her institution address, his/ her telephone, fax and e-mail. The authors will send this information in the same format as that in the published articles.

\section{The Structured Abstract}

The abstract can have a maximum of 250 words. After the abstract, the author(s) must mention a maximum of 5 keywords. Keywords must be selected from Medline Mesh. Abbreviations are not accepted in the title or the abstract.

The abstract for Original Scientific Articles should be no more than 250 words using the following structure: Introduction; Methodology; Results; Conclusion.

The abstract for Review Articles should be no more than 250 words with the authors covering all the following information regarding the subject presented under the following subheadings: Background, Objective, Data Sources, Study Selection, Data Extraction, Data Synthesis

The abstract for Case Reports should be no more than 250 words using the following structure: Aim, Summary and Key learning points: provide up to 5 short statements of the report. The abstract for Clinical Articles should be no more than 250 words using the following structure: Aim, Methodology, Results and Conclusions. 


\section{The Article Text}

Headings and Sub-headings

Except for special names (e.g. GABAergic), capitalize only the first letter of headings and subheadings. Headings and subheadings need to be defined in Times New Roman, 12, bold. You may insert up to 5 heading levels into your manuscript (not more than for example: 3.2.2.1.2 Heading title).

For original articles:

1. Introduction - a presentation of the most important aspects in the studied domain without doing a review of the literature. The purpose of this part is to present and backup the hypothesis on which the study was based.

2. Material and Methods - this section will include all required information so that the reader can verify the validity of the study including, but not limited to, subjects, measurements, statistics and ethics. The methods used should be discussed (why the methods have been chosen, which the limitations/ advantages). A paragraph about the statistical analysis is required as well.

3. Results - the results of the study will be presented in a descending order of importance. An interpretation of the results will not be done in this section.

4. Discussion - the authors will present the way the results backup the original hypothesis, as well as the way in which the results are backed up or contradicted by the published literature. A paragraph must be dedicated to presenting the limitations of the study.

5. Conclusion - The conclusion presents the implications of this latest work. In addition, authors may consider discussing future plans or recommendations for future research etc. For all other types of articles, we recommend the use of a clear structure based on sections and sub-sections.

\section{E. Author Contributions}

The Author Contributions section is mandatory for all articles, including articles by sole authors. The Author Contributions statement must describe the contributions of individual authors and, in doing so, all authors agree to be accountable for the content of the work. Please list only 2 initials for each author, without periods, but separated by commas (e.g. AC, AS). In the case of two authors with the same initials, please use their middle initial to differentiate between them (e.g. AEC, ASC). Each author must be able to prove his active participation in the study by contributing to the concept, protocol, data gathering or analysis, their interpretation or by critically revising the manuscript.

\section{F. Acknowledgments}

Acknowledge persons who have made substantive contributions to the study. Specify grant or other financial support, citing the name of the supporting organization and grant number.

\section{G. References}

- The references will be written using the Vancouver style (https://www.imperial.ac.uk/media/imperial-college/ administration-and-support-services/library/public/vancouver. pdf). All references that are identified with DOI (Digital Object Identifier) must be mentioned.

- For each reference use active links to the full text (DOI link), free PMC article, PubMed, Google Scholar, and Scopus pages, were they exist:

- For all references identified with DOI the full-text link must be the CrossRef hyperlink

\section{Examples}

\section{Articles with DOI}

Singbartl G. Pre-operative autologous blood donation: clinical parameters and efficacy. Blood Transfus. 2011;9(1):10-18.

[CrossRef] [Free PMC Article] [PubMed] Google Scholar Scopus Articles without DOI

Mehta H, Shah S. Management of Buccal Gap and Resorption of Buccal Plate in Immediate Implant Placement: A Clinical Case Report. J Int Oral Health. 2015;7(Suppl 1):72-75.

\section{[Full text links] [PubMed] Google Scholar}

- The references will be numbered, in the order they appear in the text, in square brackets, as such: [3], [5,7-9].

- All sources found in the text must be present in the bibliography and all the papers mentioned in the bibliography must appear in the text.

- For references with more than 5 authors, list the first 3 authors followed by "et al."
- Full-page ranges should be given in expanded form (e.g., 426 429, not 426-9).

- If non-English-language titles are translated into English, bracketed indication of the original language should follow the title.

- All journals will be abbreviated and italicized names of journals according to the style in PubMed; refer to the National Library of Medicine (NLM) Journals Database (http://www.ncbi.nlm. nih.gov/nlmcatalog/journals) if needed. Journal names will be abbreviated according to the List of Title Word Abbreviations - Information obtained from sources which are not published yet, but accepted for publishing will include at the end of the reference the mention "in print" between round parentheses.

- If the cited results have not been published yet the mention will be "personal communication" written in the text of article between round parentheses.

- Only references read by the authors of the article will be cited.

- An original article will have at most 50 references, a review will have at most 100 references, a letter to the editor 5 references, whilst all other types of articles will have the minimum number of references required.

\section{Curriculum Vitae - Ultra Short version}

Please provide a brief presentation of the first author and his contribution in the field, of maximum 130 words (with a $3.5 \times 4.5$ $\mathrm{cm}$ color photo)

\section{Figures, Images, Tables}

All illustrations must be numbered and cited in the text in order of appearance.

Figures and Images will be drawn professionally and sent in separate file(s) as jpeg, tiff or png files. Illustrations should preferably fill single column width $(54 \mathrm{~mm})$ after reduction, although in some cases $113 \mathrm{~mm}$ (double column) and $171 \mathrm{~mm}$ (full page) widths will be accepted. See the Image quality specifications chart for details. Image files also must be cropped as close to the actual image as possible.

In the text, each figure must be represented by a number, a title and a description. The authors will indicate where should the figure be placed in the text. All images or figures must come from the author's personal collection or the author must have rights to publish the image or figure. All images must be at or above intended display size, with the following image resolutions: Line Art $800 \mathrm{dpi}$, Combination (Line Art + Halftone) 600 dpi, Halftone 300 dpi. We do not accept images or figures taken from the Internet.

The Tooth Identification System used in manuscripts must conform to the FDI International System. Units used in manuscripts must conform to the Système Internationale d'Unités (SI).

Tables will be included in the text and each table will have a number and a short description if required.

\section{Ownership Rights}

By sending the article for publication the author(s):

- take full responsibility for the scientific content of the text and for the accuracy of the send data;

- become (co)author(s) of the manuscript (all further plagiarism accusation are addressed solely to the author(s) who signed the manuscript);

- declare they are the rightful owners of the images, figures and/or information sent for publishing and that they have the permission to publish all the materials for which they do not own the intellectual property rights;

- declare that the message/content of the manuscript is not influenced in anyway by commercial interests/previous engagements/ any sort of relations with other people or companies;

- transfer all rights for the manuscript to the Editorial Council for the Stomatology Edu Journal.

\section{Other}

Previously mentioned limitations can be ignored in special cases with the agreement of the chief-editor and/or the publisher. All published materials cannot be returned.

Not taking into consideration the recommendations mentioned before can lead to delay in publishing the materials or may lead to not publishing the article.

The Stomatology Edu Journal (Stoma Edu J) also helps authors measure the impact of their research through specialist partnerships with Kudos and Altmetric. 


\section{SUBSCRIPTION}

\section{I want to subscribe to Stonacoj}

- 1 year Subscription (4 issues of the journal) - 280 RON (72 Euro for foreign subscribers)

- 2 years Subscription ( 8 issues of the journal) - 540 RON (136 Euro for foreign subscribers)

- Single Issue - 80 RON (20 Euro for foreign subscribers)

Please send the filled subscription at the following e-mail: roposturo@gmail.com.

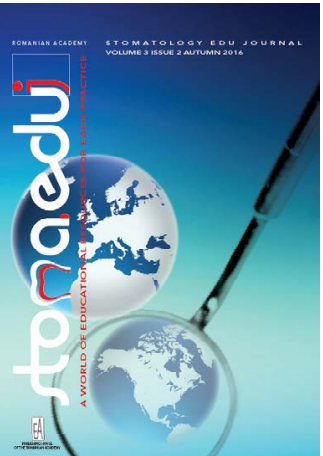

\section{PLEASE COMPLETE ALL THE SUBSCRIPTION FIELDS IN CAPITAL LETTERS!}

Name

Surname

Mrs. $\square$ Mr. $\square$ Ms.

Home Address

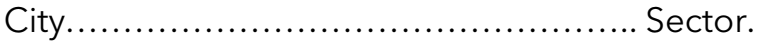

District

Post office code.

Mobile phone....

Web.

E-mail:

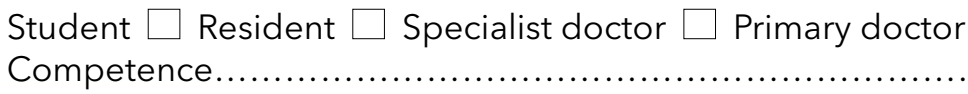

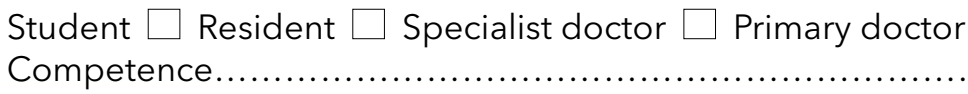

Institution....

Activity domain: $\square$ Private $\square$ Public

Department.

Position.

Specialty

Institution address

City. ...

Sector

District

Post office code

Phone...

E-mail:

Web

CUI (Institution Unique Registration Code)

VAT Payer: $\square$ Yes $\square$ No

Invoice - please fill all the necessary details for invoice:

Name.

CNP (Personal Identification Number)

$\mathrm{Or}$

Institution

CUI (Institution Unique Registration Code).

Date

After filling the subscription, please send it together with the proof of payment to:

\section{ROPOSTURO}

Romanian Association of Oral Rehabilitation and Posturotherapy

10, lonel Perlea St., $1^{\text {st }}$ District, RO-010209 Bucharest, Romania

Tel: +4021314 1062, Fax: +40213121357

e-mail: roposturo@gmail.com

www.roposturo.ro 


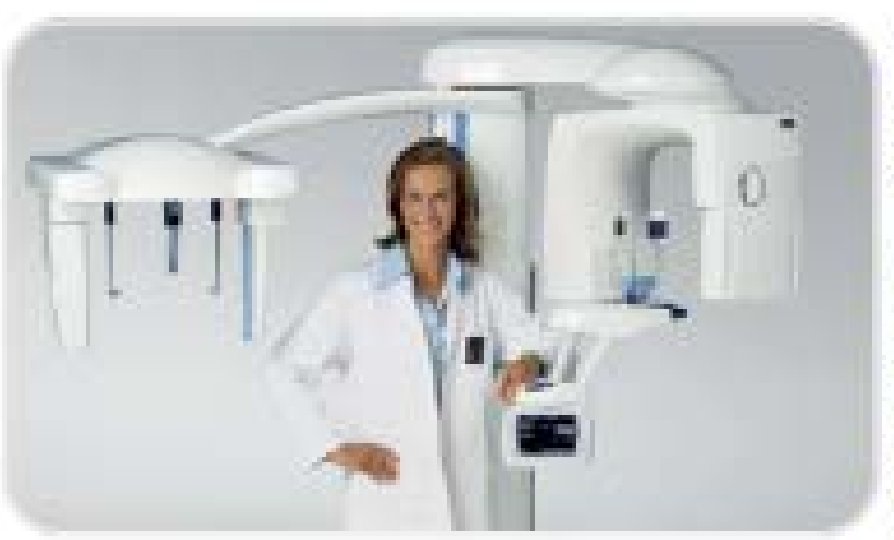

The Plevnei Gral Medical Dental Imaging Center provides dental imaging services dedicated to obtaining a quick and correct dental diagnostic in order to plan an adequate and efficient treatement.

Our state-of-the-art equipment provides dentists, implantologists or maxillofacial surgeons with accurate 2D and 3D images of the structures they will work upon, being of real service to the patients, by practically eliminating all major intervention-associated risks, both due to the use of very low radiation doses and the easy and comfortable positioning of the patient.

\section{ORTHODONTIC X-RAYS (RADIOGRAPHS)}

Profile (lateral) cephalometric views

Standard OPG (Orthopantomogram) for adults and children (magnification 1.3-1.6)

Orthodontic diagnostic photos

\section{X-RAYS (RADIOGRAPHS) FOR SPECIAL TREATMENTS} Standard OPG (Orthopantomogram) for adults and children (magnification 1.3-1.6)

Ortoradial orthopantogram for adults and

children (magnification 1.3-1.6)

Orthopantogram with reduced for adults and children

Combination for the same patient

(standard OPG +orthoradial+ reduced shadow)

Four-view TMJ-right to left joint

Anterior maxillary sinus panoramic radiographs

Posterior maxillary sinus panoramic radiographs

Salivary gland panoramic radiographs

Prophile (lateral) cephalometric radiographs

Orthodontic diagnostic photos

\section{D CT SCANS}

Full maxilla and mandible CT scan

Maxilla and maxillary sinus CT scan

Mandible and mandible

Mandible and mandibular canal CT scan

Partial maxillary and mandibular CT scan

TMJ CT scan

CT scan of included teeth

\section{MRI -CT}

Ortho-maxillofacial MRI

Ortho-maxillofacial CT

Examination of the throat using a special protocol for: cavum; oropharynx, oral cavity, tongue, soft palate, salivary glands, larynx and hypopharynx is conducted only at 79-91, Traian Popovici Street, $3^{\text {rd }}$ District,

RO-031422 Bucharest, ROMANIA

Tel: 021-323.00.00 | 0731-494.688
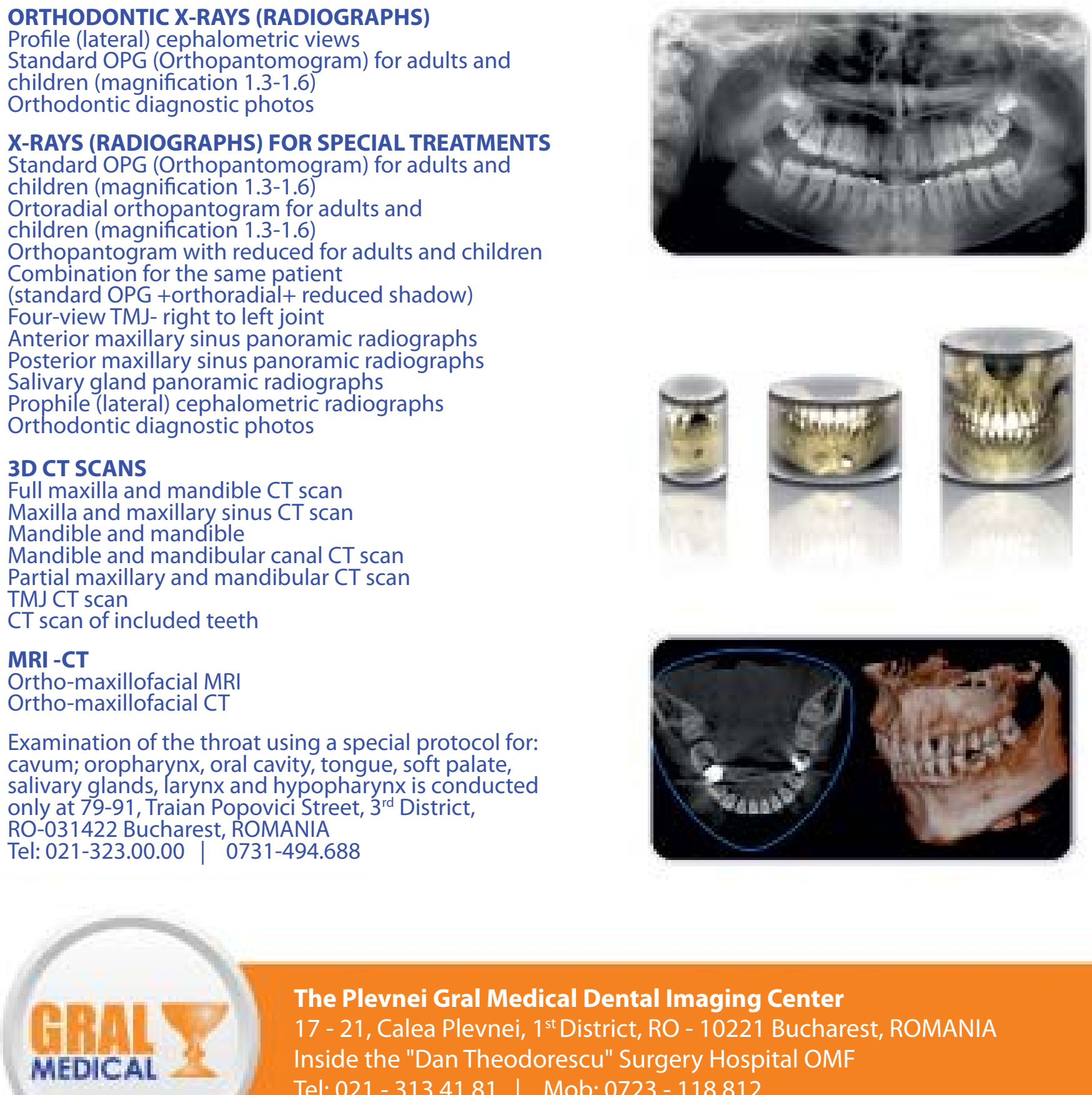

The Plevnei Gral Medical Dental Imaging Center

17 - 21, Calea Plevnei, $1^{\text {st }}$ District, RO - 10221 Bucharest, ROMANIA

Inside the "Dan Theodorescu" Surgery Hospital OMF

Tel: $021-313.41 .81$ | Mob: $0723-118.812$ 
